\title{
WestVirginiaUniversity
}

THE RESEARCH REPOSITORY @ WVU

Graduate Theses, Dissertations, and Problem Reports

2018

\section{Emotion Socialization during Emerging Adulthood}

Karena M. Moran

Follow this and additional works at: https://researchrepository.wvu.edu/etd

\section{Recommended Citation}

Moran, Karena M., "Emotion Socialization during Emerging Adulthood" (2018). Graduate Theses,

Dissertations, and Problem Reports. 7216.

https://researchrepository.wvu.edu/etd/7216

This Dissertation is protected by copyright and/or related rights. It has been brought to you by the The Research Repository @ WVU with permission from the rights-holder(s). You are free to use this Dissertation in any way that is permitted by the copyright and related rights legislation that applies to your use. For other uses you must obtain permission from the rights-holder(s) directly, unless additional rights are indicated by a Creative Commons license in the record and/ or on the work itself. This Dissertation has been accepted for inclusion in WVU Graduate Theses, Dissertations, and Problem Reports collection by an authorized administrator of The Research Repository @ WVU.

For more information, please contact researchrepository@mail.wvu.edu. 
Emotion Socialization during Emerging Adulthood

\author{
Karena M. Moran, M.S. \\ Dissertation submitted \\ to the Eberly College of Arts and Sciences \\ at West Virginia University
}

in partial fulfillment of the requirements for the degree of

Doctor of Philosophy in

Psychology
Amy Gentzler, PhD., Chair
Aaron Metzger, Ph.D.
Amy Root, Ph.D.
Christine Rittenour, Ph.D.

Department of Psychology

Morgantown, West Virginia

2018

Keywords: emotion socialization, emotion regulation, well-being, emerging adults, parents, friends

Copyright 2018 Karena M. Moran 


\section{ABSTRACT \\ Emotion Socialization during Emerging Adulthood}

\section{Karena M. Moran, M.S.}

The present study examined emotion socialization (i.e., the socialization of understanding, experiencing, and regulating emotions) from parents and friends and its associations with emotion regulation and well-being in emerging adults. All participants (612 emerging adults; 461 parents; 261 friends) reported their use of emotion regulation (ER) strategies with negative and positive emotions as well as multiple indices of well-being (i.e., subjective happiness, life satisfaction, positive affect, negative affect). Parents and friends each completed a survey assessing how they socialize the emerging adults' negative and positive emotions, while emerging adults completed surveys on how they socialize their parents' and friends' negative and positive emotions. We expected supportive emotion socialization methods to predict more positive outcomes (i.e., more functional ER, less dysfunctional ER, higher well-being) whereas unsupportive socialization methods would predict fewer positive outcomes (i.e., less functional ER, more dysfunctional ER, lower well-being). Results were analyzed using structural equation modeling in Amos (version 25). Models predicting emerging adult functional ER showed that unsupportive socialization from parents was negatively related while modeling of functional ER from friends was positively associated. Only parents' modeling of dysfunctional ER and wellbeing were positively linked to emerging adults' dysfunctional ER and well-being, respectively. An indirect effect of emerging adults' functional ER was found such that parents' supportive emotion socialization was positively related to emerging adults' well-being through emerging adults' functional ER. Conversely, parents' unsupportive emotion socialization was indirectly related to emerging adults' well-being through emerging adults' dysfunctional ER. Additionally, analyses examining the role of emerging adults' emotion socialization efforts on their parents' and friends' emotion regulation and well-being were also examined. However, little evidence for emotion socialization effects was found in these models. Overall, the present study extended the prior work on emotion socialization with children and adolescents to emerging adults, suggesting socialization is still relevant in emerging adults in college. 


\section{ACKNOWLEDGEMENTS}

They say it takes a village, and for this accomplishment there are many people I would like to acknowledge as having been a part of helping me get to where I am today and where I will be tomorrow:

First, I would like to extend my professional gratitude to my dissertation committee members: Dr. Amy Gentzler for her expertise and guidance throughout this project, Dr. Aaron Metzger for always letting me come "next door" for help, Dr. Amy Root for her knowledge and excitement about emotion socialization research, and Dr. Christy Rittenour for always being supportive. I would also like to thank the Department of Psychology, Eberly College of Arts and Sciences, and the Office of Academic Affairs for awarding me the Doctoral Research Grant that funded this project.

Next, I would like to thank my family for always supporting me, even when they weren't quite sure exactly what I was doing. My parents have helped shape me into the woman I am today, and I don't know where I would be without their blind love and support. My grandparents, who have gone above and beyond to ensure that no matter what, I have always been able to pursue my dreams. My sister, for always listening, for pushing me, and for knowing when to just let my nephew, Caysen, run around with her phone instead. And to my boyfriend, Davey, for always being by my side, even when we couldn't actually be together, for pushing me to keep moving forward, and for simultaneously pursuing his own dreams while I pursue mine.

I also would like to recognize my colleagues who have become great friends over the last four years. To my lab mates, Katy, Katie, and Tyia, your support and friendship have meant the world to me. I'm so thankful to have had the opportunity to work with each of you and to have become your friend. To Nicole, Colleen, Matthew, and Emily, thank you for always lending an ear, a hand, or a brain when I was stumped. To my undergraduate research assistants, Lora, Joe, Kayley, and Ginny, for your immense amounts of hard work and dedication to this project, for your diligence and attention to detail, and for your thirst for knowledge.

Last, I would like to extend my deepest gratitude to Ashli and Sara, for being there during the most trying of times, for always helping me to find the positives, and for pushing me to be the best person I can be. Your companionship has been unwavering, and I thank you for that. 


\section{TABLE OF CONTENTS}

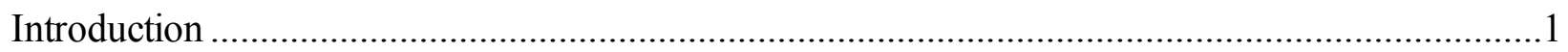

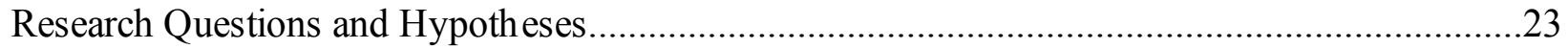

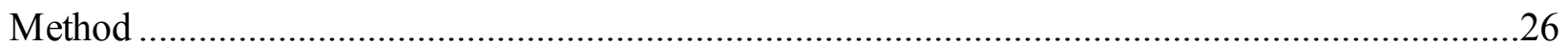

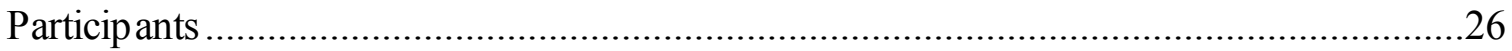

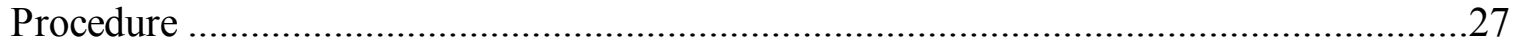

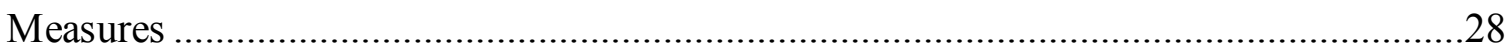

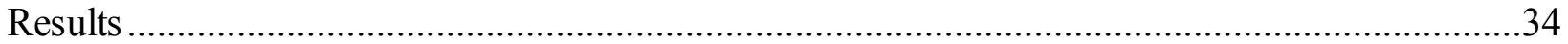

Data Cleaning and Preliminary Analyses ........................................................................34

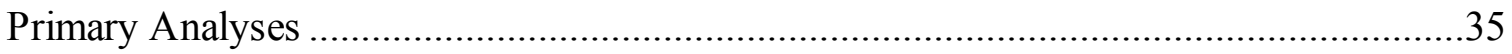

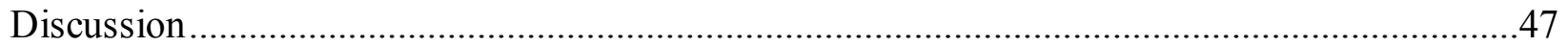

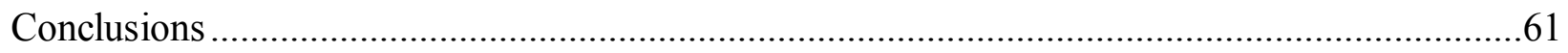

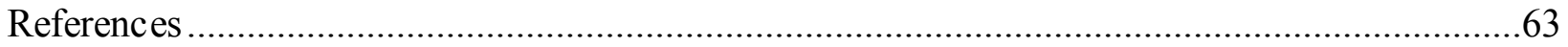

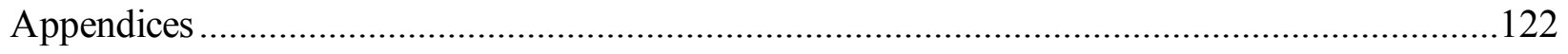

Appendix A: Emerg ing Adult Measures ........................................................... 123

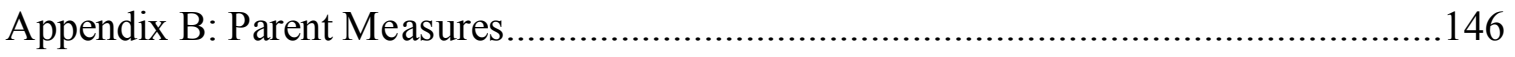

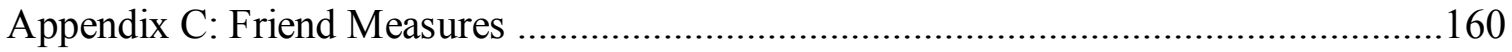

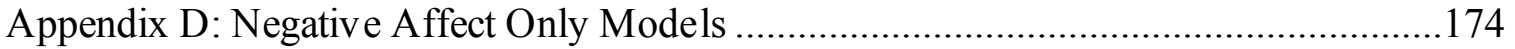

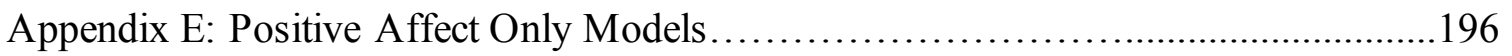

Appendix F: Comparisons across Combined, Negative Affect, and Positive Affect

Models...................................................................218 


\section{LIST OF TABLES}

Table 1. Demographic Information for All Reporters. .......................................................... 83

Table 2. Demographic Information for All Reporters Continued ............................................ 84

Table 3. Descriptive Statistics of Emotion Specific Socialization Variables Reported by Emerging Adult Participants.

Table 4. Descriptive Statistics of Emotion Specific Socialization Variables Reported by Parent and Friend Participants. ........................................................................................ 86

Table 5. Descriptive Statistics of Outcome Variables for All Reporters. .................................. 87

Table 6. Descriptive Statistics and Reliability for Emerging Adult-report Negative Affect

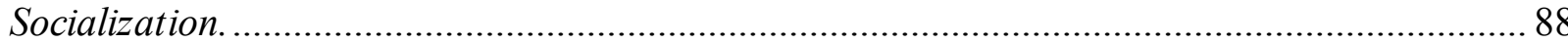

Table 7. Descriptive Statistics and Reliability for Parent- and Friend-report Negative Affect Socialization.

Table 8. Bivariate Correlations among Parent Socialization, Emerging Adult Outcomes, Emerging Adult-reported Closeness with Parents......

Table 9. Bivariate Correlations among Friend Socialization, Emerging Adult Outcomes, Emerging Adult-reported Closeness with Friend.

Table 10. Bivariate Correlations among Emerging Adult Socialization with Mothers, Mother Outcomes, Mother-reported Closeness with Emerging Adult.

Table 11. Bivariate Correlations among Emerging Adult Socialization with Fathers, Father Outcomes, Father-reported Closeness with Emerging Adult.

Table 12. Bivariate Correlations among Emerging Adult Socialization with Friend, Friend Outcomes, Friend-reported Closen ess with Emerging Adult. ............................................... 94

Table 13. Bivariate Correlations among Emerging Adult Demographics and Outcomes. ......... 95

Table 14. Bivariate Correlations among Parent Demographics and Outcomes........................ 96

Table 15. Bivariate Correlations among Friend Demographics and Outcomes....................... 97

Table 16. Independent Samples T-Tests between Gender and Variables of Interest.................. 98

Table F1. Comparisons across Combined, NA, and PA Models. RQ2a: Parents' Emotion Socialization Predicting Emerging Adult Functional Emotion Regulation, Controlling for Emerging Adult-reported Closeness with Mother and Father.

Table F2. Comparisons across Combined, NA, and PA Models. RQ2b: Parents' Emotion Socialization Predicting Emerging Adult Dysfunctional Emotion Regulation, Controlling for Emerging Adult-reported Closeness with Mother and Father.

Table F3. Comparisons across Combined, NA, and PA Models. RQ2c: Parents' Emotion Socialization Predicting Emerging Adult Well-being, Controlling for Emerging Adultreported Closeness with Mother and Father. 
Table F4. Comparisons across Combined, NA, and PA Models. RQ3a: Parents ' and Friends' Emotion Socialization Predicting Emerging Adult Functional Emotion Regulation, Controlling for Emerging Adult-reported Closeness with Mother, Father, and Friend. .......... 221

Table F5. Comparisons across Combined, NA, and PA Models. RQ3b: Parents ' and Friends' Emotion Socialization Predicting Emerging Adult Dysfunctional Emotion Regulation, Controlling for Emerging Adult-reported Closeness with Mother, Father, and Friend. .......... 222

Table F6. Comparisons across Combined, NA, and PA Models. RQ3c: Parents ' and Friends' Emotion Socialization Predicting Emerging Adult Well-being, Controlling for Emerging Adult-reported Closeness with Mother, Father, and Friend.

Table F7. Comparisons across Combined, NA, and PA Models. RQ4aa: Emerging Adults' Emotion Socialization Predicting Mothers' Functional Emotion Regulation, Controlling for Mother-reported Closeness with Emerging Adult Child.

Table F8. Comparisons across Combined, NA, and PA Models. RQ4ab: Emerging Adults' Emotion Socialization Predicting Mothers' Dysfunctional Emotion Regulation, Controlling for Mother-reported Closeness with Emerging Adult Child.

Table F9. Comparisons across Combined, NA, and PA Models. RQ4ac: Emerging Adults' Emotion Socialization Predicting Mothers' Well-being, Controlling for Mother-reported Closeness with Emerging Adult Child.

Table F10. Comparisons across Combined, NA, and PA Models. RQ4ba: Emerging Adults' Emotion Socialization Predicting Fathers' Functional Emotion Regulation, Controlling for Father-reported Closeness with Emerging Adult Child.

Table F11. Comparisons across Combined, NA, and PA Models. RQ4bb: Emerging Adults' Emotion Socialization Predicting Fathers' Dysfunctional Emotion Regulation, Controlling for Father-reported Closen ess with Emerging Adult Child.

Table F12. Comparisons across Combined, NA, and PA Models. RQ4bc: Emerging Adults' Emotion Socialization Predicting Fathers' Well-being, Controlling for Father-reported Closeness with Emerging Adult Child.

Table F13. Comparisons across Combined, NA, and PA Models. RQ5a: Emerging Adults' Emotion Socialization Predicting Friends' Functional Emotion Regulation, Controlling for Friend-reported Closeness with Emerging Adult Friend.

Table F14. Comparisons across Combined, NA, and PA Models. RQ5a: Emerging Adults' Emotion Socialization Predicting Friends' Dysfunctional Emotion Regulation, Controlling for Friend-reported Closeness with Emerging Adult Friend.

Table F15. Comparisons across Combined, NA, and PA Models. RQ5a: Emerging Adults' Emotion Socialization Predicting Friends' Well-being, Controlling for Friend-reported Closeness with Emerging Adult Friend.

Table F16. Comparisons across Combined, NA, and PA Models. RQ6a: Parents ' and Friends' Emotion Socialization Predicting Emerging Adult Well-being through Emerging 
Adult Functional Emotion Regulation, Controlling for Emerging Adult-reported Closeness with Mother, Father, and Friend and Parent and Friend Modeling Functional Emotion Regulation and Well-being

Table F17. Comparisons across Combined, NA, and PA Models. RQ6a: Parents' and Friends' Emotion Socialization Predicting Emerging Adult Well-being through Emerging Adult Dysfunctional Emotion Regulation, Controlling for Emerging Adult-reported Closeness with Mother, Father, and Friend and Parent and Friend Modeling Dysfunctional Emotion Regulation and Well-being. 


\section{LIST OF FIGURES}

Figure 1. Data cleaning.

Figure 2. Confirmatory Factor Analysis of Emerging Adult-report of their Socialization of their Mothers' Emotions.

Figure 3. Confirmatory Factor Analysis of Emerging Adult-report of their Socialization of their Fathers' Emotions.

Figure 4. Confirmatory Factor Analysis of Emerging Adult-report of their Socialization of their Friends' Emotions.

Figure 5. Confirmatory Factor Analysis of Parent-report of their Socialization of their Emerging Adults Child's Emotions.

Figure 6. Confirmatory Factor Analysis of Friend-report of their Socialization of their Emerging Adults Friend's Emotions......

Figure 7. Research Question 2, Hypothesis 2a. Parents' Emotion Socialization predicting Emerging Adult Functional Emotion Regulation, Controlling for Parent-reported Functional Emotion Regulation and Emerging Adult-reported Closeness with Mother and Father.

Figure 8. Research Question 2, Hypothesis 2b. Parents' Emotion Socialization predicting Emerging Adult Dysfunctional Emotion Regulation, Controlling for Parent-reported Dysfunctional Emotion Regulation and Emerging Adult-reported Closeness with Mother and Father.

Figure 9. Research Question 2, Hypothesis 2c. Parents' Emotion Socialization predicting Emerging Adult Well-being, Controlling for Parent-reported Well-being and Emerging Adult-reported Closeness with Mother and Father.

Figure 10. Research Question 3, Hypothesis 3a. Parents' and Friends'Emotion Socialization predicting Emerging Adult Functional Emotion Regulation, Controlling for Parent- and Friend-reported Functional Emotion Regulation and Emerging Adult-reported Closeness with Mother, Father, and Friend.

Figure 11. Research Question 3, Hypothesis 3b. Parents' and Friends' Emotion Socialization predicting Emerging Adult Dysfunctional Emotion Regulation, Controlling for Parent- and Friend-reported Dysfunctional Emotion Regulation and Emerging Adult-reported Closeness with Mother, Father, and Friend.

Figure 12. Research Question 3, Hypothesis 3c. Parents' and Friends' Emotion Socialization predicting Emerging Adult Well-being, Controlling for Parent- and Friend-reported Wellbeing and Emerging Adult-reported Closeness with Mother, Father, and Friend.

Figure 13. Research Question 4, Hypothesis 4a with Mothers. Emerging Adults' Emotion Socialization of their Mothers predicting Mothers' Functional Emotion Regulation, 
Controlling for Emerging Adult-reported Functional Emotion Regulation and Motherreported Closeness with their Emerging Adult Child.

Figure 14. Research Question 4, Hypothesis 4 a with Fathers. Emerging Adults' Emotion Socialization of their Fathers predicting Fathers' Functional Emotion Regulation, Controlling for Emerging Adult-reported Functional Emotion Regulation and Father-reported Closeness with their Emerging Adult Child.......................................................112

Figure 15. Research Question 4, Hypothesis 4b with Mothers. Emerging Adults' Emotion Socialization of their Mothers predicting Mothers' Dysfunctional Emotion Regulation, Controlling for Emerging Adult-reported Dysfunctional Emotion Regulation and Motherreported Closeness with their Emerging Adult Child....

Figure 16. Research Question 4, Hypothesis $4 b$ with Fathers. Emerging Adults' Emotion Socialization of their Fathers predicting Fathers' Dysfunctional Emotion Regulation, Controlling for Emerging Adult-reported Dysfunctional Emotion Regulation and Fatherreported Closeness with their Emerging Adult Child....

Figure 17. Research Question 4, Hypothesis 4c with Mothers. Emerging Adults' Emotion Socialization of their Mothers predicting Mothers' Well-being, Controlling for Emerging Adultreported Well-being and Mother-reported Closeness with their Emerging Adult Child.

Figure 18. Research Question 4, Hypothesis 4c with Fathers. Emerging Adults' Emotion Socialization of their Fathers predicting Fathers' Well-being, Controlling for Emerging Adultreported Well-being and Father-reported Closeness with their Emerging Adult Child..........116

Figure 19. Research Question 5, Hypothesis 5a. Emerging Adults' Emotion Socialization of their Friends predicting Friends' Functional Emotion Regulation, Controlling for Emerging Adultreported Functional Emotion Regulation and Friend-reported Closeness with their Emerging Adult Friend ........................................................................117

Figure 20. Research Question 5, Hypothesis 5b. Emerging Adults' Emotion Socialization of their Friends predicting Friends' Dysfunctional Emotion Regulation, Controlling for Emerging Adultreported Dysfunctional Emotion Regulation and Friend-reported Closeness with their Emerging Adult Friend. 118

Figure 21. Research Question 5, Hypothesis 5c. Emerging Adults' Emotion Socialization of their Friends predicting Friends' Well-being, Controlling for Emerging Adult-reported Well-being and Friend-reported Closeness with their Emerging Adult Friend.

Figure 22. Research Question 6. Parents' and Friends' Emotion Socialization predicting Emerging Adults' Well-being through Emerging Adults' Functional Emotion Regulation, Controlling for Parent- and Friend-reported Well-being and Emerging Adult-reported Closeness with their Mother, Father, and Friend. 
Figure 23. Research Question 6. Parents' and Friends' Emotion Socialization predicting Emerging Adults' Well-being through Emerging Adults' Dysfunctional Emotion Regulation, Controlling for Parent- and Friend-reported Well-being and Emerging Adult-reported Closeness with their Mother, Father, and Friend.

Figure D1. RQ1 - Confirmatory Factor Analysis of Parent-report of their Socialization of their Emerging Adults Child's Negative Emotions.

Figure D2. RQ1 - Confirmatory Factor Analysis of Friend-report of their Socialization of their Emerging Adult Friends' Negative Emotions...

Figure D3. RQ1 - Confirmatory Factor Analysis of Emerging adult-report of their Socialization of their Mothers' Negative Emotions.

Figure D4. RQ1 - Confirmatory Factor Analysis of Emerging adult-report of their Socialization of their Fathers' Negative Emotions

Figure D5. RQ1 - Confirmatory Factor Analysis of Emerging adult-report of their Socialization of their Friends' Negative Emotions.

Figure D6. RQ2a - Parent-reported Negative Emotion Socialization predicting Emerging Adultreported Functional Emotion Regulation, controlling for Emerging Adult-reported Closeness with Mother and Father....

Figure D7. RQ2b - Parent-reported Negative Emotion Socialization predicting Emerging Adultreported Dysfunctional Emotion Regulation, controlling for Emerging Adult-reported Closeness with Mother and Father.

Figure D8. RQ2c - Parent-reported Negative Emotion Socialization predicting Emerging Adultreported Well-being, controlling for Emerging Adult-reported Closeness with Mother and Father.

Figure D9. RQ3a - Parent- and Friend-reported Negative Emotion Socialization predicting Emerging Adult-reported Functional Emotion Regulation, controlling for Emerging Adultreported Closeness with Mother, Father, and Friend.

Figure D10. RQ3b - Parent- and Friend reported Negative Emotion Socialization predicting Emerging Adult-reported Dysfunctional Emotion Regulation, controlling for Emerging Adultreported Closeness with Mother, Father, and Friend.

Figure D11. RQ3c-Parent- and Friend-reported Negative Emotion Socialization predicting Emerging Adult-reported Well-being, controlling for Emerging Adult-reported Closeness with Mother, Father, and Friend.... 
Figure D12. RQ4aa - Emerging Adult-reported Negative Emotion Socialization predicting Mother-reported Functional Emotion Regulation, controlling for Mother-reported Closeness with Emerging Adult Child.

Figure D13. RQ4ab - Emerging Adult-reported Negative Emotion Socialization predicting Mother-reported Dysfunctional Emotion Regulation, controlling for Mother-reported Closeness with Emerging Adult Child.

Figure D14. RQ4ac-Emerging Adult-reported Negative Emotion Socialization predicting Mother-reported Well-being, controlling for Mother-reported Closeness with Emerging Adult Child....

Figure D15. RQ4ba-Emerging Adult-reported Negative Emotion Socialization predicting Father-reported Functional Emotion Regulation, controlling for Father-reported Closeness with Emerging Adult Child.

Figure D16. RQ4bb - Emerging Adult-reported Negative Emotion Socialization predicting Father-reported Dysfunctional Emotion Regulation, controlling for Father-reported Closeness with Emerging Adult Child.

Figure D17. RQ4bc-Emerging Adult-reported Negative Emotion Socialization predicting Father-reported Well-being, controlling for Father-reported Closeness with Emerging Adult

Child......

Figure D18. RQ5a-Emerging Adult-reported Negative Emotion Socialization predicting Friend-reported Functional Emotion Regulation, controlling for Friend-reported Closeness with Emerging Adult Friend....

Figure D19. RQ5b - Emerging Adult-reported Negative Emotion Socialization predicting Friend-reported Dysfunctional Emotion Regulation, controlling for Friend-reported Closeness with Emerging Adult Friend.

Figure D20. RQ5c-Emerging Adult-reported Negative Emotion Socialization predicting Friend-reported Well-being, controlling for Friend-reported Closeness with Emerging Adult Friend.

Figure D21. RQ6a - Emerging Adult-reported Functional Emotion Regulation Mediates the Link between Parent- and Friend-reported Negative Emotion Socialization and Emerging Adultreported Well-being, controlling for Emerging Adult Closeness with Mother, Father, and Friend.

Figure D22. RQ6b - Emerging Adult-reported Dysfunctional Emotion Regulation Mediates the Link between Parent- and Friend-reported Negative Emotion Socialization and Emerging Adultreported Well-being, controlling for Emerging Adult Closeness with Mother, Father, and Friend. 
Figure E1. RQ1 - Confirmatory Factor Analysis of Parent-report of their Socialization of their Emerging Adults Children's Positive Emotions...

Figure E2. RQ1 - Confirmatory Factor Analysis of Friend-report of their Socialization of their Emerging Adults Friends' Positive Emotions.....

Figure E3. RQ1 - Confirmatory Factor Analysis of Emerging Adult-report of their Socialization of their Mothers' Positive Emotions.

Figure E4. RQ1 - Confirmatory Factor Analysis of Emerging Adult-report of their Socialization of their Fathers' Positive Emotions....

Figure E5. RQ1 - Confirmatory Factor Analysis of Emerging Adult-report of their Socialization of their Friends' Positive Emotions....

Figure E6. RQ2a - Parent-reported Positive Emotion Socialization predicting Emerging Adultreported Functional Emotion Regulation, controlling for Emerging Adult-reported Closeness with Mother and Father.

Figure E7. RQ2b - Parent-reported Positive Emotion Socialization predicting Emerging Adultreported Dysfunctional Emotion Regulation, controlling for Emerging Adult-reported Closeness with Mother and Father...

Figure E8. RQ2c-Parent-reported Positive Emotion Socialization predicting Emerging Adultreported Well-being, controlling for Emerging Adult-reported Closeness with Mother and Father....

Figure E9. RQ3a-Parent- and Friend-reported Positive Emotion Socialization predicting Emerging Adult-reported Functional Emotion Regulation, controlling for Emerging Adultreported Closeness with Mother, Father, and Friend.

Figure E10. RQ3b - Parent- and Friend-reported Positive Emotion Socialization predicting Emerging Adult-reported Dysfunctional Emotion Regulation, controlling for Emerging Adultreported Closeness with Mother, Father, and Friend.

Figure E11. RQ3c-Parent- and Friend-reported Positive Emotion Socialization predicting Emerging Adult-reported Well-being, controlling for Emerging Adult-reported Closeness with Mother, Father, and Friend.

Figure E12. RQ4aa-Emerging Adult-reported Positive Emotion Socialization predicting Mother-reported Functional Emotion Regulation, controlling for Mother-reported Closeness with Emerging Adult Child.

Figure E13. RQ4ab - Emerging Adult-reported Positive Emotion Socialization predicting Mother-reported Dysfunctional Emotion Regulation, controlling for Mother-reported Closeness with Emerging Adult Child. 
Figure E14. RQ4ac-Emerging Adult-reported Positive Emotion Socialization predicting Mother-reported Well-being, controlling for Mother-reported Closeness with Emerging Adult

Child. . .

Figure E15. RQ4ba-Emerging Adult-reported Positive Emotion Socialization predicting Father-reported Functional Emotion Regulation, controlling for Father-reported Closeness with Emerging Adult Child.....

Figure E16. RQ4bb - Emerging Adult-reported Positive Emotion Socialization predicting Father-reported Dysfunctional Emotion Regulation, controlling for Father-reported Closeness with Emerging Adult Child.

Figure E17. RQ4bc-Emerging Adult-reported Positive Emotion Socialization predicting Father-reported Well-being, controlling for Father-reported Closeness with Emerging Adult

Child.

Figure E18. RQ5a - Emerging Adult-reported Positive Emotion Socialization predicting Friendreported Functional Emotion Regulation, controlling for Friend-reported Closeness with Emerging Adult Friend...............................................................213

Figure E19. RQ5b - Emerging Adult-reported Positive Emotion Socialization predicting Friendreported Dysfunctional Emotion Regulation, controlling for Friend-reported Closeness with Emerging Adult Friend.

Figure E20. RQ5c-Emerging Adult-reported Positive Emotion Socialization predicting Friendreported Well-being, controlling for Friend-reported Closeness with Emerging Adult Friend

Figure E21. RQ6a - Emerging Adult-reported Functional Emotion Regulation Mediates the Link between Parent- and Friend-reported Positive Emotion Socialization and Emerging Adultreported Well-being, controlling for Emerging Adult Closeness with Mother, Father, and Friend.

Figure E22. RQ6b - Emerging Adult-reported Dysfunctional Emotion Regulation Mediates the Link between Parent- and Friend-reported Positive Emotion Socialization and Emerging Adultreported Well-being, controlling for Emerging Adult Closeness with Mother, Father, and Friend. 


\section{Emotion Socialization during Emerging Adulthood}

A vast amount of research has focused on parental emotion socialization in childhood (e.g., Dunsmore \& Karn, 2004; Eisenberg \& Valiente, 2004; Garner \& Estep, 2001; Premo \& Kiel, 2014) and adolescence (e.g., Buckholdt, Parra, \& Jobe-Shields, 2014; Klimes-Dougan et al., 2007; Miller-Slough \& Dunsmore, 2016). However, little research has explored the socialization of emotion with individuals older than adolescence. Some work in other areas (e.g., financial literacy; Jorgensen \& Savla, 2010) has shown that parents continue to socialize their children during emerging and young adulthood. Many researchers have also emphasized the importance of understanding and exploring development as a life-long process (Baltes, 1987; Baltes, Lindenberger, \& Staudinger, 2006; Carstensen, 1995). However, previous work has not examined the specific influence parents may continue to have in the socialization of emotions with their adult children.

Additionally, previous research has shown that as children age, friends become increasingly important (Buhrmester, 1996; Buhrmester \& Furman, 1987). Prior work suggests that friends play an important role in the socialization of emotions during both childhood (e.g., Burleson \& Kunkel, 2002; Dunsmore \& Karn, 2004) and adolescence (e.g., Klimes-Dougan et al., 2014; Reindl, Gniewosz, \& Reinders, 2016). However, research has not thoroughly examined the potential importance of friends as agents of emotion socialization during emerging adulthood, a period commonly characterized by substantial amounts of time spent in the company of friends (Arnett, 2004; Buhrmester \& Carbery, 1992). It is important to examine how parents and friends socialize emerging adults' emotions because emotion socialization has been related to outcomes such as emotion regulation and well-being in children (e.g., Rogers, 
Halberstadt, Castro, MacCormack, \& Garrett-Peters, 2016) and adolescence (e.g., see MillerSlough \& Dunsmore, 2016).

Furthermore, socialization has been widely considered a bidirectional process (Bell, 1968; Grusec, 2011; Kuczynski \& Parkin, 2008), suggesting parents are likely influenced by their children as well (Kuczynski, Pitman, Ta-Young, \& Harach, 2016; Roest, Dubas, \& Gerris, 2009). Therefore, the aims of the present study are to examine: 1) if emotion socialization during emerging adulthood can be assessed in a way that is consistent with previous research conducted with children and adolescents, 2) how parents' and friends' socialization of emotions is associated with emerging adults' emotion regulation and well-being, and 3) how emerging adults' socialization of their parents' and friends' emotions is associated with parents' and friends' emotion regulation and well-being, respectively.

\section{Emotions and Emotion Regulation}

Emotional experiences consist of subjective "feeling" reactions as well as cognitive, physiological, and behavioral changes in response to a stimulus (Shiota \& Kalat, 2012). Historically, emotions were considered disruptive (e.g., Young, 1943); however, more recently, emotions have become widely regarded as functional and even beneficial in many instances (see Keltner \& Gross, 1999). Although most often emotions serve adaptive purposes (e.g., facilitate decision making; Gross, 1998), inappropriate emotional experiences and expressions (e.g., extreme intensity or long duration) need to be regulated to avoid interference with functioning (e.g., attention, social relations; Cole, Michel, \& Teti, 1994; Gross, 1998, 2015a). Emotion regulation can be described as the way in which individuals manage their emotions by increasing, maintaining, or decreasing the experienced emotion in a contextually appropriate manner (Aldao, 2013; Gross, 2015b; Gross \& Thompson, 2007). 
One popular theoretical conception of emotion regulation, the Process Model of Emotion Regulation (Gross, 1998, 2015b), identifies specific categories of emotion regulation strategies that can be employed either before an emotion is elicited (e.g., selecting a situation; antecedantfocused emotion regulation) or after an emotion is experienced (e.g., suppressing the expression of an emotion; response-focused emotion regulation). Previous research has commonly emphasized the outcomes related to specific emotion regulation strategies to determine their functionality, and a consistent pattern of findings has emerged. Generally, antecedent-focused strategies are related to greater positive outcomes (e.g., well-being; De Castella et al., 2013; John \& Gross, 2004) and fewer negative outcomes (e.g., psychopathology; Aldao \& Nolen-Hoeksema, 2012; Aldao, Nolen-Hoeksema, \& Schweizer, 2010; Subic-Wrana et al., 2014). Conversely, response-focused strategies tend to be associated with more negative outcomes in terms of both physical (e.g., DeSteno, Gross, \& Kubzansky, 2013) and psychological health (Aldao et al., 2010; Gross \& John, 2003; John \& Gross, 2004). However, it is important to note that certain response-focused strategies are still considered more functional (e.g., sharing; Magai, Consedine, Fiori, \& King, 2009; Quoidbach, Berry, Hansenne, \& Mikolajczak, 2010; Reis et al., 2010) than others (e.g., negative rumination; Aldao et al., 2010; Nolen-Hoeksema \& Aldao, 2011). In the current study, both functional and dysfunctional emotion regulation strategies were examined to gain a more complete understanding of the development and maintenance of emotion regulation during emerging adulthood.

Most of the research on emotion regulation has focused on negative emotions. However, recent work has shown that positive emotions are also important for overall well-being and adaptive functioning (e.g., Fredrickson, 1998b). Specifically, strategies which up-regulate or increase positive emotions (i.e., savoring) have been related to greater positive outcomes (e.g., 
higher life satisfaction; Bryant, 2003; Gentzler, Palmer, \& Ramsey, 2016; Quoidbach et al., 2010) and fewer negative outcomes (e.g., fewer depressive symptoms; Bryant, 2003; Ramsey \& Gentzler, 2014). Strategies that down-regulate or decrease positive emotions (i.e., dampening) have been conversely related to fewer positive outcomes (e.g., lower life satisfaction; Quoidbach et al., 2010) and greater negative outcomes (e.g., more depressive symptoms; Feldman, Joormann, \& Johnson, 2008; Gentzler et al., 2016). Because emotion regulation, functional and dysfunctional strategies with both negative and positive emotions, has consistently exhibited associations with mental health and well-being, it is important to understand its development and how it may manifest during different periods of the life span. Many researchers interested in the development of emotion regulation have focused on the socialization process as a key aspect in understanding the emergence and maintenance of emotion regulation abilities.

\section{Parental Socialization of Emotions}

Emotion socialization is the process by which others influence an individual's understanding of, responses to, or coping with an emotionally evocative situation (Eisenberg, Cumberland, \& Spinrad, 1998; Garner \& Estep, 2001). As theory and research on emotion socialization has evolved, it has become necessary to find a consistent manner of discussing emotion socialization methods. Denham, Mitchell-Copeland, Strandberg, Auerbach, and Blair (1997) have combined previous theoretical and empirical work to offer a comprehensive presentation of three main methods of parental emotion socialization: contingent responding, modeling, and coaching (Eisenberg, Cumberland, et al., 1998; Gottman, Katz, \& Hooven, 1996; Magai, 1991; Saarni, 1993; Tomkins, 1962, 1963). Contingent responding, or socialization agents' responses and reactions to the target individual's emotions, generally either reinforces or punishes emotional expressions. Modeling occurs when socialization agents display and express 
their own emotions and thereby, sometimes inadvertently, teach the target individual about emotions and the extent to which they are acceptable to express. Lastly, coaching is characterized by clear instruction or explanation about emotions and proper emotional expression (Denham, 2007; Denham et al., 1997; Saarni, 1993, 1999).

The present study focused on the emotion socialization strategy of contingent responding because it is ubiquitous as people express negative and positive emotions to others regardless of their age (e.g., Gable \& Reis, 2010). We also wanted to tease apart the more explicit emotion socialization method of contingent responding from less overt methods, specifically, modeling. Below, we briefly discuss all three prominent emotion socialization strategies to provide a comprehensive review, although only the first two methods were examined within the present study. Overlap among different emotion socialization methods and the developmental trajectory of parental emotion socialization across infancy, childhood, and adolescence are also discussed.

Contingent responding. Parents' responses to their children's emotional expressions have been commonly studied throughout the child and adolescent literatures. Much of this research has applied Carol Magai's (1996) model of emotion socialization which suggests there are five main strategies that parents use to encourage or discourage their children's negative and positive emotional expressions. First, parents can reward their children's emotional expressions by encouraging, comforting, assisting, or empathizing with them. Generally, reward is considered an adaptive or functional socialization strategy that is related to positive outcomes (e.g., experiencing more positive affect; Garside, 2005). Second, parents can punish their children by expressing disapproval, shame, or making fun of children's negative and positive emotional expressions. Punishment of emotional expressions has been linked to negative outcomes in studies conducted with 3- to 14-year olds (e.g., more internalizing and externalizing 
behaviors; O’Neal \& Magai, 2005; Silk et al., 2011). Third, parents can override their children's negative and positive emotions by dismissing the emotional expression (e.g., being told to "cheer up" when sad) or distracting the child with external stimuli (e.g., buying them something). In studies including samples ranging in age from 3- to 16-year olds, override responses' associations with outcomes have been mixed, but have been generally considered a functional strategy (Brand \& Klimes-Dougan, 2010; O’Neal \& Magai, 2005; Silk et al., 2011). Fourth, parents can neglect their child's negative and positive emotions by ignoring the emotional expression. Retrospective reports with college students of neglect of emotional expressions in childhood have been associated with negative outcomes (e.g., psychological distress; Garside \& Klimes-Dougan, 2002a). Lastly, parents can magnify their children's emotional expressions by reacting in such a way that they match or exacerbate the expressed emotion. Magnifying children's emotional responses with negative emotions is considered dysfunctional and related to poorer outcomes (e.g., more internalizing and externalizing behaviors with 3- to 14- year olds; O’Neal \& Magai, 2005; Silk et al., 2011). Conversely, magnifying positive emotions is generally considered functional and has been hypothesized to be linked to more positive and/or less negative outcomes (Fredrickson, 1998a; Garside, 2005). To summarize, responses of reward and magnify facilitate the expression of an emotion, whereas responses of punish, override, and neglect inhibit the expression of an emotion (Garside, 2005; Garside \& Klimes-Dougan, 2002a; Magai, 1996), though the functionality of some responses is dependent upon the valence of the emotion (e.g., magnify; Garside, 2005).

Other researchers have also examined contingent parental responses to their children's emotional expressions. For example, the Coping with Children's Negative Emotions Scale (CCNES; Fabes, Eisenberg, \& Bernzweig, 1990; Fabes, Poulin, Eisenberg, \& Madden-Derdich, 
2002) is a popular measure of parents' responses to hypothetical situations in which their child has an experience that evokes a negative emotion. Parents reactions are generally categorized as supportive (e.g., expressing encouragement) or unsupportive (e.g., minimizing; Fabes et al., 2002; Morelen, Shaffer, \& Suveg, 2016; Smith et al., 2006). The subscales of the CCNES generally match those in Magai's (1996) theoretical model and their associations with outcomes are also analogous to Magai's (1996) scales (e.g., supportive responses are related to better emotion regulation in 8- to 16-year olds; Morelen et al., 2016; Smith et al., 2006). Conversely, with positive emotions, the Parents Responses to Children's Positive Emotions Scale (PRCPS; Ladouceur, Reid, \& Jacques, 2002; Yap, Allen, \& Ladouceur, 2008) is a common vignette-based measure of positive emotion socialization. The PRCPS consists of four subscales (socialization, encouragement, reprimand, and discomfort) which are generally aggregated into two broader scales: validating reactions (encouragement) and invalidating reactions (e.g., reprimand; Yap et al., 2008). Consistent with work on emotion socialization with negative emotions, subscales of the PRCPS were associated with outcomes in expected ways in a sample of 7- to 12-year olds (e.g., invalidating responses are associated with more internalizing symptoms; Yi, Gentzler, Ramsey, \& Root, 2016).

Although the previous work on contingent responses as emotion socialization has been correlational, many prominent researchers theorize based on this work that parental emotion socialization behaviors directly influence many aspects of children's functioning (Eisenberg, Cumberland, et al., 1998; Miller-Slough \& Dunsmore, 2016; Morris, Silk, Steinberg, \& Robinson, 2007). Further, prior studies conducted with children and adolescents have found support for the indirect effect of children's emotion regulation on the link between parents' emotion socialization and indices of children's adjustment (Eisenberg et al., 2001; Smith et al., 
2006; Yap, Allen, \& Ladouceur, 2008; Yap, Schwartz, Byrne, Simmons, \& Allen, 2010).

Extending previous work, the current study examined a mediation model where parental and friend emotion socialization influences how emerging adults regulate their own emotions, which in turn influences their own well-being.

Modeling. Others' displays of emotion and emotion regulation, specifically parents', have shown a direct link to how infants, children, and adolescents display and regulate their own emotions. This direct link could be due to children mimicking their parents' emotional responses. Conversely, genetic components shared between parents and children could also account for these similar emotional responses (e.g., Calkins \& Hill, 2007; Grusec, 2011). Previous work with 9- to 12-year old children suggests that the manner in which parents regulate their emotions is related to how their children regulate their own emotions (Kliewer, Fearnow, \& Miller, 1996; see Bariola, Gullone, \& Hughes, 2011 for a review). Additionally, parents' modeling expressions of specific negative emotions have been associated with their 8- to 12-year old children's expressions of the same emotions (e.g., fear, anxiety; Burstein \& Ginsburg, 2010; Muris, Steerneman, Merckelbach, \& Meesters, 1996). Parents' expressions of positive emotions during the first three years of life have also been linked to their infants' and toddlers' expression of positive emotions (e.g., happiness, joy; Denham, 1989; Haviland \& Lelwica, 1987; Termine \& Izard, 1988). Expressivity within the family, more generally, has been examined as a form of modeling emotionally expressive behaviors with prior work suggesting that general expressivity within the family is associated with children's expressiveness. For instance, both parental positive and negative expressivity have been associated with 4.5- to 12-year old children's functional emotion regulation positively and negatively, respectively (Eisenberg et al., 2003; Valiente, Fabes, Eisenberg, \& Spinrad, 2004). 
Emotion contagion, which occurs when exposure to one individual's emotions leads to other individuals acquiring that emotional state (Izard, 1977), is another manner in which observing parents' emotions and behaviors could influence children's own emotional expressions and regulation (Garside, 2005; Morris et al., 2007). Emotion contagion is suggested to occur as early as infancy and continue throughout the life span (Dimberg, 1982, 1990; Saarni, Campos, Camras, \& Witherington, 1998; Wild, Erb, \& Bartels, 2001). Although much of the research on emotional contagion focuses on negative emotions (e.g., anger; Dimberg, 1982, 1990; Lundqvist \& Dimberg, 1995), positive emotions such as laughter can also be contagious (e.g., Provine, 1992, 2000). Specifically, the overall amount of emotions, positive and negative, within the family and parents' emotional displays toward their children likely induces emotion in the children (Garside, 2005; Morris et al., 2007).

Coaching. Another manner through which parents can socialize their children's emotions is through explicit and direct teaching or discussion about emotions. Previous theory and research has proposed that there are two main meta-emotion philosophies (i.e., set of beliefs and approaches to parents' own emotions and to their children's emotions) which parents can ascribe to when socializing their children's emotions: emotion-coaching and emotion-dismissing (Gottman et al., 1996; Katz, Maliken, \& Stettler, 2012). The emotion-coaching philosophy involves being aware and accepting of children's emotions whereas emotion-dismissing parents are often unaware of children's emotions and view them as harmful which results in ignoring or denying children's emotional expressions (Gottman et al., 1996; Lunkenheimer, Shields, \& Cortina, 2007). In studies with toddlers and children, parents who have an emotion-coaching philosophy often also have children who are more socioemotionally competent (Brophy- Herb et al., 2011; Loop \& Roskam, 2016; see Morris et al., 2007 for a review) and better at regulating 
their emotions (Gottman et al., 1996; Hooven, Gottman, \& Katz, 1995). Conversely, children between 8- and 12-years old with parents who endorse an emotion-dismissing philosophy tend to have more behavioral problems and difficulty regulating their emotions (Lunkenheimer et al., 2007; Raval, Raval, \& Deo, 2013). Moreover, an intervention, Tuning into Kids/Teens, which has focused on teaching parents emotion-coaching skills, has shown to not only improve parents' emotion socialization abilities but also reduce problem-behavior and improve emotion knowledge in both children (aged 4 to 5 years) and adolescents (aged 10 to 13 years; Havighurst et al., 2013; Havighurst, Harley, \& Prior, 2004; Havighurst, Wilson, Harley, \& Prior, 2009; Havighurst, Wilson, Harley, Prior, \& Kehoe, 2010; Kehoe, Havighurst, \& Harley, 2014). The success of the Tuning into Kids/Teens intervention lends support to the notion that parents' emotion socialization styles are malleable and can have a direct impact on child outcomes (Loop \& Roskam, 2016).

Although Gottman and colleagues' (1996) meta-emotion philosophy has garnered a lot of empirical consideration, other researchers have called attention to the methodological issues in that it is problematic to study a mixture of beliefs, thoughts, and behaviors about oneself and their child as a single, coherent construct (Halberstadt et al., 2013; Morey \& Gentzler, 2017). Specifically, with a single measure, researchers are unable to separate parental beliefs from their behaviors and consequently cannot determine which aspect influences child outcomes (Cowan, 1996; Eisenberg, 1996). In response to this issue, researchers have begun to create measures which separate parental beliefs from their behaviors (e.g., Parents' Beliefs about Children's Emotions; Halberstadt et al., 2013; Parents' Responses to Children's Positive Events; Gentzler, Ramsey, \& Black, 2015). Although the construct of meta-emotion philosophy itself encompasses 
a myriad of components, all three of the main socialization methods reviewed above also seem to share largely overlapping components with one another.

Overlap among emotion socialization methods. Considerable overlap exists among the three main emotion socialization methods proposed by Denham and colleagues (1997). For instance, Gottman and colleagues' (1996) meta-emotion philosophy of emotion-coaching has shown to facilitate emotion regulation in a similar manner as Magai's (1996) reward socialization strategy. Additionally, the emotion-dismissing philosophy discourages emotional expression and functional emotion regulation which is comparable to the contingent response of punish (Magai, 1996). However, Magai's (1996) model of emotion socialization makes further distinctions between strategies that facilitate (i.e., reward, magnify) and discourage (i.e., punish, override, neglect) emotional expressions. It has also been proposed by others that modeling of emotional expressions and emotion regulation is likely related to parents' meta-emotion philosophy (Garside, 2005; Gottman et al., 1996) providing further overlap among the main methods of emotion socialization. Because of the overlap among the three main emotion socialization strategies, the method of contingent responding, specifically Magai's (1996) five socialization strategies, was the main focus of the present study. Magai's (1996) model provides more nuanced information among types of strategies that socialization agents may use to facilitate or discourage emotional expression compared to previous theories and measures of modeling and emotion-coaching. Therefore, focusing on contingent responding should provide a wealth of information about the structure and function of emotion socialization during emerging adulthood. Additionally, as done in previous studies with children and adolescents (e.g., Bariola et al., 2011; Bariola, Hughes, \& Gullone, 2012), parents’ own emotion regulation was examined as a way of modeling emotion regulation with their adult children. By providing a primary focus on 
contingent responding and a secondary focus on modeling, the present study provides a foundation for future work on parental emotion socialization with emerging adults. Coaching was not examined in the present study because of its broad overlap with both contingent responding and modeling. Moreover, it likely that socialization agents will expect emerging adults to know what appropriate emotional expressions are. Therefore, it is less likely that emotion coaching, which involves direct and explicit teaching about emotions, occurs during this developmental period. The present study's goal was to provide a starting point in the examination of emotion socialization during emerging adulthood.

\section{Changes in parental emotion socialization across childhood and adolescence. As} children grow older, parents' emotion socialization tactics seem to shift, possibly to match their child's acquisition of emotion-related skills (Mirabile, Oertwig, \& Halberstadt, 2016). It has been proposed that modeling and contingent responding are prevalent methods of emotion socialization during infancy (e.g., Malatesta \& Haviland, 1982). However, as children get older another strategy which focuses on discussing and explaining emotions to children (e.g., coaching) may further aid in fostering children's emotional abilities (Eisenberg, Cumberland, et al., 1998; Garside, 2005; Gottman et al., 1996). For example, a previous study, with assessments at 5, 9, and 11 years old, showed that parents' overall coaching of negative emotions increased across childhood (Stettler \& Katz, 2014). However, specific facets of emotion socialization (i.e., awareness and acceptance of negative emotions) simultaneously decreased across the same time period (Stettler \& Katz, 2014). Additionally, emotion socialization may be differentially predictive of outcomes depending upon the child's age. For instance, in a group of 3- to 6-year old children, Mirabile and colleagues (2016) found that supportive emotion socialization with negative emotions predicted better emotion regulation and fewer internalizing and externalizing 
problems in younger children, while associations with older children were non-significant but in the opposite direction. Moreover, in a sample of 11- to 16-year olds, Klimes-Dougan and colleagues (2007) found that parents of older adolescents, compared to younger adolescents, were less supportive and more punitive toward negative emotional displays. The limited work that has examined changes in parental emotion socialization longitudinally across childhood and adolescence suggests that as parents' expectations of their children's emotional abilities change, so does their emotion socialization practices. However, research has not previously explored parental socialization of emotions in age periods after adolescence. It has been hypothesized, by others (e.g., Garside, 2005) and in the current study, that parental methods of emotion socialization may become less relevant or overshadowed during adolescence and later as friends begin to play a larger role in the socialization process.

\section{Friend Socialization of Emotions}

Across the life span, friends ${ }^{1}$ have been revealed as a significant source of information separate from parents (Buhrmester \& Furman, 1987; Burleson \& Kunkel, 2002; Dunsmore \& Karn, 2004). Children's ability to provide emotional support to others and follow display rules are important predictors in the likelihood of being accepted by their peers (e.g., Burleson \& Kunkel, 2002; Crick \& Dodge, 1994). Additionally, as children age, they often turn to friends, more so than parents, for emotional support (Helsen, Vollebergh, \& Meeus, 2000; Hunter \& Youniss, 1982; Rapini, Farmer, Clark, Micka, \& Barnett, 1990). Friends often provide feedback

\footnotetext{
${ }^{1}$ According to Merriam-Webster dictionary (2017), a friend is defined as someone who is attached to another individual by affection or esteem. Conversely, a peer is considered someone of equal standing with another individual. However, throughout the literature on emotion socialization, the terms "friend" and "peer" are often used interchangeably in that research on peers is actually conducted with friends (as indexed by the authors' description in the study's methodology; e.g., Kandel \& Andrews, 1987; Lougheed, Craig, et al., 2016; Parr, Zeman, Braunstein, \& Price, 2016; Prinstein, 2007). In this literature review and proposed study, the term "friend" will be used to represent close others whom the target participant nominates as a close or best friend.
} 
regarding the appropriateness and effectiveness of skills, which can lead to refinement in deficient areas (Buhrmester, 1996; Burleson \& Kunkel, 2002). Consequently, friends serve as another model for behavior and play an important role in the development of emotions and emotion regulation (Dunsmore \& Karn, 2004; Reindl et al., 2016; Spinrad et al., 2004).

Contrary to family members, friends do not feel responsible for socializing (i.e., teaching, responding to, or modeling emotions; Eisenberg et al., 1998) one another, but rather support and sharing is expected within friendships during childhood (see von Salisch, 2001 for a review) and adolescence (e.g., Klimes-Dougan et al., 2014). Generally, receiving supportive responses to emotional expressions from friends facilitates functional emotion regulation while unsupportive responses have been associated with emotion dysregulation (see Miller-Slough \& Dunsmore, 2016 for a review). Emotion socialization responses from friends have also been linked to physical symptoms, with punitive responses (i.e., when one friend diminishes the importance or validity of the other's problem or criticizes the friend's response) being related to more somatic complaints in a sample of 11- to 15-year olds (Parr, Zeman, Braunstein, \& Price, 2016). The expectation of specific emotion socialization responses from friends has also shown to be important. Specifically, in a sample of 10- to 16-year olds expectations of aggression and magnifying responses (i.e., matching or mirroring the other's emotions) to expressions of negative emotions were associated with more dysfunctional emotion regulation whereas expectations of supportive responses from friends were associated with less dysfunctional emotion regulation (Borowski, Zeman, \& Braunstein, 2016). Moreover, adolescents (aged 12 to 14 years) who receive supportive responses from their friends are more likely to share again in the future, providing friends with further opportunity to socialize emotions (Legerski, Biggs, Greenhoot, \& Sampilo, 2015). 
Emotion socialization from friends has also been related to broader indices of functioning such as internalizing and externalizing symptoms. Adolescents aged 12- to 17-years old with elevated internalizing symptoms tended to have friends with higher internalizing symptoms (Deater-Deckard, 2001; Giletta et al., 2011; Prinstein, 2007). Conversely, adolescents that used more functional emotion regulation strategies tended to also have friends who used more functional emotion regulation strategies (Reindl et al., 2016). Similar to parental responses, research on friend responses to emotions suggests that supportive responses from friends are related to fewer externalizing behaviors whereas unsupportive responses are related to increases in externalizing behaviors in 11- to 17-year olds (Klimes-Dougan et al., 2014). However, other studies have shown that emotional support from friends should be sought out in moderation. Some research suggests that, during childhood and adolescence, seeking friend support too frequently may lead to increases in depressive symptoms over time, possibly through corumination (i.e., repeatedly focusing on and discussing problems and negative feelings; Prinstein, Borelli, Cheah, Simon, \& Aikins, 2005; Rose, 2002; Rose, Carlson, \& Waller, 2007). While corumination among close friends has been linked to positive relationship quality, it has also been associated with increased depressive and anxiety symptoms in children, adolescents, and adults (Calmes \& Roberts, 2008; Rose, 2002; Starr \& Davila, 2009; Stone, Hankin, Gibb, \& Abela, 2011). Additionally, co-rumination with mothers is predictive of internalizing symptoms in adolescents in $5^{\text {th }}, 8^{\text {th }}$, and $11^{\text {th }}$ grades; however, this association was no longer significant once co-rumination with friends was statistically controlled for in the model (Waller \& Rose, 2010, 2013). Furthermore, for girls in $3^{\text {rd }}, 5^{\text {th }}, 7^{\text {th }}$, and $9^{\text {th }}$ grades, a reciprocal association has been found with co-rumination longitudinally linked to increased internalizing symptoms and positive friendship quality which were in turn associated with increases in co-rumination six months later 
(Rose et al., 2007). In a sample of adult graduate students, co-rumination was found to be a suppressor variable and mediate the association between social support and emotion exhaustion (Boren, 2013), suggesting that this process is not limited to the adolescent age period. Although the literature on friendships across the life span, more generally, is quite expansive (e.g., Newcomb \& Bagwell, 1995; Tesch, 1983; Wrzus, Hanel, Wagner, \& Neyer, 2013), friends have not been examined as thoroughly, compared to parents, as agents of emotion socialization (see Miller-Slough \& Dunsmore, 2016 for a review) and even less often in conjunction with parents (see Burleson \& Kunkel, 2002 for an exception). Additionally, all of the previously reviewed work has been conducted during the childhood and adolescent age periods with no empirical work on emotion socialization from friends at later periods in the life span.

\section{Emerging Adulthood}

Emerging adulthood is the period between adolescence and adulthood, ranging in age from 18 to 25 years (Arnett, 1998, 2007). This stage has been considered a critical normative life transition because the potential for change exists in almost every aspect of life (e.g., school/work, romantic relationships; Schulenberg, Sameroff, \& Cicchetti, 2004). Additionally, these major changes, which normally involve developing skills considered necessary for adulthood by the broader culture, take place over just a few years (Arnett, 1998; Scharf \& Mayseless, 2010; Schulenberg et al., 2004). Moreover, Arnett (2000) has suggested that emerging adulthood is the period of the life span that allows the most opportunity for identity exploration and is also when most exploration takes place.

Emerging adulthood has become more widely recognized as a distinct age period likely because individuals between the ages of 18 and 25 do not view themselves as adolescents nor do they feel as though they are adults (Arnett, 2000). According to emerging adults, there are three 
main criteria necessary for adulthood that they generally have not yet achieved: accepting responsibility for one's self, making independent decisions, and becoming financially independent. Interestingly, emerging adults ranked other more common conceptions of adulthood (e.g., getting married) as less important in the achievement of adult status (Arnett, 1998, 2000). Furthermore, given the lack of independence shown by individuals during this period, support and guidance from others (e.g., parents, friends) may be especially beneficial for a successful transition to adulthood.

Socialization during emerging adulthood. Previous research on parental emotion socialization with the emerging adult population has not assessed current socialization of emotions; rather, a retrospective approach is commonly used where emerging adult participants report how their parents reacted to specific emotions when they were children (e.g., Garside \& Klimes-Dougan, 2002a; Magai, Consedine, Gillespie, O’Neal, \& Vilker, 2004). Although research on parental emotion socialization with their adult children has not been conducted, other areas of research suggest that parents continue to be important in socializing behaviors and beliefs during this period. For instance, parents have been found to influence or socialize their adult children's values (Roest et al., 2009), health beliefs (Lau, Quadrel, \& Hartman, 1990), and financial literacy (Jorgensen \& Savla, 2010). From a life-span developmental perspective (Baltes, 1987; Baltes et al., 2006), development does not end after childhood but continues across the entire life span. Researchers who focus on emotional development support this notion and suggest that this development occurs in complex ways (e.g., Butler \& Randall, 2013; Carstensen, 1995; Cole, 2014). As other regulatory abilities are still developing during this time (e.g., self-control; Burt, Sweeten, \& Simons, 2014; Duckworth \& Steinberg, 2015), and research suggests that emerging adults are still learning how best to regulate their emotions (Magai, 
Consedine, Krivoshekova, Kudadjie-Gyamfi, \& McPherson, 2006; Zimmermann \& Iwanski, 2014), it was proposed in the present study that parents continue to be pivotal in the socialization of emotions during emerging adulthood. Additionally, given the generally low levels of wellbeing found in today's college students (e.g., more than one in three report "feeling so depressed it was difficult to function"; American College Health Association, 2008), it is important to examine potential predictors of well-being in this population.

Previous work has also not thoroughly examined the potential importance of friend emotion socialization during emerging adulthood. Although emerging adulthood is characterized by substantial amounts of time spent with friends (Arnett, 2004; Buhrmester \& Carbery, 1992), much of the research during this period has focused on the importance of romantic relationships (e.g., Gonzaga, Turner, Keltner, Campos, \& Altemus, 2006; Simpson, Collins, Tran, \& Haydon, 2007) or how friends may influence engagement in risky behaviors (e.g., Gardner \& Steinberg, 2005; Poelen, Scholte, Willemsen, Boomsma, \& Engels, 2007). Similar to research with parents, work in other areas (e.g., substance use; Andrews, Tildesley, Hops, \& Li, 2002; West, Sweeting, \& Ecob, 1999) has suggested that friends continue to be an influential force during emerging adulthood. Research on childhood and adolescence suggests that parents may facilitate or hinder the formation of friendships through support, monitoring, and active engagement in their children's social world (Knoester, Haynie, \& Stephens, 2006; R. D. Parke \& Bhavnagri, 1989; R. D. Parke \& Ladd, 1992; Vernberg, Beery, Ewell, \& Abwender, 1993). However, parents may be less likely to influence their children's friendships in college. For instance, previous work suggests that the importance of friends, compared to parents, increases from adolescence to adulthood (Helsen et al., 2000; Hunter \& Youniss, 1982; Rapini et al., 1990). Therefore, it is 
possible that friends continue to socialize emotions during this time and that socialization from friends may even be more important than that from parents.

Bidirectionality of emotion socialization. Historically, socialization has been conceptualized as a unidirectional process where parental behaviors predicted child behaviors (Kuczynski \& Parkin, 2008). However, this basic model is now regarded as an inaccurate representation of the socialization process (Bell, 1968; Kuczynski \& Parkin, 2008). Instead, many scholars agree that socialization is a "two-way street," in that socialization agents influence the target individual, while the target individual also influences the socializing agent, suggesting the socialization process is bidirectional and reciprocal in nature (Grusec, 2011; Saarni, 1999; Zahn-Waxler, 2010).

The bidirectional nature of emotion socialization has been widely theorized and discussed throughout the existing literature (e.g., Campos, Campos, \& Barrett, 1989; Zahn-Waxler, 2010), but less research has empirically examined bidirectional associations with emotion socialization. Specifically, previous research has rarely directly examined children as active socialization agents of their parents' emotions. One manner in which previous work has assessed bidirectionality in the socialization process is through work examining in-the-moment coregulation between child-mother dyads (Aureli \& Presaghi, 2010; Haviland \& Lelwica, 1987; Kochanska, Forman, \& Coy, 1999; Lougheed et al., 2016; Mancini, Luebbe, \& Bell, 2016); but this research has not yet extended to adult children and their parents or friends.

While children are considered active in the socialization process beginning very early in life (Morris et al., 2007; Zahn-Waxler, 2010), the focus of previous research has been on how child characteristics elicit socialization responses from adults (e.g., temperament; Eisenberg \& Fabes, 1994; Yap, Allen, Leve, \& Katz, 2008), how children's emotions can indirectly affect 
their parents' emotions (e.g., Durbin, Klein, Hayden, Buckley, \& Moerk, 2005; Martini, Root, \& Jenkins, 2004), or how children can actively choose whether or not to accept the information being socialized (e.g., Barni, Ranieri, Scabini, \& Rosnati, 2011; Maccoby, 2008). Little to no empirical research exists to support the notion that children may act as active socialization agents that directly influence their parents' emotions similar to the ways that parents directly socialize their children (e.g., child asking what is wrong when the parent is sad). However, research in other areas suggest that children can influence their parents' values and attitudes (Knafo \& Galansky, 2008; Peters, 1985; Pinquart \& Silbereisen, 2004; Roest et al., 2009) lending to the hypothesis that children may also actively socialize their parents' emotions.

Closeness. The parent-adult child relationship experiences change during emerging adulthood. In general, parents' interaction frequency with their adult children remains stable while relationship satisfaction and emotional closeness increases (Carstensen, 1992; Lye, 1996; Thornton, Orbuch, \& Axinn, 1995). Additionally, adult children and their parents often exchange mutual support for one another (Aquilino, 1997; Mancini \& Blieszner, 1989). A sample of German adults further showed that after romantic partners, individuals feel most supported by their own children followed by their mothers, friends, and fathers (Buhl, 2009). Close friendships also seem to thrive during emerging adulthood. Specifically, interaction frequency, relationship satisfaction, and emotional closeness with close friends are all relatively high during this time (Carstensen, 1992). Overall, this research suggests that emerging adulthood is a time of transition during which the quality of parent and close friend relationships may be especially important. Similar to work with children and adolescents (Blair et al., 2014; Lougheed et al., 2016; Prinstein, 2007), the quality of relationships with parents and friends may be important to 
consider when examining the emotion socialization process (see Morris, Criss, Silk, \& Houltberg, 2017 for a review).

\section{An Integrative Model of Emotion Socialization}

A number of researchers have called for a more integrative model of socialization (Kerr, Stattin, Biesecker, \& Ferrer-Wreder, 2003; Vandell, 2000). Specifically, it has been suggested that socialization is not experienced from one agent alone, but rather exchanges with multiple individuals is a more accurate representation of the socialization process (Bugental \& Grusec, 1998; von Salisch, 2001). Within research on emotions more generally, very few studies have compared the effects of multiple socialization agents (Miller-Slough \& Dunsmore, 2016). However, the studies that have empirically examined both parents and friends within the same model, support the notion that these are two socialization agents that relate to child outcomes in different ways. For example, in a sample of early elementary school-aged children, Burleson and Kunkel (2002) found that while mother-reported comforting skills were the strongest predictor of children's comforting skills, peer-reported comforting skills also significantly contributed to the model. Furthermore, in the prediction of children's affective perspective-taking, peer comforting skills were a significant predictor while mothers' were not (Burleson \& Kunkel, 2002). In another study of slightly older elementary school-aged children, it was found that children's perceptions of best friends' supportive responses were a better predictor of children's sadness regulation than both mother supportive and discouraging responses (Tillery, Cohen, Parra, Kitzmann, \& Howard Sharp, 2015). Lastly, in a sample of adolescents it was found that as adolescents get older, they disclose more emotional information to friends than parents. Specifically, 12-year-olds were more likely to disclose to their parents while 15-year-olds were more likely to disclose to friends (Rapini et al., 1990). This limited research suggests that 
examining the effects of parents and friends in the same model provides a more thorough understanding of the processes taking place. With respect to the emerging adulthood period, prior work has not compared emotion socialization from multiple agents within a single model. Therefore, it may be especially beneficial to examine a more inclusive model of emotion socialization with both parents and friends during this period.

\section{Statement of the Problem}

Previous work has emphasized the importance of parents and friends, individually, in the socialization of emotion; however, this research is limited to childhood and adolescent age periods. Additionally, the research that has been conducted with children and adolescents suggests there are differential associations between certain types of emotion socialization strategies and outcomes such as emotion regulation abilities and well-being. Furthermore, previous work has generally only examined one agent of socialization at a time rather than examining the effects of multiple agents on individuals' emotional abilities and well-being. Research conducted previously has also focused on socialization from the parent to the child while not examining potential direct effects in the opposite direction, from the child to the parent. Lastly, little research exists on the socialization of positive emotions which may be just as important in relation to well-being as the socialization of negative emotions. Examining how parents' and friends' emotion socialization is related to outcomes with emerging adults is a topic of particular importance because of the generally low well-being reported in college students (e.g., American College Health Association, 2008) as well as that managing emotions has been found to relate to the low levels of well-being in this population (Freire, Ferradás, Valle, Núñez, \& Vallejo, 2016).

The present study extends previous literature by: (a) utilizing a multiple-reporter sample including emerging adults, their parent(s), and a friend, (b) utilizing measures of socialization for 
both negative and positive emotions, (c) examining how socialization from parents and friends is associated with indices of emerging adult emotion regulation with positive and negative emotions and well-being, (d) examining and comparing the effects of parental and friend emotion socialization within the same model, (e) examining if emerging adult socialization of their parents' emotions is related to their parents' emotion regulation and well-being, (f) examining if emerging adult socialization of their friend's emotions is related to their friend's emotion regulation and well-being, and (g) examining emerging adult emotion regulation as a mediator of the link between parent and friend emotion socialization responses and emerging adult well-being.

\section{Research Questions and Hypotheses}

\section{Research Question 1}

Is the factor structure for emotion socialization with parents, friends, and emerging adults consistent with previous research on parent-child socialization?

Hypothesis 1. Emotion socialization as reported by parents, friends, and emerging adults will consist of two latent factors: Supportive Emotion Socialization and Unsupportive Emotion Socialization. For all reporters, the Supportive Emotion Socialization factor will consist of four items: Reward and Override with negative affect (NA) and Reward and Magnify with positive affect (PA). For all reporters, the Unsupportive Emotion Socialization factor will consist of six items: Punish, Neglect, and Magnify with NA and Punish, Neglect, and Override with PA.

\section{Research Question 2}

Does parents' emotion socialization relate to emerging adult outcomes? 
Hypothesis 2a. More supportive parental socialization and less unsupportive parental socialization will be related to emerging adults' use of more functional emotion regulation strategies.

Hypothesis 2b. More supportive parental socialization and less unsupportive parental socialization will be related to emerging adults' use of less dysfunctional emotion regulation strategies.

Hypothesis 2c. More supportive parental socialization and less unsupportive parental socialization will be related to emerging adults' higher well-being (i.e., higher PA, life satisfaction, subjective happiness, and lower NA).

\section{Research Question 3}

Does friend emotion socialization relate more strongly to emerging adult outcomes than parent emotion socialization?

Hypothesis 3a. More supportive friend socialization and less unsupportive friend socialization will be more strongly related to emerging adults' use of more functional emotion $\underline{\text { regulation strategies, compared to more supportive parental socialization and less unsupportive }}$ parental socialization.

Hypothesis 3b. More supportive friend socialization and less unsupportive friend socialization will be more strongly related to emerging adults' use of less dysfunctional emotion $\underline{\text { regulation strategies, compared to more supportive parental socialization and less unsupportive }}$ parental socialization.

Hypothesis 3c. $\underline{\text { More supportive friend socialization and less unsupportive friend }}$ socialization will be more strongly related to emerging adults' higher well-being compared to more supportive parental socialization and less unsupportive parental socialization. 


\section{Research Question 4}

Does emerging adult socialization of their parents' emotions relate to parent outcomes?

Hypothesis 4a. More supportive emerging adult socialization and less unsupportive socialization with their parents will be related to parents' use of more functional emotion regulation strategies.

Hypothesis 4b. More supportive emerging adult socialization and less unsupportive socialization with their parents will be related to parents' use of less dysfunctional emotion

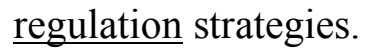

Hypothesis 4c. More supportive emerging adult socialization and less unsupportive socialization with their parents will be related to parents' higher well-being.

\section{Research Question 5}

Does emerging adult socialization of their friends' emotions relate to friend outcomes?

Hypothesis 5a. More supportive emerging adult socialization and less unsupportive socialization with their friends will be related to friends' use of more functional emotion regulation strategies.

Hypothesis 5b. More supportive emerging adult socialization and less unsupportive socialization with their friends will be related to friends' use of less dysfunctional emotion regulation strategies.

Hypothesis 5c. More supportive emerging adult socialization and less unsupportive socialization with their friends will be related to friends' higher well-being.

\section{Research Question 6 (exploratory)}

Do emerging adults' emotion regulation strategies mediate the association between parent and friend emotion socialization responses and emerging adult well-being? 
Hypothesis 6a. Emerging adults' functional and dysfunctional emotion regulation with will mediate the association between parent and friend supportive and unsupportive emotion socialization and emerging adult well-being.

\section{Method}

\section{Participants}

Main study participants were 612 emerging adult college students ranging in age from 18 to 25 years old $(M=19.31, S D=1.11 ; 20.3 \%$ male $)$. The participants reflected the sociodemographic characteristics of the university from which they were recruited. Specifically, $86.7 \%$ of the sample self-identified as White/European American, 8.5\% as other or multiple ethnicities, $2.8 \%$ as Black/African-American, $1.3 \%$ as Hispanic/Latin-American, and .70\% as Asian or Asian- American. Participants also reported their class rank: 23.7\% Freshmen, 48.9\% Sophomores, $20.6 \%$ Juniors, $4.6 \%$ Seniors, $1.8 \%$ Fifth years, . $1 \%$ Sixth years or more. Additionally, the vast majority of participants reported not being first-generation college students (80.7\%). See Tables 1 and 2 for additional demographic information. Of all emerging adult participants, $65.0 \%$ had at least one parent/guardian participate, $10.5 \%$ had two parents participate, $42.6 \%$ had a friend participate, and 34.5\% had one parent and one friend participate. There were no significant differences on main study variables for those who had a parent and/or friend also participate compared to those who did not. However, emerging adults who had a friend participate were significantly more likely to also have a parent participate, $\chi 2(1)=47.20, p$ $<.001$. Additionally, emerging adults who had a parent participate reported their parents having significantly less difficulty paying bills $(M=1.73, S D=.86)$ compared to those who did not have a parent participate $(M=1.97, S D=.95), t(624)=3.20, p=.001$. 
Participating parents $(N=461)$ ranged in age from 36 to 74 years old $(M=49.69, S D=$ $5.96 ; 26.7 \%$ male). Similar to their emerging adult children, $92.0 \%$ of the parent sample selfidentified as White/European American, 2.2\% as Black/African-American, 2.2\% as other or multiple ethnicities, $1.5 \%$ as Hispanic/Latin-American, $1.1 \%$ as Asian or Asian-American, .2\% as Native American or Alaskan Native, and .8\% preferred not to answer. See Tables 1 and 2 for additional demographic information.

Participating friends $(N=261)$ ranged in age from 18 to 64 years old $(M=20.14, S D=$ $4.52 ; 31.4 \%$ male). Similar to their emerging adult friends, $87.6 \%$ of the friend sample selfidentified as White/European American, 4.6\% as Black/African-American, $4.2 \%$ as other or multiple ethnicities, 1.8\% as Hispanic/Latin-American, 1.1\% as Asian or Asian- American, and $0.7 \%$ as Native Hawaiian or Pacific Islander. The majority reported being a college student $(93.5 \%)$, many of whom also attended the same university as the emerging adult participants (65.5\%). See Tables 1 and 2 for additional demographic information.

The above reported samples were derived from larger samples of emerging adults, parents, and friends. However, a number of participants' responses were discarded due to failing validity checks (e.g., "Answer '5' strongly agree for this question") or not being able to connect the data to an emerging adult participant. See Figure 1 for a breakdown of data cleaning for each sample.

\section{Procedure}

Emerging adult participants were recruited through advertisements in Psychology courses. Emerging adults completed a survey through Qualtrics and provided contact information for at least one parent and a close friend. Parents and friends were contacted via email and/or text message with a link to complete their own survey through Qualtrics. For compensation, 
emerging adults and their friends earned extra credit toward a Psychology course of their choosing. If friends were not currently enrolled in a Psychology course or at the University, they could choose to give extra course credit to their friend or enter a drawing to win one of $10 \$ 25$ Amazon gift cards. Similarly, parents were given a choice between giving their son/daughter extra course credit and entering a drawing to win one of 10 \$25 Amazon gift cards

Prior to participation, emerging adults, their parent(s), and friend received an electronic explanation of the study's procedure to which they had to give informed consent to continue on to the survey. First, the emerging adult participants accessed and completed a battery of questionnaires online through Qualtrics. As part of their participation, and to receive compensation, they were required to leave contact information for at least one parent and one close, non-romantic and non-familial relative, friend. After parent and friend contact information was verified, emerging adult participants were awarded extra course credit for their participation. Parents and friends were contacted via email or text message and sent an electronic link to an online survey through Qualtrics.

\section{Measures}

Emotion socialization. Because existing measures of emotion socialization have focused on socialization during childhood (concurrent or retrospectively reported), the measures of emotion socialization used in the current study were adapted from their previous forms. Emerging adult participants reported how they socialized their mother's, father's, and friend's emotions of sadness, anger, worry, and happiness by reporting their own use of five socialization strategies during the last six months (i.e., reward, override, magnify, neglect, punish; Magai, 1996). Additionally, parents and friends each reported how they socialized emerging adult participants' emotions of sadness, anger, worry, and happiness by reporting their (parents' and 
friends') use of the same five socialization strategies during the last six months. Specific measure adaptations and further explanations are outlined below.

Emerging adult-report. Emerging adults, the main study participants, reported how they socialize their mothers' and fathers', as well as their friends', positive and negative emotions. To report how they socialize their parents, emerging adult participants responded to an adapted version of the Emotions as a Child 1.2 parent-report (EAC; Klimes-Dougan et al., 2007) and EAC 2 (Garside, 2005; Garside \& Klimes-Dougan, 2002b). Specifically, wording for this measure was adapted from assessing parents' socialization of their children's emotions to assess how emerging adults socialized their parents' feelings during the last six months. Emerging adults rated how each of 15 responses to their parents' emotional expressions was for them by rating on a 5 -point scale $(1=$ Not at all typical to $5=$ Very typical $)$. Specifically, there are five subscales (reward, override, magnify, neglect, punish) consisting of three items for each emotion (i.e., sadness, anger, worry, happiness). An example item from the sad override scale is "In the last six months, when your mother/mother-figure was sad, what did you do? Tell my mother to cheer up." Adaptations to this measure for the present study included adding the phrase "in the last six months", changing the wording from "child" to "mother-/father-figure", and changing item wording from past tense to present tense. These changes were made to facilitate the report of recent emotion socialization responses. Additionally, the originally used "afraid" emotion was changed to "worried/anxious" (Klimes-Dougan et al., 2014), and a few other items that seemed less appropriate in adult child-parent relationships were altered (e.g., "Hold my mother/father" was changed to "Hug them"). See Table 3 for descriptive statistics and scale reliability.

Emerging adult participants also reported on their socialization of their friends' emotions using a combination of the EAC and You and Your Friends measures (YYF; Klimes-Dougan et 
al., 2014) that was created for the present study. Rather than using the hypothetical situations from the YYF measures, which emphasize more intense feelings of sadness, anger, worry, and happiness (e.g., "You are with your friend when they find out about something really unfair and annoying that was done to them, and that has made them feel really, really angry."), we used the original wording from the EAC ("In the last six months, when your friend was sad, what did you do?"). However, we used the socialization response options from the YYF which have been previously validated with 11-17 years olds (Klimes-Dougan et al., 2014) that seemed more specific and relevant to friend relationships compared to parent-child relationships. Emerging adult participants reported how typical each of 18 responses to their friends' expressions of emotion was for them by rating each response on a 5 -point scale $(1=$ Not at all typical to $5=$ Very typical). Specifically, there are six subscales (reward, override, magnify, neglect, overt aggression, relational aggression) consisting of three items for each emotion (i.e., sadness, anger, worry, happiness). An example item from the angry reward scale is "In the last six months, when your friend was sad, what did you do? Ask them about what has made them feel angry." Similar adaptations as for the above measure reporting on parents were made to this measure. Specifically, we added the phrase "in the last six months", changed the wording from "child" to "friend" and specified to think of the friend they nominated to also participate in the study, changed item wording from past tense to present tense, and changed the originally used "afraid" emotion to "worried/anxious" (Klimes-Dougan et al., 2014). See Table 3 for descriptive statistics and scale reliability for emotion-specific subscales; see Table 6 for descriptives and reliabilities for NA combined subscales. See Appendix A for all Emerging Adult-report measures.

Friend-report. Friend participants reported on their socialization of emerging adult participants' positive and negative emotions using the same measure that the emerging adults 
used to report how they socialize their friends' emotions. See above for specific adaptations made to this measure. See Table 4 for descriptive statistics and scale reliability for emotionspecific subscales; see Table 7 for descriptives and reliabilities for NA combined subscales. See Appendix $\mathrm{C}$ for all Friend-report measures.

Parent-report. Parent participants reported their socialization of emerging adult participants' positive and negative emotions using an adapted version of the EAC 1.2 parentreport (Klimes-Dougan et al., 2007). Specifically, parents reported how typical each of 15 responses were for them when their son/daughter was experiencing sadness, anger, worry, and happiness during the last six months $(1=$ Not at all typical to $5=$ Very typical $)$. Minor changes were made to the original EAC 1.2 parent-report: the phrase "in the last six months" was added, "child" was changed to "son/daughter", and items were changed from past tense to present tense. All of these changes were made to avoid facilitating retrospective-report but rather report of current emotion socialization responses. Further, the "afraid" emotion was changed to "worried/anxious" (Klimes-Dougan et al., 2014), and other items that seemed less appropriate in adult child-parent relationships were adapted (e.g., "Hold my child" was changed to "Hug them"). See Table 4 for descriptive statistics and scale reliability for emotion-specific subscales; see Table 7 for descriptives and reliabilities for NA combined subscales. See Appendix B for all Parent-report measures.

Emotion regulation. All participants reported the strategies they use to regulate their emotions when experiencing both positive and negative emotions. Specifically, the Positive Affect and Responses Survey (PAARS; Gentzler \& Ramsey, 2015) was administered to assess general emotion regulation with PA. The PAARS includes 17 items regarding the use of emotion regulation strategies to up- or down-regulate positive emotions. Items were rated on a 5-point 
scale $(1=$ Not at all likely to $5=$ Very likely). An additional seven items from the Responses to Positive Affect scale (RPA; Feldman et al., 2008), which further assess down-regulation of PA, were also added to the PAARS (e.g., "Think 'I don't deserve this"'). Items on the RPA were originally assessed on a 4-point scale $(1=$ Almost never to $4=$ Almost always $)$; however, to be analogous with the PAARS, all PA emotion regulation items were assessed on the same 5-point scale $(1=$ Not at all likely to $5=$ Very likely $)$. Two subscales were derived from the combined PAARS and RPA items: Functional Emotion Regulation with PA consists of 12 items that sustain or up-regulate PA, while Dysfunctional Emotion Regulation with PA is made up of 12 items that diminish or down-regulate PA. See Table 5 for descriptive statistics and scale reliability.

The Regulation of Emotions Questionnaire (REQ; Phillips \& Power, 2007) was used to measure emotion regulation with NA. The REQ consists of 21 items that assess how often individuals engage in functional and dysfunctional responses to their negative emotions. Items were rated on a 7 -point scale $(1=$ Never to $7=$ Always $)$. The four subscales derived from the REQ (i.e., internal-dysfunctional, internal-functional, external-dysfunctional, externalfunctional) further examine personal/internal and environmental/external resources used to regulate NA. However, for the present study, internal and external items were aggregated to create two broad subscales: Functional Emotion Regulation with NA (11 items) and Dysfunctional Emotion Regulation with NA (10 items). See Table 5 for descriptive statistics and scale reliability.

Well-being. Three measures of well-being were assessed with all participants in the present study. First, the Scale of Positive and Negative Experience (SPANE; Diener et al., 2010), which consists of 12 items and assesses positive and negative experiences over the last month, 
was administered. Participants indicated how often they have experienced each feeling by rating on a 5 -point scale $(1=$ Very rarely or never to $5=$ Very often or always $)$. Six items make up the Positive scale (positive, good, pleasant, happy, joyful, contented) and six items make up the Negative scale (negative, bad, unpleasant, sad, afraid angry). Scores for both the Positive and Negative scales were individually summed with higher scores indicating more experiences of that valence. Both subscales of the SPANE have demonstrated good internal consistency in previous research (SPANE-P alphas .84-.88; SPANE-N alphas .80-.81; Diener et al., 2009, 2010; Howell \& Buro, 2015) as well as the present study (see Table 5).

Next, participants reported their subjective happiness using the 4-item Subjective Happiness Scale (SHS; Lyubomirsky \& Lepper, 1999). Items were rated on a 7-point scale with differing anchor points. For example, one item's (“In general, I consider myself:”) rating scale ranges from $1=$ not a very happy person to $7=$ a very happy person. Items were summed with higher scores on the scale indicating greater subjective happiness. The SHS has shown good internal consistency in previous work (alphas .79-.94; Lyubomirsky \& Lepper, 1999; Ramsey \& Gentzler, 2014) and the present study (see Table 5).

Finally, general life satisfaction was examined using the Satisfaction with Life Scale (SWLS; Diener, 2006; Diener, Emmons, Larsen, \& Griffin, 1985). Participants rated five items using a 7-point Likert scale ranging from $1=$ Strongly disagree to $7=$ Strongly agree. An example item is, "In most ways my life is close to my ideal." Item scores were summed with higher scores indicating more satisfaction with life. The SWLS has demonstrated high internal consistency in previous research (alphas .85-.94; Diener et al., 1985; Ramsey \& Gentzler, 2014) as well as the present study (see Table 5). 
Closeness. Emerging adult participants reported relationship quality with their mother, and father using the Closeness to Parents scale (Buchanan, Maccoby, \& Dornbusch, 1991). Emerging adult-report of relationship quality with friends as well as parent- and friend-report of relationship quality with the emerging adult was reported using a version of the same measure that was slightly adapted for the current study. Specifically, the adapted version substituted "mother/father" for "friend" and "son/daughter" in the respective surveys. The measure consists of 10 items assessing closeness/relationship quality with the intended target on a 5-point scale (1 $=$ Not at all to $5=$ Very). An example item is "How close do you feel to your mother/father/friend/son/daughter?" Items were summed where higher scores indicated higher relationship quality. The original Closeness to Parents scale has shown high reliability in previous research (alphas .89-.90; Buchanan et al., 1991) and the present study (see Table 5).

\section{Results}

\section{Data Cleaning and Preliminary Analyses}

Data were screened following procedures outlined by Tabachnick and Fidell (2013) in the emerging adult-, parent-, and friend-report datasets. See Figure 1 for a breakdown of data cleaning for all three datasets. Means, standard deviations, and Cronbach's alpha for key study variables can be found in Tables 3-7. There were no notable deviations from normality, so transformations were not necessary. Seven emerging adult participants had been excluded from analyses for extreme missing data (no values reported on main study measures). Multivariate outliers were assessed on key study variables. Based on a Mahalanobis Distance with a critical chi-square cutoff value of 45.32 at $p<.001,11$ emerging adult participants and two parent participants had been indicated as outliers and excluded from analyses. 
Additionally, bivariate correlations were conducted among relevant predictor and outcome variables per respective research questions. Specifically, five sets of correlations are reported (see Tables 8-12): emerging adult outcomes with parent-reported emotion socialization of emerging adults, emerging adult outcomes with friend-reported emotion socialization of emerging adults, parent outcomes (separately for mothers and fathers) with emerging adultreported socialization of mothers and fathers, and friend-reported outcomes with emerging adultreported emotion socialization of friends. In general, few statistically significant correlations were observed between emotion socialization subscales and outcomes, which were in the expected directions. Separate bivariate correlations were also conducted among demographic and outcome variables for each participant (see Tables 13-15). Independent samples $t$-test were conducted with gender and variables of interest (see Table 16). From these preliminary analyses, we derived three potential covariates across all participants: gender, difficulty paying bills, and relationship closeness. Model fit for all analyses was examined with and without the covariates present in the model. Specifically, CFI change $>.01$ indicated inclusion of the covariates significantly improved model fit (Little, 2013). If model fit was not significantly improved, covariates were removed from the model.

Lastly, two additional paired-samples $t$-tests were conducted to assess friendship reciprocity. There was no significant difference between emerging adult- $(M=41.21, S D=5.14)$ and friend-report $(M=41.06, S D=5.79)$ of closeness, $t(274)=.42, p=.676$. Similarly, there was no significant difference between emerging adult- $(M=89.33, S D=14.81)$ and friend-report $(M$ $=89.94, S D=14.97$ ) of friendship type rated on a 0 (friend) to 100 (best friend) slider scale, $t(268)=-.69, p=.491$.

\section{Primary Analyses}


All emerging adult-report data were used for the validation of the emotion socialization latent variables (RQ1; $N=612$ ). For the remaining research questions (RQs 2-6) that also include parent- and/or friend-report data, only emerging adults who also had a parent and/or friend participate were included in those analyses. Standard cut offs for statistical significance were used $(p<.05)$. Concerning missing data at the item level, it was required that participants have at least $80 \%$ of the items present to receive a value on averaged or summed created scales. All primary analyses were conducted in a structural equation modeling framework using maximum likelihood estimation in SPSS Amos version 25. To account for any additional scale level missing data, means and intercepts were estimated by Amos. As a rule of thumb, acceptable model fit indices are as follows: $\mathrm{CMIN} / \mathrm{df}<3.0, \mathrm{CFI}>.90$, and $\mathrm{RMSEA} \leq .08$. Mediocre model fit indices are as follows: CFI between .85 and .90, RMSEA between .08 and .10 (Little, 2013). Although bivariate correlations suggested significant associations between covariates and outcome variables, across all models, the inclusion of gender and difficulty paying bills did not significantly improve model fit and therefore were dropped from the analyses. Closeness, as reported by the target individual (i.e., the same participant who reported the outcome variable), was retained as a covariate in all models.

Research question 1. Is the factor structure for emotion socialization with parents, friends, and emerging adults consistent with previous research on parent-child socialization?

Emotion socialization latent variable structure. Two latent factors each were constructed for emerging adult-report of their emotion socialization with their mother, father, and friend, parent-report of their emotion socialization with their emerging adult child, and friendreport of their emotion socialization with their emerging adult friend. Indicators on the latent factors were the same for all five reports. Based on prior research with children and adolescents 
(e.g., Klimes-Dougan et al., 2014; Magai, 1996), we hypothesized the indicators on the Supportive Emotion Socialization latent factor would be Reward with PA, Reward with NA, Magnify with PA, and Override with NA. For the Unsupportive Emotion Socialization latent factor, Punish with PA, Neglect with PA, Override with PA, Punish with NA, Neglect with NA, and Magnify with NA were the hypothesized indicators.

Emerging adult-report of emotion socialization. In all Emerging Adult models, the Magnify with NA indicator on the Unsupportive Emotion Socialization latent factor always loaded below .30 and was therefore dropped from all models (Tabachnick \& Fidell, 2013). With Emerging Adult-report of Override with NA with Friends was also dropped for loading below .30. Model fit indices suggest poor to acceptable fit for Emerging Adult-report for Emotion Socialization with Mothers $\left(\chi^{2}(23, N=612)=235.15, p<.001, \mathrm{CMIN} / \mathrm{df}=10.22, \mathrm{CFI}=.93\right.$, RMSEA $=.12[.11, .14])$, Fathers $\left(\chi^{2}(23, N=612)=239.93, p<.001, \mathrm{CMIN} / \mathrm{df}=10.43, \mathrm{CFI}=\right.$ $.92, \operatorname{RMSEA}=.12[.11, .14])$, and Friends $\left(\chi^{2}(18, N=612)=153.12, p<.001, \mathrm{CMIN} / \mathrm{df}=8.51\right.$, $\mathrm{CFI}=.96, \mathrm{RMSEA}=.11[.10, .13]$; see Figures 2-4).

Parent-report of emotion socialization. Similar to the Emerging Adult-report models, Magnify with NA was on the Unsupportive Emotion Socialization loaded below .30 and was dropped from the model. The model fit for Parent-report of Emotion Socialization with their Emerging Adult Child was mediocre, $\chi^{2}(23, N=461)=111.24, p<.001, \mathrm{CMIN} / \mathrm{df}=4.84, \mathrm{CFI}=$ .91, RMSEA $=.09[.08, .11]$, see Figure 5 .

Friend-report of emotion socialization. Similar to the Emerging Adult- and Parent-report models, Magnify with NA loaded below .30 and was dropped from the model. The model fit for Friend-report of Emotion Socialization with their Emerging Adult Friend was mediocre, $\chi^{2}(24, N$ $=261)=118.65, p<.001, \mathrm{CMIN} / \mathrm{df}=4.94, \mathrm{CFI}=.94, \mathrm{RMSEA}=.12[.10, .15]$, see Figure 6. 
Research question 2. Does parents' emotion socialization relate to emerging adult outcomes?

\section{Associations between parental emotion socialization and emerging adult outcomes.}

Structural equation models were performed for each emerging adult outcome with Parent Emotion Socialization as exogenous latent variables predicting Emerging Adult Functional Emotion Regulation, Dysfunctional Emotion Regulation, and Well-Being, while controlling for Emerging Adult-report of Closeness with their Mother and Father as well as Parent-reported modeling of each emerging adult outcome (functional emotion regulation, dysfunctional emotion regulation, well-being) within their respective models. To be included in these analyses, emerging adult participants needed to have at least one parent also participate $(N=461)$.

Functional emotion regulation. The proposed model provided mediocre fit to the data, $\chi^{2}(112, N=461)=432.33, p<.001, \mathrm{CMIN} / \mathrm{df}=3.86, \mathrm{CFI}=.84, \mathrm{RMSEA}=.08[.07, .09] . \mathrm{In}$ partial support of hypothesis 2a, Parents' Unsupportive Emotion Socialization was significantly negatively related Emerging Adults' use of Functional Emotion Regulation $(\beta=-.16, p=.017)$ while Parents' Supportive Emotion Socialization was not significantly related Emerging Adults' use of Functional Emotion Regulation $(\beta=.11, p=.056)$. Parents' own Functional Emotion Regulation was not related to Emerging Adults' Functional Emotion Regulation $(\beta=-.003, p=$ .961). However, Emerging Adult-report of Closeness with both Mother $(\beta=.40, p<.001)$ and Father $(\beta=.21, p<.001)$ were related to Emerging Adults' use of more Functional Emotion Regulation in expected ways (see Figure 7).

Dysfunctional emotion regulation. The proposed model provided adequate fit to the data, $\chi^{2}(112, N=461)=344.94, p<.001, \mathrm{CMIN} / \mathrm{df}=3.08, \mathrm{CFI}=.86, \mathrm{RMSEA}=.07[.06, .08]$. Contrary to hypothesis $2 \mathrm{~b}$, neither Parents' Supportive $(\beta=-.05, p=.395)$ nor Unsupportive 
Emotion Socialization $(\beta=.13 p=.077)$ were related to Emerging Adults' use of Dysfunctional Emotion Regulation. However, Parents' own Dysfunctional Emotion Regulation was positively related to Emerging Adults' Dysfunctional Emotion Regulation $(\beta=.19, p<.001)$. Additionally, Emerging Adults' report of Closeness with both Mother $(\beta=-.12, p=.025)$ and Father $(\beta=-.22$, $p<.001$ ) were related to Emerging Adults' use of less Dysfunctional Emotion Regulation (see Figure 8).

Well-being. The proposed model provided acceptable fit to the data, $\chi^{2}(145, N=461)=$ 402.096, $p<.001, \mathrm{CMIN} / \mathrm{df}=2.77, \mathrm{CFI}=.90, \mathrm{RMSEA}=.06[.05, .07]$. Counter to hypothesis 2c, neither Parents' Supportive $(\beta=.04, p=.454)$ nor Unsupportive Emotion Socialization $(\beta=$ $.01, p=.877$ ) were related to Emerging Adults' Well-being. However, Parents' own Well-being was positively associated with Emerging Adults' Well-being $(\beta=.15, p=.006)$. Additionally, Emerging Adult-report of Closeness with both Mother $(\beta=.39, p<.001)$ and Father $(\beta=.22, p$ $<.001$ ) were related to Emerging Adults' higher Well-being (see Figure 9).

Research question 3. Does friend emotion socialization relate more strongly to emerging adult outcomes than parent emotion socialization?

\section{Associations between parental and friend emotion socialization and emerging adult}

outcomes. Structural equation models were performed for each emerging adult outcome with Parent and Friend Emotion Socialization as exogenous latent variables predicting Emerging Adult Functional Emotion Regulation, Dysfunctional Emotion Regulation, and Well-being, while controlling for Emerging Adult-report of Closeness with their Mother, Father, and Friend as well as Friends' and Parents' modeling of each emerging adult outcome (functional emotion regulation, dysfunctional emotion regulation, well-being) within their respective models. To be included in these analyses, emerging adult participants needed to have at least one parent, or a 
friend also participate $(N=512)$. Means and intercepts were estimated for those with missing data from a particular reporter (parent or friend) or on specific items/scales.

Functional emotion regulation. The proposed model provided mediocre fit to the data, $\chi^{2}(393, N=512)=1070.09, p<.001, \mathrm{CMIN} / \mathrm{df}=2.72, \mathrm{CFI}=.83, \mathrm{RMSEA}=.06[.05, .06]$. Contrary to hypothesis 3a, Friends' Supportive $(\beta=-.01, p=.849)$ and Unsupportive Emotion Socialization $(\beta=-.06, p=.350)$ were unrelated to Emerging Adults' use of Functional Emotion Regulation. However, Parents' Unsupportive Emotion Socialization was significantly negatively associated with Emerging Adults' use of Functional Emotion Regulation $(\beta=-.15, p=.020)$. Parents' Supportive Emotion Socialization was unrelated to Emerging Adults' use of Functional Emotion Regulation $(\beta=.12, p=.060) .^{2}$ Moreover, Friends' own Functional Emotion Regulation was positively associated with Emerging Adults' Functional Emotion Regulation $(\beta=$ $.19, p=.008)$, while Parents' own Functional Emotion Regulation was not $(\beta=.01, p=.868)$. Emerging Adult-report of Closeness with Mother $(\beta=.35, p<.001)$, Father $(\beta=.18, p<.001)$, and Friend $(\beta=.26, p<.001)$ were all linked to Emerging Adults' use of more Functional Emotion Regulation (see Figure 10).

Dysfunctional emotion regulation. The proposed model provided acceptable fit to the data, $\chi^{2}(393, N=512)=984.86, p<.001, \mathrm{CMIN} / \mathrm{df}=2.50, \mathrm{CFI}=.84, \mathrm{RMSEA}=.05[.05, .06]$. Counter to hypothesis 3b, neither Friends' Supportive ( $\beta=-.06, p=.357)$ nor Unsupportive Emotion Socialization $(\beta=.06, p=.394)$ were related to Emerging Adults' use of Dysfunctional Emotion Regulation. Friends' own Dysfunctional Emotion Regulation was also unrelated to Emerging Adults' Dysfunctional Emotion Regulation $(\beta=.09, p=.212)$. Additionally, Parents'

\footnotetext{
${ }^{2}$ Critical ratios were examined to determine if Parents' and Friends' Emotion Socialization significantly differed in predicating Emerging Adult Functional Emotion Regulation, values must exceed 1.96. Neither Supportive Emotion Socialization $(C R=1.40)$, nor Unsupportive Emotion Socialization $(C R=-.96)$ significantly differed between parents and friends.
} 
Supportive $(\beta=-.05, p=.438)$ and Unsupportive Emotion Socialization $(\beta=.11, p=.108)$ were not associated with Emerging Adults' use of Dysfunctional Emotion Regulation. ${ }^{3}$ However, Parents' own Dysfunctional Emotion Regulation was positively related to Emerging Adults' use of Dysfunctional Emotion Regulation $(\beta=.19, p<.001)$. Emerging Adults' report of Closeness with Fathers $(\beta=-.22, p<.001)$ and Friends $(\beta=-.14, p<.006)$ were linked to Emerging Adults' use of less Dysfunctional Emotion Regulation, but Closeness with Mothers was not associated $(\beta=-.08, p=.128$; see Figure 11).

Well-being. The proposed model provided adequate fit to the data, $\chi^{2}(483, N=512)=$ 993.68, $p<.001, \mathrm{CMIN} / \mathrm{df}=2.06, \mathrm{CFI}=.89, \mathrm{RMSEA}=.04[.04, .05]$. Contrary to hypotheses 3c, neither Friends' Supportive $(\beta=-.02, p=.730)$ nor Unsupportive Emotion Socialization $(\beta=$ -.02, $p=.708)$ were related to Emerging Adults' Well-being. Friends' own Well-being was also unrelated to Emerging Adults' Well-being $(\beta=.07, p=.320)$. Further, Parents' Supportive $(\beta=$ $.03, p=.542)$ and Unsupportive Emotion Socialization $(\beta=-.003, p=.960)$ were unrelated Emerging Adults' Well-being. ${ }^{4}$ However, Parents' own Well-being was positively associated with Emerging Adults' Well-being $(\beta=.14, p=.012)$. Also, Emerging Adult-report of Closeness with Mother $(\beta=.31, p<.001)$, Father $(\beta=.25, p<.001)$, and Friend $(\beta=.16, p<.001)$ were all positively related to Emerging Adults' Well-being (see Figure 12).

Research question 4. Does emerging adult socialization of their parents' emotions relate to parent outcomes?

\footnotetext{
${ }^{3}$ Critical ratios were examined to determine if Parents' and Friends' Emotion Socialization significantly differed in predicating Emerging Adult Dysfunctional Emotion Regulation, values must exceed 1.96. Neither Supportive Emotion Socialization $(\mathrm{CR}=.18)$, nor Unsupportive Emotion Socialization $(\mathrm{CR}=-.05)$ significantly differed between parents and friends.

${ }^{4}$ Critical ratios were examined to determine if Parents' and Friends' Emotion Socialization significantly differed in predicating Emerging Adult Well-being, values must exceed 1.96. Neither Supportive Emotion Socialization $(\mathrm{CR}=$ -.66), nor Unsupportive Emotion Socialization $(\mathrm{CR}=-.24)$ significantly differed between parents and friends.
} 


\section{Associations between emerging adult emotion socialization and parent outcomes.}

Structural equation models were performed for each parent outcome with Emerging Adult Emotion Socialization as exogenous latent variables predicting Parent Functional Emotion Regulation, Dysfunctional Emotion Regulation, and Well-being, while controlling for Parentreport of Closeness with their Emerging Adult Child as well as Emerging Adults' modeling of each parent outcome (functional emotion regulation, dysfunctional emotion regulation, wellbeing) within their respective models. Separate models were conducted for mothers and father because emerging adults reported on their socialization of their parents' emotions separately. To be included in the analyses, emerging adults needed to have a mother $(N=338)$ or father $(N=$ 123) participate for that respective model.

Functional emotion regulation. With mothers, the proposed model provided mediocre fit to the data, $\chi^{2}(97, N=338)=416.76, p<.001, \mathrm{CMIN} / \mathrm{df}=4.30, \mathrm{CFI}=.85, \mathrm{RMSEA}=.10[.09$, .11]. Contrary to hypothesis 4 a with mothers, neither Emerging Adults' Supportive $(\beta=-.08, p=$ $.205)$ nor Unsupportive Emotion Socialization $(\beta=-.09, p=.20)$ were related to Mothers' Functional Emotion Regulation. Emerging Adults' own Functional Emotion Regulation was also unrelated to Mothers' Functional Emotion Regulation $(\beta=-.11, p=.105)$. However, Motherreport of Closeness with their Emerging Adult Child was positively related to Mothers' use of Functional Emotion Regulation $(\beta=.34, p<.001$; see Figure 13).

With fathers, the proposed model provided mediocre fit to the data, $\chi^{2}(97, N=123)=$ $159.19, p<.001, \mathrm{CMIN} / \mathrm{df}=1.64, \mathrm{CFI}=.87, \mathrm{RMSEA}=.07[.05, .09]$. Counter to hypothesis $4 \mathrm{a}$ with fathers, Emerging Adults' Supportive $(\beta=-.02, p=.909)$ and Unsupportive Emotion Socialization $(\beta=-.13, p=.339)$ were unrelated Fathers' use of Functional Emotion Regulation. Emerging Adults' own Functional Emotion Regulation was also not associated with Fathers' 
Functional Emotion Regulation $(\beta=.01, p=.956)$. However, Father-report of Closeness with their Emerging Adult Child $(\beta=.47, p<.001)$ was positively related to Fathers' use of Functional Emotion Regulation (see Figure 14).

Dysfunctional emotion regulation. With mothers, the proposed model provided adequate fit to the data, $\chi^{2}(97, N=338)=308.75, p<.001, \mathrm{CMIN} / \mathrm{df}=3.18, \mathrm{CFI}=.89, \mathrm{RMSEA}=.08$ $[.07, .09]$. Contrary to hypothesis $4 \mathrm{~b}$ with mothers, neither Emerging Adults' Supportive $(\beta=$ $.08, p=.112)$ nor Unsupportive Emotion Socialization $(\beta=.06, p=.229)$ were related to Mothers’ Dysfunctional Emotion Regulation. However, Emerging Adults’ own Dysfunctional Emotion Regulation was positively related to Mothers' Dysfunctional Emotion Regulation $(\beta=$ $.20, p=.002)$. Mother-report of Closeness with their Emerging Adult Child was also related to Mothers' less use of Dysfunctional Emotion Regulation $(\beta=-.12, p=.015$; see Figure 15).

With fathers, the proposed model provided adequate fit to the data, $\chi^{2}(97, N=123)=$ $143.47, p<.001, \mathrm{CMIN} / \mathrm{df}=1.48, \mathrm{CFI}=.89, \mathrm{RMSEA}=.06[.04, .08]$. In contradiction with hypothesis $4 \mathrm{~b}$ with fathers, Emerging Adults' Supportive $(\beta=.02, p=.859)$ and Unsupportive Emotion Socialization $(\beta=-.21, p=.151)$ were not associated with Fathers' use of Dysfunctional Emotion Regulation. Additionally, Emerging Adults' own Dysfunctional Emotion Regulation was unrelated to Fathers' Dysfunctional Emotion Regulation $(\beta=.10, p=.438)$. However, Father-report of Closeness with their Emerging Adult Child $(\beta=-.46, p<.001)$ was linked to Fathers' use of less Dysfunctional Emotion Regulation (see Figure 16).

Well-being. With mothers, the proposed model provided acceptable fit to the data, $\chi^{2}(128, N=338)=387.65, p<.001, \mathrm{CMIN} / \mathrm{df}=3.03, \mathrm{CFI}=.90, \mathrm{RMSEA}=.08[.07, .09] . \mathrm{In}$ contrast to hypothesis $4 \mathrm{c}$ with mothers, Emerging Adults' Supportive Emotion Socialization $(\beta=$ $-.06, p=.299$ ) and Emerging Adults' Unsupportive Emotion Socialization were not significantly 
related to Mothers' Well-being. ( $\beta=-.13, p=.054)$. However, Emerging Adults' own Wellbeing was significantly positively associated with Mothers' Well-being $(\beta=.23, p<.001)$. Additionally, Mother-report of Closeness with their Emerging Adult Child was related to Mothers' higher Well-being $(\beta=.33, p<.001$; see Figure 17).

With fathers, the proposed model provided adequate fit to the data, $\chi^{2}(128, N=123)=$ 215.33, $p<.001, \mathrm{CMIN} / \mathrm{df}=1.68, \mathrm{CFI}=.87, \mathrm{RMSEA}=.08[.06, .09]$. Against hypothesis $4 \mathrm{c}$ with fathers, neither Emerging Adults' Supportive $(\beta=-.15, p=.224)$ nor Unsupportive Emotion Socialization $(\beta=-.08, p=.508)$ were related to Fathers' Well-being. Emerging Adults' own Well-being was also unrelated to Fathers' Well-being $(\beta=-.03, p=.826)$. However, Fatherreport of Closeness with their Emerging Adult Child was positively related to Fathers' Wellbeing $(\beta=.53, p<.001$; see Figure 18$)$.

Research question 5. Does emerging adult socialization of their friends' emotions relate to friend outcomes?

\section{Associations between emerging adult emotion socialization and friend outcomes.}

Structural equation models were performed for each friend outcome with Emerging Adult Emotion Socialization as exogenous latent variables predicting Friend Functional Emotion Regulation, Dysfunctional Emotion Regulation, and Well-being, while controlling for Friendreport of Closeness with their Emerging Adult Friend as well as Emerging Adults' modeling of each friend outcome (functional emotion regulation, dysfunctional emotion regulation, wellbeing) within their respective models. To be included in the analyses, emerging adults needed to have a friend participate. Means and intercepts were estimated for those with missing data on specific items/scales. 
Functional emotion regulation. The proposed model provided mediocre fit to the data, $\chi^{2}(7=85, N=261)=263.02, p<.001, \mathrm{CMIN} / \mathrm{df}=3.09, \mathrm{CFI}=.86, \mathrm{RMSEA}=.09[.08, .10]$. Contrary to hypothesis 5a, Emerging Adults' Supportive $(\beta=.08, p=.286)$ and Unsupportive Emotion Socialization $(\beta=.05, p=.525)$ were not associated with Friends' use of Functional Emotion Regulation. However, Emerging Adults' own Functional Emotion Regulation was positively related to Friends' Functional Emotion Regulation $(\beta=.14, p=.045)$. Friends' report of Closeness with their Emerging Adult Friend was also positively linked to Friends' use of more Functional Emotion Regulation $(\beta=.37, p<.001$; see Figure 19).

Dysfunctional emotion regulation. The proposed model provided acceptable fit to the data, $\chi^{2}(85, N=261)=219.75, p<.001, \mathrm{CMIN} / \mathrm{df}=2.59, \mathrm{CFI}=.88, \mathrm{RMSEA}=.08[.07, .09]$. Contrary to hypothesis 5b, neither Emerging Adults' Supportive $(\beta=-.15, p=.064)$ nor Unsupportive Emotion Socialization $(\beta=.05, p=.522)$ were related to Friends' use of Dysfunctional Emotion Regulation. Likewise, Emerging Adults' own Dysfunctional Emotion Regulation $(\beta=.10, p=.168)$ and Friends' report of Closeness with their Emerging Adult Friend $(\beta=-.04, p=.582)$ were not associated with Friends' Dysfunctional Emotion Regulation (see Figure 20).

Well-being. The proposed model provided acceptable fit to the data, $\chi^{2}(114, N=261)=$ $216.55, p<.001, \mathrm{CMIN} / \mathrm{df}=1.90, \mathrm{CFI}=.94, \mathrm{RMSEA}=.06[.05, .07]$. Counter to hypothesis $5 \mathrm{c}$, neither Emerging Adults' Supportive $(\beta=.05, p=.539)$ nor Unsupportive Emotion Socialization $(\beta=-.08, p=.330)$ were linked to Friends' Well-being. Emerging Adults' own Well-being was also not associated with Friends' Well-being $(\beta=.11, p=.117)$. However, Friends' report of Closeness with their Emerging Adult Friend $(\beta=.22, p<.001)$ was related to Friends' higher Well-being (see Figure 21). 
Research question 6 (exploratory). Do emerging adults' emotion regulation strategies mediate the association between parent and friend emotion socialization responses and emerging adult well-being?

\section{Examining emerging adult emotion regulation as a mediator between parent and} friend emotion socialization and emerging adult well-being. Two structural equation models using 5000 bootstrapped samples were performed for each emerging adult mediator (functional and dysfunctional emotion regulation). Parent and Friend Emotion Socialization were exogenous latent variables predicting Emerging Adult Functional and Dysfunctional Emotion Regulation (in separate models), which in turn predicted Emerging Adult Well-being, while controlling for Emerging Adult-report of Closeness with their Mother, Father, and Friend as well as Parents' and Friends' modeling of Functional and Dysfunctional Emotion Regulation, within their respective models, and Parents' and Friends' Well-being. To be included in the analyses, emerging adult participants needed to have both a parent and a friend also participate. Additionally, in order to perform bootstrapping, only participants with full data were used in the analyses $(N=190)$.

Functional emotion regulation. The proposed model provided mediocre fit to the data, $\chi^{2}(804, N=190)=1499.77, p<.001, \mathrm{CMIN} / \mathrm{df}=1.87, \mathrm{CFI}=.80, \mathrm{RMSEA}=.07[.06, .07]$. As hypothesized, both Parent $(\beta=.31, p<.001)$ and Friend $(\beta=.19, p=.021)$ Supportive Emotion Socialization were positively related to Emerging Adult Functional Emotion Regulation while Unsupportive Emotion Socialization from both Parents $(\beta=-.04, p=.681)$ and Friends $(\beta=-.06$, $p=$.436) were not. Emerging Adult Functional Emotion Regulation was significantly positively associated with Emerging Adult Well-being $(\beta=.48, p<.001)$. As hypothesized, Emerging Adult Functional Emotion Regulation significantly explained the link between Parent Supportive 
Emotion Socialization and Emerging Adult Well-being, $(\beta=.15, p=.003,95 \%$ CI $[.05, .31])$. No other indirect effects were statistically significant. The total model accounted for $39 \%$ of the variance in Emerging Adult Well-being.

Dysfunctional emotion regulation. The proposed model provided mediocre fit to the data, $\chi^{2}(804, N=190)=1572.95, p<.001, \mathrm{CMIN} / \mathrm{df}=1.96, \mathrm{CFI}=.78, \mathrm{RMSEA}=.07[.07, .08]$. In line with hypotheses, Parent Unsupportive Emotion Socialization was positively related to Emerging Adult Dysfunctional Emotion Regulation $(\beta=.32, p=.002)$ while Unsupportive Emotion Socialization from Friends $(\beta=.04, p=.615)$, and Supportive Emotion Socialization from both Parents $(\beta=.04, p=.674)$ and Friends $(\beta=-.06, p=.484)$ were unrelated. Emerging Adult Dysfunctional Emotion Regulation was significantly negatively associated with Emerging Adult Well-being $(\beta=-.78, p<.001)$. As hypothesized, Emerging Adult Dysfunctional Emotion Regulation significantly explained the link between Parent Unsupportive Emotion Socialization and Emerging Adult Well-being, $(\beta=-.25, p=.005,95 \% \mathrm{CI}[-.51,-.07])$. No other indirect effects were statistically significant. The total model accounted for $68 \%$ of the variance in Emerging Adult Well-being. ${ }^{5}$

\section{Discussion}

The current study indicated that different modes of socialization from parents and friends were related to emerging adults' use of functional and dysfunctional emotion regulation strategies as well as emerging adults' well-being. By examining two modes of socialization (i.e., contingent responses and modeling), we were better able to comprehensively assess emotion socialization compared to studies that only assess one type of emotion socialization (e.g.,

\footnotetext{
${ }^{5}$ Additional analyses were conducted separately for negative and positive affect. Models with negative affect only are presented in Appendix D. Positive affect only models are presented in Appendix E. Tables showing standardized regression weights across all three models (i.e., combined, negative affect, positive affect) are reported in Appendix F.
} 
Bariola, Hughes, \& Gullone, 2012; Garside, 2005; Klimes-Dougan et al., 2014). Additionally, by having both parents and friends report on their own emotion socialization practices with the emerging adults, we were able to answer previous researchers' call for an integrative model examining emotion socialization and by comparing the effects of multiple socialization agents within the same model (Kerr et al., 2003; Miller-Slough \& Dunsmore, 2016; Vandell, 2000).

\section{Measurement Models of Emotion Socialization during Emerging Adulthood}

The current study examined whether the factor structure of emotion socialization previously used with children and adolescents extended to the measurement of emotion socialization with emerging adults, their parents, and their friends. Research with children and adolescents has used the same five subscales (i.e., reward, override, magnify, punish, neglect), aggregated them across negative emotions (i.e., sad, angry, worry), and combined them into supportive and unsupportive scales (e.g., Borowski et al., 2016; Klimes-Dougan et al., 2014; Silk et al., 2011; Tillery et al., 2015) in similar ways as the current study. However, previous research has not examined current emotion socialization during this period of the life span. Additionally, very few studies to date have used latent variables in a structural equation modeling framework, which accounts for measurement error better than aggregate scores (see Guo, Mrug, \& Knight, 2017 and O’Neal \& Magai, 2005 for exceptions). Overall, our findings suggest that emotion socialization from emerging adults, parents, and friends can be assessed in similar ways as has been used in previous research with children and adolescents. Although the model fit indices of some of the confirmatory factor analyses were not always within the acceptable range (Little, 2013), below we provide potential explanations for these poor model fits. It is important to note that throughout previous literature using other versions of this measure, reliability of individual scales is often low ( $\alpha$ ranging from .51-.88; Klimes-Dougan et al., 2007; Miller-Slough, Zeman, 
Poon, \& Sanders, 2016; Sanders, Zeman, Poon, \& Miller, 2015; Silk et al., 2011; Tillery et al., 2015). Moreover, some controversy exists with the override and magnify subscales in terms whether they are supportive or unsupportive because of their associations with different outcomes (e.g., Klimes-Dougan et al., 2014). We suggest future work examine this measure of current emotion socialization more closely to better understand the emotion socialization process, as reported by multiple individuals, during this emerging adulthood period.

\section{Parents' Socialization Predicting Emerging Adults' Outcomes}

We hypothesized that supportive contingent responses from parents would be related to more functional emotion regulation, less dysfunctional emotion regulation, and lower well-being in emerging adults whereas unsupportive responses would be related in opposite ways. In partial support of hypotheses, contingent responses reported by parents were associated with emerging adults' use of functional emotion regulation but were not related to dysfunctional emotion regulation or well-being. Specifically, as expected, more unsupportive responses from parents were associated with emerging adults' use of less functional emotion regulation. This finding is supported by previous research conducted with children and adolescents (e.g., Miller-Slough, Zeman, Poon, \& Sanders, 2016; Shewark \& Blandon, 2015; Williams \& Woodruff-Borden, 2015). Similar to previous research with children (e.g., Bariola, Hughes, \& Gullone, 2012), parents' own use of dysfunctional emotion regulation, or modeling, was also related to emerging adults' use of dysfunctional emotion regulation, potentially suggesting the role of parental modeling. As discussed in Bariola, Gullone, and Hughes's (2011) review, very few studies to date have examined the direct effects of parents' emotion regulation on their children's emotion regulation. However, the importance of parental modeling emotion regulation has been suggested by previous work with children (e.g., Moran, Root, Vizy, Wilson, \& Gentzler, under 
review). In addition, parents' well-being was related to emerging adults' well-being. This finding is consistent with previous research conducted with adolescents (Casas et al., 2008, 2012). However, the present study's findings with parents' modeling of dysfunctional emotion regulation and well-being were especially interesting because parents and their emerging adult children interact less often with one another compared to time spent with emerging adult friends (Arnett, 2004; Buhrmester \& Carbery, 1992). Because of this lack of in-person interaction, it is possible that parents and emerging adult children interact with one another through other means of communication. Phone calls, text messaging, video chatting, and social media are all forms of communications that may be commonly used within parent-adult child relationships. For instance, emerging adults may call or video chat with their parents to share emotional events and parents may respond to their children's emotions in ways that are similar to how they would respond if they were in person. Yet, other forms of communication (e.g., texting, social media) may not promote the same types of socialization responses. Given the prevalence of communication technology, it is important to learn more about how socialization may look when experienced through these means. Despite these issues, our findings suggest emotion socialization between parents and emerging adult children is still occurring. It has also been suggested that the overlap in parents' and their children's emotion regulation and well-being may occur due to similar genetics and/or shared environments (see Canli, Ferri, \& Duman, 2009 and Hawn, Overstreet, Stewart, \& Amstadter, 2015 for reviews on genetics and emotion regulation), potentially constituting a gene X environment correlation (Champagne \& Mashoodh, 2009; Gottlieb, 2007; Scarr \& McCartney, 1983). Emerging adults' report of their closeness with their mothers and fathers were each individually related to all outcomes in expected directions. Previous research with emerging adults suggests that closeness (e.g., warmth, responsiveness) is 
an important factor in the parent-child relationship (Kenny \& Sirin, 2006; Tubman \& Lerner, 1994) and in relation to outcomes (e.g., higher well-being; Turner, Sarason, \& Sarason, 2001). The current study's findings suggest that this notion also extends to parents and their emerging adult children. In sum, findings from these models suggest that parents continue to socialize their children's emotions during emerging adulthood and that these effects remain even after controlling for the closeness between mothers, fathers, and emerging adults.

\section{Parents' and Friends' Socialization Predicting Emerging Adults' Outcomes}

With the focus on emerging adults, the novel hypothesis was tested that contingent responses from friends would be more strongly related to emerging adults' emotion regulation and well-being than the contingent responses from parents. However, contingent responding as reported by friends was not associated with any emerging adult outcomes. Instead, the findings of the present study suggest that modeling emotion regulation and closeness with friends were more influential in predicting emotion regulation strategy use and well-being than contingent responding. Specifically, friends' use of functional emotion regulation was positively related to emerging adults' use of functional emotion regulation. Prior research shows a similar direct association between adolescents and their friends' use of functional emotion regulation strategies (Reindl et al., 2016). However, research on adolescents in other areas (e.g., general friendship formation and depression) suggests that both selection (i.e., choosing friends like oneself) and socialization are important in understanding similarities among friends' behaviors and characteristics (Brown \& Larson, 2013; Kandel, 1978). For example, some work has shown that adolescents choose friends with similar depression levels as themselves (Van Zalk, Kerr, Branje, Stattin, \& Meeus, 2010) and friends' depressive symptoms increase in similarity as the friendship endures (Giletta et al., 2011; Van Zalk et al., 2010). This process may also occur with 
emotion regulation strategy use within emerging adult friendships. Similar to closeness with parents, closeness with friends was related to both types of emotion regulation in the expected directions. However, even though our study specifically recruited "close" friends, and emerging adult and friends' individual ratings of closeness suggest this to be accurate, friends' well-being was not significantly associated with emerging adults' well-being. ${ }^{6}$

Also, we hypothesized that friends' emotion socialization would be more influential than parents', but this hypothesis was not supported. The results indicated that parents seem to continue to be an influential socialization agent during emerging adulthood, even when considered in the same context as friends who are in contact with emerging adults more often. Specifically, all significant paths from the parent-only models remained significant in models including friends with one exception. Emerging adult-reported closeness with mothers did not significantly relate to emerging adults' dysfunctional emotion regulation when friend emotion socialization and emerging adult-reported closeness with friends were included in the model. Previous work examining co-rumination among adolescents, their mothers, and their friends suggests that co-rumination with mothers is not predictive of adolescent outcomes when corumination with friends is covaried within the model (Waller \& Rose, 2010, 2013). In line with our findings, closeness with friends may be especially important in associations with dysfunctional emotion regulation due to emerging adults' proximity and reliance on their friends for support. As shown by literature in other areas (e.g., values), even during emerging adulthood, parents may influence their children's beliefs and behaviors (e.g., Roest et al., 2009).

\footnotetext{
${ }^{6}$ Additional models with only friend emotion socialization variables predicting emerging adult outcomes were conducted but were not included in the current paper. All non-significant findings with friend emotion socialization in the combined parent and friend models were also non-significant in the friend only models, with one exception. Friend-reported well-being (modeling) was positively related to emerging adult well-being when parents were not included in the model.
} 


\section{Emerging Adults' Socialization Predicting Parents' Outcomes}

To examine the potential for reciprocal emotion socialization between emerging adults and their parents, we hypothesized that supportive contingent responses from emerging adults would be related to more functional emotion regulation, less dysfunctional emotion regulation, and lower well-being in parents whereas unsupportive responses would be related to outcomes in opposite ways. Our findings did not support the hypothesis that emerging adult children socialize their mothers' or fathers' emotions via contingent responding. However, we did find that emerging adult children's report of their own use of dysfunctional emotion regulation and wellbeing were positively related to their mothers', but not fathers', reports of the same behaviors. In general, socialization is considered a bidirectional, reciprocal process (Bell, 1968; Grusec, 2011; Kuczynski \& Parkin, 2008), and some research in other areas has suggested that adolescent and emerging adult children influence their parents' beliefs and behaviors (e.g., value transmissions; Kuczynski, Marshall, \& Schell, 1997; Kuczynski, Pitman, Ta-Young, \& Harach, 2016; Roest et al., 2009). It may be that because emerging adults in college are generally not completely considered adults, by others or themselves (Arnett, 2000), that they are not yet seen as equals within the parent-adult child relationship. This may result in parents being less likely to share emotions, especially negative ones, with their children due to parents not wanting their children to take on emotional burdens. Overall, both mothers' and fathers' report of their closeness with their emerging adult children was the only consistent predictor of parent emotion regulation and well-being. As expected, mothers' and fathers' own reports of closeness with their emerging adult children were related to mothers' and fathers' more use of functional emotion regulation strategies, less use of dysfunctional emotion regulation strategies, and higher well-being. Although in most examinations of closeness within parent-child dyads, the focus is upon the 
effects it has on children's outcomes (Kenny \& Sirin, 2006; Tubman \& Lerner, 1994; Turner, Sarason, \& Sarason, 2001), our findings suggest that closeness is similarly important for parents' emotion regulation and well-being.

\section{Emerging Adults' Socialization Predicting Friends' Outcomes}

We hypothesized that supportive contingent responses from emerging adults would be related to their friends' reports of more functional emotion regulation, less dysfunctional emotion regulation, and lower well-being whereas unsupportive responses would be related to friends' outcomes in opposite ways. Contrary to expectations, emerging adults' report of contingent responding to their friends' emotions was unrelated to friends' report of their functional emotion regulation, dysfunctional emotion regulation, and well-being. Other work with adolescent friend pairs suggests that friends' responses to one another's emotions is related to adolescent outcomes (Borowski et al., 2016; Klimes-Dougan et al., 2014; Parr et al., 2016), although parents' emotion socialization was not considered within these studies. However, in the current study we found that emerging adults' modeling of functional emotion regulation was positively related to friends' functional emotion regulation. Similar to our explanation of findings with parents, socialization has been deemed a bidirectional process (Bell, 1968; Grusec, 2011; Kuczynski \& Parkin, 2008) and these findings within emerging adult friendships further suggest the validity of this argument. However, the current study's data cannot assess whether this finding is due to self-selection of similar others or socialization by the emerging adult. Analogous to parents, friends' report of their closeness with emerging adult friends was positively related to their own functional emotion regulation and well-being but was unrelated to friends' dysfunctional emotion regulation. Previous work has argued the importance of friendship quality and its implications for positive development (e.g., Berndt, 2002). Further, our findings support notions 
by previous researchers that higher friendship quality relates to higher self-esteem, better coping, and overall adjustment (Hartup, 1996; Hartup \& Stevens, 1997). Overall, these findings suggest potential for bidirectional associations among modeling of functional emotion regulation strategies within emerging adult friend pairs.

\section{Parents' and Friends' Socialization Predicting Emerging Adults' Well-being through Emerging Adults' Emotion Regulation}

Exploratory mediation models were conducted to examine emerging adult emotion regulation as a mediator of the link between parent and friend contingent responding and emerging adult well-being. The findings suggested that parents', but not friends', contingent responding was related to emerging adult emotion regulation which in turn was associated with emerging adult well-being. Specifically, supportive socialization from parents was related to emerging adults' use of more functional emotion regulation and thereby higher well-being. Meanwhile, unsupportive socialization from parents was related to emerging adults' use of more dysfunctional emotion regulation strategies and thereby lower well-being. These mediated findings provide empirical support for conceptual models of parental socialization of children's emotion (Eisenberg, Cumberland, et al., 1998; Miller-Slough \& Dunsmore, 2016; Morris et al., 2007) and extend previous findings with children and adolescents (Eisenberg et al., 2001; Smith et al., 2006; Yap, Allen, \& Ladouceur, 2008; Yap et al., 2010) to the emerging adult developmental period. Because of the particularly low levels of well-being observed in emerging adult college students (American College Health Association, 2008), these mediated findings provide at least two areas in which increasing well-being can be targeted in this population. For example, emerging adults experiencing low well-being could be taught how to better regulate their emotions through socioemotional learning programs similar to existing programs for 
children and adolescents (e.g., RULER; Rivers, Tominey, O’Bryon, \& Brackett, 2013).

Alternatively, interventions targeting parents' socialization techniques with their children and adolescents (e.g., Tuning into Kids/Teens; Havighurst et al., 2013, 2010; Kehoe et al., 2014) could be extended to emerging adult parents as our findings suggest the ways in which parents socialize emotions impacts their emerging adult children's socioemotional functioning.

\section{Strengths and Limitations of the Present Study}

Overall, the results of the current study suggest that socialization is a life-long process that continues to be important for well-being during emerging adulthood. The present study has a number of strengths that have built upon previous research on emotion socialization. First, by using multiple reporters (i.e., emerging adult, parents, and friends) we were able to examine how the socialization agents' self-reported emotion socialization practices relate to the socialization targets' self-reported outcomes. Second, examination of parent-reported current emotion socialization with their emerging adult children, as opposed to retrospective-report self-report from the emerging adults (e.g., Garside, 2005), has not been previously explored. Because the current study's questionnaires specified to report how participants have responded to the target in the last six months, we were able to assess current emotion socialization practices and explore if emotion socialization is still occurring during emerging adulthood. Third, the examination of the effects of both parents' and friends' emotion socialization within the same model has seldom been explored by previous work (see Burleson \& Kunkel, 2002 and Tillery, Cohen, Parra, Kitzmann, \& Howard Sharp, 2015 for exceptions with children), but is important for understanding emotion socialization as whole (Bugental \& Grusec, 1998; von Salisch, 2001). Lastly, while few prior studies have simultaneously examined more than one method of emotion socialization (see Moran et al., under review for one exception with children), no previous work 
has examined self-reports from multiple socialization agents within a single statistical model during emerging adulthood. The current study examined the effects of both contingent responses and modeling, as reported by parents and friends, on emerging adult outcomes.

However, the present study's results should be interpreted in light of a few limitations. First, all three samples (emerging adult, parent, and friend) mainly identified as White/European American and female. Although these demographics generally represent the area from which participants were recruited, the lack of diversity leaves us unable to ensure these findings would generalize to other populations. Previous work has shown differences in emotion socialization by parent gender (e.g., Denham, 2007; Zeman \& Garber, 1996), friend gender (e.g., Klimes-Dougan et al., 2014), and ethnicity (e.g., Nelson, Leerkes, O’Brien, Calkins, \& Marcovitch, 2012). Second, our sample size for some analyses was quite small and likely underpowered to detect all effects (e.g., emerging adults' emotion socialization with father related to fathers' outcomes). A general rule of thumb when utilizing structural equation modeling is to have more than 200 full cases of data (Garver \& Mentzer, 1999; Hoe, 2008; Hoelter, 1983; MacCallum, Browne, \& Sugawara, 1996; Marsh, Hau, Balla, \& Grayson, 1998; Wolf, Harrington, Clark, \& Miller, 2013); we did not meet this suggested minimum in all of our analyses. Third, our emerging adult participants likely experienced survey fatigue while taking our hour-long survey that consisted of repetitive questionnaires with only slight differences in wording. Although we did use validity checks to ensure participants were paying attention throughout, it is possible that survey fatigue could have affected participants' ability to accurately answer all questions. Fourth, there may have been order effects within our emotion socialization surveys for all participants but particularly the emerging adults. All reporters reported on emotion socialization measures in the same order. For example, emerging adult participants first reported what other individuals 
(mother, father, and friend) do to socialize their emotions (the emerging adult; not used in the current study), then they reported what they (the emerging adult) do to socialize others' (mother, father, and friend) emotions. These order effects in combination with survey fatigue could have affected emerging adults' ability to accurately report on all of the emotion socialization measures for all socialization agents. Lastly, the confirmatory factor analyses of the structure for latent variables of emotion socialization across all reporters generally showed poor to adequate fit as indicated by multiple model fit indices (Little, 2013). The EAC measure has not previously been examined as latent variables in the same manner as was done in the present study. Specifically, the reliability of the individual, emotion-specific EAC subscales have been unstable and poor in many cases (e.g., punish; Silk et al., 2011). To address this issue, many studies have created scales of supportive and unsupportive socialization and used these observed variables to examine their hypotheses (e.g., Sanders, Zeman, Poon, \& Miller, 2015; Tillery, Cohen, Parra, Kitzmann, \& Howard Sharp, 2015). While in the current study the reliability for emotion-specific subscales (e.g., angry override; $\alpha=.52$ ) was similar to previous research, the reliability of the collapsed NA subscales (e.g., sad, angry, and worried reward; $\alpha=.82$ ) that were used as indicators on our latent variables, was generally moderate to high.

\section{Future Directions for Emotion Socialization Research}

This study constitutes an initial step in the examination of parent and friend emotion socialization during emerging adulthood, but much research remains to be done both to address the current study's limitations and to further the field of emotion socialization research beyond the child and adolescent age periods. First, more diverse samples should be recruited to examine if the same phenomena occur within different ethnicities. For instance, children of AfricanAmerican mothers have reported their mothers as more punitive (Leerkes \& Siepak, 2006; 
Montague, Magai, Consedine, \& Gillespie, 2003), less accepting, and less supportive of negative emotional expressions (Nelson et al., 2012) compared to children of non-African-American mothers. However, with positive emotions, African American mothers may be more likely to engage in positive emotion talk (Garrett-Peters et al., 2008) and up-regulate or expand upon their children's positive emotional experiences by reinforcing and encouraging further positive experiences (Mckee, Faro, O’Leary, Spratt, \& Jones, 2015) compared to non-African American mothers. These findings suggest there may be ethnic differences in the emotion socialization process which warrant further examination.

Next, in relation to sample demographics, active efforts to include more emerging adult males, fathers, and male friends, should be pursued in future research. Across earlier periods of the life span, research has shown that fathers respond more negatively to their sons' expressions of negative emotions than their daughters' (Denham, 2007; Garside \& Klimes-Dougan, 2002a; Zeman \& Garber, 1996). Prior work with friends suggests a similar pattern with boys using neglect and victimization strategies more often than girls (Klimes-Dougan et al., 2014). Given gendered norms and stereotypes about emotions persist into adulthood (Hutson-Comeaux \& Kelly, 2002; Kelly \& Hutson-Comeaux, 1999; Plant, Hyde, Keltner, \& Devine, 2000; Robinson, Johnson, \& Shields, 1998) and gender differences in emotional intensity and expression are found in adults (e.g., Diener, Sandvik, \& Larsen, 1985; Kring \& Gordon, 1998), it is likely that gender differences in emotion socialization continues into emerging adulthood. Future research should consider gender of the socialization agent and target as potential moderators within their models. Moreover, the examination of multi-group models to assess potential gender differences in the structure of emotion socialization, emotion regulation, and outcomes should be considered. 
Last, although the EAC has been widely used as a measurement of emotion socialization (Brand \& Klimes-Dougan, 2010; Garside, 2005; Garside \& Klimes-Dougan, 2002a; Magai, 1996; O’Neal \& Magai, 2005; Silk et al., 2011) and other survey-based measures of emotion socialization exist (e.g., Fabes et al., 1990, 2002, Gentzler et al., 2016, 2015; Ladouceur et al., 2002; Yap, Allen, \& Ladouceur, 2008), these measures do not assess in-the-moment reactions that individuals experience during an emotional situation. Future work should pursue observational measures examining what individuals are sharing, with who they are sharing, and how the other individual reacts to better understand current emotion socialization during emerging adulthood.

Furthering emotion socialization research during emerging adulthood. There are also numerous other areas of emotion socialization research that should be extended to and examined during the emerging adulthood period. Specifically, other methods of emotion socialization, such as coaching (i.e., explicit instruction or explanation about emotions) and niche-picking (i.e., socialization agents' selection and/or modification of situations), should be explored. Previous research with children and adolescents suggest that emotion coaching practices by parents are important in predicting children's overall adjustment (Havighurst et al., 2013; Loop \& Roskam, 2016; Ramsden \& Hubbard, 2002). Although it may intuitively seem as though parents (and/or others) may not directly coach emerging adults through emotionally-evocative situations in the same manner as they do with children and adolescents, it is possible that emerging adults still seek out support and advice from others when dealing with emotionally-taxing situations. Instead of parents choosing to use an emotional situation their child is experiencing as an opportunity to coach them about their emotions (Gottman et al., 1996), emerging adults may actively seek out 
emotion coaching from others. It will be important for future work to examine if and how emotion coaching may evolve during emerging adulthood.

Another emotion socialization strategy is niche-picking, or selective approaching or avoiding of specific emotional situations/stimuli (Morris et al., 2007). Niche-picking could be construed as either emotion socialization or regulation during childhood where parents have more direct control over children's involvement in activities and can select to involve their children in different situations as a way of preemptively regulating the children's emotions (Aspinwall \& Taylor, 1997; Eisenberg, Spinrad, \& Cumberland, 1998; Ross D Parke, 1994). Emerging adults generally have more autonomy and freedom to make these types of choices on their own, but suggestions made by parents, friends, and others may still influence emerging adults' choices and should be explored by future work. It has further been suggested that emotion socialization tactics used by socialization agents may differ depending upon the specific emotion being examined (e.g., O’Neal \& Magai, 2005). Future work should more carefully examine potential nuances among the socialization of different specific negative and positive emotions during emerging adulthood.

It may also be informative to examine how parents' socialization is related to friends' socialization of emerging adults' emotions. Again, drawing from previous literature on friendship formation and selection vs. socialization (Brown \& Larson, 2013; Giletta et al., 2011; Kandel, 1978; Van Zalk et al., 2010), emerging adults may choose to form friendships with individuals who respond to emotions in similar ways as their parents. Conversely, emerging adults whose parents respond to their emotions in unsupportive ways may instead seek out friends that respond in supportive ways to their emotions. In this case, friends' emotion socialization responses may buffer against the negative effects of parents' unsupportive emotion 
socialization practices. Therefore, future research should examine if parents' and friends' emotion socialization methods interact to predict emerging adult outcomes.

Lastly, future work on emotion socialization during emerging adulthood should consider other agents of socialization; specifically, romantic partners. During late adolescence and early adulthood, romantic partners' influence becomes especially salient in comparison to parents' and friends' (e.g., Meeus, Branje, van der Valk, \& de Wied, 2007). Adolescents approaching emerging adulthood report interacting with romantic partners more than parents, friends, and siblings (Laursen \& Williams, 1997). Moving into emerging adulthood, time spent with romantic partners further increases at the expense of time spent with friends (Reis, Lin, Bennett, \& Nezlek, 1993) and emerging adults perceive more support from their romantic partners compared to their mothers (Furman \& Shomaker, 2008). Moreover, a secure attachment with romantic partners has been related to higher ability to up-regulate, or savor, positive experiences (Gentzler, Kerns, \& Keener, 2010). The wealth of literature emphasizing the importance of romantic partners during this time suggest future work needs to examine the role that romantic partners play in the emotion socialization process during emerging adulthood. Additionally, recent research found that adults tend to seek out specific individuals when experiencing specific emotions (e.g., turning to a sibling for cheering up when feeling down; Cheung, Gardner, \& Anderson, 2015). This work suggests that research on emotion socialization during adulthood must consider a multitude of individuals who may be in a position to influence outcomes in the target individual.

Other variables playing a role in the emotion socialization process. Finally, there are many other variables that should be considered when examining the emotion socialization process. Emotional intelligence (i.e., the ability to be aware of, understand, and regulate your 
own and others' emotions; Mayer, Salovey, Caruso, \& Cherkasskiy, 2011) of the socialization agent and/or target may play an important role in how the socialization process unfolds. For instance, if the socialization agent is low in emotional intelligence, they may be worse at responding to the socialization target's emotions, they may provide inaccurate coaching, and they may model dysfunctional behaviors whereas the opposite may be true if they are high in emotional intelligence. Conversely, if the target individual is high in emotional intelligence, they may need less emotional guidance or socialization.

Another potential variable to consider is meta-emotion, which broadly includes one's feelings and thoughts about one's own, and others', emotions (Gottman et al., 1996). Previous research has connected parents' meta-emotion to their accuracy labeling emotions in boy children and their willingness to interact with children (Morey \& Gentzler, 2017). Moreover, parents' meta-emotion philosophy (i.e., emotion-coaching or dismissing) has also been linked to their general parenting, their children's emotion regulation abilities, and broader outcomes in children and adolescents (e.g., internalizing and externalizing behaviors; Cunningham, Kliewer, \& Garner, 2009; Gottman et al., 1996). Encompassed within meta-emotion is each individuals’ specific beliefs about their own, and others, controllability of emotions (i.e., if one believes they are capabable of changing their emotions or that emotions are stable and uncontrolable; Tamir, John, Srivastava, \& Gross, 2007). The belief that emotions are malleable has been linked to more active emotion regulation efforts (see Kneeland, Dovidio, Joormann, \& Clark, 2016 for a review) and may also be related to more acceptance of emotion socialization efforts from others. Therefore, these could be important variables to consider when examining the emotion socialization process. 
Lastly, when studying genetic relatives, like parents and their emerging adult children, researchers must take into account the genetic makeup and environment that these individuals share with one another (Champagne \& Mashoodh, 2009; Scarr \& McCartney, 1983). Research on emotion socialization between parents and adult children should carefully consider both genetic and environmental aspects individuals as well as how they may interact with one another, especially when examining modeling of behaviors within the context of familial relatives.

\section{Conclusions}

The present study's findings provided some evidence that emotion socialization from parents is related to emerging adults' emotion regulation and well-being after they leave home and pursue more autonomous lives. Additionally, our findings suggest that parents may be particularly important, even though emerging adults are spending significantly more time interacting with friends. We also found evidence to support mediation with parents' contingent responses to emerging adults' emotions predicting emerging adult well-being through the emerging adults' use of emotion regulation strategies. Finally, our results show potential for bidirectional effects of emotion socialization among parents and their emerging adult children as well as among emerging adult friend pairs. All of these findings taken together could have implications for individuals' well-being and should continue to be examined in future work. 


\section{References}

Aldao, A. (2013). The future of emotion regulation research: Capturing context. Perspectives on Psychological Science, 8(2), 155-172. https://doi.org/10.1177/1745691612459518

Aldao, A., \& Nolen-Hoeksema, S. (2012). When are adaptive strategies most predictive of psychopathology? Journal of Abnormal Psychology, 121(1), 276-281.

https://doi.org/10.1037/a0023598

Aldao, A., Nolen-Hoeksema, S., \& Schweizer, S. (2010). Emotion regulation strategies across psychopathology: A meta-analytic review. Clinical Psychology Review, 30(2), 217-37. https://doi.org/10.1016/j.cpr.2009.11.004

Andrews, J. A., Tildesley, E., Hops, H., \& Li, F. (2002). The influence of peers on young adult substance use. Health Psychology, 21(4), 349-357. https://doi.org/10.1037//02786133.21.4.349

Aquilino, W. S. (1997). From adolescent to young adult: A prospective study of parent-child relations during the transition to adulthood. Journal of Marriage and Family, 59(3), 670686. https://doi.org/10.2307/353953

Arnett, J. J. (1998). Learning to stand alone: The contemporary American transition to adulthood in cultural and historical context. Human Development, 41(5-6), 295-315. https://doi.org/10.1159/000022591

Arnett, J. J. (2000). Emerging adulthood: A theory of development from the late teens through the twenties. American Psychologist, 55(5), 469-480. https://doi.org/10.1037//0003066X.55.5.469

Arnett, J. J. (2004). Friends and peers. In Adolescence and Emerging Adulthood: A Cultural Approach. Pearson Education, Inc.

Arnett, J. J. (2007). Emerging adulthood: What is it, and what is it good for? Child Development Perspectives, 1(2), 68-73. https://doi.org/10.1111/j.1750-8606.2007.00016.x

Aspinwall, L. G., \& Taylor, S. E. (1997). A stitch in time: Self-regulation and proactive coping. Psychological Bulletin, 121, 417-436. https://doi.org/10.1056/NEJMcps062601

Association., A. C. H. (2008). National college health assessment: Reference group executive summary. Baltimore, MD.

Aureli, T., \& Presaghi, F. (2010). Developmental trajectories for mother-infant coregulation in the second year of life. Infancy, 15(6), 557-585. https://doi.org/10.1111/j.15327078.2010.00034.x

Baltes, P. B. (1987). Theoretical propositions of life-span developmental psychology: On the dynamics between growth and decline. Developmental Psychology, 23(5), 611-626. https://doi.org/10.1037//0012-1649.23.5.611

Baltes, P. B., Lindenberger, U., \& Staudinger, U. (2006). Life span theory in developmental psychology. In Handbook of Child Psychology (pp. 569-664).

Bariola, E., Gullone, E., \& Hughes, E. K. (2011). Child and adolescent emotion regulation: The 
role of parental emotion regulation and expression. Clinical Child and Family Psychology Review, 14(2), 198-212. https://doi.org/10.1007/s10567-011-0092-5

Bariola, E., Hughes, E. K., \& Gullone, E. (2012). Relationships between parent and child emotion regulation strategy use: A brief report. Journal of Child and Family Studies, 21(3), 443-448. https://doi.org/10.1007/s10826-011-9497-5

Barni, D., Ranieri, S., Scabini, E., \& Rosnati, R. (2011). Value transmission in the family: Do adolescents accept the values their parents want to transmit? Journal of Moral Education, 40(1), 105-121. https://doi.org/10.1080/03057240.2011.553797

Bell, R. Q. (1968). A reinterpretation of the direction of effects in studies of socialization. Psychological Review, 75(2), 81-95.

Berndt, T. J. (2002). Friendship quality and social development. Current Directions in Psychological Science, 11, 7-10. https://doi.org/10.1093/acrefore/9780199975839.013.362

Blair, B. L., Perry, N. B., Brien, M. O., Calkins, S. D., Keane, S. P., \& Shanahan, L. (2014). The indirect effects of maternal emotion socialization on friendship quality in middle childhood. Developmental Psychology, 50(2), 566-576. https://doi.org/10.1037/a0033532.The

Boren, J. P. (2013). Co-rumination partially mediates the relationship between social support and emotional exhaustion among graduate students. Communication Quarterly, 61(3), 253-267. https://doi.org/10.1080/01463373.2012.751436

Borowski, S. K., Zeman, J., \& Braunstein, K. (2016). Social anxiety and socioemotional functioning during early adolescence: The mediating role of best friend emotion socialization. The Journal of Early Adolescence, 1-23.

https://doi.org/10.1177/0272431616665212

Brand, A. E., \& Klimes-Dougan, B. (2010). Emotion socialization in adolescence: The roles of mothers and fathers. In A. K. Root \& S. A. Denham (Eds.), The Role of Gender in the Socialization of Emotion: Key Concepts and Critical Issues. New Directions of Child and Adolescent Development (Vol. 128, pp. 85-100). San Francisco: Jossey-Bass. https://doi.org/10.1002/cd

Brophy- Herb, H. E., Schiffman, R. F., Bocknek, E. L., Dupuis, S. B., Fitzgerald, H. E., Horodynski, M., ... Hillaker, B. (2011). Toddlers' social- emotional competence in the contexts of maternal emotion socialization and contingent responsiveness in a low- income sample. Social Development, 20(1), 73-92. https://doi.org/10.1111/j.14679507.2009.00570.x

Brown, B. B., \& Larson, J. (2013). Peer relationships in adolescence, 1-20.

Bryant, F. B. (2003). Savoring Beliefs Inventory (SBI): A scale for measuring beliefs about savouring. Journal of Mental Health, 12(2), 175-196. https://doi.org/10.1080/0963823031000103489

Buchanan, C. M., Maccoby, E. E., \& Dornbusch, S. M. (1991). Caught between parents: Adolescents' experience in divorced homes. Child Development, 62(5), 1008-1029.

Buckholdt, K. E., Parra, G. R., \& Jobe-Shields, L. (2014). Intergenerational transmission of 
emotion dysregulation through parental invalidation of emotions: Implications for adolescent internalizing and externalizing behaviors. Journal of Child and Family Studies, 23(2), 324-332. https://doi.org/10.1007/s10826-013-9768-4

Bugental, D. B., \& Grusec, J. E. (1998). Socialization Processes. In Handbook of Child Psychology.

Buhl, H. M. (2009). My mother: My best friend? Adults' relationships with significant others across the lifespan. Journal of Adult Development, 16(4), 239-249. https://doi.org/10.1007/s10804-009-9070-2

Buhrmester, D. (1996). Need fulfillment, interpersonal competence, and the developmental contexts of early adolescent friendship. In W. M. Bukowski, A. F. Newcomb, \& W. W. Hartup (Eds.), The Company They Keep: Friendship in Childhood and Adolescence (pp. 158-185). New York: Cambridge University Press.

Buhrmester, D., \& Carbery, J. (1992). Daily patterns of self-disclosure and adolescent adjustment. In Biennial meeting of the Society for Research on Adolescence. Washington, DC.

Buhrmester, D., \& Furman, W. (1987). The development of companionship and intimacy. Child Development, 58(4), 1101-1113. https://doi.org/10.1111/1467-8624.ep8590161

Burleson, B. R., \& Kunkel, A. (2002). Parental and peer contributions to the emotional support skills of the child: From whom do children learn to express support? The Journal of Family Communication, 2(2), 79-97. https://doi.org/10.1207/S15327698JFC0202_02

Burstein, M., \& Ginsburg, G. S. (2010). The effect of parental modeling of anxious behaviors and cognitions in school-aged children: An experimental pilot study. Behaviour Research and Therapy, 48(6), 506-515. https://doi.org/10.1016/j.brat.2010.02.006

Burt, C. H., Sweeten, G., \& Simons, R. L. (2014). Self-control through emerging adulthood: Instability, multidimensionality, and criminological significance. Criminology, (January 2015). https://doi.org/10.1111/1745-9125.12045

Butler, E. A., \& Randall, A. K. (2013). Emotional coregulation in close relationships. Emotion Review, 5(2), 202-210. https://doi.org/10.1177/0192513X12437708

Calkins, S. D., \& Hill, A. (2007). Caregiver influences on emerging emotion regulation. In Handbook of emotion regulation (pp. 229-248).

Calmes, C. A., \& Roberts, J. E. (2008). Rumination in interpersonal relationships: Does corumination explain gender differences in emotional distress and relationship satisfaction among college students? Cognitive Therapy and Research, 32(4), 577-590. https://doi.org/10.1007/s10608-008-9200-3

Campos, J. J., Campos, R. G., \& Barrett, K. C. (1989). Emergent themes in the study of emotional development and emotion regulation. Developmental Psychology, 25(3), 394402. https://doi.org/10.1037/0012-1649.25.3.394

Canli, T., Ferri, J., \& Duman, E. A. (2009). Genetics of emotion regulation. Neuroscience, 164, 43-54. https://doi.org/10.1016/j.tics.2011.07.009 
Carstensen, L. L. (1992). Social and emotional patterns in adulthood: Support for socioemotional selectivity theory. Psychology and Aging, 7(3), 331-338. https://doi.org/10.1037/08827974.7.3.331

Carstensen, L. L. (1995). Evidence for a life-span theory of socioemotional selectivity. Current Directions in Psychological Science, 4(5), 151-156. https://doi.org/10.1111/14678721.ep11512261

Casas, F., Coenders, G., Cummins, R. A., González, M., Figuer, C., \& Malo, S. (2008). Does subjective well-being show a relationship between parents and their children? Journal of Happiness Studies, 9, 197-205. https://doi.org/10.1007/s10902-007-9044-7

Casas, F., Coenders, G., González, M., Malo, S., Bertran, I., \& Figuer, C. (2012). Testing the relationship between parents' and their children's subjective well-being. Journal of Happiness Studies, 13(6), 1031-1051. https://doi.org/10.1007/s10902-011-9305-3

Champagne, F. A., \& Mashoodh, R. (2009). Genes in context. Current Directions in Psychological Science, 18(3), 127-132.

Cheung, E. O., Gardner, W. L., \& Anderson, J. F. (2015). Emotionships: Examining people's emotion-regulation relationships and their consequences for well-being. Social Psychological and Personality Science, 6(4), 407-414. https://doi.org/10.1177/1948550614564223

Cole, P. M. (2014). Moving ahead in the study of the development of emotion regulation. International Journal of Behavioral Development, 38(2), 203-207. https://doi.org/10.1177/0165025414522170

Cole, P. M., Michel, M. K., \& Teti, L. O. (1994). The development of emotion regulation and dysregulation: A clinical perspective. Monographs of the Society for Research in Child Development, 59(2-3), 73-100. https://doi.org/10.1111/j.1540-5834.1994.tb01278.x

Cowan, P. A. (1996). Meta-thoughts on the role of meta-emotion in children's development: Comment on Gottman et al. (1996). Journal of Family Psychology, 10(3), 277-283. https://doi.org/10.1037//0893-3200.10.3.277

Crick, N. R., \& Dodge, K. A. (1994). Review and reformulation of social information-processing mechanisms in children's social adjustment. Psychological Bulletin, 115(1), 74-101. https://doi.org/10.1037/0033-2909.115.1.74

Cunningham, J. N., Kliewer, W., \& Garner, P. W. (2009). Emotion socialization, child emotion understanding and regulation, and adjustment in urban African American families: Differential associations across child gender. Development and Psychopathology, 21, 261283. https://doi.org/10.1017/S0954579409000157

De Castella, K., Goldin, P., Jazaieri, H., Ziv, M., Dweck, C. S., \& Gross, J. J. (2013). Beliefs about emotion: Links to emotion regulation, well-being, and psychological distress. Basic and Applied Social Psychology, 35(6), 497-505.

Deater-Deckard, K. (2001). Recent research examining the role of peer relationships in the development of psychopathology. Journal of Child Psychology and Psychiatry, 42(5), 565579. https://doi.org/10.1111/1469-7610.00753 
Denham, S. A. (1989). Maternal affect and toddlers' social-emotional competence. American Journal of Orthopsychiatry, 59, 368-376.

Denham, S. A. (2007). Dealing with feelings: How children negotiate the worlds of emotions and social relationships. Cognition, Brain, Behavior, XI(1), 1-48.

Denham, S. A., Mitchell-Copeland, J., Strandberg, K., Auerbach, S., \& Blair, K. (1997). Parental contributions to preschoolers' emotional competence: Direct and indirect effects.

Motivation and Emotion, 21(1), 65-86.

DeSteno, D., Gross, J. J., \& Kubzansky, L. (2013). Affective science and health: The importance of emotion and emotion regulation. Health Psychology, 32(5), 474-486.

https://doi.org/10.1037/a0030259

Diener, E. (2006). Understanding scores on the Satisfaction with Life Scale.

Diener, E., Emmons, R., Larsen, J., \& Griffin, S. (1985). The Satisfaction with Life scale. Journal of Personality Assessmemt, 49(1), 71-75. https://doi.org/10.1207/s15327752jpa4901_13

Diener, E., Sandvik, E., \& Larsen, R. (1985). Age and sex effects for emotional intensity. Developmental Psychology, 21(3), 542-546. https://doi.org/10.1037/0012-1649.21.3.542

Diener, E., Wirtz, D., Biswas-Diener, R., Tov, W., Kim-Prieto, C., Choi, D., \& Oishi, S. (2009). New measures of well-being. Assessing Well-Being, 247-266. https://doi.org/10.1007/97890-481-2354-4

Diener, E., Wirtz, D., Tov, W., Kim-Prieto, C., Choi, D. won, Oishi, S., \& Biswas-Diener, R. (2010). New well-being measures: Short scales to assess flourishing and positive and negative feelings. Social Indicators Research, 97(2), 143-156. https://doi.org/10.1007/s11205-009-9493-y

Dimberg, U. (1982). Facial reactions to facial expressions. Psychophysiology, 19(6), 643-647. https://doi.org/10.1111/j.1469-8986.1982.tb02516.x

Dimberg, U. (1990). Facial electromyography and emotional reactions. Psychophysiology, 27(5), 481-494. https://doi.org/10.1111/j.1469-8986.1990.tb01962.x

Duckworth, A. L., \& Steinberg, L. (2015). Unpacking self-control. Child Development Perspectives, 9(1), 32-37. https://doi.org/10.1111/cdep.12107

Dunsmore, J. C., \& Karn, M. A. (2004). The influence of peer relationships and maternal socialization on kindergartners' developing emotion knowledge. Early Education \& Development, 15(1), 39-56. https://doi.org/10.1207/s15566935eed1501

Durbin, C. E., Klein, D. N., Hayden, E. P., Buckley, M. E., \& Moerk, K. C. (2005). Temperamental emotionality in preschoolers and parental mood disorders. Journal of Abnormal Psychology, 114(1), 28-37. https://doi.org/10.1037/0021-843X.114.1.28

Eisenberg, N. (1996). Meta-emotion and socialization of emotion in the family--A topic whose time has come: Comment on Gottman et al. (1996). Journal of Family Psychology, 10(3), 269-276. https://doi.org/10.1037/0893-3200.10.3.269 
Eisenberg, N., Cumberland, A., \& Spinrad, T. L. (1998). Parental socialization of emotion. Psychological Inquiry, 9(4), 241-273.

Eisenberg, N., \& Fabes, R. A. (1994). Mothers' reactions to children's negative emotions: Relations to children's temperament and anger behavior. Merrill-Palmer Quarterly, 40(1), $138-156$.

Eisenberg, N., Gershoff, E. T., Fabes, R. A., Shepard, S. A., Cumberland, A. J., Losoya, S. H., ... Murphy, B. C. (2001). Mother's emotional expressivity and children's behavior problems and social competence: Mediation through children's regulation. Developmental Psychology, 37(4), 475-490. https://doi.org/10.1037/0012-1649.37.4.475

Eisenberg, N., Spinrad, T. L., \& Cumberland, A. (1998). The socialization of emotion : Reply to commentaries. Psychological Inquiry, 9, 317-333.

Eisenberg, N., \& Valiente, C. (2004). Elaborations on a theme: Beyond main effects in relations of parenting to children's coping and regulation. Parenting, 4(4), 319-323. https://doi.org/10.1207/s15327922par0404_2

Eisenberg, N., Valiente, C., Morris, A. S., Fabes, R. A., Cumberland, A., Reiser, M., ... Losoya, S. (2003). Longitudinal relations among parental emotional expressivity, children's regulation, and quality of socioemotional functioning. Developmental Psychology, 39(1), 319. https://doi.org/10.1037/0012-1649.39.1.3

Fabes, R. A., Eisenberg, N., \& Bernzweig, J. (1990). Coping with children's negative emotions scale (CCNES): Description and scoring. Tempe, AZ.

Fabes, R. A., Poulin, R. E., Eisenberg, N., \& Madden-Derdich, D. A. (2002). The Coping with Children's Negative Emotions Scale (CCNES): Psychometric properties and relations with children's emotional competence. Marriage \& Family Review, 34(3-4), 285-310. https://doi.org/10.1177/0192513X12437708

Feldman, G. C., Joormann, J., \& Johnson, S. L. (2008). Responses to positive affect: A selfreport measure of rumination and dampening. Cognitive Therapy and Research, 32(4), 507525. https://doi.org/10.1007/s10608-006-9083-0

Fredrickson, B. L. (1998a). Cultivated emotions: Parental socialization of positive emotions and self-conscious emotions. Psychological Inquiry, 9(4), 279-281.

Fredrickson, B. L. (1998b). What good are positive emotions? Review Of, 2(3), 300-319. https://doi.org/10.1037/1089-2680.2.3.300. What

Freire, C., Ferradás, M. D. M., Valle, A., Núñez, J. C., \& Vallejo, G. (2016). Profiles of psychological well-being and coping strategies among university students. Frontiers in Psychology, 7, 1-11. https://doi.org/10.3389/fpsyg.2016.01554

Furman, W., \& Shomaker, L. B. (2008). Patterns of interaction in adolescent romantic relationships: Distinct features and Llnks to other close relationships. Journal of Adolescence, 31, 771-788. https://doi.org/10.1002/ana.22528.Toll-like

Gable, S. L., \& Reis, H. T. (2010). Good news! Capitalizing on positive events in an interpersonal context. Advances in Experimental Social Psychology, 42, 195-257. 
https://doi.org/10.1016/S0065-2601(10)42004-3

Gardner, M., \& Steinberg, L. (2005). Peer influence on risk taking, risk preference, and risky decision making in adolescence and adulthood: An experimental study. Developmental Psychology, 41(4), 625-635. https://doi.org/10.1037/a0026993

Garner, P. W., \& Estep, K. M. (2001). Emotional competence, emotion socialization, and young children's peer-related social competence. Early Education \& Development, 12(1), 29-48. https://doi.org/10.1207/s15566935eed1201

Garrett-Peters, P., Mills-Koonce, R., Adkins, D., Veron-Feagans, L., Cox, M., \& Investigators, T. F. L. P. K. (2008). Early environmental correlates of maternal emotion talk. Parenting: Science and Practice, 8(2), 117-152. https://doi.org/10.1016/j.ydbio.2009.10.046.Hippo

Garside, R. B. (2005). Parental socialization of discrete positive and negative emotions. The Catholic University of America. https://doi.org/10.1016/0161-5890(89)90134-X

Garside, R. B., \& Klimes-Dougan, B. (2002a). Socialization of discrete negative emotions: Gender differences and links with psychological distress. Sex Roles, 47(3-4), 115-128. https://doi.org/10.1023/A:1021090904785

Garside, R. B., \& Klimes-Dougan, B. (2002b). The EAC Negative and Positive Scales Version 2. Unpublished Scale. The Catholic University of America.

Garver, M. S., \& Mentzer, J. T. (1999). Logistics research methods: Employing structural equation modeling to test for construct validity. Journal of Business Logistics, 20(1), 33-57.

Gentzler, A. L., Kerns, K. A., \& Keener, E. (2010). Emotional reactions and regulatory responses to negative and positive events: Associations with attachment and gender. Motivation and Emotion, 34(1), 78-92. https://doi.org/10.1007/s11031-009-9149-x

Gentzler, A. L., Palmer, C. A., \& Ramsey, M. A. (2016). Savoring with intent: Investigating types of and motives for responses to positive events. Journal of Happiness Studies, 17(3), 937-958. https://doi.org/10.1007/s10902-015-9625-9

Gentzler, A. L., \& Ramsey, M. A. (2015). Positive Affect and Responses Survey. Unpublished Measure.

Gentzler, A. L., Ramsey, M. A., \& Black, K. R. (2015). Mothers' attachment styles and their children's self-reported security, as related to maternal socialization of children's positive affect regulation. Attachment \& Human Development, 17(4), 376-398. https://doi.org/10.1080/14616734.2015.1055507

Giletta, M., Scholte, R. H. J., Burk, W. J., Engels, R. C. M. E., Larsen, J. K., Prinstein, M. J., \& Ciairano, S. (2011). Similarity in depressive symptoms in adolescents' friendship dyads: Selection or socialization? Developmental Psychology, 47(6), 1804-1814. https://doi.org/10.1037/a0023872.Similarity

Gonzaga, G. C., Turner, R. A., Keltner, D., Campos, B., \& Altemus, M. (2006). Romantic love and sexual desire in close relationships. Emotion (Washington, D.C.), 6(2), 163-179. https://doi.org/10.1037/1528-3542.6.2.163 
Gottlieb, G. (2007). Probabilistic epigenesis. Developmental Science, 10(1), 1-11. https://doi.org/10.1111/j.1467-7687.2007.00556.x

Gottman, J. M., Katz, L. F., \& Hooven, C. (1996). Parental meta-emotion philosophy and the emotional life of families: Theoretical models and preliminary data. Journal of Family Psychology, 10(3), 243-268. https://doi.org/10.1037/0893-3200.10.3.243

Gross, J. J. (1998). The emerging field of emotion regulation: An integrative review. Review of General Psychology, 2(3), 271-299.

Gross, J. J. (2015a). Emotion regulation: Conceptual and empirical foundations. In J. J. Gross (Ed.), Handbook of Emotion Regulation (2nd ed., pp. 3-20). New York: The Guilford Press.

Gross, J. J. (2015b). Emotion regulation: Current status and future prospects. Psychological Inquiry, 26(1), 1-26. https://doi.org/10.1080/1047840X.2014.940781

Gross, J. J., \& John, O. P. (2003). Individual differences in two emotion regulation processes: Implications for affect, relationships, and well-being. Journal of Personality and Social Psychology, 85(2), 348-362. https://doi.org/10.1037/0022-3514.85.2.348

Gross, J. J., \& Thompson, R. A. (2007). Emotion regulation: Conceptual foundations. In J. J. Gross (Ed.), Handbook of Emotion Regulation (1st ed., pp. 3-24). New York: The Guilford Press.

Grusec, J. E. (2011). Socialization processes in the family: Social and emotional development. Annual Review of Psychology, 62, 243-269. https://doi.org/10.1146/annurev.psych.121208.131650

Guo, J., Mrug, S., \& Knight, D. C. (2017). Factor structure of the emotions as a child scale in late adolescence and emerging adulthood. Psychological Assessment, 29(9), 1082-1095. https://doi.org/10.1037/pas0000412

Halberstadt, A. G., Dunsmore, J. C., Bryant, A., Parker, A. E., Beale, K. S., \& Thompson, J. a. (2013). Development and validation of the Parents' Beliefs About Children's Emotions questionnaire. Psychological Assessment, 25(4), 1195-210. https://doi.org/10.1037/a0033695

Hartup, W. W. (1996). The company they keep: Friendships and their developmental significance. Child Development, 67(1), 1-13.

Hartup, W. W., \& Stevens, N. (1997). Friendships and adaptation across the life span. Current Directions in Psychological Science, 8, 355-370. https://doi.org/10.1111/1467-8721.00018

Havighurst, S. S., Harley, A. E., \& Prior, M. R. (2004). Building preschool children's emotional competence: A parenting program. Early Education \& Development, 15(4).

Havighurst, S. S., Wilson, K. R., Harley, A. E., Kehoe, C., Efron, D., \& Prior, M. R. (2013). "Tuning into kids": Reducing young children's behavior problems using an emotion coaching parenting program. Child Psychiatry and Human Development, 44(2), 247-264. https://doi.org/10.1007/s10578-012-0322-1

Havighurst, S. S., Wilson, K. R., Harley, A. E., \& Prior, M. R. (2009). Turning into Kids: An 
emotion-focused parenting program - Initial findings from a community trial. Journal of Community Psychology, 37(8), 1008-1023. https://doi.org/10.1002/jcop

Havighurst, S. S., Wilson, K. R., Harley, A. E., Prior, M. R., \& Kehoe, C. (2010). Tuning into Kids: Improving emotion socialization practices in parents of preschool children-findings from a community trial. Journal of Child Psychology and Psychiatry, 51(12), 1342-1350. https://doi.org/10.1111/j.1469-7610.2010.02303.x

Haviland, J. M., \& Lelwica, M. (1987). The induced affect response: 10-week-old infants' responses to three emotion expressions. Developmental Psychology, 23(1), 97-104. https://doi.org/10.1037/0012-1649.23.1.97

Hawn, S. E., Overstreet, C., Stewart, K. E., \& Amstadter, A. B. (2015). Recent advances in the genetics of emotion regulation: A review. Current Opinion in Psychology, 3, 108-116. https://doi.org/10.1016/j.copsyc.2014.12.014

Helsen, M., Vollebergh, W., \& Meeus, W. (2000). Social support from parents and friends and emotional problems in adolescence. Journal of Youth and Adolescence, 29(3), 319-335. https://doi.org/10.1023/A:1005147708827

Hoe, S. L. (2008). Issues and procedures in adopting structural equation modeling technique. Journal of Applied Quantitative Methods, 3(1), 76-83.

Hoelter, J. W. (1983). The analysis of covariance structures: Goodness-of-fit indices. Sociological Methods Research, 11(3), 325-344.

Hooven, C., Gottman, J. M., \& Katz, L. F. (1995). Parental meta-emotion structure predicts family and child outcomes. Cognition \& Emotion (Vol. 9). https://doi.org/10.1080/02699939508409010

Howell, A. J., \& Buro, K. (2015). Measuring and predicting student well-being: Further evidence in support of the Flourishing Scale and the Scale of Positive and Negative Experiences. Social Indicators Research, 121(3), 903-915. https://doi.org/10.1007/s11205-014-0663-1

Hunter, F. T., \& Youniss, J. (1982). Changes in functions of three relations during adolescence. Developmental Psychology, 18(6), 806-811. https://doi.org/10.1037/0012-1649.18.6.806

Hutson-Comeaux, S. L., \& Kelly, J. R. (2002). Gender stereotypes of emotional reactions: How we judge an emotion as valid. Sex Roles, 47(1-2), 1-10. https://doi.org/10.1023/A:1020657301981

Izard, C. E. (1977). Human emotions. New York: Plenum Press.

John, O. P., \& Gross, J. J. (2004). Healthy and unhealthy emotion regulation: Personality processes, individual differences, and life span development. Journal of Personality, 72(6), 1301-1333. https://doi.org/10.1111/j.1467-6494.2004.00298.x

Jorgensen, B. L., \& Savla, J. (2010). Financial literacy of young adults: The importance of parental socialization. Family Relations, 59, 465-478. https://doi.org/10.1111/j.17413729.2010.00616.x

Kandel, D. B. (1978). Homophily, selection, and socialization in adolescent friendships. 
American Journal of Sociology, 84(2), 427-436.

Katz, L. F., Maliken, A. C., \& Stettler, N. M. (2012). Parental meta-emotion philosophy: A review of research and theoretical framework. Child Development Perspectives, 6(4), 417422. https://doi.org/10.1111/j.1750-8606.2012.00244.x

Kehoe, C. E., Havighurst, S. S., \& Harley, A. E. (2014). Tuning into Teens: Improving parent emotion socialization to reduce youth internalizing difficulties. Social Development, 23(2), 413-431. https://doi.org/10.1111/sode. 12060

Kelly, J. R., \& Hutson-Comeaux, S. L. (1999). Gender-emotion stereotypes are context specific. Sex Roles, 40(1/2), 107-22. https://doi.org/0360-0025/99/0100-0107\$16.00/0 Ó

Keltner, D., \& Gross, J. J. (1999). Functional account of emotions. Cognition \& Emotion, 13, $467-480$.

Kenny, M. E., \& Sirin, S. R. (2006). Parental attachment, self-worth, and depressive symptoms among emerging adults. Journal of Counseling \& Development, 84, 61-71.

Kerr, M., Stattin, H., Biesecker, G., \& Ferrer-Wreder, L. (2003). Relationships with Parents and Peers in Adolescence. In R. M. Lerner, M. A. Easterbrooks, \& J. Mistry (Eds.), Handbook of Psychology (6th ed., pp. 395-419). Hoboken, New Jersey: John Wiley \& Sons, Inc. Retrieved from papers2://publication/uuid/CED0C729-E2AD-4D0F-BFAD096B2C604A0C

Kliewer, W., Fearnow, M. D., \& Miller, P. A. (1996). Coping socialization in middle childhood: Tests of maternal and paternal influences. Child Development, 67(5), 2339-2357. https://doi.org/10.2307/113162

Klimes-Dougan, B., Brand, A. E., Zahn-Waxler, C., Usher, B., Hastings, P. D., Kendziora, K., \& Garside, R. B. (2007). Parental emotion socialization in adolescence: Differences in sex, age and problem status. Social Development, 16(2), 326-342.

https://doi.org/10.1111/j.1467-9507.2007.00387.x

Klimes-Dougan, B., Pearson, T. E., Jappe, L., Mathieson, L., Simard, M. R., Hastings, P., \& Zahn-Waxler, C. (2014). Adolescent emotion socialization: A longitudinal study of friends' responses to negative emotions. Social Development, 23(2), 395-412. https://doi.org/10.1111/sode.12045

Knafo, A., \& Galansky, N. (2008). The influence of children on their parents' values. Social and Personality Psychology Compass, 2(3), 1143-1161. https://doi.org/10.1111/j.17519004.2008.00097.x

Kneeland, E. T., Dovidio, J. F., Joormann, J., \& Clark, M. S. (2016). Emotion malleability beliefs, emotion regulation, and psychopathology: Integrating affective and clinical science. Clinical Psychology Review, 45, 81-88. https://doi.org/10.1016/j.cpr.2016.03.008

Knoester, C., Haynie, D. L., \& Stephens, C. M. (2006). Parenting practices and adolescents' friendship networks. Journal of Marriage and Family, 68, 1247-1260.

Kochanska, G., Forman, D. R., \& Coy, K. C. (1999). Implications of the mother-child relationship in infancy for socialization in the second year of life. Infant Behavior and 
Development, 22(2), 249-265. https://doi.org/10.1016/S0163-6383(99)00009-0

Kring, A. M., \& Gordon, A. H. (1998). Sex differences in emotion: Expression, experience and physiology. Journal of Personality and Social Psychology, 74(3), 686-703.

Kuczynski, L., Marshall, S., \& Schell, K. (1997). Value socialization in a bidrectional context. Parenting and the Internalization of Values: A Handbook of Contemporary Theory, 23-50.

Kuczynski, L., \& Parkin, C. M. (2008). Agency and bidirectionality in socialization: Interactions, transactions, and relational dialectics. In J. E. Grusec \& P. D. Hastings (Eds.), Handbook of Socialization: Theory and Research (1st ed., pp. 259-283). New York: The Guilford Press.

Kuczynski, L., Pitman, R., Ta-Young, L., \& Harach, L. (2016). Children's influence on parents' adult development: Mothers' and fathers' receptivity to children's requests for change. Journal of Adult Development.

Ladouceur, C., Reid, L., \& Jacques, A. (2002). Construction and validation of the Questionnaire on Parental Reactions to Children's Expression of Positive Emotions. [French]. Canadian Journal of Behavioural Science, 34(1), 8-18. https://doi.org/10.1037/h0087150

Lau, R. R., Quadrel, M. J., \& Hartman, K. A. (1990). Development and change of young adults' preventive health beliefs and behavior: Influence from parents and peers. Journal of Health and Social Behavior, 31(3), 240-259.

Laursen, B., \& Williams, V. A. (1997). Perceptions of interdependence and closeness in family and peer relationships among adolescents with and without romantic partners. In S. Shulman \& W. A. Collins (Eds.), Romantic Relationships in Adolescence: Developmental Perspectives (pp. 3-20). San Francisco, CA: Jossey-Bass.

Leerkes, E. M., \& Siepak, K. J. (2006). Attachment linked predictors of women's emotional and cognitive responses to infant distress. Attachment \& Human Development, 8(1), 11-32. https://doi.org/10.1080/14616730600594450

Legerski, J. P., Biggs, B. K., Greenhoot, A. F., \& Sampilo, M. L. (2015). Emotion talk and friend responses among early adolescent same-sex friend dyads. Social Development, 24(1), 20 38. https://doi.org/10.1111/sode.12079

Little, T. D. (2013). Longitudinal structural equation modeling. New York, NY: The Guilford Press.

Loop, L., \& Roskam, I. (2016). Do children behave better when parents' emotion coaching practices are stimulated? A micro-trial study. Journal of Child and Family Studies, 25(7), 2223-2235. https://doi.org/10.1007/s10826-016-0382-0

Lougheed, J. P., Koval, P., Hollenstein, T., Lougheed, J. P., Koval, P., \& Hollenstein, T. (2016). Sharing the burden: The interpersonal regulation of emotional arousal in mother-daughter dyads. Emotion, 16(1), 83-93.

Lundqvist, L.-O., \& Dimberg, U. (1995). Facial expressions are contagious. Journal of Psychophysiology, 9, 203-211. https://doi.org/10.1177/0192513X12437708

Lunkenheimer, E. S., Shields, A. M., \& Cortina, K. S. (2007). Parental emotion coaching and 
dismissing in family interaction. Social Development, 16(2), 232-248.

https://doi.org/10.1111/j.1467-9507.2007.00382.x

Lye, D. N. (1996). Adult child - parent relationships. Annual Review of Sociology, 22(1994), 79102. https://doi.org/10.1146/annurev.soc.22.1.79

Lyubomirsky, S., \& Lepper, H. (1999). A measure of subjective hap- piness: Preliminary reliability and construct validation. Social Indicators Research, 46, 137-155.

MacCallum, R. C., Browne, M. W., \& Sugawara, H. M. (1996). Power analysis and determination of sample size for covariance structure modeling. Psychological Methods, 1(2), 130-149. https://doi.org/10.1037/1082-989X.1.2.130

Maccoby, E. (2008). Historical overview of socialization research and theory. In J. E. Grusec \& P. D. Hastings (Eds.), Handbook of Socialization: Theory and Research (1st ed., pp. 1341). New York: The Guilford Press.

Magai, C. (1991). Emotional socialization: Its role in personality and developmental psychopathology. In D. Cicchetti \& S. L. Toth (Eds.), Internalizing and Externalizing Expressions of Dysfunction: Rochester Symposium on Developmental Psychopathology (pp. 203-224). Hillsdale, NJ: Lawrence Erlbaum.

Magai, C. (1996). Emotions as a child self-rating scale. Unpublished Scale. Long Island University, Brooklyn, New York.

Magai, C., Consedine, N., Fiori, K., \& King, A. R. (2009). Sharing the good, sharing the bad: The benefits of emotional self-disclosure among middle-aged and older adults. Journal of Aging and Health, 21(2), 286-313.

Magai, C., Consedine, N. S., Gillespie, M., O’Neal, C., \& Vilker, R. (2004). The differential roles of early emotion socialization and adult attachment in adult emotional experience: Testing a mediator hypothesis. Attachment \& Human Development, 6(4), 389-417. https://doi.org/10.1080/1461673042000303118

Magai, C., Consedine, N. S., Krivoshekova, Y. S., Kudadjie-Gyamfi, E., \& McPherson, R. (2006). Emotion experience and expression across the adult life span: Insights from a multimodal assessment study. Psychology and Aging, 21(2), 303-317. https://doi.org/10.1037/0882-7974.21.2.303

Malatesta, C. Z., \& Haviland, J. M. (1982). Learning display rules: The socialization of emotion expression in infancy. Child Development, 53(4), 991-1003.

Mancini, J. A., \& Blieszner, R. (1989). Aging parents and adult children: Research themes in intergenerational relations. Journal of Marriage and Family, 51(2), 275-290. https://doi.org/10.1111/j.1741-3737.2010.00723.x

Mancini, K. J., Luebbe, A. M., \& Bell, D. J. (2016). Valence-specific emotion transmission: Potential influences on parent-adolescent emotion coregulation. Emotion. https://doi.org/10.1037/emo0000160

Marsh, H. W., Hau, K., Balla, J. R., \& Grayson, D. (1998). Is more ever too much? The number of indicators per factor in confirmatory factor analysis. Multivariate Behavioral Research, 
33(2), 181-220. https://doi.org/10.1207/s15327906mbr3302

Martini, T. S., Root, C. A., \& Jenkins, J. M. (2004). Low and middle income mothers' regulation of negative emotion: Effects of children's temperament and situational emotional responses. Social Development, 13(4), 515-530. https://doi.org/10.1111/j.1467-9507.2004.00281.x

Mayer, J. D., Salovey, P., Caruso, D. R., \& Cherkasskiy, L. (2011). Emotional intelligence.

Mckee, L. G., Faro, A. L., O’Leary, J. L., Spratt, K. H., \& Jones, D. J. (2015). Socializing positive emotion: A qualitative study of African American single mothers and their adolescent youth. Family Relations, 64(5), 635-650. https://doi.org/10.1111/fare.12160

Meeus, W. H. J., Branje, S. J. T., van der Valk, I., \& de Wied, M. (2007). Relationships with intimate partner, best friend, and parents in adolescence and early adulthood: A study of the saliency of the intimate partnership. International Journal of Behavioral Development, 31(6), 569-580. https://doi.org/10.1177/0165025407080584

Miller-Slough, R. L., \& Dunsmore, J. C. (2016). Parent and friend emotion socialization in adolescence: Associations with psychological adjustment. Adolescent Research Review. https://doi.org/10.1007/s40894-016-0026-z

Miller-Slough, R. L., Zeman, J. L., Poon, J. A., \& Sanders, W. M. (2016). Children's maternal support-seeking: Relations to maternal emotion socialization responses and children's emotion management. Journal of Child and Family Studies, 25, 3009-3021. https://doi.org/10.1007/s10826-016-0465-y

Mirabile, S. P., Oertwig, D., \& Halberstadt, A. G. (2016). Parent emotion socialization and children's socioemotional adjustment: When is supportiveness no longer supportive? Social Development, (August), 1-16. https://doi.org/10.1111/sode.12226

Montague, D. P. F., Magai, C., Consedine, N. S., \& Gillespie, M. (2003). Attachment in African American and European American older adults: The roles of early life socialization and religiosity. Attachment \& Human Development, 5(2), 188-214. https://doi.org/10.1080/1461673031000108487

Moran, K. M., Root, A. E., Vizy, B. K., Wilson, T. K., \& Gentzler, A. L. (n.d.). Maternal socialization of children's positive affect regulation: Associations with children's savoring, dampening, and depressive symptoms.

Morelen, D., Shaffer, A., \& Suveg, C. (2016). Maternal emotion regulation: Links to emotion parenting and child emotion regulation. Journal of Family Issues, 37(13), 1891-1916. https://doi.org/10.1177/0192513X14546720

Morey, J. N., \& Gentzler, A. L. (2017). Parents' perceptions of and responses to children's emotions: Relations with meta-emotion philosophy and adult attachment. Parenting: Science and Practice, 17, 73-103. https://doi.org/10.1080/15295192.2017.1304782

Morris, A. S., Criss, M. M., Silk, J. S., \& Houltberg, B. J. (2017). The impact of parenting on emotion regulation during childhood and adolescence. Child Development Perspectives, 11(4), 233-238. https://doi.org/10.1111/cdep.12238

Morris, A. S., Silk, J. S., Steinberg, L., \& Robinson, L. R. (2007). The role of the family context 
in the development of emotion regulation. Social Development, 16(2), 361-388.

https://doi.org/10.1111/j.1467-9507.2007.00389.x.The

Muris, P., Steerneman, P., Merckelbach, H., \& Meesters, C. (1996). The role of parental fearfulness and modeling in children's fear. Behaviour Research and Therapy, 34(3), 265268. https://doi.org/10.1016/0005-7967(95)00067-4

Nelson, J. A., Leerkes, E. M., O’Brien, M., Calkins, S. D., \& Marcovitch, S. (2012). African American and European American Mothers' Beliefs about Negative Emotions and Emotion Socialization Practices. Parenting: Science and Practice, 12(1), 22-41. https://doi.org/10.1016/j.micinf.2011.07.011.Innate

Newcomb, A. F., \& Bagwell, C. L. (1995). Children's friendship relations: A meta-analytic review. Psychological Bulletin, 117(2), 306-347. https://doi.org/10.1037//00332909.117.2.306

Nolen-Hoeksema, S., \& Aldao, A. (2011). Gender and age differences in emotion regulation strategies and their relationship to depressive symptoms. Personality and Individual Differences, 51(6), 704-708. https://doi.org/10.1016/j.paid.2011.06.012

O’Neal, C. R., \& Magai, C. (2005). Do parents respond in different ways when children feel different emotions? The emotional context of parenting. Development and Psychopathology, 17, 467-487. https://doi.org/10.1177/0192513X12437708

Parke, R. D. (1994). Progress, paradigms, and unresolved problems: A commentary on recent advances in our understanding of children's emotions. Merrill-Palmer Quarterly, 40, 157169.

Parke, R. D., \& Bhavnagri, N. P. (1989). Parents as managers of children's peer relationships. In D. Belle (Ed.), Children's social networks and social supports (pp. 241-259). New York: Wiley.

Parke, R. D., \& Ladd, G. (1992). Family-peer relationships. Hillsdale, NY: Erlbaum.

Parr, N. J., Zeman, J., Braunstein, K., \& Price, N. (2016). Peer emotion socialization and somatic complaints in adolescents. Journal of Adolescence, 50, 22-30.

https://doi.org/10.1016/j.adolescence.2016.04.004

Peters, J. F. (1985). Adolescents as socialization agents to parents. Adolescence, 20(80), 921933. https://doi.org/10.1177/0192513X12437708

Phillips, K. F. V, \& Power, M. J. (2007). A new self-report measure of emotion regulation in adolescents: The Regulation of Emotions Questionnaire. Clinical Psychology and Psychotherapy, 14, 145-156.

Pinquart, M., \& Silbereisen, R. K. (2004). Transmission of values from adolescents to their parents: The role of value content and authoritative parenting. Adolescence, 39(153), 83100 .

Plant, E. A., Hyde, J. S., Keltner, D., \& Devine, P. G. (2000). The gender stereotyping of emotions. Psychology of Women Quarterly, 24, 81-92. 
Poelen, E. A. P., Scholte, R. H. J., Willemsen, G., Boomsma, D. I., \& Engels, R. C. M. E. (2007). Drinking by parents, siblings, and friends as predictors of regular alcohol use in adolescents and young adults: A longitudinal twin-family study. Alcohol and Alcoholism, 42(4), 362-369. https://doi.org/10.1093/alcalc/agm042

Premo, J. E., \& Kiel, E. J. (2014). The effect of toddler emotion regulation on maternal emotion socialization: Moderation by toddler gender. Emotion, 14(4), 782-793. https://doi.org/10.1037/a0036684.The

Prinstein, M. J. (2007). Moderators of peer contagion: A longitudinal examination of depression socialization between adolescents and their best friends. Journal of Clinical Child \& Adolescent Psychology, 36(2), 159-170. https://doi.org/10.1080/15374410701274934

Prinstein, M. J., Borelli, J. L., Cheah, C. S. L., Simon, V. A., \& Aikins, J. W. (2005). Adolescent girls' interpersonal vulnerability to depressive symptoms: A longitudinal examination of reassurance seeking and peer relationships. Journal of Abnormal Psychology, 114(4), 676688. https://doi.org/10.1037/0021-843x.114.4.676

Provine, R. R. (1992). Contagious laughter: Laughter is a sufficient stimulus for laughs and smiles. Bulletin of the Psychonomic Society, 30(1), 1-4. https://doi.org/10.3758/BF03330380

Provine, R. R. (2000). Laughter: A scientific investigation. New York: Viking Penguin Group.

Quoidbach, J., Berry, E. V., Hansenne, M., \& Mikolajczak, M. (2010). Positive emotion regulation and well-being: Comparing the impact of eight savoring and dampening strategies. Personality and Individual Differences, 49(5), 368-373. https://doi.org/10.1016/j.paid.2010.03.048

Ramsden, S. R., \& Hubbard, J. A. (2002). Family expressiveness and parental emotion coaching: Their role in children's emotion regulation and aggression. Journal of Abnormal Child Psychology, 30(6), 657-667. https://doi.org/10.1023/A

Ramsey, M. A., \& Gentzler, A. L. (2014). Age differences in subjective well-being across adulthood: The roles of savoring and future time perspective. The International Journal of Aging and Human Development, 78(1), 3-22. https://doi.org/10.2190/AG.78.1.b

Rapini, D. R., Farmer, F. F., Clark, S. M., Micka, J. C., \& Barnett, J. K. (1990). Early adolescent age and gender differences in patterns of emotional self-disclosure to parents and friends. Adolescence, 25(100), 959.

Raval, V. V., Raval, P. H., \& Deo, N. (2013). Mothers' socialization goals, mothers' emotion socialization behaviors, child emotion regulation, and child socioemotional functioning in urban India. The Journal of Early Adolescence, 34(2), 229-250. https://doi.org/10.1177/0272431613485821

Reindl, M., Gniewosz, B., \& Reinders, H. (2016). Socialization of emotion regulation strategies through friends. Journal of Adolescence, 49, 146-157. https://doi.org/10.1016/j.adolescence.2016.03.008

Reis, H. T., Lin, Y. C., Bennett, M. E., \& Nezlek, J. B. (1993). Change and consistency in social participation during early adulthood. Developmental Psychology, 29, 622-645. 
https://doi.org/10.4324/9780203311851

Reis, H. T., Smith, S. M., Carmichael, C. L., Caprariello, P. A., Tsai, F.-F., Rodrigues, A., \& Maniaci, M. R. (2010). Are you happy for me? How sharing positive events with others provides personal and interpersonal benefits. Journal of Personality and Social Psychology, 99(2), 311-29. https://doi.org/10.1037/a0018344

Rivers, S. E., Tominey, S., O’Bryon, E., \& Brackett, M. (2013). Developing emotional skills in early childhood settings using preschool RULER. The Psychology of Education Review.

Robinson, M. D., Johnson, J. T., \& Shields, S. A. (1998). The gender heuristic and the database: Factors affecting the perception of gender-related differences in the experience and display of emotions. Basic and Applied Social Psychology, 20(3), 206-219. https://doi.org/10.1207/s15324834basp2003

Roest, A. M. C., Dubas, J. S., \& Gerris, J. R. M. (2009). Value transmissions between fathers, mothers, and adolescent and emerging adult children: The role of the family climate. Journal of Family Psychology :, 23(2), 146-155. https://doi.org/10.1037/a0015075

Rogers, M. L., Halberstadt, A. G., Castro, V. L., MacCormack, J. K., \& Garrett-Peters, P. (2016). Maternal emotion socialization differentially predicts third-grade children's emotion regulation and lability. Emotion, 16(2), 280-291. https://doi.org/10.1037/emo0000142

Rose, A. J. (2002). Co-rumination in the friendships of girls and boys. Child Development, 73(6), 1830-1843. https://doi.org/10.1111/1467-8624.00509

Rose, A. J., Carlson, W., \& Waller, E. M. (2007). Prospective associations of co-rumination with friendship and emotional adjustment: Considering the socioemotional trade-offs of corumination. Developmental Psychology, 43(4), 1019-1031. https://doi.org/10.1038/nmeth.2250.Digestion

Saarni, C. (1993). Socialization of emotion. In M. Lewis \& J. M. Haviland (Eds.), Handbook of Emotions (pp. 435-446). New York: Guilford Press.

Saarni, C. (1999). How we become emotionally competent. In The Development of Emotional Competence (pp. 54-78). New York, NY: The Guilford Press.

Saarni, C., Campos, J. J., Camras, L. A., \& Witherington, D. (1998). Emotional development: Action, communication, and understanding. In Handbook of Child Psychology. John Wiley \& Sons, Inc.

Sanders, W., Zeman, J., Poon, J., \& Miller, R. (2015). Child regulation of negative emotions and depressive symptoms: The moderating role of parental emotion socialization. Journal of Child and Family Studies, 24, 402-415. https://doi.org/10.1007/s10826-013-9850-y

Scarr, S., \& McCartney, K. (1983). How people make their own environments: A theory of genotype --> environment effects. Child Development, 54(2), 424-435. https://doi.org/10.2307/1129703

Scharf, M., \& Mayseless, O. (2010). Finding the authentic self in a communal culture: Developmental goals in emerging adulthood. In S. Shulman \& J. E. Nurmi (Eds.), The role of goals in navigating individual lives during emerging adulthood. New Directions for 
Child and Adolescent Development (Vol. 130, pp. 83-95). Wiley Periodicals, Inc. https://doi.org/10.1002/cd

Schulenberg, J. E., Sameroff, A. J., \& Cicchetti, D. (2004). The transition to adulthood as a critical juncture in the course of psychopathology and mental health. Development and Psychopathology, 16, 799-806. https://doi.org/10.1017/S0954579404040015

Shewark, E. A., \& Blandon, A. Y. (2015). Mothers' and fathers' emotion socialization and children's emotion regulation: A within-family model. Social Development, 24(2), 266284. https://doi.org/10.1111/sode.12095

Shiota, M., \& Kalat, J. W. (2012). The nature of emotion. In Emotion (2nd ed., pp. 2-32). United States: Wadsworth Cengage Learning.

Silk, J. S., Shaw, D. S., Prout, J. T., O'Rourke, F., Lane, T. J., \& Kovacs, M. (2011). Socialization of emotion and offspring internalizing symptoms in mothers with childhoodonset depression. Journal of Applied Developmental Psychology, 32(3), 127-136. https://doi.org/10.1016/j.appdev.2011.02.001

Simpson, J. A., Collins, W. A., Tran, S., \& Haydon, K. C. (2007). Attachment and the experience and expression of emotions in romantic relationships: A developmental perspective. Journal of Personality and Social Psychology, 92(2), 355-367. https://doi.org/10.1037/0022-3514.92.2.355

Smith, C. L., Eisenberg, N., Spinrad, T. L., Chassin, L., Morris, A. S., Kupfer, A., ... Kwok, O.M. (2006). Children's coping strategies and coping efficacy: Relations to parent socialization, child adjustment, and familial alcoholism. Development and Psychopathology, 18(2), 445-469. https://doi.org/10.1017/S095457940606024X

Spinrad, T. L., Eisenberg, N., Harris, E., Hanish, L., Fabes, R. A., Kupanoff, K., ... Holmes, J. (2004). The relation of children's everyday nonsocial peer play behavior to their emotionality, regulation, and social functioning. Developmental Psychology, 40(1), 67-80. https://doi.org/10.1037/0012-1649.40.1.67

Starr, L. R., \& Davila, J. (2009). Symptoms and romantic involvement among adolescent girls. Journal of Adolescence, 32(1), 19-37. https://doi.org/10.1016/j.adolescence.2007.12.005.Clarifying

Stettler, N. M., \& Katz, L. F. (2014). Changes in Parents' Meta-Emotion Philosophy from Preschool to Early Adolescence. Parenting:Science and Practice, 14(3), 162-174. https://doi.org/10.1177/0192513X12437708

Stone, L. B., Hankin, B. L., Gibb, B. E., \& Abela, J. R. Z. (2011). Co-rumination predicts the onset of depressive disorders during adolescence. Journal of Abnormal Psychology, 120(3), 752-757. https://doi.org/10.1038/jid.2014.371

Subic-Wrana, C., Beutel, M. E., Brähler, E., Stöbel-Richter, Y., Knebel, A., Lane, R. D., \& Wiltink, J. (2014). How is emotional awareness related to emotion regulation strategies and self-reported negative affect in the general population? PLOS ONE, 9(3). https://doi.org/10.1371/journal.pone.0091846

Tabachnick, B. G., \& Fidell, L. S. (2013). Using multivariate statistics (6th ed.). New York: 


\section{Harper Collins.}

Tamir, M., John, O. P., Srivastava, S., \& Gross, J. J. (2007). Implicit theories of emotion: Affective and social outcomes across a major life transition. Journal of Personality and Social Psychology, 92(4), 731-744. https://doi.org/10.1037/0022-3514.92.4.731

Termine, N. T., \& Izard, C. E. (1988). Infants' responses to their mothers' expressions of joy and sadness. Developmental Psychology, 24(2), 223-229. https://doi.org/10.1037/00121649.24.2.223

Tesch, S. A. (1983). Review of friendship development across the life span. Human Development, 26(5), 266-276. https://doi.org/doi:10.1159/000272888

Thornton, A., Orbuch, T. L., \& Axinn, W. G. (1995). Parent-child relationships during the transition to adulthood. Journal of Family Issues. https://doi.org/10.1177/019251395016005003

Tillery, R., Cohen, R., Parra, G. R., Kitzmann, K. M., \& Howard Sharp, K. M. (2015). Friendship and the socialization of sadness. Merrill-Palmer Quarterly, 61(4), 486-508. https://doi.org/10.13110/merrpalmquar1982.61.4.0486

Tomkins, S. S. (1962). Affect imagery consciousness: Volume I: The positive affects (Vol 2.). Springer.

Tomkins, S. S. (1963). Affect imagery consciousness: Volume II: The negative affects (Vol. 2). Springer.

Tubman, J. G., \& Lerner, R. M. (1994). Affective experiences of parents and their children from adolescence to young adulthood: Stability of affective experiences. Journal of Adolescence, $17,81-98$.

Turner, A. P., Sarason, I. G., \& Sarason, B. R. (2001). Exploring the link between parental acceptance and young adult adjustment. Cognitive Therapy and Research, 25(2), 185-199. https://doi.org/10.1023/A:1026420025379

Valiente, C., Fabes, R. A., Eisenberg, N., \& Spinrad, T. L. (2004). The relations of parental expressivity and support to children's coping with daily stress. Journal of Family Psychology, 18(1), 97-106. https://doi.org/10.1037/0893-3200.18.1.97

Van Zalk, M. H. W., Kerr, M., Branje, S. J. T., Stattin, H., \& Meeus, W. H. J. (2010). It takes three: Selection, influence, and de-selection processes of depression in adolescent friendship networks. Developmental Psychology, 46(4), 927-938. https://doi.org/10.1037/a0019661

Vandell, D. L. (2000). Parents, peer groups, and other socializing influences. Developmental Psychology, 36(6), 699-710. https://doi.org/10.1037/0012-1649.36.6.699

Vernberg, E. M., Beery, S. H., Ewell, K. K., \& Abwender, D. A. (1993). Parents' use of friendship facilitation strategies and the formation of friendships in early adolescence: A prospective study. Journal of Family Psychology, 7(3), 356-369.

https://doi.org/10.1037/0893-3200.7.3.356

von Salisch, M. (2001). Children's emotional development: Challenges in their relationships to 
parents, peers, and friends. International Journal of Behavioral Development, 25(4), 310319. https://doi.org/10.1080/01650250143000058

Waller, E. M., \& Rose, A. J. (2010). Adjustment trade-offs of co-rumination in motheradolescent relationships. Journal of Adolescence, 33(3), 487-497.

https://doi.org/10.1038/jid.2014.371

Waller, E. M., \& Rose, A. J. (2013). Adolescents' co-rumination with mother, co-rumination with friends, and internalizing symptoms. Journal of Adolescence, 36(2), 429-433. https://doi.org/10.1021/n1061786n.Core-Shell

West, P., Sweeting, H., \& Ecob, R. (1999). Family and friends' influences on the uptake of regular smoking from mid-adolescence to early adulthood. Addiction, 94(9), 1397-411. https://doi.org/10.1046/j.1360-0443.1999.949139711.x

Wild, B., Erb, M., \& Bartels, M. (2001). Are emotions contagious? Evoked emotions while viewing emotionally expressive faces: Quality, quantity, time course and gender differences. Psychiatry Research, 102(2), 109-124. https://doi.org/10.1016/S01651781(01)00225-6

Williams, S. R., \& Woodruff-Borden, J. (2015). Parent emotion socialization practices and child self-regulation as predictors of child anxiety: The mediating role of cardiac variability. Child Psychiatry and Human Development, 46(4), 512-522.

https://doi.org/10.1007/s10578-014-0492-0

Wolf, E. J., Harrington, K. M., Clark, S. L., \& Miller, M. W. (2013). Sample size requirements for structural equation models: An evaluation of power, bias, and solution propriety. Educational and Psychological Measurement, 76(6), 913-934. https://doi.org/10.1177/0013164413495237.Sample

Wrzus, C., Hanel, M., Wagner, J., \& Neyer, F. J. (2013). Social network changes and life events across the life span: A meta-analysis. Psychological Bulletin, 139(1), 53-80. https://doi.org/10.1037/a0028601

Yap, M. B. H., Allen, N. B., \& Ladouceur, C. D. (2008). Maternal socialization of positive affect: The impact of invalidation on adolescent emotion regulation and depressive symptomatology. Child Development, 79(5), 1415-1431.

Yap, M. B. H., Allen, N. B., Leve, C., \& Katz, L. F. (2008). Maternal meta-emotion philosophy and socialization of adolescent affect: The moderating role of adolescent temperament. Journal of Family Psychology, 22(5), 688-700. https://doi.org/10.1037/a0013104

Yap, M. B. H., Schwartz, O. S., Byrne, M. L., Simmons, J. G., \& Allen, N. B. (2010). Maternal positive and negative interaction behaviors and early adolescents' depressive symptoms: Adolescent emotion regulation as a mediator. Journal of Research on Adolescence, 20(4), 1014-1043. https://doi.org/10.1111/j.1532-7795.2010.00665.x

Yi, C. Y., Gentzler, A. L., Ramsey, M. A., \& Root, A. E. (2016). Linking maternal socialization of positive emotions to children's behavioral problems: The moderating role of self-control. Journal of Child and Family Studies, 25(5), 1550-1558. https://doi.org/10.1007/s10826015-0329-x 
Young, P. T. (1943). Emotion in man and animal: Its nature and relation to attitude and motive. New York: Wiley.

Zahn-Waxler, C. (2010). Socialization of emotion: Who influences whom and how? In A. E. Root \& S. A. Denham (Eds.), The Role of Gender in the Socialization of Emotion: Key Concepts and Critical Issues (pp. 101-109). San Francisco: Jossey-Bass. https://doi.org/10.1002/cd

Zeman, J., \& Garber, J. (1996). Display rules for anger, sadness, and pain: It depends on who is watching. Child Development, 67(3), 957-973. https://doi.org/10.1111/j.14678624.1996.tb01776.x

Zimmermann, P., \& Iwanski, A. (2014). Emotion regulation from early adolescence to emerging adulthood and middle adulthood: Age differences, gender differences, and emotion-specific developmental variations. International Journal of Behavioral Development, 38(2), 182194. https://doi.org/10.1177/0165025413515405 
Table 1. Demographic Information for All Reporters.

\begin{tabular}{|c|c|c|c|c|c|c|}
\hline & \multicolumn{2}{|c|}{ Emerging adult-report } & \multicolumn{2}{|c|}{ Parent-report } & \multicolumn{2}{|c|}{ Friend-report } \\
\hline & $\mathrm{N}$ & Percent & $\mathrm{N}$ & Percent & $\mathrm{N}$ & Percent \\
\hline \multicolumn{7}{|l|}{ Difficulty Paying Bills: } \\
\hline None/not at all & 284 & $45.4 \%$ & 213 & $45.4 \%$ & 140 & $50.5 \%$ \\
\hline A little & 210 & $33.5 \%$ & 126 & $26.9 \%$ & 87 & $31.5 \%$ \\
\hline Some & 95 & $15.2 \%$ & 80 & $17.1 \%$ & 33 & $11.9 \%$ \\
\hline A great deal & 37 & $5.9 \%$ & 28 & $5.9 \%$ & 17 & $6.1 \%$ \\
\hline Prefer not to answer & --- & --- & 22 & $4.7 \%$ & --- & --- \\
\hline \multicolumn{7}{|l|}{ Current Living Situation: } \\
\hline I live alone & 58 & $8.1 \%$ & --- & --- & 18 & $6.5 \%$ \\
\hline I live with a roommate(s) & 483 & $76.9 \%$ & --- & --- & --- & --- \\
\hline $\begin{array}{l}\text { I live with my friend } \\
\text { (who the survey is about) }\end{array}$ & --- & --- & --- & --- & 33 & $11.9 \%$ \\
\hline I live with other roommate(s) & --- & --- & --- & --- & 134 & $48.4 \%$ \\
\hline I live with both parents & 45 & $7.2 \%$ & --- & --- & 45 & $16.2 \%$ \\
\hline I live with my mother only & 19 & $3.0 \%$ & --- & --- & 19 & $6.9 \%$ \\
\hline I live with my father only & 7 & $1.1 \%$ & --- & --- & 4 & $1.4 \%$ \\
\hline Other & 23 & $3.7 \%$ & --- & --- & 24 & $8.7 \%$ \\
\hline \multicolumn{7}{|l|}{ Parents' Relationship Status: } \\
\hline Married & 379 & $60.4 \%$ & 366 & $77.5 \%$ & 177 & $63.9 \%$ \\
\hline Separated & 22 & $3.5 \%$ & 14 & $3.0 \%$ & 12 & $4.3 \%$ \\
\hline Divorced & 150 & $23.9 \%$ & 62 & $13.1 \%$ & 47 & $17.1 \%$ \\
\hline Together, not married & 11 & $1.8 \%$ & --- & --- & --- & --- \\
\hline Never together, never married & 65 & $10.4 \%$ & --- & --- & --- & --- \\
\hline Living with partner & --- & --- & 9 & $1.9 \%$ & 2 & $0.7 \%$ \\
\hline Single & --- & --- & 13 & $2.8 \%$ & 35 & $12.6 \%$ \\
\hline Widowed & --- & --- & 8 & $1.7 \%$ & 4 & $1.4 \%$ \\
\hline
\end{tabular}


Table 2. Demographic Information for All Reporters Continued.

\begin{tabular}{|c|c|c|c|c|c|c|}
\hline & \multicolumn{2}{|c|}{ Emerging adult-report } & \multicolumn{2}{|c|}{ Parent-report } & \multicolumn{2}{|c|}{ Friend-report } \\
\hline & $\mathrm{N}$ & Percent & $\mathrm{N}$ & Percent & $\mathrm{N}$ & Percent \\
\hline Mothers' Education: & \multicolumn{6}{|c|}{ Own Education } \\
\hline $8^{\text {th }}$ grade or less & 1 & $0.2 \%$ & --- & --- & 1 & $0.4 \%$ \\
\hline $9^{\text {th }}-11^{\text {th }}$ grade & 7 & $1.1 \%$ & --- & --- & 5 & $1.8 \%$ \\
\hline High school/ Equivalent & 118 & $18.8 \%$ & 68 & $14.5 \%$ & 55 & $19.9 \%$ \\
\hline Some college & 93 & $14.8 \%$ & 82 & $17.4 \%$ & 38 & $13.7 \%$ \\
\hline 2-9year degree & 88 & $14.0 \%$ & 75 & $16.0 \%$ & 40 & $14.5 \%$ \\
\hline 4-year degree & 166 & $26.4 \%$ & 126 & $26.8 \%$ & 84 & $30.3 \%$ \\
\hline Some graduate school & 13 & $2.1 \%$ & 19 & $4.0 \%$ & 4 & $1.4 \%$ \\
\hline Master's or 2-3-year degree & 120 & $19.1 \%$ & 79 & $16.8 \%$ & 40 & $14.4 \%$ \\
\hline MD or PHD & 22 & $3.5 \%$ & 21 & $4.5 \%$ & 10 & $3.6 \%$ \\
\hline \multicolumn{7}{|l|}{ Fathers' Education: } \\
\hline I did not attend school & 1 & $0.2 \%$ & --- & --- & 2 & $0.7 \%$ \\
\hline $8^{\text {th }}$ grade or less & 4 & $0.6 \%$ & --- & --- & 1 & $0.4 \%$ \\
\hline $9^{\text {th }}-11^{\text {th }}$ grade & 14 & $2.2 \%$ & --- & --- & 6 & $2.2 \%$ \\
\hline High school/ Equivalent & 153 & $24.4 \%$ & --- & --- & 76 & $27.5 \%$ \\
\hline Some college & 107 & $17.1 \%$ & --- & --- & 41 & $14.9 \%$ \\
\hline 2-year degree & 56 & $8.9 \%$ & --- & --- & 22 & $8.0 \%$ \\
\hline 4-year degree & 152 & $24.3 \%$ & --- & --- & 81 & $29.3 \%$ \\
\hline Some graduate school & 9 & $1.4 \%$ & --- & --- & 2 & $0.7 \%$ \\
\hline Master's or 2-3-year degree & 93 & $14.8 \%$ & --- & --- & 34 & $12.3 \%$ \\
\hline MD or PHD & 38 & $6.1 \%$ & --- & --- & 11 & $4.0 \%$ \\
\hline
\end{tabular}


Table 3. Descriptive Statistics of Emotion Specific Socialization Variables Reported by Emerging Adult Participants.

\begin{tabular}{|c|c|c|c|c|c|c|c|c|c|}
\hline & \multicolumn{3}{|c|}{$\begin{array}{c}\text { Emerging adult-report of their own } \\
\text { socialization with mother }\end{array}$} & \multicolumn{3}{|c|}{$\begin{array}{l}\text { Emerging adult-report of their own } \\
\text { socialization with father }\end{array}$} & \multicolumn{3}{|c|}{$\begin{array}{c}\text { Emerging adult-report of their own } \\
\text { socialization with friend }\end{array}$} \\
\hline & Mean(SD) & Range & Alpha & Mean(SD) & Range & Alpha & Mean(SD) & Range & Alpha \\
\hline Sad Reward & $4.04(.95)$ & $1-5$ & .85 & $3.17(1.36)$ & $1-5$ & .90 & $3.79(.93)$ & $1-5$ & .65 \\
\hline Sad Override & $2.96(.97)$ & $1-5$ & .63 & $2.31(1.07)$ & $1-5$ & .76 & $3.08(1.03)$ & $1-5$ & .70 \\
\hline Sad Magnify & $2.61(1.12)$ & $1-5$ & .82 & $2.20(1.17)$ & $1-5$ & .87 & $2.84(1.02)$ & $1-5$ & .68 \\
\hline Sad Neglect & $1.80(.65)$ & $1-5$ & .45 & $1.99(.81)$ & $1-5$ & .45 & $1.22(.58)$ & $1-5$ & .82 \\
\hline Sad Punish & $1.21(.50)$ & $1-4.33$ & .75 & $1.17(.52)$ & $1-4.33$ & .85 & $1.24(.52)$ & $1-5$ & .86 \\
\hline Angry Reward & $3.67(1.08)$ & $1-5$ & .85 & $3.12(1.24)$ & $1-5$ & .87 & $3.68(.89)$ & $1-5$ & .62 \\
\hline Angry Override & $2.16(.89)$ & $1-5$ & .52 & $1.99(.90)$ & $1-5$ & .61 & $2.96(1.01)$ & $1-5$ & .69 \\
\hline Angry Magnify & $1.81(.84)$ & $1-5$ & .66 & $1.75(.89)$ & $1-5$ & .75 & $2.68(.98)$ & $1-5$ & .71 \\
\hline Angry Neglect & $1.86(.64)$ & $1-5$ & .42 & $2.03(.77)$ & $1-5$ & .41 & $1.25(.63)$ & $1-5$ & .86 \\
\hline Angry Punish & $1.17(.50)$ & $1-4.67$ & .80 & $1.19(.54)$ & $1-5$ & .82 & $1.27(.57)$ & $1-5$ & .85 \\
\hline Worried Reward & $3.81(1.13)$ & $1-5$ & .85 & $3.07(1.33)$ & $1-5$ & .86 & $3.68(.94)$ & $1-5$ & .67 \\
\hline Worried Override & $2.79(1.07)$ & $1-5$ & .71 & $2.33(1.14)$ & $1-5$ & .80 & $3.02(1.03)$ & $1-5$ & .71 \\
\hline Worried Magnify & $2.60(1.20)$ & $1-5$ & .89 & $2.29(1.21)$ & $1-5$ & .91 & $2.62(.97)$ & $1-5$ & .67 \\
\hline Worried Neglect & $1.78(.66)$ & $1-5$ & .45 & $1.98(.87)$ & $1-5$ & .57 & $1.23(.60)$ & $1-5$ & .85 \\
\hline Worried Punish & $1.24(.50)$ & $1-4.33$ & .55 & $1.18(.46)$ & $1-3.67$ & .67 & $1.22(.54)$ & $1-5$ & .88 \\
\hline Happy Reward & $4.12(.95)$ & $1-5$ & .87 & $3.75(1.22)$ & $1-5$ & .91 & 4.44(.67) & $1.33-5$ & .52 \\
\hline Happy Override & $1.30(.60)$ & $1-5$ & .67 & $1.29(.65)$ & $1-5$ & .69 & $1.29(.65)$ & $1-5$ & .74 \\
\hline Happy Magnify & $3.90(1.05)$ & $1-5$ & .90 & $3.54(1.29)$ & $1-5$ & .93 & $4.06(.93)$ & $1-5$ & .87 \\
\hline Happy Neglect & $1.36(.66)$ & $1-5$ & .73 & $1.47(.80)$ & $1-5$ & .76 & $1.23(.60)$ & $1-5$ & .83 \\
\hline Happy Punish & $1.18(.55)$ & $1-5$ & .78 & $1.18(.52)$ & $1-5$ & .73 & $1.25(.65)$ & $1-5$ & .78 \\
\hline
\end{tabular}


Table 4. Descriptive Statistics of Emotion Specific Socialization Variables Reported by Parent and Friend Participants.

\begin{tabular}{|c|c|c|c|c|c|c|}
\hline & \multicolumn{3}{|c|}{$\begin{array}{c}\text { Parent-report of their socialization with } \\
\text { emerging adult }\end{array}$} & \multicolumn{3}{|c|}{$\begin{array}{c}\text { Friend-report of their socialization with } \\
\text { emerging adult }\end{array}$} \\
\hline & Mean(SD) & Range & Alpha & Mean(SD) & Range & Alpha \\
\hline Sad Reward & $4.50(.66)$ & $1-5$ & .79 & $3.73(.97)$ & $1-5$ & .73 \\
\hline Sad Override & 2.93(.99) & $1-5$ & .63 & $2.95(1.05)$ & $1-5$ & .69 \\
\hline Sad Magnify & $2.25(.96)$ & $1-5$ & .68 & $2.58(.94)$ & $1-5$ & .64 \\
\hline Sad Neglect & $1.94(.52)$ & $1-4$ & .26 & $1.23(.58)$ & $1-5$ & .85 \\
\hline Sad Punish & $1.43(.62)$ & $1-3.67$ & .49 & $1.22(.47)$ & $1-3.40$ & .80 \\
\hline Angry Reward & $4.14(.78)$ & $1-5$ & .72 & $3.55(1.05)$ & $1-5$ & .75 \\
\hline Angry Override & $2.37(.88)$ & $1-5$ & .56 & $2.80(1.09)$ & $1-5$ & .73 \\
\hline Angry Magnify & $1.63(.71)$ & $1-4.33$ & .67 & $2.48(.98)$ & $1-5$ & .72 \\
\hline Angry Neglect & $1.98(.55)$ & $1-4.33$ & .40 & $1.19(.50)$ & $1-3.67$ & .80 \\
\hline Angry Punish & $1.21(.43)$ & $1-3.67$ & .50 & $1.21(.47)$ & $1-3.50$ & .82 \\
\hline Worried Reward & $4.34(.72)$ & $1-5$ & .66 & $3.60(1.12)$ & $1-5$ & .80 \\
\hline Worried Override & 2.57(.99) & $1-5$ & .65 & $2.85(1.10)$ & $1-5$ & .73 \\
\hline Worried Magnify & $2.50(1.10)$ & $1-5$ & .83 & $2.37(.98)$ & $1-5$ & .75 \\
\hline Worried Neglect & $1.87(.48)$ & $1-4$ & .19 & $1.17(.51)$ & $1-4.33$ & .86 \\
\hline Worried Punish & $1.26(.42)$ & $1-3$ & .33 & $1.19(.46)$ & $1-3.50$ & .84 \\
\hline Happy Reward & $4.53(.63)$ & $1-5$ & .69 & $4.43(.69)$ & $2-5$ & .60 \\
\hline Happy Override & $1.22(.44)$ & $1-4$ & .46 & $1.24(.57)$ & $1-4.33$ & .77 \\
\hline Happy Magnify & $4.29(.80)$ & $1-5$ & .76 & $3.99(1.03)$ & $1-5$ & .88 \\
\hline Happy Neglect & $1.29(.52)$ & $1-5$ & .45 & $1.20(.47)$ & $1-3.33$ & .78 \\
\hline Happy Punish & $1.10(.29)$ & $1-3.67$ & .32 & $1.14(.43)$ & $1-3.33$ & .74 \\
\hline
\end{tabular}


Table 5. Descriptive Statistics of Outcome Variables for All Reporters.

\begin{tabular}{|c|c|c|c|c|c|c|c|c|c|}
\hline & \multicolumn{3}{|c|}{ Emerging adult-report } & \multicolumn{3}{|c|}{ Parent-report } & \multicolumn{3}{|c|}{ Friend-report } \\
\hline & Mean(SD) & Range & Alpha & Mean(SD) & Range & Alpha & Mean(SD) & Range & Alpha \\
\hline \multicolumn{10}{|l|}{ Emotion Regulation } \\
\hline PA Functional & $3.55(.71)$ & $1-5$ & .87 & $3.39(.67)$ & $1.33-4.83$ & .85 & $3.54(.72)$ & $1-5$ & .86 \\
\hline PA Dysfunctional & $2.04(.74)$ & $1-4.67$ & .87 & $1.81(.59)$ & $1-4.25$ & .83 & $2.22(.86)$ & $1-4.67$ & .90 \\
\hline NA Internal Functional & $3.31(.76)$ & $1-5$ & .74 & $3.01(.75)$ & $1-5$ & .72 & $3.34(.79)$ & $1-5$ & .74 \\
\hline NA Internal Dysfunctional & $2.32(.80)$ & $1-5$ & .74 & $1.32(.30)$ & $1-3.80$ & .62 & $2.27(.84)$ & $1-4.80$ & .75 \\
\hline NA External Functional & $3.22(.82)$ & $1-5$ & .77 & $3.31(.66)$ & $1-5$ & .79 & $3.25(.82)$ & $1-5$ & .76 \\
\hline NA External Dysfunctional & $1.43(.47)$ & $1-5$ & .69 & $1.75(.54)$ & $1-2.60$ & .56 & $1.39(.46)$ & $1-3.20$ & .66 \\
\hline NA Functional & $3.26(.69)$ & $1-5$ & .82 & $3.15(.61)$ & $1.36-4.82$ & .82 & $3.29(.70)$ & $1-5$ & .81 \\
\hline NA Dysfunctional & $1.87(.54)$ & $1-5$ & .75 & $1.54(.36)$ & $1-2.90$ & .69 & $1.83(.56)$ & $1-3.80$ & .77 \\
\hline \multicolumn{10}{|l|}{ Well-Being } \\
\hline PA & $22.56(3.72)$ & $9-30$ & .87 & $24.00(3.56)$ & $12-30$ & .89 & $22.43(3.79)$ & $10-30$ & .84 \\
\hline NA & $15.71(4.23)$ & $6-30$ & .84 & $13.40(3.59)$ & $5-24$ & .83 & $15.49(4.24)$ & $6-28$ & .81 \\
\hline SHS & $5.17(1.18)$ & $1-7.25$ & .86 & $5.68(.92)$ & $2-7.33$ & .52 & $4.34(.98)$ & $1-6.67$ & .72 \\
\hline SWLS & $24.53(6.17)$ & $5-35$ & .86 & $25.71(6.21)$ & $5-35$ & .90 & $24.08(6.20)$ & $9-35$ & .85 \\
\hline \multicolumn{10}{|l|}{$\underline{\text { Relationship Quality }}$} \\
\hline With Emerging Adult & --- & --- & --- & $39.80(5.57)$ & $10-50$ & .74 & $40.97(5.85)$ & $20-50$ & .81 \\
\hline With Mother & 40.93(7.09) & $10-50$ & .86 & --- & --- & --- & --- & --- & --- \\
\hline With Father & $35.30(10.71)$ & $1-50$ & .92 & --- & --- & --- & --- & --- & --- \\
\hline With Friend & $41.25(5.46)$ & $21-50$ & .80 & --- & --- & --- & --- & --- & --- \\
\hline
\end{tabular}

Note. $\mathrm{PA}=$ positive affect. NA = negative affect. $\mathrm{SHS}=$ Subjective Happiness Scale. SWLS $=$ Satisfaction with Life scale. 
Table 6. Descriptive Statistics and Reliability for Emerging Adult-report Negative Affect Socialization.

\begin{tabular}{|c|c|c|c|c|c|c|c|c|c|}
\hline & \multicolumn{3}{|c|}{$\begin{array}{c}\text { Emerging adult-report of their own } \\
\text { socialization with mother }\end{array}$} & \multicolumn{3}{|c|}{$\begin{array}{c}\text { Emerging adult-report of their own } \\
\text { socialization with father }\end{array}$} & \multicolumn{3}{|c|}{$\begin{array}{l}\text { Emerging adult-report of their own } \\
\text { socialization with friend }\end{array}$} \\
\hline & Mean(SD) & Range & Alpha & Mean(SD) & Range & Alpha & Mean(SD) & Range & Alpha \\
\hline NA Reward & $3.85(.97)$ & $1-5$ & .93 & $3.12(1.22)$ & $1-5$ & .95 & $3.72(.84)$ & $1-5$ & .87 \\
\hline NA Override & $2.64(.82)$ & $1-5$ & .82 & $2.21(.91)$ & $1-4.89$ & .88 & $3.02(.96)$ & $1-5$ & .90 \\
\hline NA Magnify & $2.34(.86)$ & $1-4.78$ & .86 & $2.08(.90)$ & $1-4.89$ & .89 & $2.71(.90)$ & $1-5$ & .88 \\
\hline NA Neglect & $1.81(.57)$ & $1-4.67$ & .78 & $2.00(.71)$ & $1-4.89$ & .79 & $1.23(.55)$ & $1-5$ & .93 \\
\hline NA Punish & $1.20(.43)$ & $1-3.89$ & .85 & $1.18(.43)$ & $1-3.67$ & .89 & $1.32(.51)$ & $1-5$ & .93 \\
\hline
\end{tabular}

Note. $\mathrm{NA}=$ negative affect. 
Table 7. Descriptive Statistics and Reliability for Parent- and Friend-report Negative Affect Socialization.

\begin{tabular}{ccccccc}
\hline & \multicolumn{2}{c}{$\begin{array}{c}\text { Parent-report of their socialization with } \\
\text { emerging adult }\end{array}$} & \multicolumn{3}{c}{$\begin{array}{c}\text { Friend-report of their socialization with } \\
\text { emerging adult }\end{array}$} \\
\cline { 2 - 7 } & Mean(SD) & Range & Alpha & Mean(SD) & Range & Alpha \\
\hline NA Reward & $4.33(.61)$ & $1-5$ & .86 & $3.63(.97)$ & $1-5$ & .91 \\
NA Override & $2.63(.81)$ & $1-4.67$ & .83 & $2.87(1.03)$ & $1-5$ & .91 \\
NA Magnify & $2.13(.75)$ & $1-4.67$ & .83 & $2.48(.88)$ & $1-5$ & .88 \\
NA Neglect & $1.93(.43)$ & $1-3.67$ & .70 & $1.19(.47)$ & $1-3.56$ & .92 \\
NA Punish & $1.30(.38)$ & $1-3$ & .67 & $1.30(.38)$ & $1-3.29$ & .92 \\
\hline
\end{tabular}

Note. $\mathrm{NA}=$ negative affect. 
Table 8. Bivariate Correlations among Parent Socialization, Emerging Adult Outcomes, Emerging Adult-reported Closeness with Parents.

\begin{tabular}{|c|c|c|c|c|c|c|c|c|c|c|c|c|c|c|c|c|c|c|c|c|c|}
\hline & 1 & 2 & 3 & 4 & 5 & 6 & 7 & 8 & 9 & 10 & 11 & 12 & 13 & 14 & 15 & 16 & 17 & 18 & 19 & 20 & 21 \\
\hline 1. Reward PA & --- & & & & & & & & & & & & & & & & & & & & \\
\hline 2. Override PA & $-.18^{* * *}$ & --- & & & & & & & & & & & & & & & & & & & \\
\hline 3. Neglect PA & $-.21^{* * *}$ & $.25^{* * *}$ & --- & & & & & & & & & & & & & & & & & & \\
\hline 4. Punish PA & -.07 & $.40^{* * *}$ & $.15^{* *}$ & --- & & & & & & & & & & & & & & & & & \\
\hline 5. Magnify PA & $.64^{* * *}$ & $-.12^{*}$ & $-.17^{* * *}$ & -.00 & --- & & & & & & & & & & & & & & & & \\
\hline 6. Reward NA & $.64^{* * *}$ & $-.16^{* *}$ & $-.22^{* * *}$ & -.04 & $.51^{* * *}$ & --- & & & & & & & & & & & & & & & \\
\hline 7. Override NA & $.21^{* * *}$ & $.22^{* * *}$ & .01 & $.16^{* *}$ & $.29^{* * *}$ & $.28^{* * *}$ & --- & & & & & & & & & & & & & & \\
\hline 8. Neglect NA & $-.12^{*}$ & $.31^{* * *}$ & $.30^{* * *}$ & $.17^{* * *}$ & -.04 & -.06 & $.22^{* * *}$ & --- & & & & & & & & & & & & & \\
\hline 9. Punish NA & $-.09^{*}$ & $.39^{* * *}$ & .09 & $.32^{* * *}$ & -.05 & $-.10^{*}$ & $.46^{* * *}$ & $.25^{* * *}$ & --- & & & & & & & & & & & & \\
\hline 10. Magnify NA & .06 & $.15^{* *}$ & -.01 & $.15^{* *}$ & $.16^{* *}$ & $.14^{* *}$ & $.28^{* * *}$ & .03 & $.29^{* * *}$ & --- & & & & & & & & & & & \\
\hline 11. PA & $.12^{*}$ & -.03 & -.06 & -.03 & $.12^{*}$ & $.11^{*}$ & $.11^{*}$ & -.08 & .01 & -.06 & --- & & & & & & & & & & \\
\hline 12. NA & -.04 & .03 & -.02 & .05 & .00 & -.05 & .01 & .01 & $.11^{*}$ & .08 & $-.60^{* * *}$ & --- & & & & & & & & & \\
\hline 13. Subjective Happiness & $.13^{*}$ & -.07 & -.03 & -.03 & $.19^{* * *}$ & $.13^{*}$ & .06 & -.08 & -.02 & -.08 & $.69^{* * *}$ & $-.62^{* * *}$ & --- & & & & & & & & \\
\hline 14. Satisfaction with Life & .08 & -.06 & -.04 & -.04 & $.11^{*}$ & $.16^{* *}$ & $.11^{*}$ & -.03 & -.05 & -.09 & $.64^{* * *}$ & $-.54^{* * *}$ & $.64^{* * *}$ & --- & & & & & & & \\
\hline 15. Int. Funct. NA ER & .09 & -.07 & -.00 & -.04 & $.15^{* *}$ & $.12^{*}$ & .08 & -.06 & -.02 & .05 & $.27^{* * *}$ & $-.17^{* * *}$ & $.35^{* * *}$ & $.24^{* * *}$ & --- & & & & & & \\
\hline 16. Int. Dysf. NA ER & -.10 & $.10^{*}$ & .02 & .04 & -.09 & -.08 & .00 & .10 & .09 & .09 & $-.43^{* * *}$ & $.53^{* * *}$ & $-.52^{* * *}$ & $-.47^{* * *}$ & -.03 & --- & & & & & \\
\hline 17. Ext. Funct. NA ER & $.13^{*}$ & $-.17^{* *}$ & $-.10^{*}$ & $-.11^{*}$ & $.12^{*}$ & $.21^{* * *}$ & .08 & $-.12^{*}$ & -.04 & .02 & $.39^{* * *}$ & $-.24^{* * *}$ & $.42^{* * *}$ & $.42^{* * *}$ & $.50^{* * *}$ & $-.27^{* * *}$ & --- & & & & \\
\hline 18. Ext. Dysf. NA ER & -.05 & .03 & -.02 & .05 & -.03 & -.01 & -.03 & .07 & .09 & -.01 & $-.20^{* * *}$ & $.30^{* * *}$ & $-.24^{* * *}$ & $-.17^{* * *}$ & $-.10^{*}$ & $.38^{* * *}$ & -.03 & --- & & & \\
\hline 19. Funct. PA ER & $.16^{* *}$ & $-.14^{* *}$ & -.05 & $-.11^{*}$ & $.19^{* * *}$ & $.20^{* * *}$ & .06 & -.07 & -.04 & .01 & $.36^{* * *}$ & $-.16^{* * *}$ & $.38^{* * *}$ & $.39^{* * *}$ & $.49^{* * *}$ & $-.14^{* * *}$ & $.61^{* * *}$ & -.06 & --- & & \\
\hline 20. Dysf.PA ER & $-.10^{*}$ & $.12^{*}$ & .00 & .07 & -.06 & -.06 & -.04 & $.12^{*}$ & $.12^{*}$ & $.13^{*}$ & $-.42^{* * *}$ & $.49^{* * *}$ & $-.45^{* * *}$ & $-.40^{* * *}$ & -.04 & $.63^{* * *}$ & $-.17^{* * *}$ & $.37^{* * *}$ & $-.17^{* * *}$ & --- & \\
\hline 21. Mom Closeness & $.15^{* *}$ & -.05 & -.06 & -.05 & $.23^{* * *}$ & $.16^{* *}$ & $.14^{* *}$ & -.09 & -.01 & .04 & $.31^{* * *}$ & $-.15^{* * *}$ & $.30^{* * *}$ & $.36^{* * *}$ & $.24^{* * *}$ & $-.14^{* *}$ & $.32^{* * *}$ & -.07 & $.35^{* * *}$ & $-.14^{* *}$ & --- \\
\hline 22. Dad Closeness & .04 & -.07 & -.01 & .02 & .05 & $.12^{*}$ & .03 & -.07 & .00 & -.09 & $.23^{* * *}$ & $-.16^{* * *}$ & $.25^{* * *}$ & $.38^{* * *}$ & $.12^{* *}$ & $-.19^{* * *}$ & $.19^{* * *}$ & $-.09^{*}$ & $.21^{* * *}$ & $.14^{* * *}$ & $.18^{* * *}$ \\
\hline
\end{tabular}

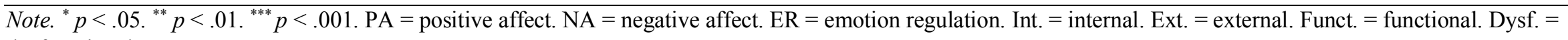
dysfunctional. 
Table 9. Bivariate Correlations among Friend Socialization, Emerging Adult Outcomes, Emerging Adult-reported Closeness with Friend.

\begin{tabular}{|c|c|c|c|c|c|c|c|c|c|c|c|c|c|c|c|c|c|c|c|c|}
\hline & 1 & 2 & 3 & 4 & 5 & 6 & 7 & 8 & 9 & 10 & 11 & 12 & 13 & 14 & 15 & 16 & 17 & 18 & 19 & 20 \\
\hline 1. Reward PA & --- & & & & & & & & & & & & & & & & & & & \\
\hline 2. Override PA & $-.35^{* * *}$ & --- & & & & & & & & & & & & & & & & & & \\
\hline 3. Neglect PA & $-.38^{* * *}$ & $.75^{* * *}$ & --- & & & & & & & & & & & & & & & & & \\
\hline 4. Punish PA & $-.33^{* * *}$ & $.77^{* * *}$ & $.76^{* * *}$ & --- & & & & & & & & & & & & & & & & \\
\hline 5. Magnify PA & $.72^{* * *}$ & $-.17^{* *}$ & $-.21^{* *}$ & $-.15^{*}$ & --- & & & & & & & & & & & & & & & \\
\hline 6. Reward NA & $.62^{* * *}$ & -.09 & $-.13^{*}$ & -.08 & $.63^{* * *}$ & --- & & & & & & & & & & & & & & \\
\hline 7. Override NA & $.35^{* * *}$ & .16 & .07 & $.13^{*}$ & $.45^{* * *}$ & $.72^{* * *}$ & --- & & & & & & & & & & & & & \\
\hline 8. Neglect NA & $-.38^{* * *}$ & $.70^{* * *}$ & $.70^{* * *}$ & $.70^{* * *}$ & $-.20^{* *}$ & -.12 & .09 & --- & & & & & & & & & & & & \\
\hline 9. Punish NA & $-.36^{* * *}$ & $.78^{* * *}$ & $.73^{* * *}$ & $.79^{* * *}$ & $-.16^{*}$ & -.06 & $.19^{* *}$ & $.83^{* * *}$ & --- & & & & & & & & & & & \\
\hline 10. Magnify NA & $.33^{* * *}$ & $.14^{*}$ & .08 & $.13^{*}$ & $.38^{* * *}$ & $.56^{* * *}$ & $.49^{* * *}$ & $.13^{*}$ & $.22^{* * *}$ & --- & & & & & & & & & & \\
\hline 11. PA & .11 & .03 & -.03 & .02 & $.14^{*}$ & .06 & .12 & -.01 & .01 & .06 & --- & & & & & & & & & \\
\hline 12. NA & -.00 & -.05 & .04 & -.01 & -.06 & .00 & -.10 & .01 & -.01 & .02 & $-.60^{* * *}$ & --- & & & & & & & & \\
\hline 13. Subjective Happiness & .08 & .01 & -.03 & -.01 & .12 & .05 & $.14^{*}$ & -.02 & .03 & .06 & $.69^{* * *}$ & $-.62^{* * *}$ & --- & & & & & & & \\
\hline 14. Satisfaction With Life & .06 & .04 & -.02 & -.02 & .11 & .01 & .05 & -.04 & -.02 & .06 & $.64^{* * *}$ & $-.54^{* * *}$ & $.64^{* * *}$ & --- & & & & & & \\
\hline 15. Int. Funct. NA ER & $.14^{*}$ & -.05 & -.09 & -.02 & .11 & .03 & .01 & -.12 & -.07 & .07 & $.27^{* * *}$ & $-.17^{* * *}$ & $.35^{* * *}$ & $.24^{* * *}$ & -- & & & & & \\
\hline 16. Int. Dysf. NA ER & -.08 & -.02 & .10 & .03 & $-.14^{*}$ & $-.13^{*}$ & $-.15^{*}$ & .07 & .06 & -.03 & $-.43^{* * *}$ & $.53^{* * *}$ & $-.52^{* * *}$ & $-.47^{* * *}$ & -.03 & -- & & & & \\
\hline 17. Ext. Funct. NA ER & $.23^{* * *}$ & -.01 & -.06 & -.05 & $.17^{* *}$ & $.14^{*}$ & .11 & -.07 & -.03 & .10 & $.39^{* * *}$ & $-.24^{* * *}$ & $.42^{* * *}$ & $.42^{* * *}$ & $.50^{* * *}$ & $-.27^{* * *}$ & --- & & & \\
\hline 18. Ext. Dyf. NA ER & -.04 & .12 & .11 & .11 & -.09 & -.04 & -.07 & .08 & .13 & .03 & $-.20^{* * *}$ & $.30^{* * *}$ & $-.24^{* * *}$ & $-.17^{* * *}$ & $-.10^{*}$ & $.38^{* * *}$ & -.03 & --- & & \\
\hline 19. Funct. PA ER & $.19^{* *}$ & -.09 & -.05 & -.06 & $.22^{* *}$ & $.18^{* *}$ & $.18^{* *}$ & -.10 & -.04 & $.15^{*}$ & $.36^{* * *}$ & $-.16^{* * *}$ & $.38^{* * *}$ & $.39^{* * *}$ & $.49^{* * *}$ & $-.14^{* *}$ & $.61^{* * *}$ & -.06 & --- & \\
\hline 20. Dysf. PA ER & .07 & -.01 & -.00 & .00 & .04 & .05 & .04 & .07 & .03 & .04 & $-.42^{* * *}$ & $.49^{* * *}$ & $-.45^{* * *}$ & $-.40^{* * *}$ & -.04 & $.63^{* * *}$ & $-.17^{* * *}$ & $.37^{* * *}$ & $-.17^{* * *}$ & -- \\
\hline 21. Friend Closeness & $.30^{* * *}$ & .01 & -.04 & .00 & $.29^{* * *}$ & $.32^{* * *}$ & $.23^{* * *}$ & -.06 & -.01 & $.17^{* *}$ & $.21^{* * *}$ & $-.12^{* *}$ & $.19^{* * *}$ & $.22^{* * *}$ & $.15^{* * *}$ & $-.14^{* *}$ & $.31^{* * *}$ & -.06 & $.28^{* * *}$ & $-.15^{* * *}$ \\
\hline
\end{tabular}

Note. ${ }^{*} p<.05 .{ }^{* *} p<.01 .{ }^{* * *} p<.001 . \mathrm{PA}=$ positive affect. NA $=$ negative affect. $\mathrm{ER}=$ emotion regulation. Int. $=$ internal. Ext. $=$ external. Funct. $=$ functional. Dysf. $=$ dysfunctional. 
Table 10. Bivariate Correlations among Emerging Adult Socialization with Mothers, Mother Outcomes, Mother-reported Closeness with Emerging Adult.

\begin{tabular}{|c|c|c|c|c|c|c|c|c|c|c|c|c|c|c|c|c|c|c|c|c|}
\hline & 1 & 2 & 3 & 4 & 5 & 6 & 7 & 8 & 9 & 10 & 11 & 12 & 13 & 14 & 15 & 16 & 17 & 18 & 19 & 20 \\
\hline 1. Reward PA & -- & & & & & & & & & & & & & & & & & & & \\
\hline 2. Override PA & $-.11^{*}$ & -- & & & & & & & & & & & & & & & & & & \\
\hline 3. Neglect PA & $-.39^{* * *}$ & $.34^{* * *}$ & -- & & & & & & & & & & & & & & & & & \\
\hline 4. Punish PA & -.09 & $.51^{* * *}$ & $.33^{* * *}$ & -- & & & & & & & & & & & & & & & & \\
\hline 5. Magnify PA & $.83^{* * *}$ & -.04 & $-.35^{* * *}$ & -.01 & -- & & & & & & & & & & & & & & & \\
\hline 6. Reward NA & $.79^{* * *}$ & $-.14^{*}$ & $-.40^{* * *}$ & -.09 & $.73^{* * *}$ & -- & & & & & & & & & & & & & & \\
\hline 7. Override NA & $.46^{* * *}$ & .10 & $-.11^{*}$ & $.16^{* *}$ & $.48^{* * *}$ & $.50^{* * *}$ & -- & & & & & & & & & & & & & \\
\hline 8 Neglect NA & $-.26^{* * *}$ & $.32^{* * *}$ & $.53^{* * *}$ & $.22^{* * *}$ & $-.23^{* * *}$ & $-.35^{* * *}$ & .07 & -- & & & & & & & & & & & & \\
\hline 9. Punish NA & $-.11^{*}$ & $.57^{* * *}$ & $.34^{* * *}$ & $.60^{* * *}$ & -.05 & -.09 & $.26^{* * *}$ & $.34^{* * *}$ & -- & & & & & & & & & & & \\
\hline 10. Magnify NA & $.36^{* * *}$ & .09 & -.03 & .09 & $.40^{* * *}$ & $.34^{* * *}$ & $.29^{* * *}$ & .06 & $.18^{* *}$ & -- & & & & & & & & & & \\
\hline 11. PA & $.15^{* *}$ & $-.11^{*}$ & -.03 & $-.11^{*}$ & $.13^{*}$ & .09 & .06 & -.08 & $-.12^{*}$ & -.01 & -- & & & & & & & & & \\
\hline 12. NA & -.10 & .08 & .04 & -.05 & $-.13^{*}$ & -.10 & -.04 & .06 & .04 & .02 & $-.55^{* * *}$ & -- & & & & & & & & \\
\hline 13. Subjective Happiness & .08 & -.06 & -.04 & -.01 & .06 & .07 & .02 & $-.11^{*}$ & -.10 & -.03 & $.57^{* * *}$ & $-.43^{* * *}$ & -- & & & & & & & \\
\hline 14. Satisfaction with Life & .09 & .02 & -.05 & .00 & $.11^{*}$ & .09 & .05 & $-.11^{*}$ & -.05 & -.03 & $.53^{* * *}$ & $-.41^{* * *}$ & $.53^{* * *}$ & -- & & & & & & \\
\hline 15. Int. Funct. NA ER & .08 & -.07 & -.06 & -.09 & .06 & .07 & .04 & -.01 & -.09 & -.00 & $.37^{* * *}$ & $-.22^{* * *}$ & $.27^{* * *}$ & $.19^{* * *}$ & -- & & & & & \\
\hline 16. Int. Dysf. NA ER & -.02 & .10 & .05 & .03 & -.04 & -.00 & .04 & .08 & .09 & .08 & $-.38^{* * *}$ & $.46^{* * *}$ & $-.36^{* * *}$ & $-.34^{* * *}$ & $-.12^{*}$ & -- & & & & \\
\hline 17. Ext. Funct. NA ER & .05 & .01 & -.08 & -.08 & .06 & .06 & .03 & $-.12^{*}$ & -.04 & -.05 & $.36^{* * *}$ & $-.27^{* * *}$ & $.30^{* * *}$ & $.33^{* * *}$ & $.46^{* * *}$ & $-.28^{* * *}$ & -- & & & \\
\hline 18. Ext. Dysf. NA ER & $-.11^{*}$ & .00 & .01 & -.02 & $-.12^{*}$ & -.09 & .00 & .07 & .03 & -.04 & $-.18^{* *}$ & $.26^{* * *}$ & $-.15^{* *}$ & -.10 & -.10 & $.37^{* * *}$ & -.06 & -- & & \\
\hline 19. Funct. PA ER & $.12^{*}$ & .00 & -.05 & .03 & $.12^{*}$ & $.13^{*}$ & .07 & -.07 & -.01 & -.01 & $.27^{* * *}$ & $-.19^{* * *}$ & $.25^{* * *}$ & $.19^{* * *}$ & $.37^{* * *}$ & -.08 & $.47^{* * *}$ & .04 & -- & \\
\hline 20. Dysf. PA ER & -.05 & .03 & .05 & .05 & -.03 & -.02 & $.11^{*}$ & $.13^{*}$ & .01 & .07 & $-.35^{* * *}$ & $.35^{* * *}$ & $-.32^{* * *}$ & $-.29^{* * *}$ & -.10 & $.47^{* * *}$ & $-.26^{* * *}$ & $.11^{*}$ & $-.12^{*}$ & -- \\
\hline 21. Child Closeness & $.33^{* * *}$ & .03 & $-.11^{*}$ & .06 & $.31^{* * *}$ & $.36^{* * *}$ & $.27^{* * *}$ & $-.17^{* *}$ & .01 & $.18^{* *}$ & $.32^{* * *}$ & $-.21^{* * *}$ & $.18^{* *}$ & $.21^{* * *}$ & $.24^{* * *}$ & $-.13^{*}$ & $.25^{* * *}$ & $-.16^{* *}$ & $.19^{* * *}$ & -.03 \\
\hline
\end{tabular}

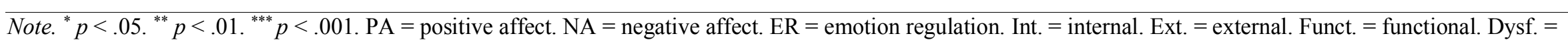
dysfunctional. 
Table 11. Bivariate Correlations among Emerging Adult Socialization with Fathers, Father Outcomes, Father-reported Closeness with Emerging Adult.

\begin{tabular}{|c|c|c|c|c|c|c|c|c|c|c|c|c|c|c|c|c|c|c|c|c|}
\hline & 1 & 2 & 3 & 4 & 5 & 6 & 7 & 8 & 9 & 10 & 11 & 12 & 13 & 14 & 15 & 16 & 17 & 18 & 19 & 20 \\
\hline 1. Reward PA & -- & & & & & & & & & & & & & & & & & & & \\
\hline 2. Override PA & -.09 & -- & & & & & & & & & & & & & & & & & & \\
\hline 3. Neglect PA & $-.35^{* *}$ & $.34^{* *}$ & -- & & & & & & & & & & & & & & & & & \\
\hline 4. Punish PA & -.01 & $.34^{* *}$ & .11 & -- & & & & & & & & & & & & & & & & \\
\hline 5. Magnify PA & $.84^{* * *}$ & -.10 & $-.52^{* * *}$ & -.05 & -- & & & & & & & & & & & & & & & \\
\hline 6. Reward NA & $.73^{* * *}$ & -.02 & $-.36^{* *}$ & -.02 & $.71^{* * *}$ & -- & & & & & & & & & & & & & & \\
\hline 7. Override NA & $.46^{* * *}$ & .23 & -.13 & $.28^{*}$ & $.52^{* * *}$ & $.64^{* * *}$ & -- & & & & & & & & & & & & & \\
\hline 8 Neglect NA & .02 & $.51^{* * *}$ & $.33^{* *}$ & .24 & -.04 & -.03 & .20 & -- & & & & & & & & & & & & \\
\hline 9. Punish NA & -.10 & $.42^{* * *}$ & $.28^{*}$ & $.34^{* *}$ & -.11 & -.01 & $.38^{* *}$ & .10 & -- & & & & & & & & & & & \\
\hline 10. Magnify NA & $.43^{* * *}$ & $.32^{* *}$ & -.02 & .021 & $.44^{* * *}$ & $.50^{* * *}$ & $.50^{* * *}$ & $.38^{* *}$ & .22 & -- & & & & & & & & & & \\
\hline 11. PA & .10 & .05 & .01 & -.02 & .14 & -.03 & -.02 & -.01 & .01 & -.02 & -- & & & & & & & & & \\
\hline 12. NA & -.09 & -.12 & .03 & -.04 & -.12 & -.13 & -.13 & -.01 & -.13 & -.18 & $-.66^{* * *}$ & -- & & & & & & & & \\
\hline 13. Subjective Happiness & .05 & -.11 & -.10 & -.02 & .03 & .03 & -.12 & -.18 & -.08 & -.11 & $.58^{* * *}$ & $-.55^{* * *}$ & -- & & & & & & & \\
\hline 14. Satisfaction with Life & .06 & -.09 & $-.27^{*}$ & -.09 & .15 & -.04 & -.13 & -.19 & -.04 & -.04 & $.55^{* * *}$ & $-.53^{* * *}$ & $.70^{* * *}$ & -- & & & & & & \\
\hline 15. Int. Funct. NA ER & .19 & .01 & -.08 & -.17 & .22 & .12 & -.01 & -.16 & .11 & .00 & $.32^{* * *}$ & $-.20^{*}$ & $.19^{*}$ & $.27^{* *}$ & -- & & & & & \\
\hline 16. Int. Dysf. NA ER & -.08 & -.12 & .01 & -.15 & -.02 & .01 & -.04 & -.17 & -.18 & -.13 & $-.43^{* * *}$ & $.54^{* * *}$ & $-.52^{* * *}$ & $-.55^{* * *}$ & -.14 & -- & & & & \\
\hline 17. Ext. Funct. NA ER & .12 & -.10 & -.08 & -.04 & .13 & .12 & .22 & -.19 & .15 & -.03 & $.33^{* * *}$ & $-.20^{*}$ & $.22^{*}$ & .17 & $.51^{* * *}$ & $-.31^{* *}$ & -- & & & \\
\hline 18. Ext. Dysf. NA ER & $-.26^{*}$ & -.02 & .05 & .02 & -.21 & -.14 & -.11 & -.19 & -.09 & -.22 & $-.35^{* * *}$ & $.49^{* * *}$ & $-.43^{* * *}$ & $-.37^{* * *}$ & $-.26^{* *}$ & $.58^{* * *}$ & $-.21^{*}$ & -- & & \\
\hline 19. Funct. PA ER & .16 & -.09 & -.14 & .06 & .22 & .06 & .03 & $-.35^{* *}$ & .08 & -.13 & $.43^{* * *}$ & $-.34^{* * *}$ & $.35^{* * *}$ & $.38^{* * *}$ & $.48^{* * *}$ & $-.31^{* *}$ & $.67^{* * *}$ & -.12 & -- & \\
\hline 20. Dysf. PA ER & $-.27^{*}$ & -.12 & .14 & -.03 & -.21 & -.12 & -.11 & -.18 & -.07 & -.23 & $-.33^{* * *}$ & $.45^{* * *}$ & $-.36^{* * *}$ & $-.36^{* * *}$ & -.08 & $.61^{* * *}$ & -.11 & $.48^{* * *}$ & -.13 & -- \\
\hline 21. Child Closeness & $.43^{* * *}$ & .05 & $-.33^{* *}$ & -.07 & $.46^{* * *}$ & $.33^{* *}$ & .21 & -.01 & .02 & .14 & $.36^{* * *}$ & $-.32^{* * *}$ & $.40^{* * *}$ & $.45^{* * *}$ & $.36^{* * *}$ & $-.37^{* * *}$ & $.33^{* * *}$ & $-.36^{* * *}$ & $.39^{* * *}$ & $-.32^{* * * *}$ \\
\hline
\end{tabular}

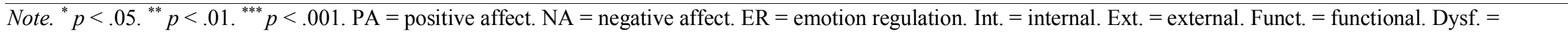
dysfunctional. 
Table 12. Bivariate Correlations among Emerging Adult Socialization with Friend, Friend Outcomes, Friend-reported Closeness with Emerging Adult.

\begin{tabular}{|c|c|c|c|c|c|c|c|c|c|c|c|c|c|c|c|c|c|c|c|c|}
\hline & 1 & 2 & 3 & 4 & 5 & 6 & 7 & 8 & 9 & 10 & 11 & 12 & 13 & 14 & 15 & 16 & 17 & 18 & 19 & 20 \\
\hline 1. Reward PA & --- & & & & & & & & & & & & & & & & & & & \\
\hline 2. Override PA & $-.40^{* * *}$ & --- & & & & & & & & & & & & & & & & & & \\
\hline 3. Neglect PA & $-.45^{* * *}$ & $.64^{* * *}$ & --- & & & & & & & & & & & & & & & & & \\
\hline 4. Punish PA & $-.40^{* * *}$ & $.71^{* * * *}$ & $.70^{* * *}$ & --- & & & & & & & & & & & & & & & & \\
\hline 5. Magnify PA & $.65^{* * *}$ & $-.14^{* *}$ & $-.27^{* * *}$ & $-.16^{* *}$ & --- & & & & & & & & & & & & & & & \\
\hline 6. Reward NA & $.59^{* * *}$ & $-.11^{* *}$ & $-.17^{* *}$ & $-.14^{* *}$ & $.54^{* * *}$ & --- & & & & & & & & & & & & & & \\
\hline 7.Override NA & $.33^{* * *}$ & $.11^{* *}$ & .02 & .08 & $.37^{* * *}$ & $.71^{* * *}$ & --- & & & & & & & & & & & & & \\
\hline 8. Neglect NA & $-.47^{* * *}$ & $.67^{* * *}$ & $.73^{* * *}$ & $.78^{* * *}$ & $-.22^{* * *}$ & $-.17^{* *}$ & .07 & --- & & & & & & & & & & & & \\
\hline 9. Punish NA & $-.37^{* * *}$ & $.69^{* * *}$ & $.69^{* * *}$ & $.78^{* * *}$ & -.08 & -.05 & $.18^{* * *}$ & $.85^{* * *}$ & --- & & & & & & & & & & & \\
\hline 10. Magnify NA & $.25^{* * *}$ & $.13^{* *}$ & .05 & $.10^{*}$ & $.41^{* * *}$ & $.50^{* * *}$ & $.41^{* * *}$ & $.10^{*}$ & $.30^{* * *}$ & --- & & & & & & & & & & \\
\hline 11. PA & .10 & $-.14^{*}$ & -.08 & -.07 & $.14^{*}$ & $.14^{*}$ & .12 & -.11 & -.03 & $.15^{*}$ & --- & & & & & & & & & \\
\hline 12. NA & -.09 & $.13^{*}$ & .08 & .06 & -.10 & $-.15^{*}$ & $-.19^{* * *}$ & .08 & -.01 & -.08 & $-.57^{* * *}$ & --- & & & & & & & & \\
\hline 13. Subjective Happiness & .02 & -.07 & -.07 & -.02 & .11 & .08 & .09 & -.08 & .03 & .10 & $.65^{* * *}$ & $-.55^{* * *}$ & --- & & & & & & & \\
\hline 14. Satisfaction with Life & .03 & -.09 & -.08 & -.04 & .07 & .05 & .09 & -.10 & .02 & .04 & $.57^{* * *}$ & $-.52^{* * *}$ & $.53^{* * *}$ & --- & & & & & & \\
\hline 15. Int. Funct. NA ER & .02 & -.01 & .08 & .03 & .04 & .04 & .09 & .02 & .11 & .11 & $.21^{* * *}$ & $-.14^{*}$ & $.20^{* * *}$ & .11 & --- & & & & & \\
\hline 16. Int. Dysf. NA ER & -.08 & .10 & $.14^{*}$ & .03 & $-.13^{*}$ & -.11 & $-.14^{*}$ & .06 & -.04 & -.12 & $-.47^{* * *}$ & $.53^{* * *}$ & $-.47^{* * *}$ & $-.48^{* * *}$ & .03 & --- & & & & \\
\hline 17. Ext. Funct. NA ER & .09 & -.04 & .02 & -.01 & $.15^{*}$ & $.17^{* *}$ & $.19^{* * * *}$ & -.03 & .04 & .11 & $.41^{* * *}$ & $-.25^{* * *}$ & $.40^{* * *}$ & $.35^{* * *}$ & $.48^{* * *}$ & $-.24^{* * *}$ & --- & & & \\
\hline 18. Ext. Dysf. NA ER & -.01 & .06 & .09 & .06 & -.02 & -.04 & -.05 & -.01 & -.02 & -.07 & $-.25^{* * *}$ & $.27^{* * *}$ & $-.29^{* * *}$ & $-.24^{* * *}$ & -.10 & $.44^{* * *}$ & -.08 & --- & & \\
\hline 19. Funct. PA ER & $.13^{*}$ & -.02 & -.02 & .01 & $.14^{*}$ & $.14^{*}$ & $.18^{* * *}$ & -.10 & .06 & $.16^{*}$ & $.44^{* * * *}$ & $-.20^{* * *}$ & $.34^{* * *}$ & $.32^{* * *}$ & $.51^{* * *}$ & -.12 & $.68^{* * *}$ & -.09 & --- & \\
\hline 20. Dysf. PA ER & $-.17^{* *}$ & $.14^{*}$ & .12 & .07 & $-.16^{* *}$ & -.12 & -.08 & .09 & .03 & -.10 & $-.44^{* * *}$ & $.47^{* * *}$ & $-.45^{* * *}$ & $-.38^{* * *}$ & .06 & $.68^{* * *}$ & $-.15^{*}$ & $.43^{* * *}$ & -.10 & --- \\
\hline 21. Friend Closeness & .08 & .04 & $-.19^{* * *}$ & -.01 & $.20^{* * *}$ & $.17^{* *}$ & .12 & $-.17^{* *}$ & .02 & .11 & $.15^{*}$ & $-.18^{* * *}$ & $.18^{* * *}$ & $.28^{* * *}$ & $.21^{* * *}$ & -.08 & $.31^{* * *}$ & .02 & $.33^{* * *}$ & -.06 \\
\hline
\end{tabular}

Note. ${ }^{*} p<.05 .{ }^{* *} p<.01 .{ }^{* * *} p<.001 . \mathrm{PA}=$ positive affect. $\mathrm{NA}=$ negative affect. $\mathrm{ER}=$ emotion regulation. Int. $=$ internal. Ext. $=$ external. Funct. $=$ functional. Dysf. $=$ dysfunctional. 
Table 13. Bivariate Correlations among Emerging Adult Demographics and Outcomes.

\begin{tabular}{|c|c|c|c|c|c|c|c|c|c|c|c|c|c|c|c|}
\hline & 1 & 2 & 3 & 4 & 5 & 6 & 7 & 8 & 9 & 10 & 11 & 12 & 13 & 14 & 15 \\
\hline 1. Age & --- & & & & & & & & & & & & & & \\
\hline 2. Gender & $-.14^{* *}$ & --- & & & & & & & & & & & & & \\
\hline 3. Mothers' education & -.04 & -.01 & --- & & & & & & & & & & & & \\
\hline 4. Fathers' education & -.01 & -.07 & $.48^{* * *}$ & --- & & & & & & & & & & & \\
\hline $\begin{array}{l}\text { 5. First-generation } \\
\text { college student }\end{array}$ & -.01 & -.01 & $.39^{* * *}$ & $.36^{* * *}$ & --- & & & & & & & & & & \\
\hline 6. Difficulty paying bills & .06 & -.01 & $-.22^{* * *}$ & $-.27^{* * *}$ & $-.15^{* * *}$ & --- & & & & & & & & & \\
\hline 7. PA & .01 & .01 & .07 & .02 & -.02 & $-.22^{* * *}$ & --- & & & & & & & & \\
\hline 8. NA & -.06 & $.12^{* *}$ & -.07 & -.05 & .01 & $.20^{* * *}$ & $-.60^{* * *}$ & --- & & & & & & & \\
\hline 9. Subjective Happiness & .02 & $-.09^{*}$ & .05 & .07 & .01 & $-.16^{* * *}$ & $.69^{* * *}$ & $-.62^{* * *}$ & --- & & & & & & \\
\hline 10. Satisfaction with Life & -.04 & .02 & .05 & .07 & .02 & $-.31^{* * *}$ & $.64^{* * *}$ & $-.54^{* * *}$ & $.64^{* * *}$ & --- & & & & & \\
\hline 11. Int. Funct. NA ER & $.10^{*}$ & -.04 & -.08 & $-.09^{*}$ & -.01 & -.03 & $.27^{* * *}$ & $-.17^{* * *}$ & $.35^{* * *}$ & $.24^{* * *}$ & --- & & & & \\
\hline 12. Int. Dysf. NA ER & .02 & .04 & .02 & -.01 & .07 & $.15^{* * *}$ & $-.43^{* * *}$ & $.53^{* * *}$ & $-.52^{* * *}$ & $-.47^{* * *}$ & -.03 & --- & & & \\
\hline 13. Ext. Funct. NA ER & -.02 & $.12^{* *}$ & .03 & -.01 & -.01 & $-.13^{* *}$ & $.39^{* * *}$ & $-.24^{* * *}$ & $.42^{* * *}$ & $.42^{* * *}$ & $.50^{* * *}$ & $-.27^{* * *}$ & --- & & \\
\hline 14. Ext. Dysf. NA ER & .06 & -.04 & .03 & -.03 & .02 & $.10^{*}$ & $-.20^{* * *}$ & $.30^{* * *}$ & $-.24^{* * *}$ & $-.17^{* * *}$ & $-.10^{*}$ & $.38^{* * *}$ & -.03 & --- & \\
\hline 15. Funct. PA ER & .02 & $.15^{* * *}$ & -.01 & -.04 & -.04 & $-.11^{* *}$ & $.36^{* * *}$ & $-.16^{* * *}$ & $.38^{* * *}$ & $.39^{* * *}$ & $.49^{* * *}$ & $-.14^{* *}$ & $.61^{* * *}$ & -.06 & --- \\
\hline 16. Dysf. PA ER & .01 & -.05 & .01 & -.03 & .03 & $.12^{* *}$ & $-.42^{* * *}$ & $.49^{* * *}$ & $-.45^{* * *}$ & $-.40^{* * *}$ & -.04 & $.63^{* * *}$ & $-.17^{* * *}$ & $.37^{* * *}$ & $-.17^{* * *}$ \\
\hline
\end{tabular}

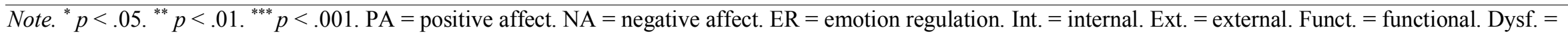
dysfunctional. 
Table 14. Bivariate Correlations among Parent Demographics and Outcomes.

\begin{tabular}{|c|c|c|c|c|c|c|c|c|c|c|c|c|c|}
\hline & 1 & 2 & 3 & 4 & 5 & 6 & 7 & 8 & 9 & 10 & 11 & 12 & 13 \\
\hline 1. Age & --- & & & & & & & & & & & & \\
\hline 2. Difficulty paying bills & -.09 & --- & & & & & & & & & & & \\
\hline 3. Parent education & $.15^{* *}$ & -.08 & --- & & & & & & & & & & \\
\hline 4. Gender & $-.19^{* * *}$ & .04 & -.04 & --- & & & & & & & & & \\
\hline 5. PA & -.01 & $-.25^{* * *}$ & .09 & $.11^{*}$ & --- & & & & & & & & \\
\hline 6. NA & $-.09^{*}$ & $.20^{* * *}$ & -.06 & $.10^{*}$ & $-.56^{* * *}$ & --- & & & & & & & \\
\hline 7. Subjective Happiness & .05 & $-.23^{* * *}$ & .01 & .03 & $.57^{* * *}$ & $-.46^{* * *}$ & --- & & & & & & \\
\hline 8. Satisfaction with Life & .05 & $-.34^{* * *}$ & $.17^{* * *}$ & .01 & $.53^{* * *}$ & $-.44^{* * *}$ & $.58^{* * *}$ & --- & & & & & \\
\hline 9. Int. Funct. NA ER & .05 & -.05 & $.13^{* *}$ & .03 & $.36^{* * *}$ & $-.21^{* * *}$ & $.25^{* * *}$ & $.21^{* * *}$ & --- & & & & \\
\hline 10. Int. Dysf. NA ER & $-.11^{*}$ & $.18^{* * *}$ & -.06 & $-.10^{*}$ & $-.40^{* * *}$ & $.46^{* * *}$ & $-.41^{* * *}$ & $-.40^{* * *}$ & $-.13^{* *}$ & --- & & & \\
\hline 11. Ext. Funct. NA ER & -.01 & $-.15^{* *}$ & $.10^{*}$ & $.22^{* * *}$ & $.37^{* * *}$ & $-.22^{* * *}$ & $.28^{* * *}$ & $.28^{* * *}$ & $.47^{* * *}$ & $-.30^{* * *}$ & --- & & \\
\hline 12. Ext. Dysf. NA ER & $-.14^{* *}$ & .02 & -.01 & .02 & $-.22^{* * *}$ & $.32^{* * *}$ & $-.23^{* * *}$ & $-.17^{* * *}$ & $-.14^{* *}$ & $.43^{* * *}$ & $-.09^{*}$ & --- & \\
\hline 13. Funct. PA ER & -.01 & -.03 & -.03 & $.22^{* * *}$ & $.33^{* * *}$ & $-.20^{* * *}$ & $.28^{* * *}$ & $.24^{* * *}$ & $.40^{* * *}$ & $-.17^{* * *}$ & $.55^{* * *}$ & -.01 & --- \\
\hline 14. Dysf. PA ER & -.06 & $.19^{* * *}$ & $-.15^{* *}$ & $-.11^{*}$ & $-.35^{* * *}$ & $.36^{* * *}$ & $-.33^{* * *}$ & $-.31^{* * *}$ & $-.10^{*}$ & $.51^{* * *}$ & $-.24^{* * *}$ & $.21^{* * *}$ & $-.14^{* *}$ \\
\hline
\end{tabular}

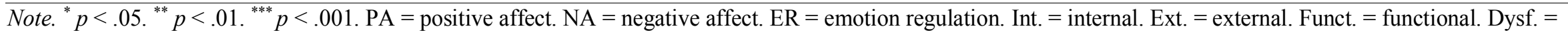
dysfunctional. 
Table 15. Bivariate Correlations among Friend Demographics and Outcomes.

\begin{tabular}{|c|c|c|c|c|c|c|c|c|c|c|c|c|c|c|c|c|}
\hline & 1 & 2 & 3 & 4 & 5 & 6 & 7 & 8 & 9 & 10 & 11 & 12 & 14 & 15 & 16 & 17 \\
\hline 1. Age & --- & & & & & & & & & & & & & & & \\
\hline 2. Gender & -.08 & --- & & & & & & & & & & & & & & \\
\hline $\begin{array}{l}\text { 3. Difficulty paying } \\
\text { bills }\end{array}$ & -.03 & -.01 & --- & & & & & & & & & & & & & \\
\hline 4. Mother education & $-.13^{*}$ & -.07 & $-.22^{* * *}$ & --- & & & & & & & & & & & & \\
\hline 5. Father education & $-.13^{*}$ & -.06 & $-.30^{* * *}$ & $.41^{* * *}$ & --- & & & & & & & & & & & \\
\hline 6. College student & $.28^{* * *}$ & $-.14^{*}$ & $.15^{*}$ & $-.13^{*}$ & -.11 & --- & & & & & & & & & & \\
\hline $\begin{array}{l}\text { 7. Attend West Virginia } \\
\text { University? }\end{array}$ & .10 & .05 & .03 & -.03 & -.07 & $.36^{* * *}$ & --- & & & & & & & & & \\
\hline 8. PA & .01 & -.01 & $-.27^{* * *}$ & .04 & .09 & -.04 & -.06 & --- & & & & & & & & \\
\hline 9. NA & -.11 & $.23^{* * *}$ & $.30^{* * *}$ & -.08 & $-.13^{*}$ & .10 & .11 & $-.57^{* * *}$ & --- & & & & & & & \\
\hline $\begin{array}{l}\text { 10. Subjective } \\
\text { Happiness }\end{array}$ & .02 & -.08 & $-.23^{* * *}$ & .05 & .05 & .01 & -.04 & $.65^{* *}$ & $-.56^{* *}$ & --- & & & & & & \\
\hline $\begin{array}{l}\text { 11. Satisfaction with } \\
\text { Life }\end{array}$ & .03 & -.01 & $-.38^{* * *}$ & .05 & $.13^{*}$ & -.10 & -.12 & $.57^{* * *}$ & $-.52^{* * *}$ & $.53^{* * *}$ & --- & & & & & \\
\hline 12. Int. Funct. NA ER & -.07 & -.08 & -.01 & .04 & -.03 & -.03 & .05 & $.21^{* *}$ & $-.14^{*}$ & $.20^{* *}$ & .11 & --- & & & & \\
\hline 13. Int. Dysf. NA ER & -.07 & .07 & $.21^{* *}$ & -.02 & -.02 & .05 & .02 & $-.47^{* * *}$ & $.53^{* * *}$ & $-.47^{* * *}$ & $-.48^{* * *}$ & .03 & --- & & & \\
\hline 14. Ext. Funct. NA ER & -.09 & $.16^{*}$ & -.09 & .01 & .01 & -.03 & .02 & $.41^{* * *}$ & $-.25^{* * *}$ & $.40^{* * *}$ & $.35^{* * *}$ & $.48^{* * *}$ & $-.24^{* * *}$ & --- & & \\
\hline 15. Ext. Dysf. NA ER & -.04 & .02 & $.14^{*}$ & -.11 & $-.19^{* *}$ & .04 & -.02 & $-.25^{* * *}$ & $.27^{* * *}$ & $-.29^{* * *}$ & $-.24^{* * *}$ & -.10 & $.44^{* * *}$ & -.08 & --- & \\
\hline 16. Funct. PA ER & -.06 & $.15^{*}$ & -.02 & -.01 & -.04 & -.03 & .03 & $.44^{* * *}$ & $-.20^{* *}$ & $.34^{* * *}$ & $.32^{* * *}$ & $.51^{* * *}$ & -.12 & $.66^{* * *}$ & -.09 & --- \\
\hline 17. Dysf. PA ER & -.07 & .01 & $.20^{* *}$ & .05 & -.03 & .04 & .02 & $-.44^{* * *}$ & $.47^{* * *}$ & $-.45^{* * *}$ & $-.38^{* * *}$ & .06 & $.68^{* * *}$ & $-.15^{*}$ & $.43^{* * *}$ & -.10 \\
\hline
\end{tabular}

Note. ${ }^{*} p<.05 .{ }^{* *} p<.01 .{ }^{* * *} p<.001 . \mathrm{PA}=$ positive affect. $\mathrm{NA}=$ negative affect. $\mathrm{ER}=$ emotion regulation. Int. $=$ internal. Ext. $=$ external. Funct. $=$ functional. Dysf. $=$ dysfunctional. 
Table 16. Independent Samples T-Tests between Gender and Variables of Interest.

\begin{tabular}{|c|c|c|c|c|c|}
\hline & \multicolumn{2}{|c|}{ Females } & \multicolumn{2}{|c|}{ Males } & \multirow{2}{*}{$t$-test } \\
\hline & $M$ & $S D$ & $M$ & $S D$ & \\
\hline \multicolumn{6}{|l|}{ Emerging Adult } \\
\hline Negative Affect & 15.98 & 4.25 & 14.73 & 3.91 & $-2.97^{* *}$ \\
\hline Subjective Happiness & 5.12 & 1.20 & 5.38 & 1.07 & $2.25^{*}$ \\
\hline $\begin{array}{l}\text { Functional Emotion } \\
\text { Regulation with PA }\end{array}$ & 3.61 & .70 & 3.34 & .66 & $-3.82^{* * *}$ \\
\hline Closeness with Friend & 41.59 & 5.26 & 39.76 & 5.85 & $-3.37^{* *}$ \\
\hline \multicolumn{6}{|l|}{ Parent } \\
\hline Positive Affect & 24.22 & 3.53 & 23.35 & 3.49 & $-2.36^{*}$ \\
\hline Negative Affect & 13.62 & 3.53 & 12.79 & 3.63 & $-2.19^{*}$ \\
\hline $\begin{array}{l}\text { Closeness with } \\
\text { Emerging Adult Child }\end{array}$ & 40.45 & 5.37 & 38.37 & 5.19 & $-3.72^{* * *}$ \\
\hline $\begin{array}{l}\text { Functional Emotion } \\
\text { Regulation with PA }\end{array}$ & 3.47 & .64 & 3.15 & .69 & $-4.67^{* * *}$ \\
\hline $\begin{array}{l}\text { Dysfunctional Emotion } \\
\text { Regulation with PA }\end{array}$ & 1.77 & .58 & 1.91 & .57 & $2.31^{*}$ \\
\hline \multicolumn{6}{|l|}{ Friend } \\
\hline Negative Affect & 16.12 & 4.01 & 14.16 & 4.42 & $-3.52^{* *}$ \\
\hline $\begin{array}{l}\text { Functional Emotion } \\
\text { Regulation with PA }\end{array}$ & 3.64 & .69 & 3.38 & .73 & $-2.75^{* *}$ \\
\hline
\end{tabular}




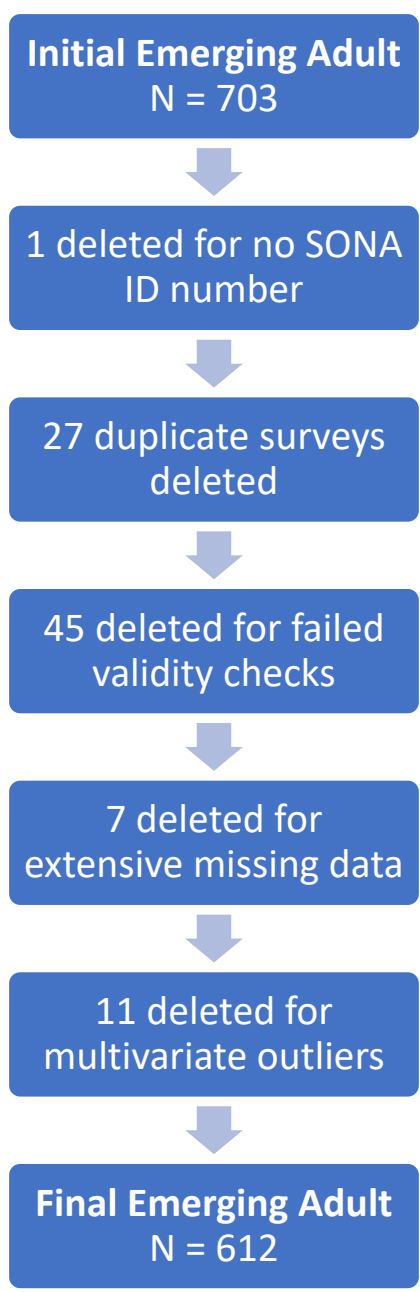

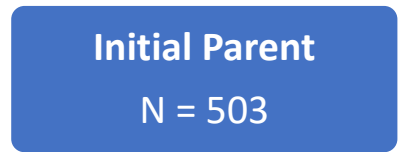

11 deleted for no child name left

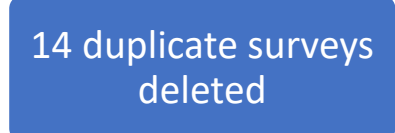

15 deleted for failing validity checks

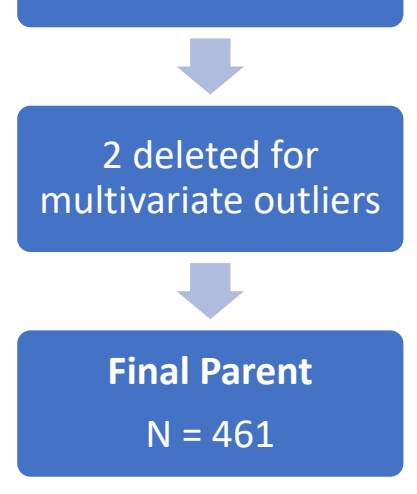

Initial Friend

$N=337$

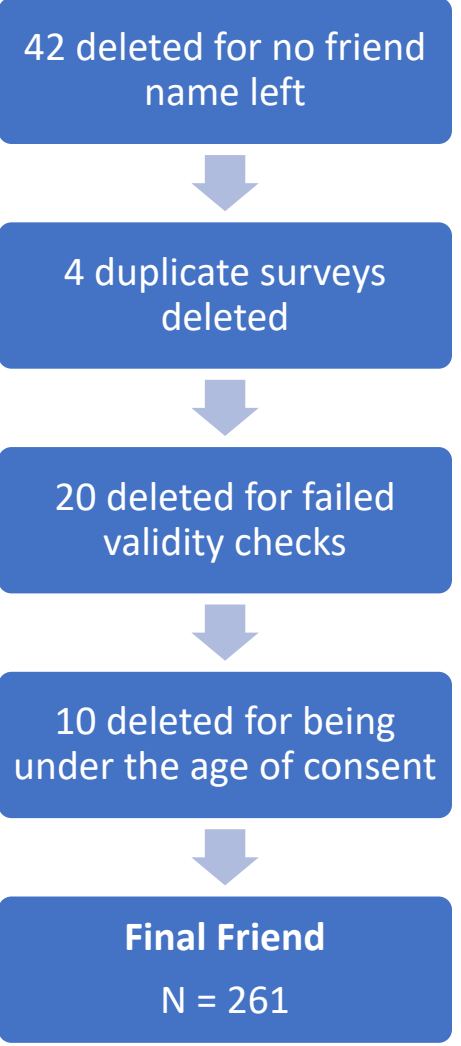

Figure 1. Data cleaning. 


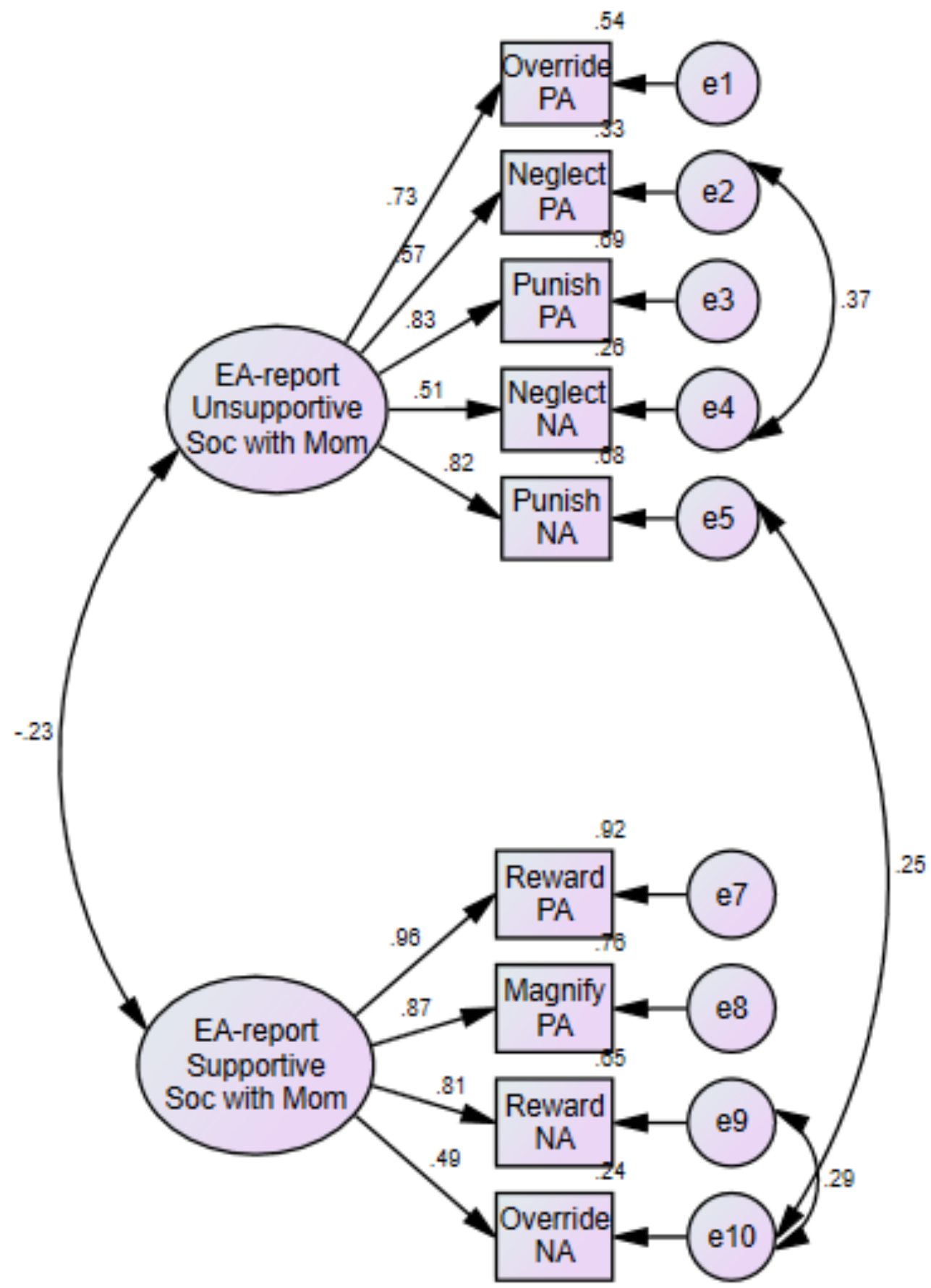

Figure 2. Confirmatory Factor Analysis of Emerging Adult-report of their Socialization of their Mothers' Emotions. 


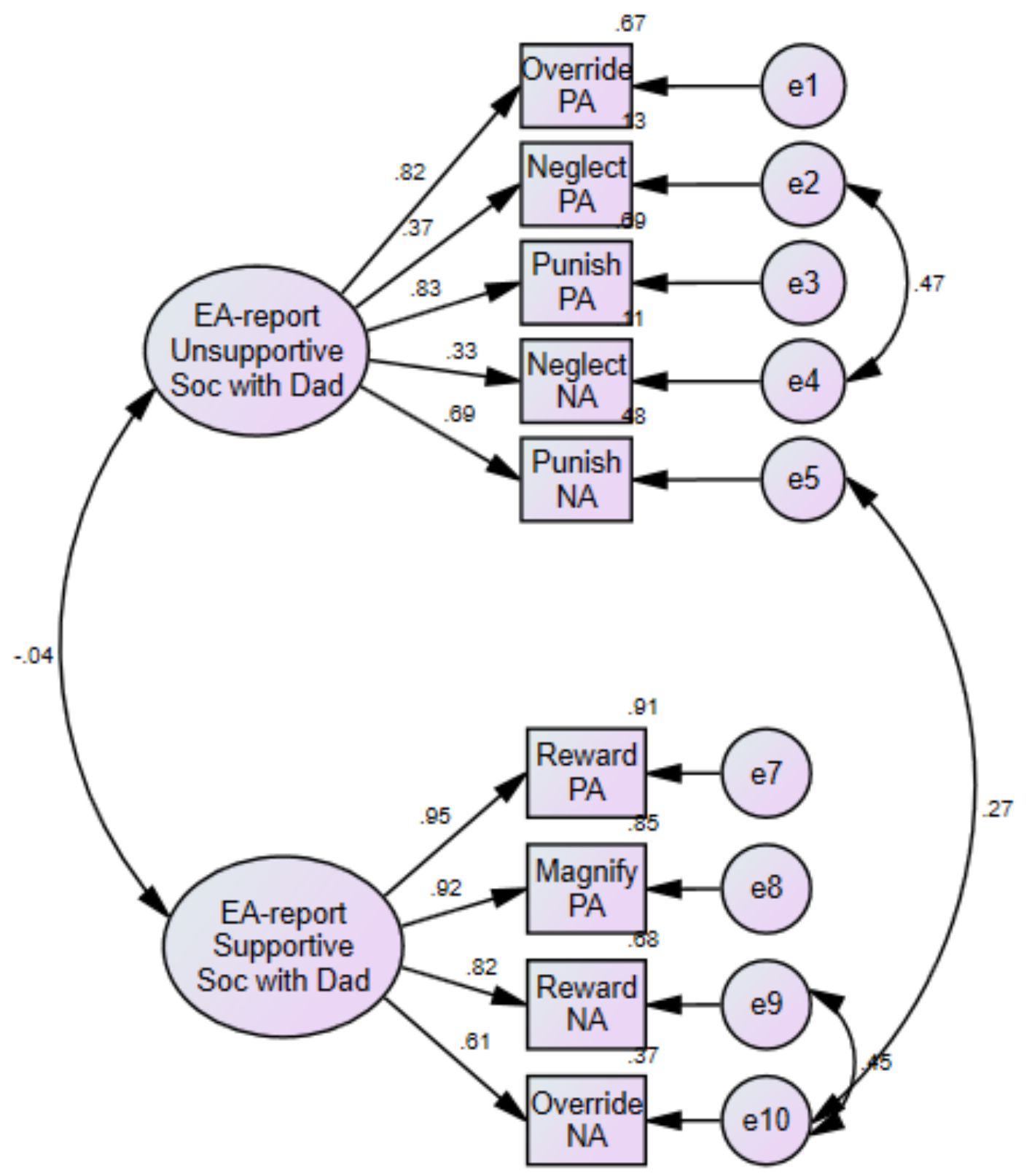

Figure 3. Confirmatory Factor Analysis of Emerging Adult-report of their Socialization of their Fathers' Emotions. 


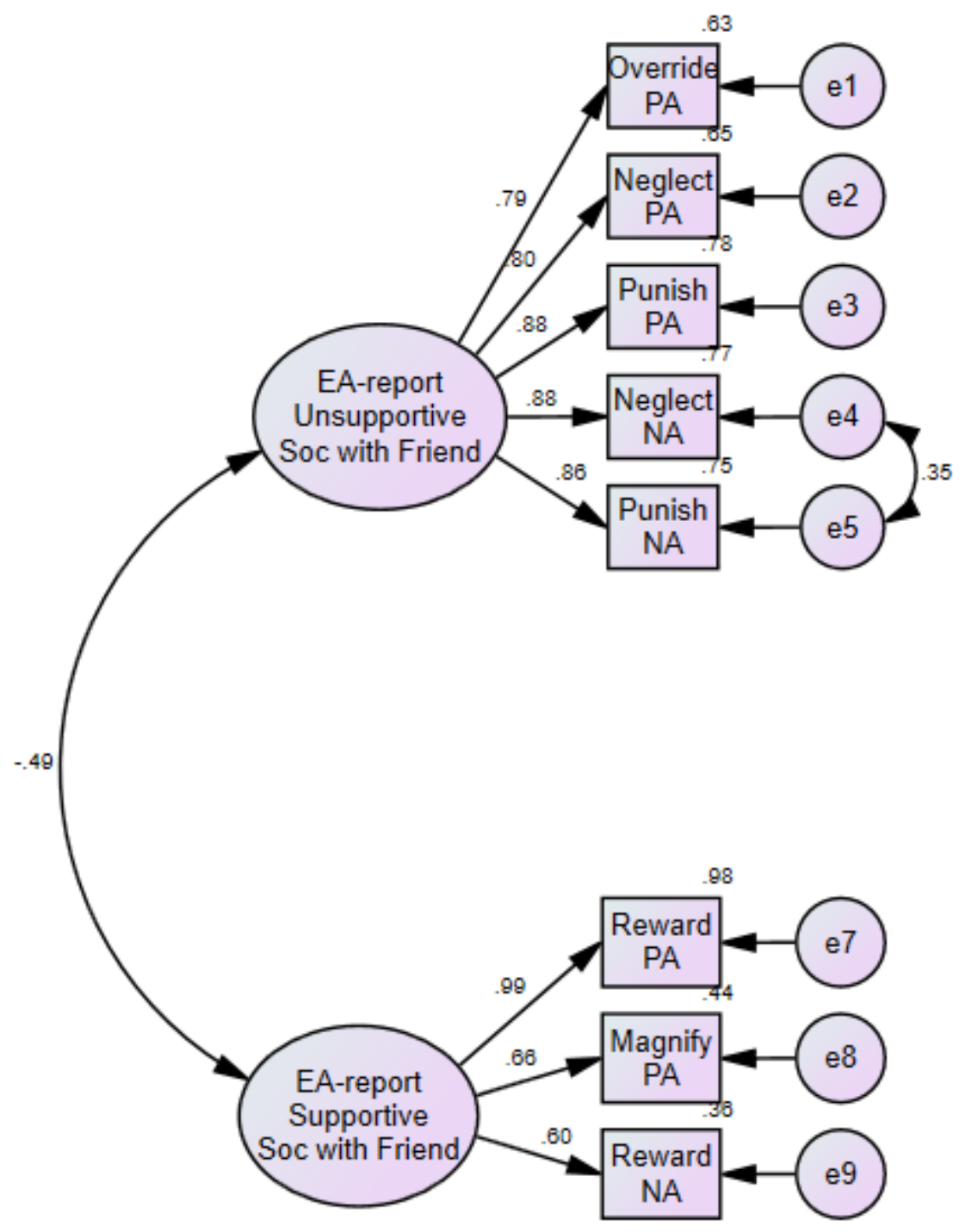

Figure 4. Confirmatory Factor Analysis of Emerging Adult-report of their Socialization of their Friends' Emotions. 


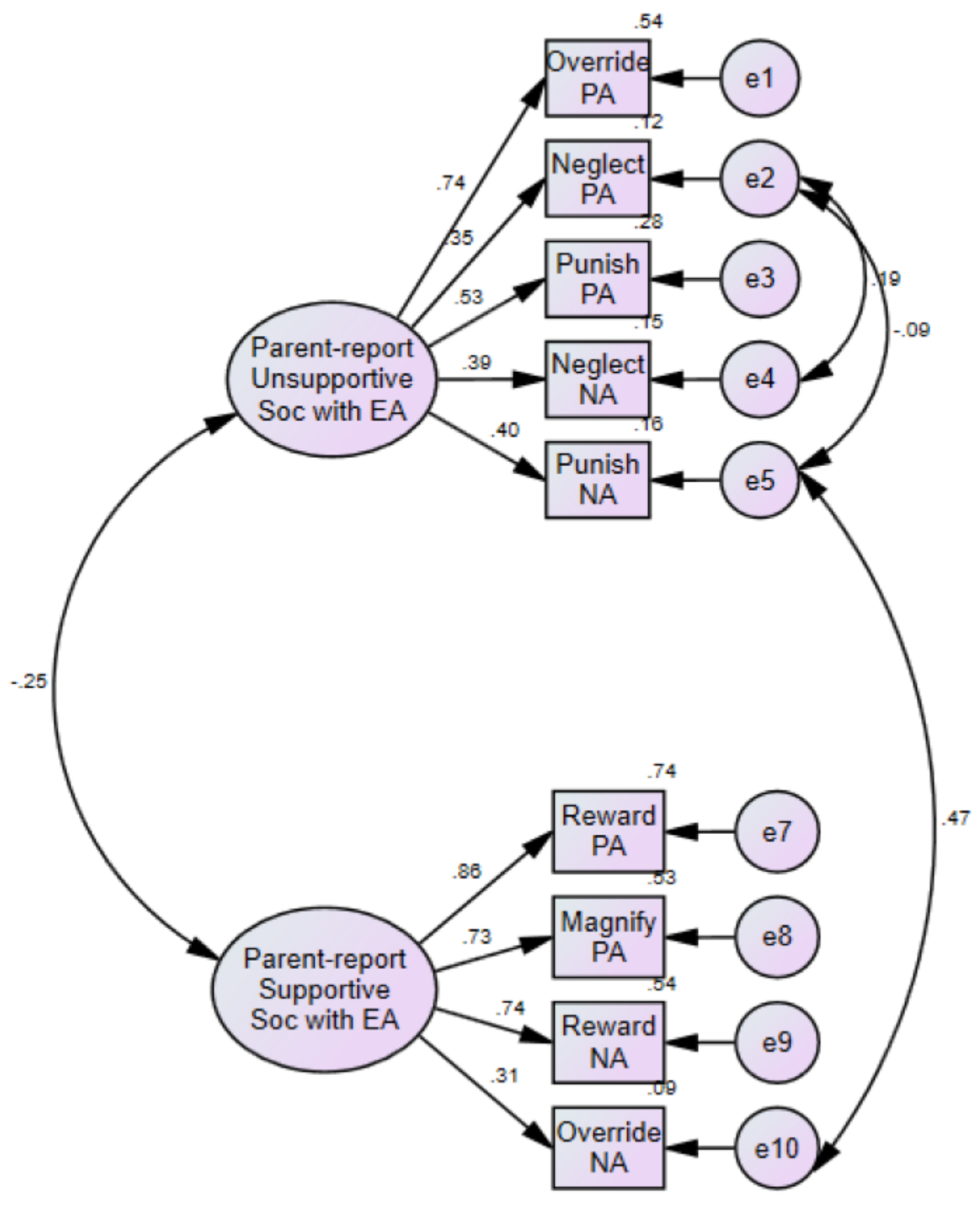

Figure 5. Confirmatory Factor Analysis of Parent-report of their Socialization of their Emerging Adults Child's Emotions. 


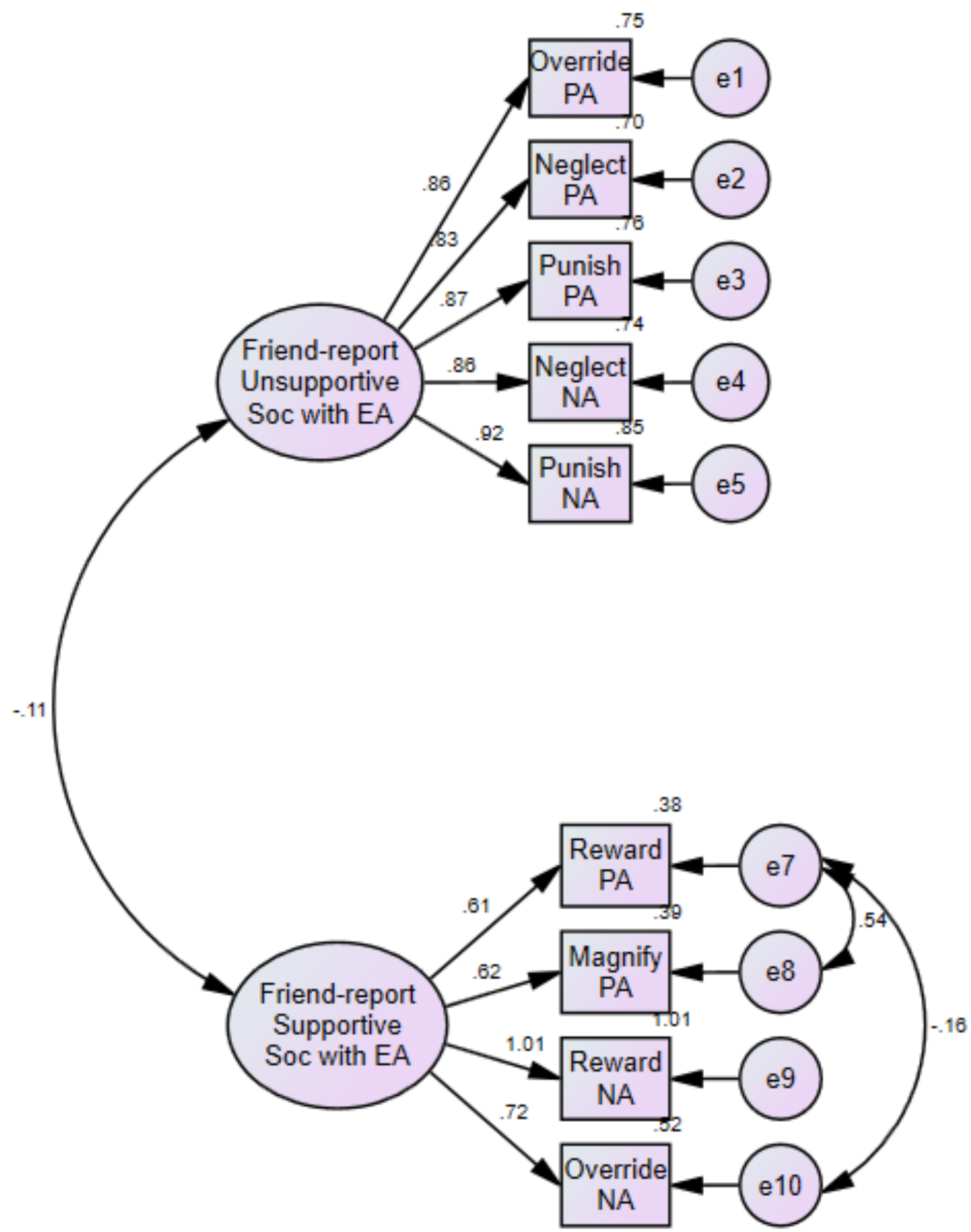

Figure 6. Confirmatory Factor Analysis of Friend-report of their Socialization of their Emerging Adults Friend's Emotions. 


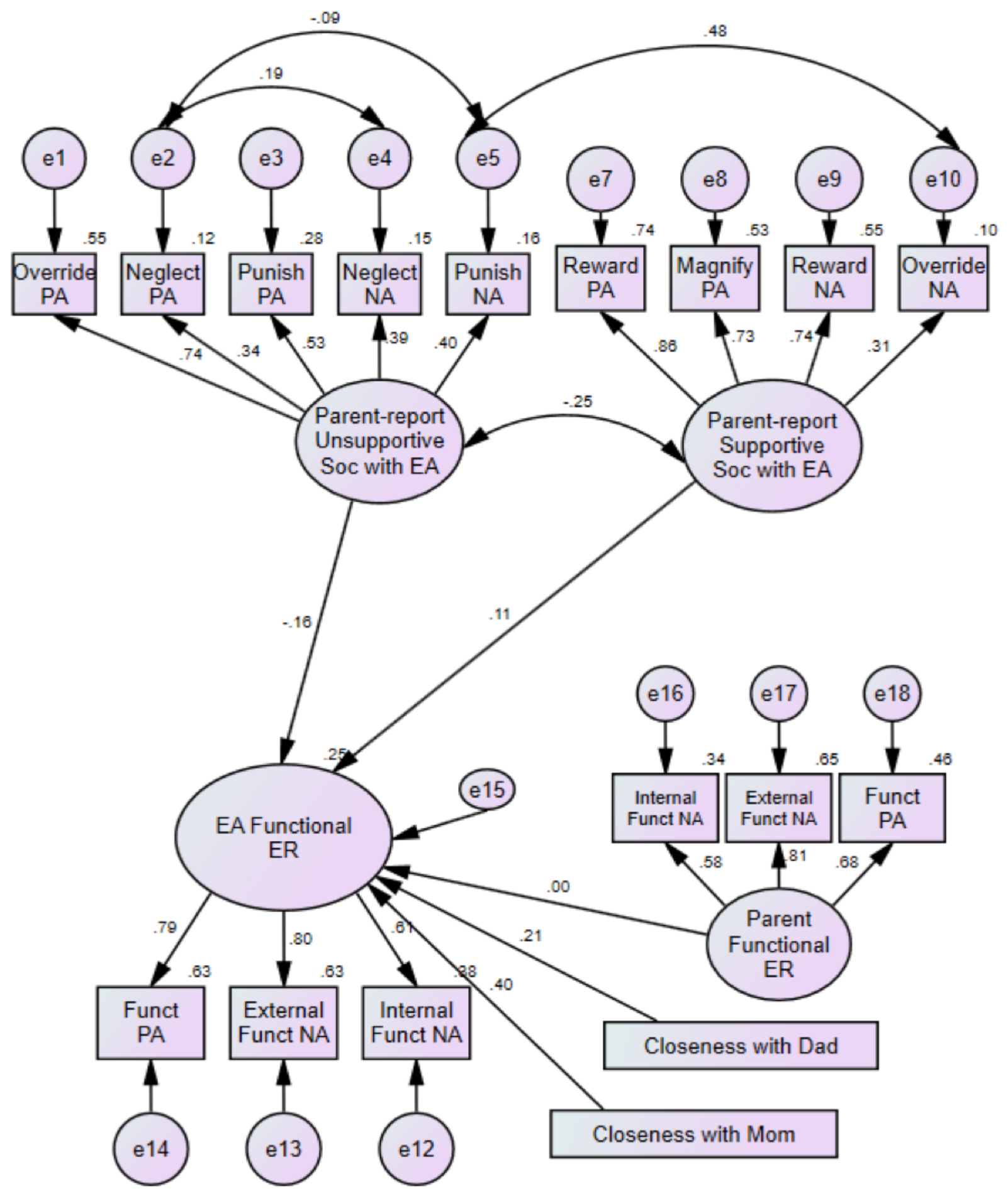

Figure 7. Research Question 2, Hypothesis 2a. Parents' Emotion Socialization predicting Emerging Adult Functional Emotion Regulation, Controlling for Parent-reported Functional Emotion Regulation and Emerging Adult-reported Closeness with Mother and Father. 


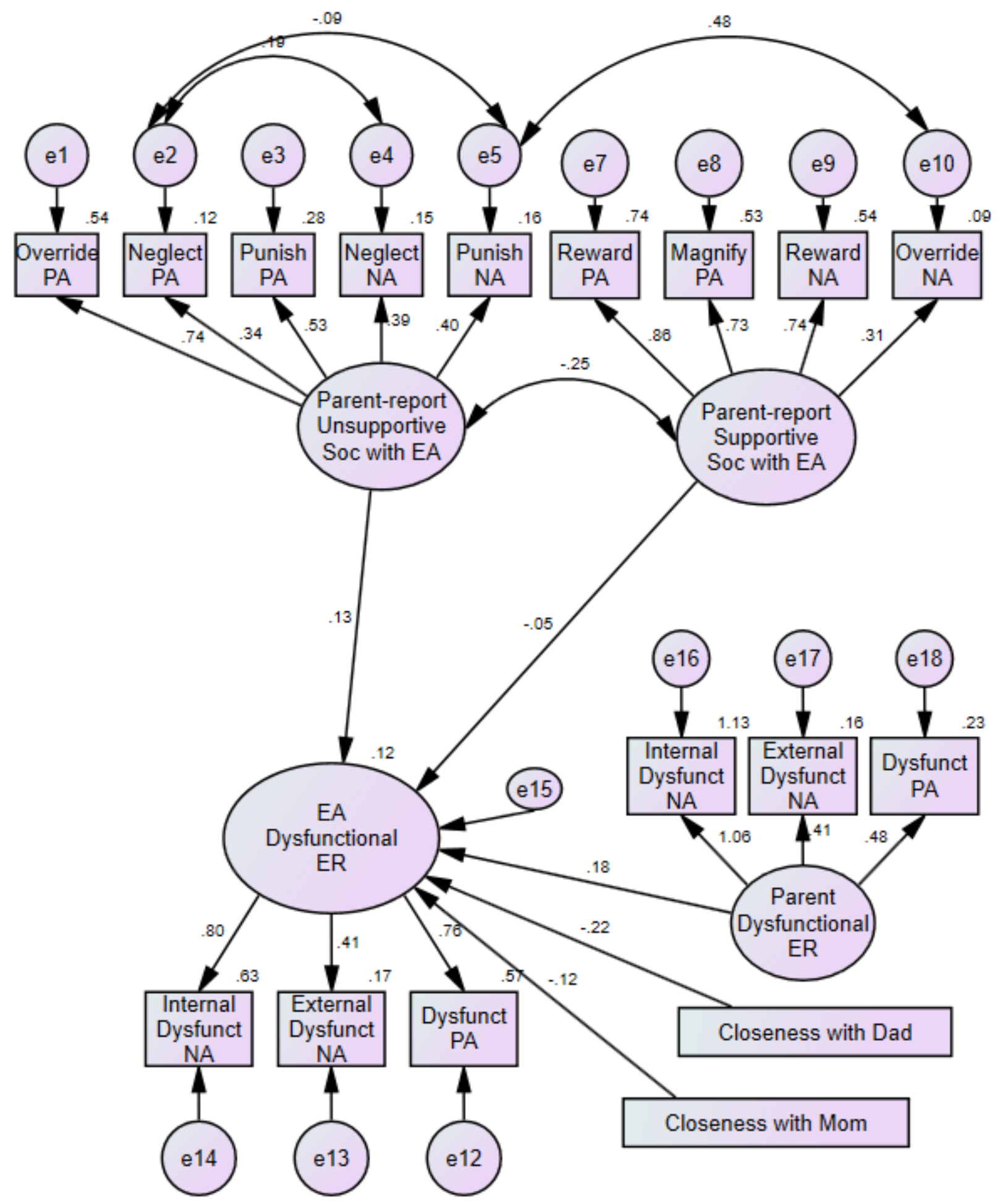

Figure 8. Research Question 2, Hypothesis 2b. Parents' Emotion Socialization predicting Emerging Adult Dysfunctional Emotion Regulation, Controlling for Parent-reported Dysfunctional Emotion Regulation and Emerging Adult-reported Closeness with Mother and Father. 


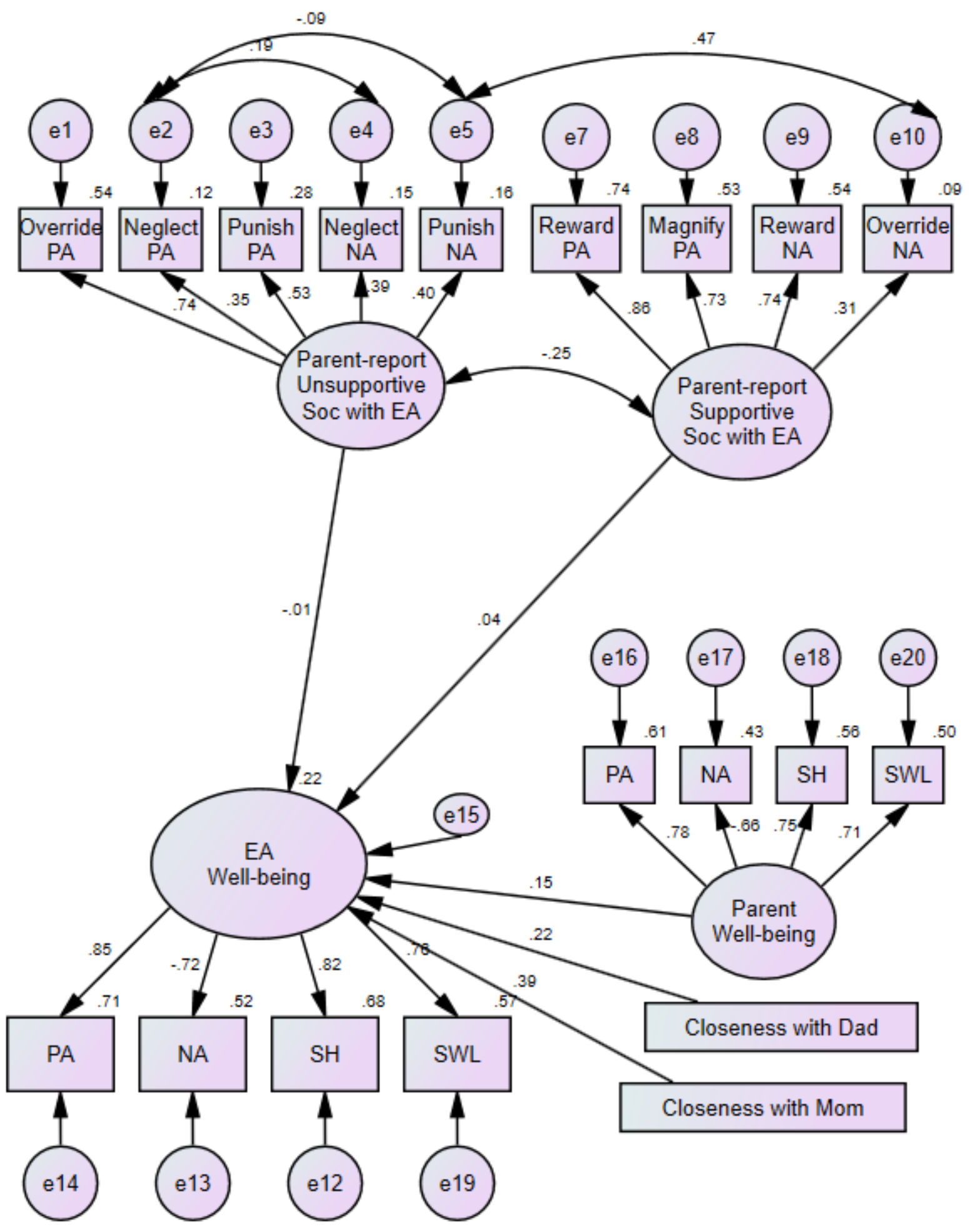

Figure 9. Research Question 2, Hypothesis 2c. Parents' Emotion Socialization predicting Emerging Adult Well-being, Controlling for Parent-reported Well-being and Emerging Adultreported Closeness with Mother and Father. 


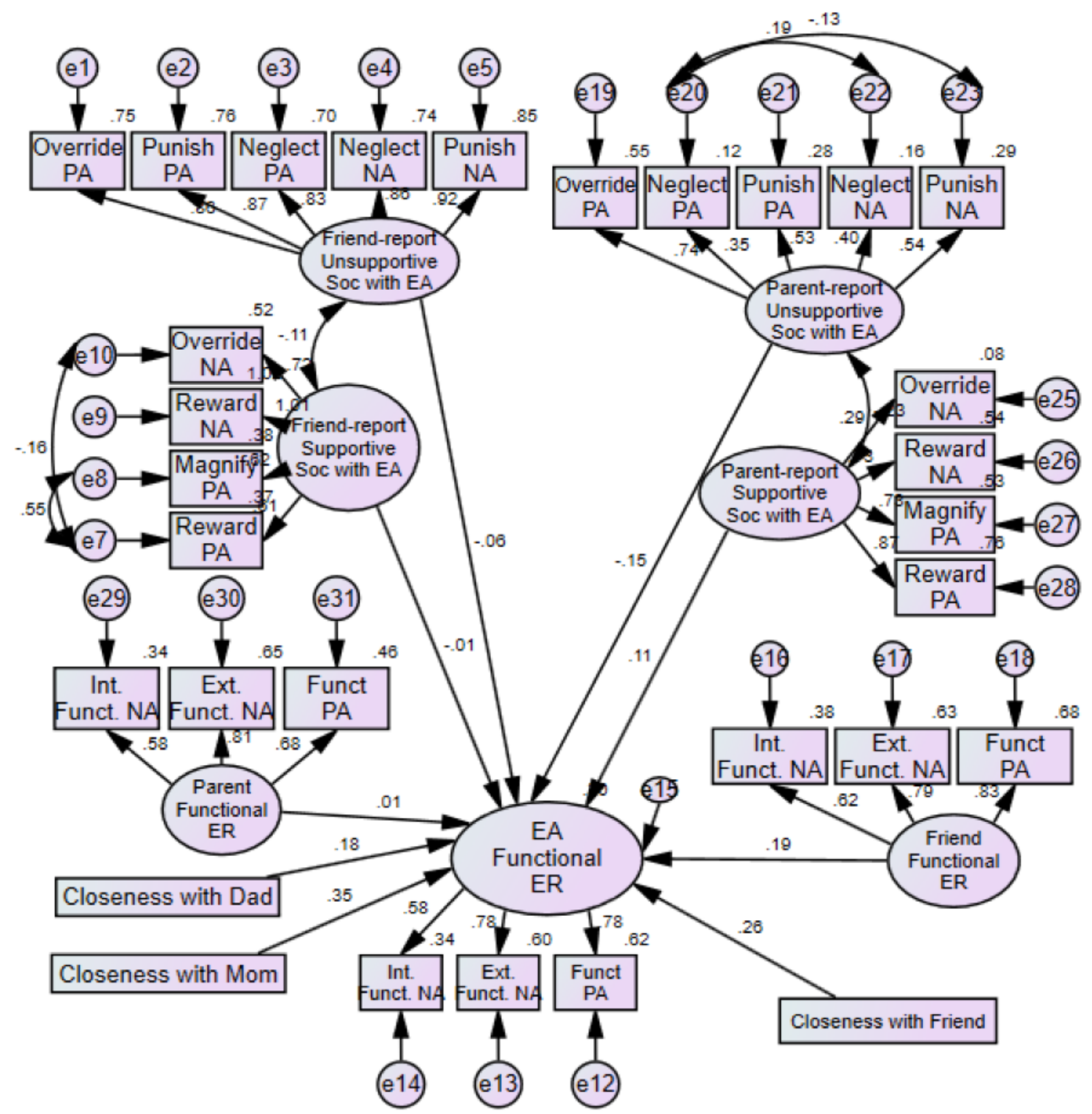

Figure 10. Research Question 3, Hypothesis 3a. Parents' and Friends' Emotion Socialization predicting Emerging Adult Functional Emotion Regulation, Controlling for Parent- and Friendreported Functional Emotion Regulation and Emerging Adult-reported Closeness with Mother, Father, and Friend. 


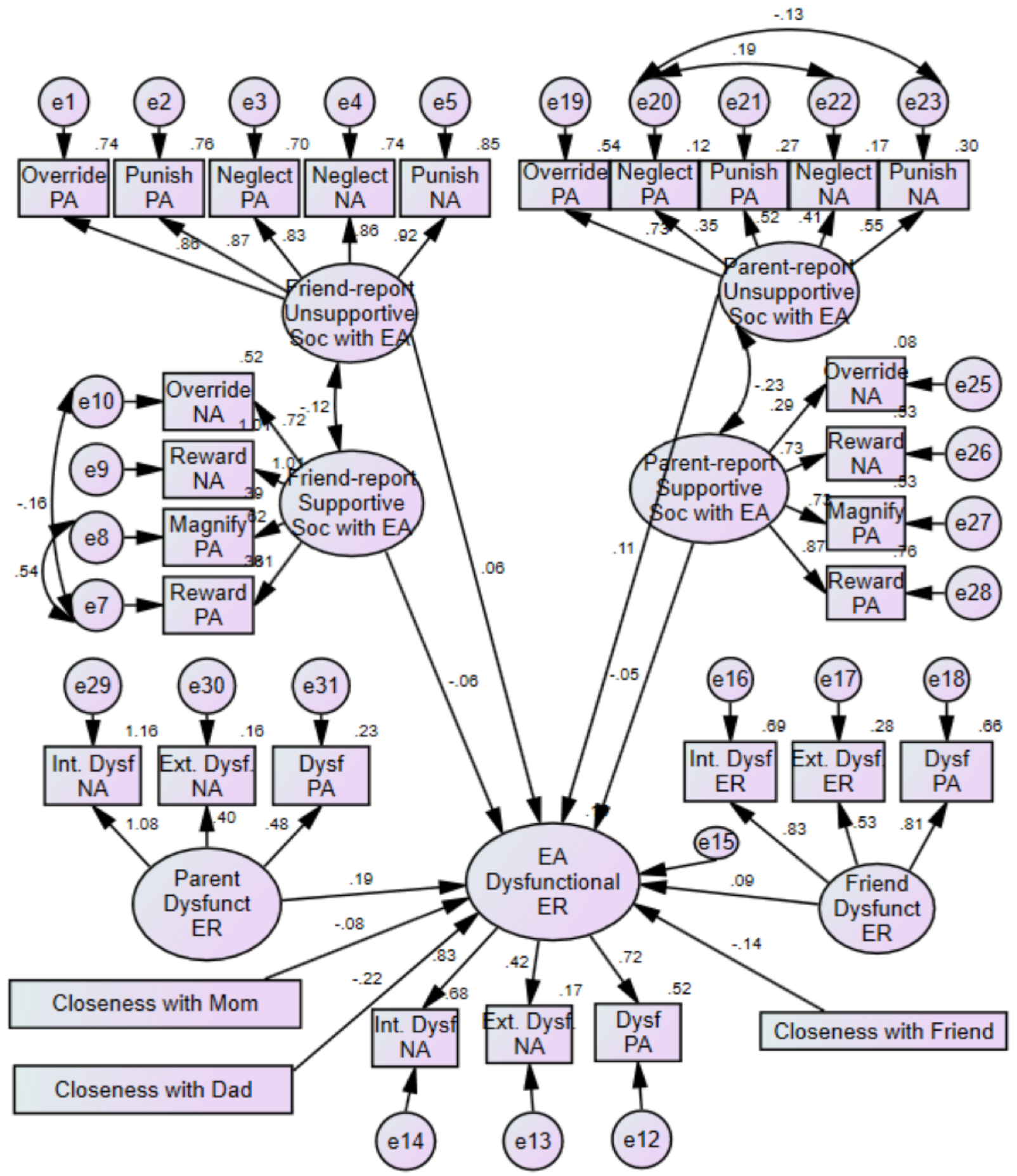

Figure 11. Research Question 3, Hypothesis 3b. Parents' and Friends' Emotion Socialization predicting Emerging Adult Dysfunctional Emotion Regulation, Controlling for Parent- and Friend-reported Dysfunctional Emotion Regulation and Emerging Adult-reported Closeness with Mother, Father, and Friend. 


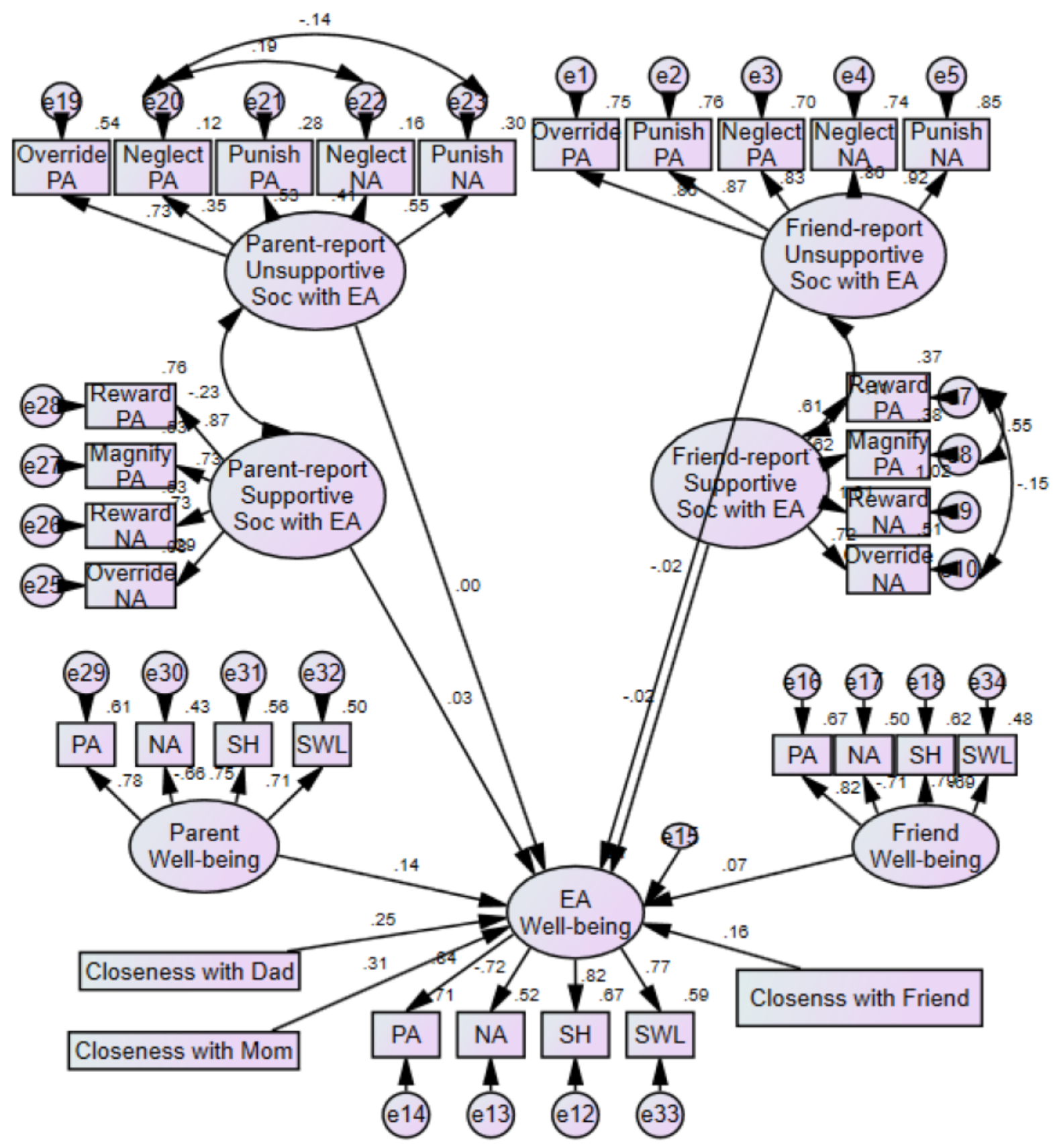

Figure 12. Research Question 3, Hypothesis 3c. Parents' and Friends' Emotion Socialization predicting Emerging Adult Well-being, Controlling for Parent- and Friend-reported Well-being and Emerging Adult-reported Closeness with Mother, Father, and Friend. 


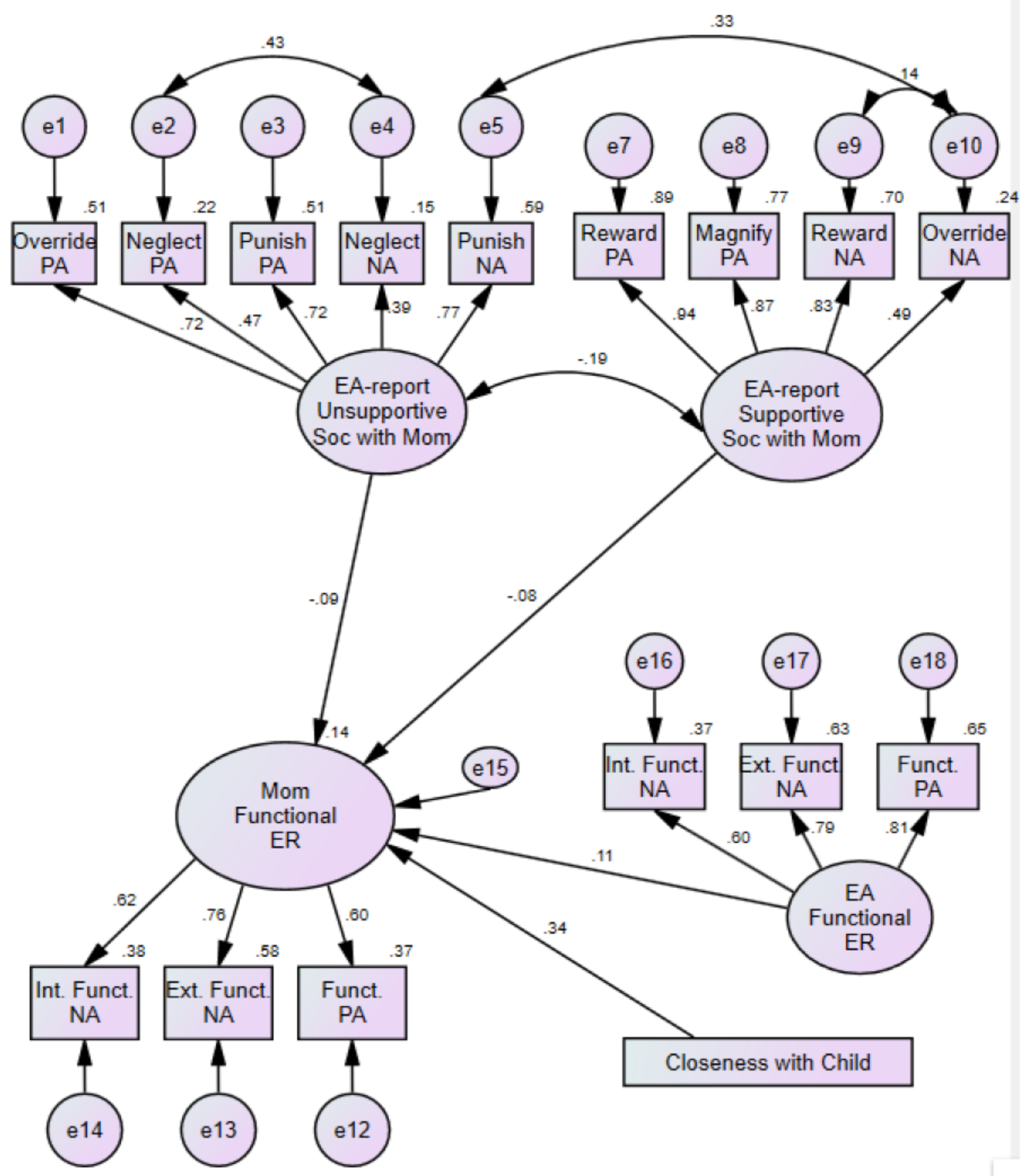

Figure 13. Research Question 4, Hypothesis 4a with Mothers. Emerging Adults' Emotion Socialization of their Mothers predicting Mothers' Functional Emotion Regulation, Controlling for Emerging Adult-reported Functional Emotion Regulation and Mother-reported Closeness with their Emerging Adult Child. 


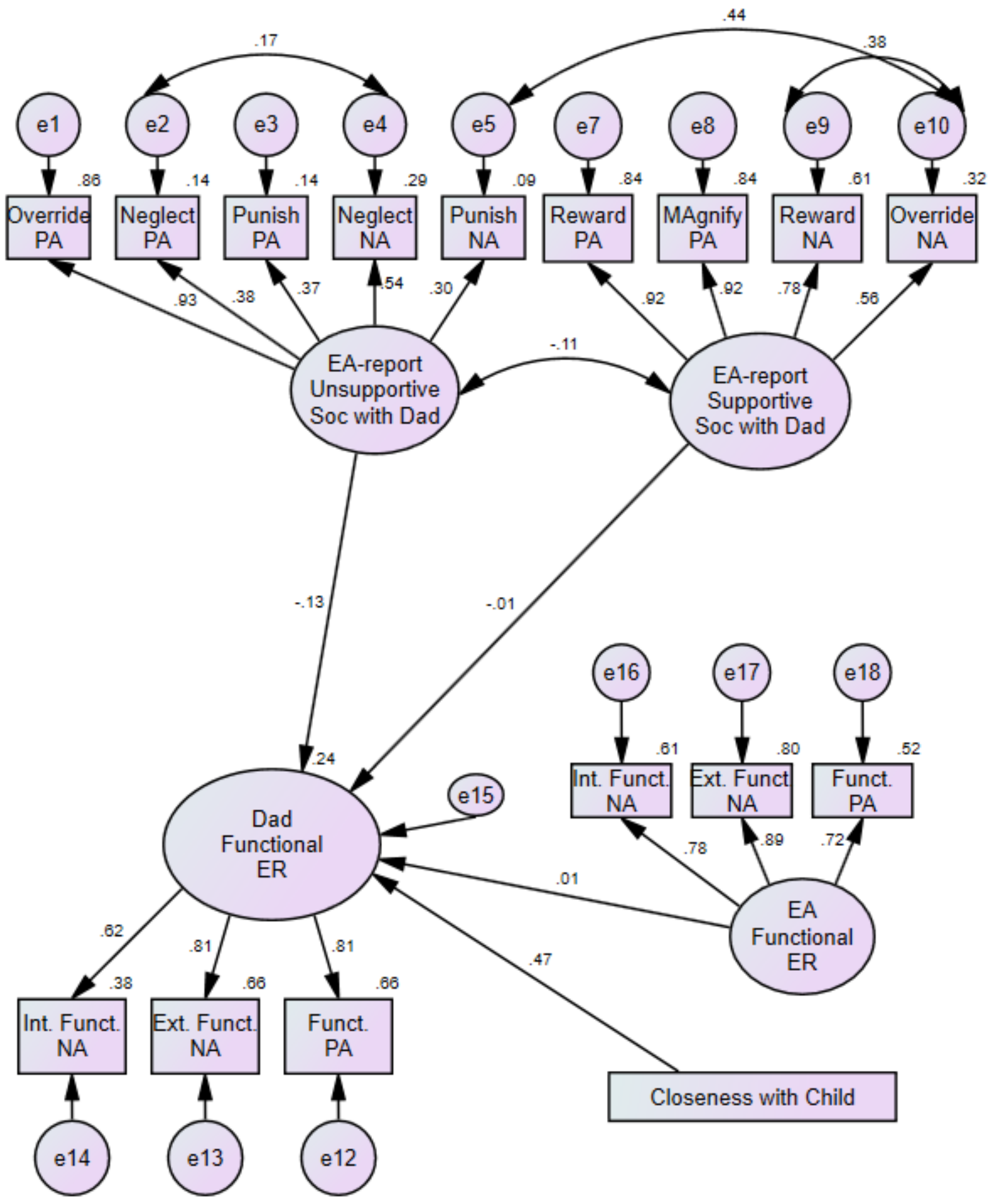

Figure 14. Research Question 4, Hypothesis 4a with Fathers. Emerging Adults' Emotion Socialization of their Fathers predicting Fathers' Functional Emotion Regulation, Controlling for Emerging Adult-reported Functional Emotion Regulation and Father-reported Closeness with their Emerging Adult Child. 


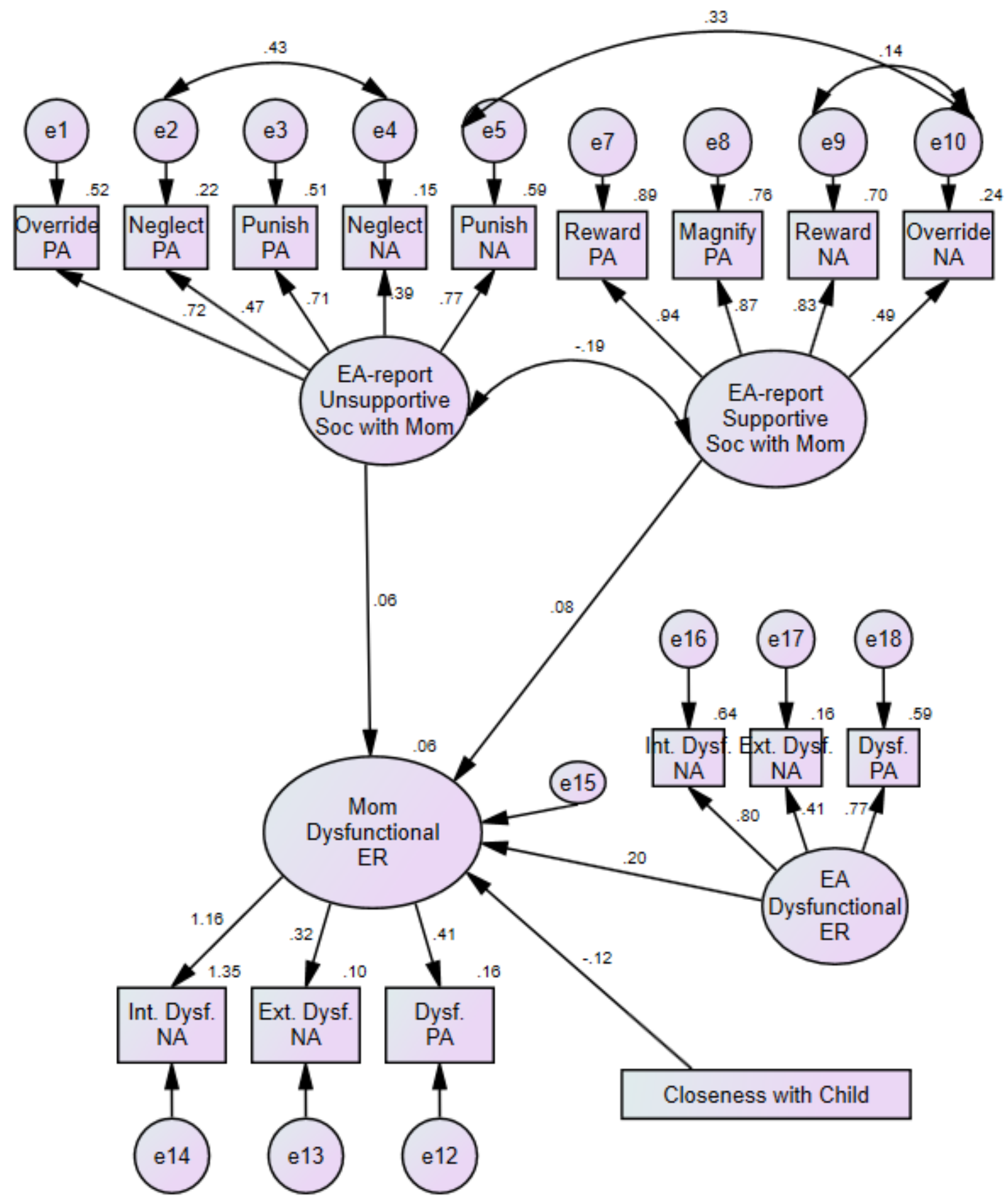

Figure 15. Research Question 4, Hypothesis 4b with Mothers. Emerging Adults' Emotion Socialization of their Mothers predicting Mothers' Dysfunctional Emotion Regulation, Controlling for Emerging Adult-reported Dysfunctional Emotion Regulation and Motherreported Closeness with their Emerging Adult Child. 


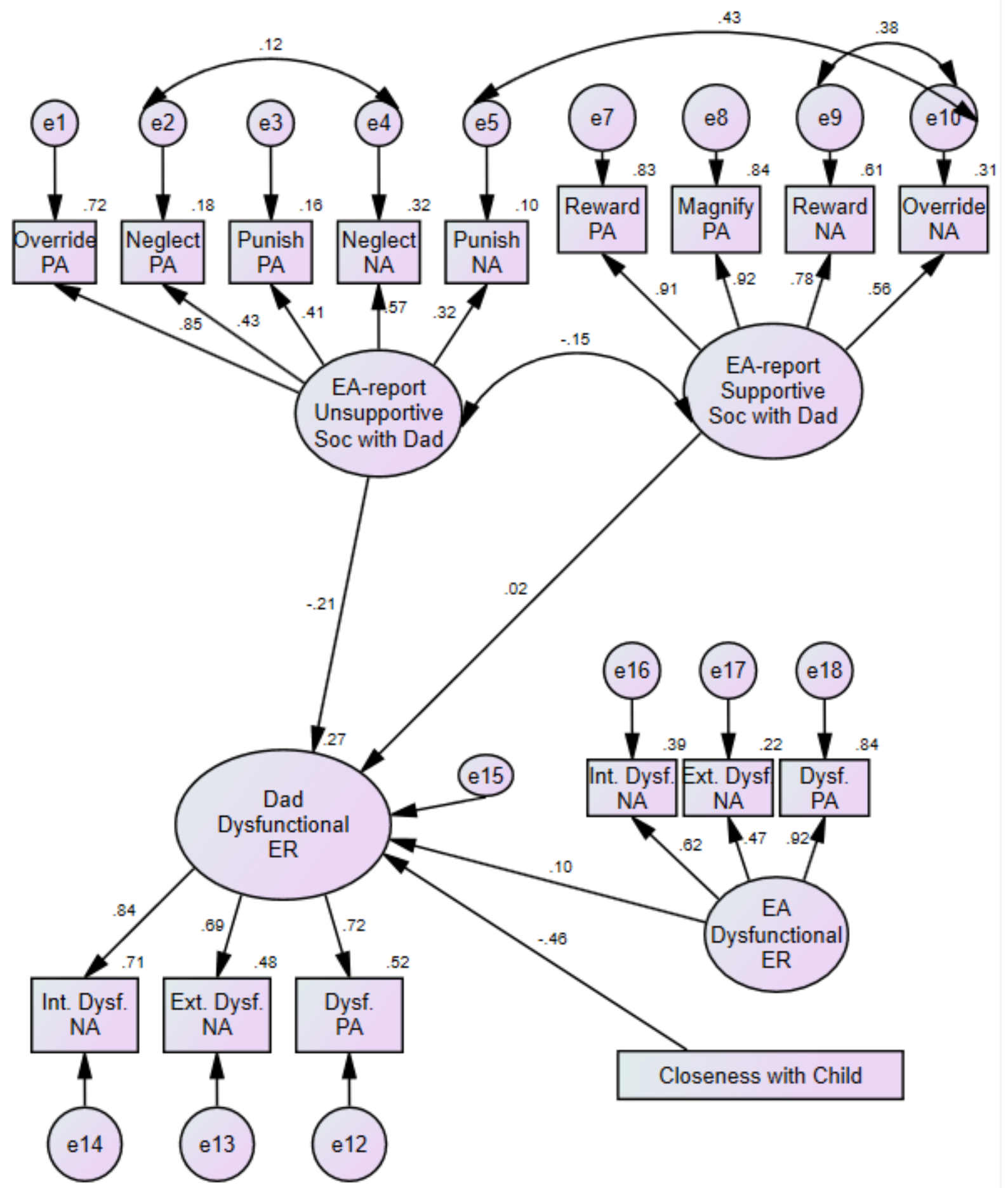

Figure 16. Research Question 4, Hypothesis 4b with Fathers. Emerging Adults' Emotion Socialization of their Fathers predicting Fathers' Dysfunctional Emotion Regulation, Controlling for Emerging Adult-reported Dysfunctional Emotion Regulation and Father-reported Closeness with their Emerging Adult Child. 


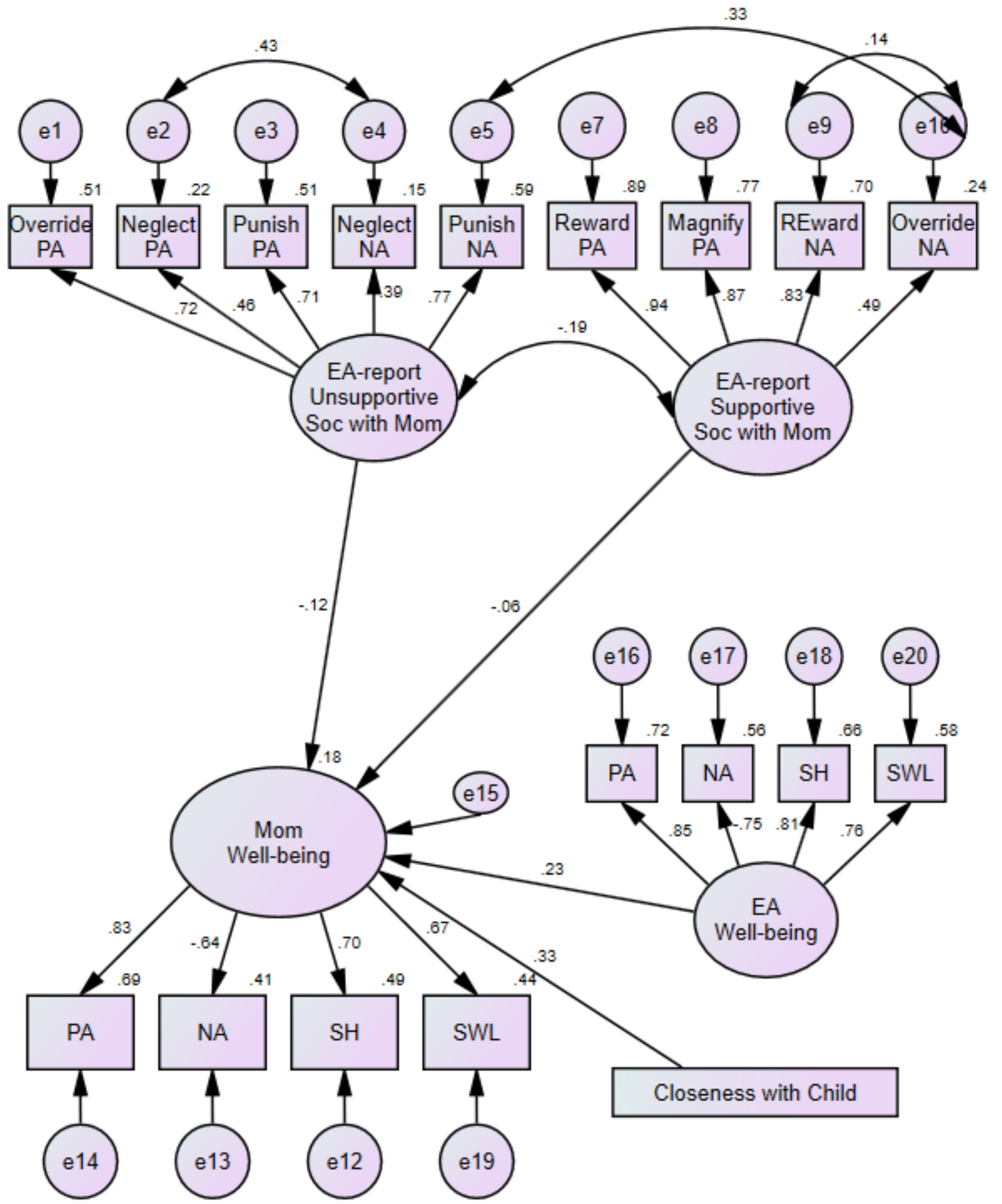

Figure 17. Research Question 4, Hypothesis 4c with Mothers. Emerging Adults' Emotion Socialization of their Mothers predicting Mothers' Well-being, Controlling for Emerging Adultreported Well-being and Mother-reported Closeness with their Emerging Adult Child. 


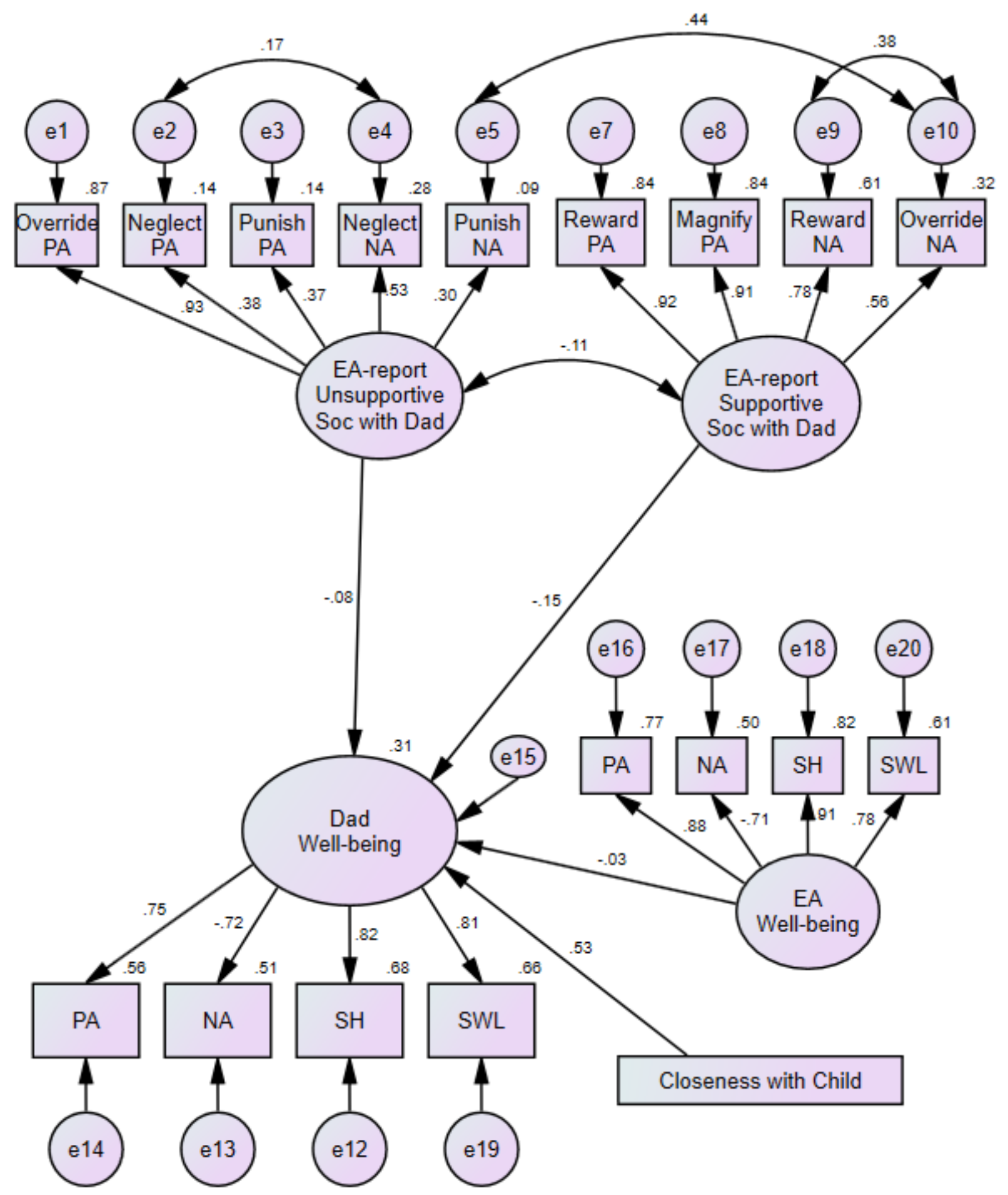

Figure 18. Research Question 4, Hypothesis 4c with Fathers. Emerging Adults' Emotion Socialization of their Fathers predicting Fathers' Well-being, Controlling for Emerging Adultreported Well-being and Father-reported Closeness with their Emerging Adult Child. 


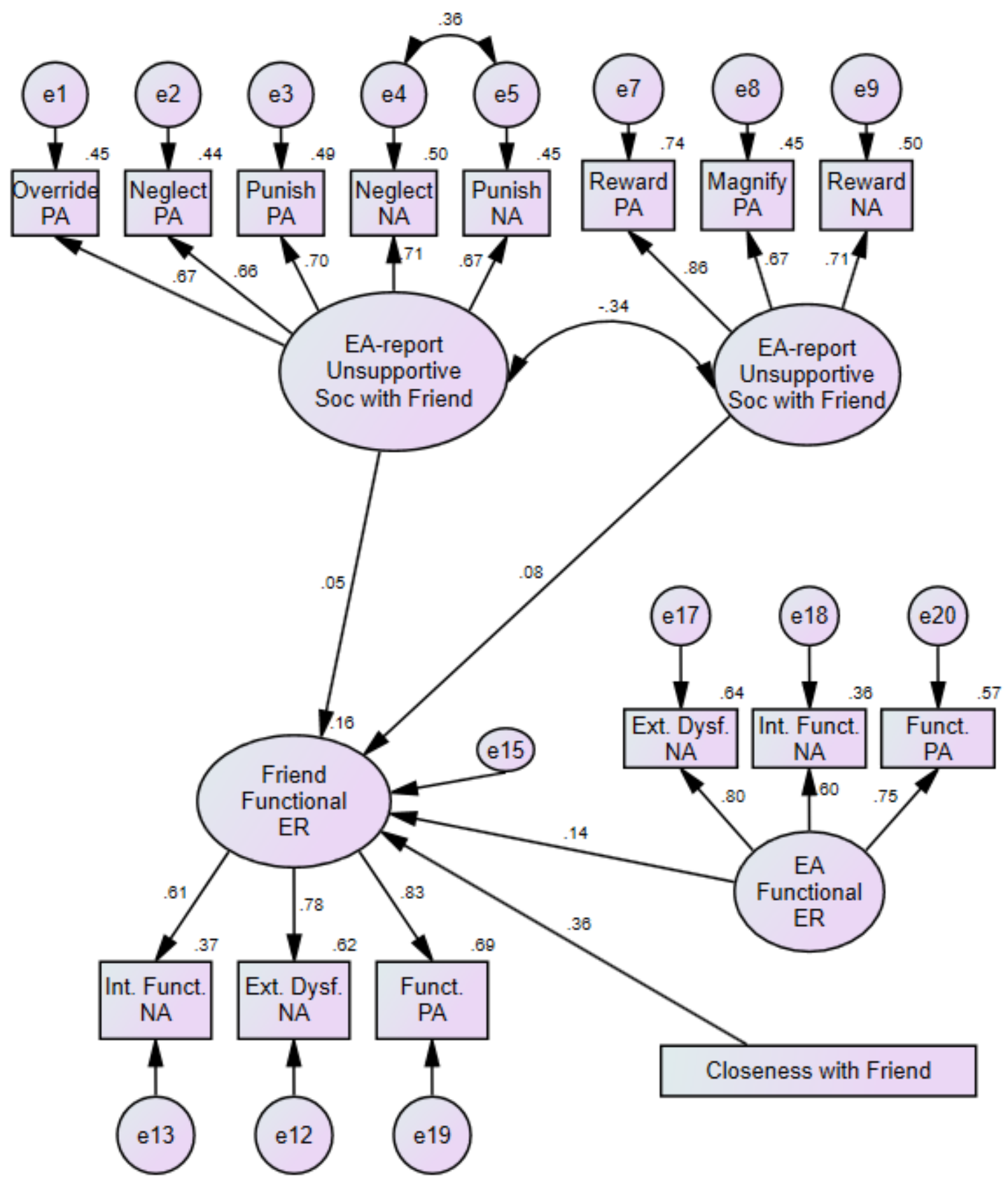

Figure 19. Research Question 5, Hypothesis 5a. Emerging Adults' Emotion Socialization of their Friends predicting Friends' Functional Emotion Regulation, Controlling for Emerging Adultreported Functional Emotion Regulation and Friend-reported Closeness with their Emerging Adult Friend. 


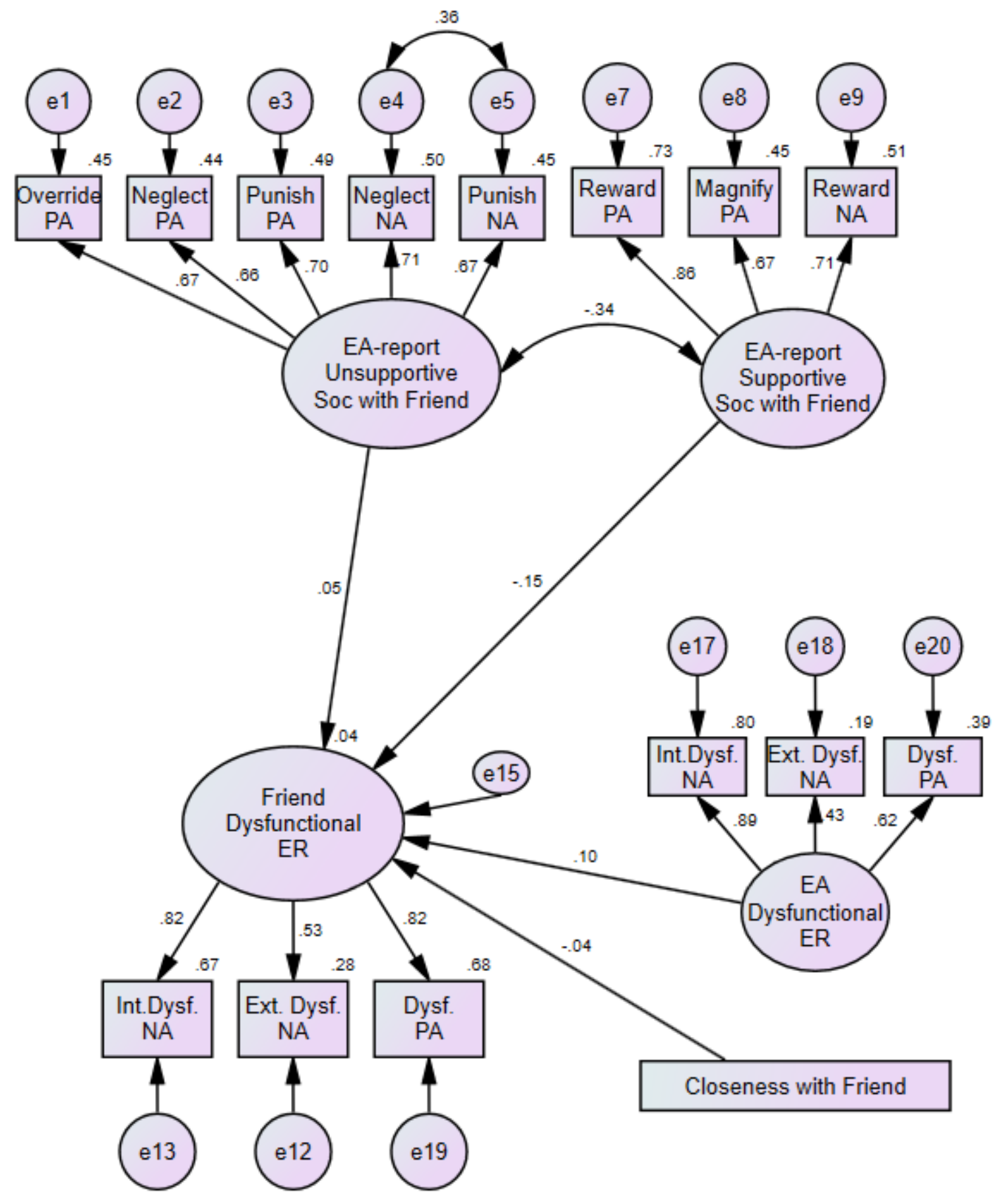




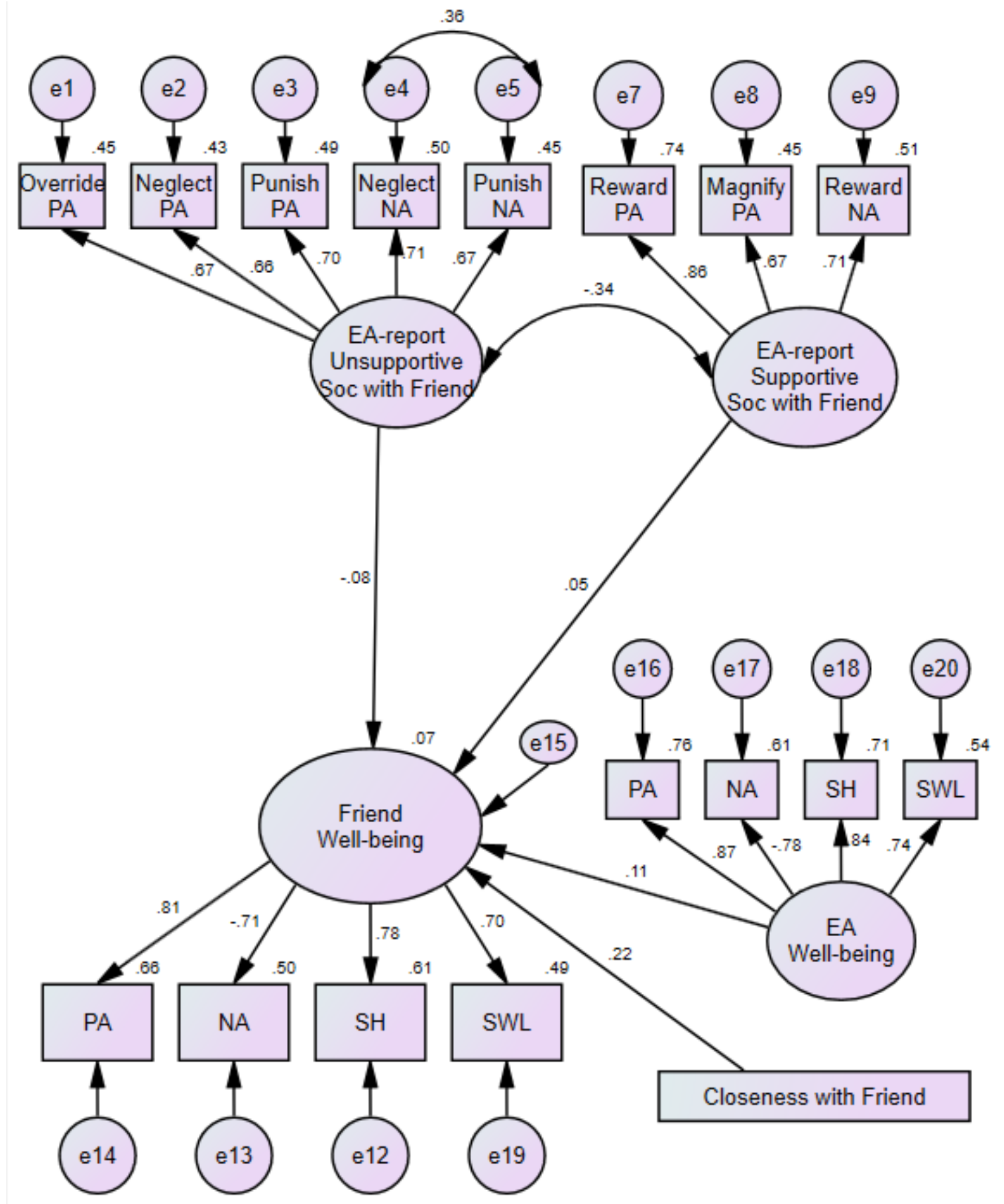

Figure 20. Research Question 5, Hypothesis 5b. Emerging Adults' Emotion Socialization of their Friends predicting Friends' Dysfunctional Emotion Regulation, Controlling for Emerging Adult-reported Dysfunctional Emotion Regulation and Friend-reported Closeness with their Emerging Adult Friend. 


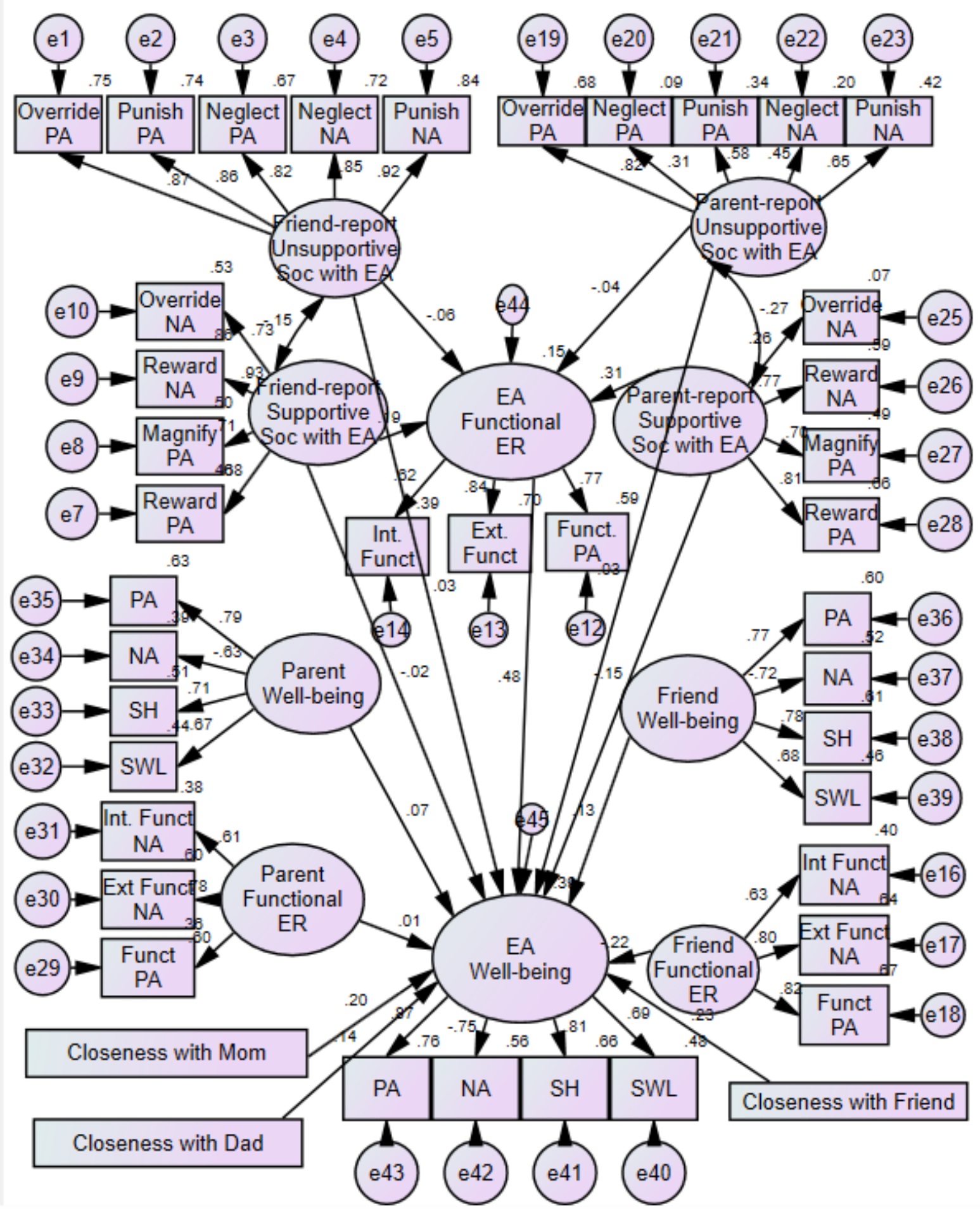

Figure 21. Research Question 6. Parents' and Friends' Emotion Socialization predicting Emerging Adults' Well-being through Emerging Adults' Functional Emotion Regulation, Controlling for Parent- and Friend-reported Well-being and Emerging Adult-reported Closeness with their Mother, Father, and Friend. 


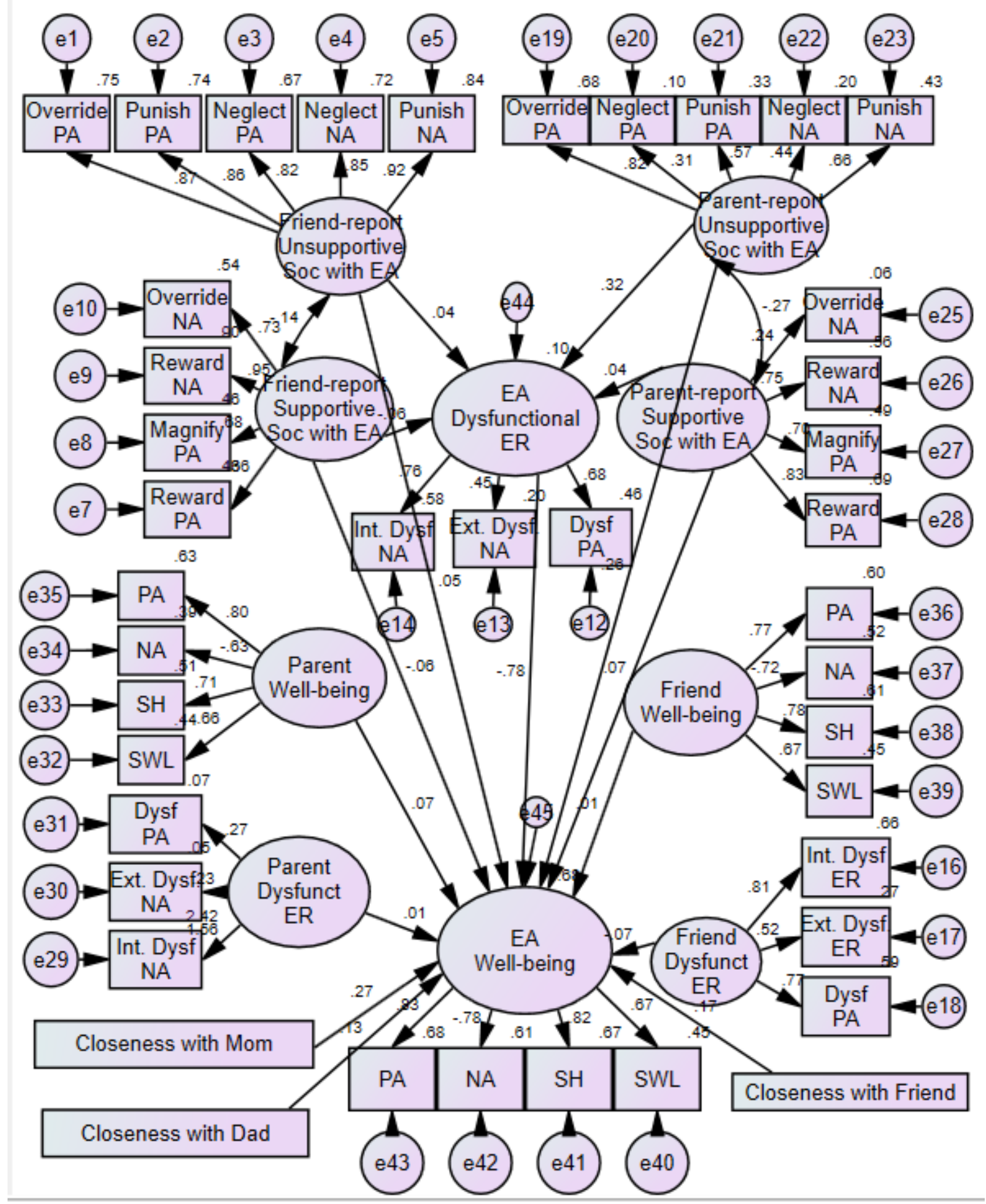

Figure 22. Research Question 6. Parents' and Friends' Emotion Socialization predicting Emerging Adults' Well-being through Emerging Adults' Dysfunctional Emotion Regulation, Controlling for Parent- and Friend-reported Well-being and Emerging Adult-reported Closeness with their Mother, Father, and Friend. 
Appendices 
Appendix A

Emerging Adult-report Measures

\section{Demographics}

What is your age in years?
- 18
○ 19
○ 20
○ 21
○ 22
○ 23
○ 24
○ 25

What is your gender?
o Male
- Female
- Nonbinary

What is your ethnicity? (choose all that apply)
$\circ$ White/European
American
○ Black/African American
- Asian/Asian
- Native American or
American
Alaskan Native
○ Hispanic/Latino
- Native Hawaiian or other Pacific Islander

o Other

What is your parents' relationship status?
- Married
○ Separated
○ Divorced
- Together, but not married
- Not together, never married

What is the highest level of education your mother or mother-figured has received?
- Did not attend school
$\bigcirc 8^{\text {th }}$ grade or less
$\circ 9^{\text {th }}-11^{\text {th }}$ grade
- High school graduate
- Some college
○ 2-year college degree or equivalent
○ 4-year college degree
- Some graduate school
- Master's or 2 to 3- year degree
- Completed MD or $\mathrm{PhD}$

What is the highest level of education your father or father-figured has received?
○ Did not attend school
$\circ 8^{\text {th }}$ grade or less
- Some college
○ Some graduate school
○ 4-year college degree
orsome graduate school
- Completed MD or $\mathrm{PhD}$
○ $9^{\text {th }}-11^{\text {th }}$ grade
○ 2-year college degree
- Master's or 2 to 3- year degree


How much difficulty do your parents have paying the bills?
- None/Not at
○ A little
○ Some
$\circ$ A great deal
all

What year in school are you?
$\circ$ First year
- Second year
- Third year
$\circ$ Fourth year
- Fifth year
- Sixth year or more

What is your current living situation?

- I live alone

- I live with my mother or mother-figure only
- I live with a roommate(s)

- I live with my father or father-figure only
- I live with both of my parents

○ Other 


\section{Schedule of Positive and Negative Experiences (SPANE)}

Please think about what you have been doing and experiencing during the past four weeks. Then report how much you experience each of the following feelings, using the scale below. For each item, select a number from 1 to 5 .

\begin{tabular}{|c|c|c|c|c|c|}
\hline & $\begin{array}{l}1 \text { Very Rarely } \\
\text { or Never }\end{array}$ & 2 Rarely & 3 Sometimes & 4 Often & $\begin{array}{c}5 \text { Very Often or } \\
\text { Always }\end{array}$ \\
\hline Positive & $\mathrm{O}$ & $\mathrm{O}$ & 0 & $\mathrm{O}$ & 0 \\
\hline Negative & $\mathrm{O}$ & $\mathrm{O}$ & $\mathrm{O}$ & $\mathrm{O}$ & $\mathrm{O}$ \\
\hline Good & $\mathrm{O}$ & $\mathrm{O}$ & $\mathrm{O}$ & O & $\mathrm{O}$ \\
\hline $\mathrm{Bad}$ & 0 & $\mathrm{O}$ & $\mathrm{O}$ & O & 0 \\
\hline Pleasant & $\mathrm{O}$ & $\mathrm{O}$ & $\mathrm{O}$ & $\mathrm{O}$ & $\mathrm{O}$ \\
\hline Unpleasant & $\mathrm{O}$ & $\mathrm{O}$ & $\mathrm{O}$ & $\mathrm{O}$ & $\mathrm{O}$ \\
\hline Happy & $\mathrm{O}$ & $\mathrm{O}$ & $\mathrm{O}$ & $\mathrm{O}$ & $\mathrm{O}$ \\
\hline $\mathrm{Sad}$ & $\mathrm{O}$ & $\mathrm{O}$ & $\mathrm{O}$ & $\mathrm{O}$ & $\mathrm{O}$ \\
\hline Afraid & $\mathrm{O}$ & $\mathrm{O}$ & $\mathrm{O}$ & $\mathrm{O}$ & $\mathrm{O}$ \\
\hline Joyful & $\mathrm{O}$ & 0 & $\mathrm{O}$ & $\mathrm{O}$ & $\mathrm{O}$ \\
\hline Angry & $\mathrm{O}$ & 0 & 0 & O & $\mathrm{O}$ \\
\hline Contented & $\mathrm{O}$ & 0 & 0 & 0 & $\mathrm{O}$ \\
\hline
\end{tabular}




\section{Subjective Happiness Scale (SHS)}

For each of the following statements and/or questions, please select the point on the scale that you feel is most appropriate in describing you.

\begin{tabular}{|c|c|c|c|c|c|c|c|}
\hline & $\begin{array}{c}1 \text { not a } \\
\text { very } \\
\text { happy } \\
\text { person }\end{array}$ & 2 & 3 & 4 & 5 & 6 & $\begin{array}{c}7 \text { a very } \\
\text { happy } \\
\text { person }\end{array}$ \\
\hline $\begin{array}{c}\text { In general, I } \\
\text { consider myself: }\end{array}$ & 0 & 0 & 0 & 0 & 0 & 0 & $\bigcirc$ \\
\hline
\end{tabular}

\begin{tabular}{|c|c|c|c|c|c|c|c|}
\hline & $\begin{array}{c}1 \text { less } \\
\text { happy }\end{array}$ & 2 & 3 & 4 & 5 & 6 & $\begin{array}{c}7 \text { more } \\
\text { happy }\end{array}$ \\
\hline $\begin{array}{c}\text { Compared to most } \\
\text { of my peers, I } \\
\text { consider myself: }\end{array}$ & 0 & 0 & 0 & $\bigcirc$ & 0 & $\bigcirc$ & $\bigcirc$ \\
\hline
\end{tabular}

\begin{tabular}{|c|c|c|c|c|c|c|c|}
\hline & $\begin{array}{c}1 \text { not at } \\
\text { all }\end{array}$ & 2 & 3 & 4 & 5 & 6 & $\begin{array}{c}7 \text { a great } \\
\text { deal }\end{array}$ \\
\hline $\begin{array}{c}\text { Some people are } \\
\text { generally very } \\
\text { happy. They enjoy } \\
\text { life regardless of } \\
\text { what is going on, } \\
\text { getting the most out } \\
\text { of everything. To } \\
\text { what extent does } \\
\text { this characterization } \\
\text { describe you? }\end{array}$ & 0 & 0 & 0 & 0 & 0 & 0 & 0 \\
\hline $\begin{array}{c}\text { Some people are } \\
\text { generally not very } \\
\text { happy. Although } \\
\text { they are not } \\
\text { depressed, they } \\
\text { never seem as } \\
\text { happy as they might } \\
\text { be. To what extent } \\
\text { does this } \\
\text { characterization } \\
\text { describe you? }\end{array}$ & 0 & 0 & 0 & 0 & 0 & 0 & \\
\hline
\end{tabular}




\section{Satisfaction with Life Scale (SWLS)}

Below are five statements that you may agree or disagree with. Using the 1-7 scale below, indicate your agreement with each item by selecting the option by that item. Please be open and honest in your responding.

\begin{tabular}{|c|c|c|c|c|c|c|c|}
\hline & $\begin{array}{c}1 \text { Strongly } \\
\text { disagree }\end{array}$ & $\begin{array}{c}2 \\
\text { Disagree }\end{array}$ & $\begin{array}{l}3 \text { Slightly } \\
\text { disagree }\end{array}$ & $\begin{array}{l}4 \text { Neither } \\
\text { agree nor } \\
\text { disagree }\end{array}$ & $\begin{array}{l}5 \text { Slightly } \\
\text { agree }\end{array}$ & 6 Agree & $\begin{array}{l}7 \text { Strongly } \\
\text { agree }\end{array}$ \\
\hline $\begin{array}{l}\text { In most ways, my } \\
\text { life is close to my } \\
\text { ideal. }\end{array}$ & 0 & 0 & 0 & 0 & 0 & 0 & 0 \\
\hline $\begin{array}{l}\text { The conditions of } \\
\text { my life are } \\
\text { excellent. }\end{array}$ & 0 & 0 & 0 & 0 & O & O & 0 \\
\hline $\begin{array}{l}\text { I am satisfied with } \\
\text { my life. }\end{array}$ & 0 & 0 & O & O & O & 0 & 0 \\
\hline $\begin{array}{l}\text { So far, I have } \\
\text { gotten the } \\
\text { important things I } \\
\text { want in life. }\end{array}$ & O & 0 & 0 & O & O & 0 & 0 \\
\hline $\begin{array}{l}\text { If I could live my } \\
\text { life over, I would } \\
\text { change almost } \\
\text { nothing. }\end{array}$ & 0 & 0 & 0 & 0 & O & 0 & 0 \\
\hline
\end{tabular}


Closeness with Mother, Father, and Friend

**Questions are the same for father and friend relationship quality.

The following questions are about your relationship with your mother/mother-figure. Please answer them as honestly as possible.

\begin{tabular}{|c|c|c|c|c|c|}
\hline & 1 Not at all & 2 & 3 & 4 & 5 Very \\
\hline $\begin{array}{l}\text { How openly do you talk } \\
\text { with your mother? }\end{array}$ & O & O & O & O & $O$ \\
\hline $\begin{array}{l}\text { How careful do you feel } \\
\text { you have to be about what } \\
\text { you say to your mother? }\end{array}$ & O & O & O & O & $O$ \\
\hline $\begin{array}{l}\text { How comfortable do you } \\
\text { feel admitting doubts and } \\
\text { fears to your mother? }\end{array}$ & O & 0 & 0 & 0 & O \\
\hline $\begin{array}{l}\text { How interested in talking to } \\
\text { you is your mother when } \\
\text { you want to talk? }\end{array}$ & O & O & O & O & 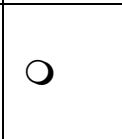 \\
\hline $\begin{array}{l}\text { How often does your } \\
\text { mother express affection, or } \\
\text { liking you? }\end{array}$ & O & O & O & O & 0 \\
\hline $\begin{array}{l}\text { How well does your mother } \\
\text { know what you are really } \\
\text { like? }\end{array}$ & O & O & O & O & O \\
\hline $\begin{array}{l}\text { How close do you feel to } \\
\text { your mother? }\end{array}$ & O & O & O & O & 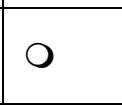 \\
\hline $\begin{array}{l}\text { How confident are you that } \\
\text { your mother would help if } \\
\text { you had a problem? }\end{array}$ & 0 & 0 & 0 & 0 & O \\
\hline $\begin{array}{l}\text { If you needed money, how } \\
\text { comfortable would you be } \\
\text { asking your mother for it? }\end{array}$ & 0 & 0 & 0 & 0 & O \\
\hline $\begin{array}{l}\text { How interested is your } \\
\text { mother in the things you } \\
\text { do? }\end{array}$ & 0 & O & O & O & O \\
\hline
\end{tabular}




\section{Positive Affect and Responses Survey (PAARS)}

When you are feeling really GOOD, and HAPPY, how likely are you to do any of the following things?

\begin{tabular}{|c|c|c|c|c|c|}
\hline & $\begin{array}{l}1 \text { Not at all } \\
\text { likely }\end{array}$ & 2 & $\begin{array}{l}3 \text { Somewhat } \\
\text { likely }\end{array}$ & 4 & 5 Very likely \\
\hline $\begin{array}{l}\text { Not think about your good } \\
\text { feelings much }\end{array}$ & $\mathrm{O}$ & $\mathrm{O}$ & O & $\mathrm{O}$ & O \\
\hline $\begin{array}{l}\text { Become physically } \\
\text { affectionate (e.g., hug } \\
\text { someone) }\end{array}$ & O & $\mathrm{O}$ & O & $\mathrm{O}$ & $\mathrm{O}$ \\
\hline $\begin{array}{l}\text { Think, "My streak of luck is } \\
\text { going to end soon." }\end{array}$ & $\mathrm{O}$ & $\mathrm{O}$ & $\mathrm{O}$ & $\mathrm{O}$ & $\mathrm{O}$ \\
\hline $\begin{array}{l}\text { Tell a lot of people at once } \\
\text { how good you feel (e.g., post } \\
\text { online, mass text) }\end{array}$ & $\mathrm{O}$ & O & O & $\mathrm{O}$ & O \\
\hline $\begin{array}{c}\text { Decide that your good } \\
\text { feelings are not important }\end{array}$ & $\mathrm{O}$ & $\mathrm{O}$ & $\mathrm{O}$ & O & $\mathrm{O}$ \\
\hline $\begin{array}{l}\text { Tell a close friend of family } \\
\text { member how happy you are }\end{array}$ & $\mathrm{O}$ & $\mathrm{O}$ & $\mathrm{O}$ & $\mathrm{O}$ & $\mathrm{O}$ \\
\hline $\begin{array}{l}\text { Think about how things could } \\
\text { go wrong }\end{array}$ & $\mathrm{O}$ & $\mathrm{O}$ & O & $\mathrm{O}$ & $\mathrm{O}$ \\
\hline $\begin{array}{l}\text { Really try to enjoy the good } \\
\text { feelings and absorb the } \\
\text { moment }\end{array}$ & $\mathrm{O}$ & $\mathrm{O}$ & $\mathrm{O}$ & $\mathrm{O}$ & $\mathrm{O}$ \\
\hline Think, "I don't deserve this." & $\mathrm{O}$ & $\mathrm{O}$ & $\mathrm{O}$ & $\mathrm{O}$ & $\mathrm{O}$ \\
\hline $\begin{array}{c}\text { Think about how good you } \\
\text { feel }\end{array}$ & $\mathrm{O}$ & $\mathrm{O}$ & $\mathrm{O}$ & $\mathrm{O}$ & $\mathrm{O}$ \\
\hline $\begin{array}{l}\text { Think about how lucky you } \\
\text { are compared to other people }\end{array}$ & $\mathrm{O}$ & $\mathrm{O}$ & $\mathrm{O}$ & $\mathrm{O}$ & $\mathrm{O}$ \\
\hline $\begin{array}{l}\text { Think about things that have } \\
\text { not gone well for you }\end{array}$ & $\mathrm{O}$ & $\mathrm{O}$ & $\mathrm{O}$ & O & $\mathrm{O}$ \\
\hline $\begin{array}{c}\text { Express your emotions in } \\
\text { some way (e.g., smile, laugh) }\end{array}$ & $\mathrm{O}$ & $\mathrm{O}$ & $\mathrm{O}$ & O & O \\
\hline $\begin{array}{c}\text { Tell a person who seems sad } \\
\text { or upset how good you are } \\
\text { feeling }\end{array}$ & O & $\mathrm{O}$ & $\mathrm{O}$ & $\mathrm{O}$ & O \\
\hline $\begin{array}{l}\text { Remind yourself these } \\
\text { feelings won't last }\end{array}$ & $\mathrm{O}$ & $\mathrm{O}$ & $\mathrm{O}$ & $\mathrm{O}$ & $\mathrm{O}$ \\
\hline $\begin{array}{l}\text { Be careful not to show people } \\
\text { how happy you feel }\end{array}$ & $\mathrm{O}$ & $\mathrm{O}$ & $\mathrm{O}$ & $\mathrm{O}$ & $\mathrm{O}$ \\
\hline Not notice that you are happy & $\mathrm{O}$ & $\mathrm{O}$ & $\mathrm{O}$ & $\mathrm{O}$ & $\mathrm{O}$ \\
\hline $\begin{array}{l}\text { Reflect on your good } \\
\text { qualities }\end{array}$ & $\mathrm{O}$ & $\mathrm{O}$ & O & $\mathrm{O}$ & $\mathrm{O}$ \\
\hline
\end{tabular}




\begin{tabular}{|c|c|c|c|c|c|}
\hline $\begin{array}{c}\text { Think, "This is too good to be } \\
\text { true." }\end{array}$ & $\mathrm{O}$ & $\mathrm{O}$ & $\mathrm{O}$ & $\mathrm{O}$ & $\mathrm{O}$ \\
\hline Celebrate your good feelings & $\mathrm{O}$ & $\mathrm{O}$ & $\mathrm{O}$ & $\mathrm{O}$ & $\mathrm{O}$ \\
\hline $\begin{array}{c}\text { Think about how hard it is to } \\
\text { concentrate }\end{array}$ & $\mathrm{O}$ & $\mathrm{O}$ & $\mathrm{O}$ & $\mathrm{O}$ & $\mathrm{O}$ \\
\hline $\begin{array}{l}\text { Mark your feelings in some } \\
\text { way (e.g., take a picture, } \\
\text { write about them) }\end{array}$ & $\mathrm{O}$ & $\mathrm{O}$ & $\mathrm{O}$ & $\mathrm{O}$ & O \\
\hline Be thankful & $\mathrm{O}$ & $\mathrm{O}$ & $\mathrm{O}$ & $\mathrm{O}$ & $\mathrm{O}$ \\
\hline $\begin{array}{l}\text { Think, "People will think I'm } \\
\text { bragging." }\end{array}$ & $\mathrm{O}$ & $\mathrm{O}$ & $\mathrm{O}$ & $\mathrm{O}$ & $\mathrm{O}$ \\
\hline $\begin{array}{c}\text { Think about your good } \\
\text { qualities and characteristics }\end{array}$ & $\mathrm{O}$ & $\mathrm{O}$ & O & $\mathrm{O}$ & O \\
\hline
\end{tabular}




\section{Regulation of Emotions Questionnaire (REQ)}

The following questions ask you to think about how often you do certain things in response to your emotions. You do not have to think about specific negative emotions but just how often you generally do the things listed below when you feel badly. Please select the answer that fits best. We all respond to our emotions in different ways so there are no right or wrong answers.

\begin{tabular}{|c|c|c|c|c|c|}
\hline & 1 Never & 2 Seldom & 3 Often & 4 Very Often & 5 Always \\
\hline $\begin{array}{l}\text { I talk to someone about how I } \\
\text { feel }\end{array}$ & O & O & $\mathrm{O}$ & $\mathrm{O}$ & $\mathrm{O}$ \\
\hline $\begin{array}{l}\text { I take my feelings out on others } \\
\text { verbally (e.g., shouting, } \\
\text { arguing) }\end{array}$ & O & O & $\mathrm{O}$ & $\mathrm{O}$ & O \\
\hline $\begin{array}{c}\text { I seek physical contact from } \\
\text { friends or family (e.g., a hug, } \\
\text { hold hands) }\end{array}$ & $\mathrm{O}$ & $\mathrm{O}$ & $\mathrm{O}$ & $\mathrm{O}$ & $\mathrm{O}$ \\
\hline $\begin{array}{l}\text { I review (rethink) my thoughts } \\
\text { or beliefs }\end{array}$ & $\mathrm{O}$ & $\mathrm{O}$ & $\mathrm{O}$ & $\mathrm{O}$ & O \\
\hline $\begin{array}{l}\text { I harm or punish myself in } \\
\text { some way }\end{array}$ & $\mathrm{O}$ & $\mathrm{O}$ & $\mathrm{O}$ & $\mathrm{O}$ & O \\
\hline $\begin{array}{l}\text { I do something energetic (e.g., } \\
\text { play sport, go for a walk) }\end{array}$ & O & $\mathrm{O}$ & $\mathrm{O}$ & $\mathrm{O}$ & O \\
\hline $\begin{array}{l}\text { I dwell on my thoughts and } \\
\text { feelings (e.g., it goes around } \\
\text { and around in my head and I } \\
\text { can't stop it) }\end{array}$ & O & $\mathrm{O}$ & O & O & O \\
\hline I ask others for advice & $\mathrm{O}$ & $\mathrm{O}$ & $\mathrm{O}$ & $\mathrm{O}$ & $\mathrm{O}$ \\
\hline $\begin{array}{l}\text { I review (rethink) my goals or } \\
\text { plans }\end{array}$ & O & O & 0 & $\mathrm{O}$ & O \\
\hline $\begin{array}{c}\text { I take my feelings out on others } \\
\text { physically (e.g., fighting, } \\
\text { lashing out) }\end{array}$ & $\mathrm{O}$ & $\mathrm{O}$ & $\mathrm{O}$ & $\mathrm{O}$ & O \\
\hline $\begin{array}{l}\text { I put the situation into } \\
\text { perspective }\end{array}$ & O & $\mathrm{O}$ & $\mathrm{O}$ & O & O \\
\hline $\begin{array}{l}\text { I concentrate on a pleasant } \\
\text { activity }\end{array}$ & $\mathrm{O}$ & $\mathrm{O}$ & O & O & O \\
\hline $\begin{array}{l}\text { I try to make others feel bad } \\
\text { (e.g., being rude, ignoring } \\
\text { them) }\end{array}$ & $\mathrm{O}$ & $\mathrm{O}$ & $\mathrm{O}$ & $\mathrm{O}$ & O \\
\hline $\begin{array}{l}\text { I think about people better off } \\
\text { and make myself feel worse }\end{array}$ & O & O & $\mathrm{O}$ & O & O \\
\hline $\begin{array}{l}\text { I keep the feeling locked up } \\
\text { inside }\end{array}$ & $\mathrm{O}$ & $\mathrm{O}$ & $\mathrm{O}$ & $\mathrm{O}$ & $\mathrm{O}$ \\
\hline
\end{tabular}




\begin{tabular}{|c|c|c|c|c|c|}
\hline $\begin{array}{c}\text { I plan what I could do better } \\
\text { next time }\end{array}$ & O & $\mathrm{O}$ & $\mathrm{O}$ & $\mathrm{O}$ & O \\
\hline $\begin{array}{l}\text { I bully other people (e.g., } \\
\text { saying nasty thinks to them, } \\
\text { hitting them) }\end{array}$ & $\mathrm{O}$ & $\mathrm{O}$ & $\mathrm{O}$ & $\mathrm{O}$ & O \\
\hline $\begin{array}{l}\text { I take my feelings out on } \\
\text { objects around me (e.g., } \\
\text { deliberately causing damage to } \\
\text { my house, or outdoor things) }\end{array}$ & $\mathrm{O}$ & $\mathrm{O}$ & $\mathrm{O}$ & $\mathrm{O}$ & $\mathrm{O}$ \\
\hline $\begin{array}{l}\text { Things feel unreal (e.g., I feel } \\
\text { strange, things around me feel } \\
\text { strange, I daydream) }\end{array}$ & $\mathrm{O}$ & $\mathrm{O}$ & $\mathrm{O}$ & $\mathrm{O}$ & $\mathrm{O}$ \\
\hline I call my friends or family & O & $\mathrm{O}$ & $\mathrm{O}$ & $\mathrm{O}$ & $\mathrm{O}$ \\
\hline $\begin{array}{l}\text { I go out and do something nice } \\
\text { (e.g., movies, shopping, go for } \\
\text { a meal, meet people) }\end{array}$ & $\mathrm{O}$ & $\mathrm{O}$ & $\mathrm{O}$ & $\mathrm{O}$ & $\mathrm{O}$ \\
\hline
\end{tabular}




\section{Emerging Adults' Emotion Socialization with Father}

In the last six months, when your father/father-figure was SAD, what did YOU do?

\begin{tabular}{|c|c|c|c|c|c|}
\hline & $\begin{array}{l}1 \text { Not at all } \\
\text { typical }\end{array}$ & 2 & $\begin{array}{l}3 \text { Somewhat } \\
\text { typical }\end{array}$ & 4 & $\begin{array}{l}5 \text { Very } \\
\text { typical }\end{array}$ \\
\hline I don't respond & $\mathrm{O}$ & $\mathrm{O}$ & $\mathrm{O}$ & $\mathrm{O}$ & $\mathrm{O}$ \\
\hline Get tearful or cry & $\mathrm{O}$ & $\mathrm{O}$ & $\mathrm{O}$ & $\mathrm{O}$ & $\mathrm{O}$ \\
\hline Get sad myself & $\mathrm{O}$ & $\mathrm{O}$ & $\mathrm{O}$ & $\mathrm{O}$ & $\mathrm{O}$ \\
\hline $\begin{array}{l}\text { Say he is being silly or } \\
\text { foolish }\end{array}$ & $\mathrm{O}$ & O & $\mathrm{O}$ & $\mathrm{O}$ & $\mathrm{O}$ \\
\hline Tell him not to worry & $\mathrm{O}$ & $\mathrm{O}$ & $\mathrm{O}$ & $\mathrm{O}$ & $\mathrm{O}$ \\
\hline Give him a discouraging look & $\mathrm{O}$ & $\mathrm{O}$ & $\mathrm{O}$ & $\mathrm{O}$ & $\mathrm{O}$ \\
\hline Tell him to cheer up & $\mathrm{O}$ & $\mathrm{O}$ & $\mathrm{O}$ & $\mathrm{O}$ & $\mathrm{O}$ \\
\hline $\begin{array}{c}\text { Give my father space to } \\
\text { deal with it }\end{array}$ & $\mathrm{O}$ & $\mathrm{O}$ & $\mathrm{O}$ & $\mathrm{O}$ & $\mathrm{O}$ \\
\hline $\begin{array}{l}\text { I don't notice my } \\
\text { father's sadness }\end{array}$ & $\mathrm{O}$ & $\mathrm{O}$ & $\mathrm{O}$ & $\mathrm{O}$ & $\mathrm{O}$ \\
\hline Buy something he likes & $\mathrm{O}$ & $\mathrm{O}$ & $\mathrm{O}$ & $\mathrm{O}$ & $\mathrm{O}$ \\
\hline Comfort him & $\mathrm{O}$ & $\mathrm{O}$ & $\mathrm{O}$ & $\mathrm{O}$ & $\mathrm{O}$ \\
\hline Ask him about it & $\mathrm{O}$ & $\mathrm{O}$ & $\mathrm{O}$ & $\mathrm{O}$ & $\mathrm{O}$ \\
\hline Help him deal with the issue & $\mathrm{O}$ & $\mathrm{O}$ & $\mathrm{O}$ & $\mathrm{O}$ & $\mathrm{O}$ \\
\hline I express disapproval verbally & $\mathrm{O}$ & $\mathrm{O}$ & $\mathrm{O}$ & $\mathrm{O}$ & $\mathrm{O}$ \\
\hline I get upset & $\mathrm{O}$ & $\mathrm{O}$ & $\mathrm{O}$ & $\mathrm{O}$ & $\mathrm{O}$ \\
\hline
\end{tabular}


In the last six months, when your father/father-figure was ANGRY, what did YOU do?

\begin{tabular}{|c|c|c|c|c|c|}
\hline & $\begin{array}{l}1 \text { Not at all } \\
\text { typical }\end{array}$ & 2 & $\begin{array}{l}3 \text { Somewhat } \\
\text { typical }\end{array}$ & 4 & $\begin{array}{l}5 \text { Very } \\
\text { typical }\end{array}$ \\
\hline Tell him things aren't so bad & $\mathrm{O}$ & $\mathrm{O}$ & $\mathrm{O}$ & $\mathrm{O}$ & $\mathrm{O}$ \\
\hline $\begin{array}{l}\text { Find out what made him } \\
\text { angry }\end{array}$ & $\mathrm{O}$ & $\mathrm{O}$ & $\mathrm{O}$ & $\mathrm{O}$ & $\mathrm{O}$ \\
\hline Get angry with him & $\mathrm{O}$ & $\mathrm{O}$ & O & $\mathrm{O}$ & $\mathrm{O}$ \\
\hline Give him space to deal with it & $\mathrm{O}$ & $\mathrm{O}$ & $\mathrm{O}$ & $\mathrm{O}$ & O \\
\hline $\begin{array}{l}\text { Say something like, } \\
\text { "get a grip" }\end{array}$ & $\mathrm{O}$ & $\mathrm{O}$ & $\mathrm{O}$ & $\mathrm{O}$ & $\mathrm{O}$ \\
\hline I don't respond & $\mathrm{O}$ & $\mathrm{O}$ & $\mathrm{O}$ & $\mathrm{O}$ & $\mathrm{O}$ \\
\hline $\begin{array}{l}\text { Give him something } \\
\text { else to do }\end{array}$ & $\mathrm{O}$ & $\mathrm{O}$ & $\mathrm{O}$ & $\mathrm{O}$ & $\mathrm{O}$ \\
\hline Empathize with him & $\mathrm{O}$ & $\mathrm{O}$ & $\mathrm{O}$ & $\mathrm{O}$ & $\mathrm{O}$ \\
\hline Get upset & $\mathrm{O}$ & $\mathrm{O}$ & $\mathrm{O}$ & $\mathrm{O}$ & $\mathrm{O}$ \\
\hline Say he should be ashamed & $\mathrm{O}$ & $\mathrm{O}$ & $\mathrm{O}$ & $\mathrm{O}$ & $\mathrm{O}$ \\
\hline $\begin{array}{l}\text { Help him deal with the } \\
\text { problem }\end{array}$ & $\mathrm{O}$ & $\mathrm{O}$ & $\mathrm{O}$ & $\mathrm{O}$ & $\mathrm{O}$ \\
\hline Yell back at him & $\mathrm{O}$ & $\mathrm{O}$ & $\mathrm{O}$ & $\mathrm{O}$ & $\mathrm{O}$ \\
\hline $\begin{array}{l}\text { Tell him to change his } \\
\text { attitude }\end{array}$ & $\mathrm{O}$ & $\mathrm{O}$ & $\mathrm{O}$ & $\mathrm{O}$ & $\mathrm{O}$ \\
\hline I don't notice his anger & $\mathrm{O}$ & $\mathrm{O}$ & $\mathrm{O}$ & $\mathrm{O}$ & $\mathrm{O}$ \\
\hline Punish him & $\mathrm{O}$ & $\mathrm{O}$ & $\mathrm{O}$ & $\mathrm{O}$ & $\mathrm{O}$ \\
\hline
\end{tabular}


In the last six months, when your father/father-figure was WORRIED/ANXIOUS, what did YOU do?

\begin{tabular}{|c|c|c|c|c|c|}
\hline & $\begin{array}{l}1 \text { Not at all } \\
\text { typical }\end{array}$ & 2 & $\begin{array}{c}3 \text { Somewhat } \\
\text { typical }\end{array}$ & 4 & $\begin{array}{l}5 \text { Very } \\
\text { typical }\end{array}$ \\
\hline Get worried myself & $\mathrm{O}$ & $\mathrm{O}$ & $\mathrm{O}$ & $\mathrm{O}$ & $\mathrm{O}$ \\
\hline Tell him to grow up & $\mathrm{O}$ & $\mathrm{O}$ & $\mathrm{O}$ & $\mathrm{O}$ & $\mathrm{O}$ \\
\hline I don't respond & $\mathrm{O}$ & $\mathrm{O}$ & $\mathrm{O}$ & $\mathrm{O}$ & $\mathrm{O}$ \\
\hline Punish him & $\mathrm{O}$ & $\mathrm{O}$ & $\mathrm{O}$ & $\mathrm{O}$ & $\mathrm{O}$ \\
\hline $\begin{array}{l}\text { Help him deal with the } \\
\text { problem }\end{array}$ & $\mathrm{O}$ & $\mathrm{O}$ & $\mathrm{O}$ & $\mathrm{O}$ & $\mathrm{O}$ \\
\hline Tell him not to be anxious & $\mathrm{O}$ & $\mathrm{O}$ & $\mathrm{O}$ & $\mathrm{O}$ & $\mathrm{O}$ \\
\hline $\begin{array}{l}\text { Give him space to deal } \\
\text { with it }\end{array}$ & $\mathrm{O}$ & $\mathrm{O}$ & O & $\mathrm{O}$ & $\mathrm{O}$ \\
\hline Tell him not to worry & $\mathrm{O}$ & $\mathrm{O}$ & $\mathrm{O}$ & $\mathrm{O}$ & $\mathrm{O}$ \\
\hline Ask him what is wrong & $\mathrm{O}$ & $\mathrm{O}$ & $\mathrm{O}$ & $\mathrm{O}$ & $\mathrm{O}$ \\
\hline I don't notice his anxiety & $\mathrm{O}$ & $\mathrm{O}$ & $\mathrm{O}$ & $\mathrm{O}$ & $\mathrm{O}$ \\
\hline Distract him & $\mathrm{O}$ & $\mathrm{O}$ & $\mathrm{O}$ & $\mathrm{O}$ & $\mathrm{O}$ \\
\hline Say I am worried, too & $\mathrm{O}$ & $\mathrm{O}$ & O & $\mathrm{O}$ & $\mathrm{O}$ \\
\hline Hug him & $\mathrm{O}$ & $\mathrm{O}$ & $\mathrm{O}$ & $\mathrm{O}$ & $\mathrm{O}$ \\
\hline Become worried myself & $\mathrm{O}$ & $\mathrm{O}$ & 0 & 0 & 0 \\
\hline $\begin{array}{l}\text { Tell him not to be a } \\
\text { "worry wart" }\end{array}$ & 0 & 0 & 0 & 0 & 0 \\
\hline
\end{tabular}


In the last six months, when your father/father-figure was HAPPY, what did YOU do?

\begin{tabular}{|c|c|c|c|c|c|}
\hline & $\begin{array}{l}1 \text { Not at all } \\
\text { typical }\end{array}$ & 2 & $\begin{array}{l}3 \text { Somewhat } \\
\text { typical }\end{array}$ & 4 & $\begin{array}{l}5 \text { Very } \\
\text { typical }\end{array}$ \\
\hline $\begin{array}{l}\text { Am interested in why he } \\
\text { is happy }\end{array}$ & $\mathrm{O}$ & $\mathrm{O}$ & $\mathrm{O}$ & $\mathrm{O}$ & $\mathrm{O}$ \\
\hline Tell him to settle down & $\mathrm{O}$ & $\mathrm{O}$ & $\mathrm{O}$ & $\mathrm{O}$ & $\mathrm{O}$ \\
\hline Don't ask about it & $\mathrm{O}$ & $\mathrm{O}$ & $\mathrm{O}$ & $\mathrm{O}$ & $\mathrm{O}$ \\
\hline Join him in his happiness & $\mathrm{O}$ & $\mathrm{O}$ & $\mathrm{O}$ & $\mathrm{O}$ & $\mathrm{O}$ \\
\hline $\begin{array}{l}\text { Show I do not like his } \\
\text { being happy }\end{array}$ & $\mathrm{O}$ & $\mathrm{O}$ & $\mathrm{O}$ & $\mathrm{O}$ & $\mathrm{O}$ \\
\hline I usually don't notice & $\mathrm{O}$ & $\mathrm{O}$ & $\mathrm{O}$ & $\mathrm{O}$ & $\mathrm{O}$ \\
\hline Listen to him & $\mathrm{O}$ & $\mathrm{O}$ & $\mathrm{O}$ & $\mathrm{O}$ & $\mathrm{O}$ \\
\hline $\begin{array}{l}\text { Notice his feelings and } \\
\text { quickly move on to } \\
\text { something else }\end{array}$ & $\mathrm{O}$ & $\mathrm{O}$ & $\mathrm{O}$ & $\mathrm{O}$ & $\mathrm{O}$ \\
\hline Become very happy myself & $\mathrm{O}$ & $\mathrm{O}$ & $\mathrm{O}$ & $\mathrm{O}$ & $\mathrm{O}$ \\
\hline $\begin{array}{l}\text { Ask him to do fun } \\
\text { activities with me }\end{array}$ & $\mathrm{O}$ & $\mathrm{O}$ & $\mathrm{O}$ & $\mathrm{O}$ & $\mathrm{O}$ \\
\hline $\begin{array}{l}\text { Tell him that there are } \\
\text { other things that are } \\
\text { more important }\end{array}$ & $\mathrm{O}$ & $\mathrm{O}$ & $\mathrm{O}$ & $\mathrm{O}$ & $\mathrm{O}$ \\
\hline Tell him to keep it to himself & $\mathrm{O}$ & $\mathrm{O}$ & $\mathrm{O}$ & $\mathrm{O}$ & $\mathrm{O}$ \\
\hline Say I am happy, too & $\mathrm{O}$ & $\mathrm{O}$ & $\mathrm{O}$ & $\mathrm{O}$ & 0 \\
\hline Change the subject & $\mathrm{O}$ & $\mathrm{O}$ & 0 & 0 & 0 \\
\hline I'm usually not around & $\mathrm{O}$ & $\mathrm{O}$ & $\mathrm{O}$ & $\mathrm{O}$ & $\mathrm{O}$ \\
\hline
\end{tabular}




\section{Emerging Adults' Emotion Socialization with Mother}

In the last six months, when your mother/mother-figure was SAD, what did YOU do?

\begin{tabular}{|c|c|c|c|c|c|}
\hline & $\begin{array}{l}1 \text { Not at all } \\
\text { typical }\end{array}$ & 2 & $\begin{array}{l}3 \text { Somewhat } \\
\text { typical }\end{array}$ & 4 & $\begin{array}{l}5 \text { Very } \\
\text { typical }\end{array}$ \\
\hline Comfort her & $\mathrm{O}$ & $\mathrm{O}$ & $\mathrm{O}$ & $\mathrm{O}$ & 0 \\
\hline Ask her about it & $\mathrm{O}$ & $\mathrm{O}$ & $\mathrm{O}$ & $\mathrm{O}$ & $\mathrm{O}$ \\
\hline Tell her not to worry & $\mathrm{O}$ & 0 & 0 & $\mathrm{O}$ & 0 \\
\hline Tell my mother to cheer up & $\mathrm{O}$ & $\mathrm{O}$ & $\mathrm{O}$ & O & $\mathrm{O}$ \\
\hline $\begin{array}{l}\text { I don't notice my } \\
\text { mother's sadness }\end{array}$ & $\mathrm{O}$ & $\mathrm{O}$ & O & $\mathrm{O}$ & O \\
\hline Help her deal with the issue & $\mathrm{O}$ & $\mathrm{O}$ & O & O & $\mathrm{O}$ \\
\hline I get upset & $\mathrm{O}$ & $\mathrm{O}$ & $\mathrm{O}$ & $\mathrm{O}$ & $\mathrm{O}$ \\
\hline Get sad myself & $\mathrm{O}$ & $\mathrm{O}$ & $\mathrm{O}$ & $\mathrm{O}$ & $\mathrm{O}$ \\
\hline Buy something she likes & $\mathrm{O}$ & $\mathrm{O}$ & $\mathrm{O}$ & $\mathrm{O}$ & $\mathrm{O}$ \\
\hline I don't respond & $\mathrm{O}$ & $\mathrm{O}$ & $\mathrm{O}$ & $\mathrm{O}$ & $\mathrm{O}$ \\
\hline Give her a discouraging look & $\mathrm{O}$ & $\mathrm{O}$ & $\mathrm{O}$ & $\mathrm{O}$ & $\mathrm{O}$ \\
\hline Say she is silly or foolish & $\mathrm{O}$ & $\mathrm{O}$ & $\mathrm{O}$ & O & $\mathrm{O}$ \\
\hline $\begin{array}{l}\text { Give my mother space } \\
\text { to deal with it }\end{array}$ & $\mathrm{O}$ & $\mathrm{O}$ & $\mathrm{O}$ & $\mathrm{O}$ & $\mathrm{O}$ \\
\hline Get tearful or cry & $\mathrm{O}$ & $\mathrm{O}$ & $\mathrm{O}$ & $\mathrm{O}$ & $\mathrm{O}$ \\
\hline I express disapproval verbally & $\mathrm{O}$ & $\mathrm{O}$ & $\mathrm{O}$ & $\mathrm{O}$ & $\mathrm{O}$ \\
\hline
\end{tabular}


In the last six months, when your mother/mother-figure was ANGRY, what did YOU do?

\begin{tabular}{|c|c|c|c|c|c|}
\hline & $\begin{array}{l}1 \text { Not at all } \\
\text { typical }\end{array}$ & 2 & $\begin{array}{l}3 \text { Somewhat } \\
\text { typical }\end{array}$ & 4 & $\begin{array}{l}5 \text { Very } \\
\text { typical }\end{array}$ \\
\hline Say she should be ashamed & $\mathrm{O}$ & $\mathrm{O}$ & $\mathrm{O}$ & $\mathrm{O}$ & $\mathrm{O}$ \\
\hline I don't notice her anger & $\mathrm{O}$ & $\mathrm{O}$ & $\mathrm{O}$ & $\mathrm{O}$ & $\mathrm{O}$ \\
\hline Get angry with her & $\mathrm{O}$ & $\mathrm{O}$ & $\mathrm{O}$ & O & $\mathrm{O}$ \\
\hline Punish her & 0 & $\mathrm{O}$ & $\mathrm{O}$ & $\mathrm{O}$ & $\mathrm{O}$ \\
\hline Get upset & $\mathrm{O}$ & $\mathrm{O}$ & $\mathrm{O}$ & $\mathrm{O}$ & $\mathrm{O}$ \\
\hline $\begin{array}{l}\text { Find out what made her } \\
\text { angry }\end{array}$ & O & O & $\mathrm{O}$ & $\mathrm{O}$ & $\mathrm{O}$ \\
\hline $\begin{array}{l}\text { Say something like, } \\
\text { "Get a grip." }\end{array}$ & $\mathrm{O}$ & $\mathrm{O}$ & $\mathrm{O}$ & O & $\mathrm{O}$ \\
\hline Empathize with her & $\mathrm{O}$ & $\mathrm{O}$ & $\mathrm{O}$ & $\mathrm{O}$ & $\mathrm{O}$ \\
\hline $\begin{array}{l}\text { Give her something } \\
\text { else to do }\end{array}$ & $\mathrm{O}$ & $\mathrm{O}$ & $\mathrm{O}$ & $\mathrm{O}$ & $\mathrm{O}$ \\
\hline $\begin{array}{c}\text { Tell her to change her } \\
\text { attitude }\end{array}$ & $\mathrm{O}$ & $\mathrm{O}$ & $\mathrm{O}$ & $\mathrm{O}$ & $\mathrm{O}$ \\
\hline Give her space to deal with it & $\mathrm{O}$ & $\mathrm{O}$ & $\mathrm{O}$ & $\mathrm{O}$ & $\mathrm{O}$ \\
\hline I don't respond & $\mathrm{O}$ & $\mathrm{O}$ & $\mathrm{O}$ & $\mathrm{O}$ & $\mathrm{O}$ \\
\hline Tell her things aren't so bad & $\mathrm{O}$ & $\mathrm{O}$ & $\mathrm{O}$ & $\mathrm{O}$ & $\mathrm{O}$ \\
\hline Yell back her & $\mathrm{O}$ & $\mathrm{O}$ & $\mathrm{O}$ & $\mathrm{O}$ & $\mathrm{O}$ \\
\hline $\begin{array}{l}\text { Help her deal with the } \\
\text { problem }\end{array}$ & O & $\mathrm{O}$ & O & $\mathrm{O}$ & $\mathrm{O}$ \\
\hline
\end{tabular}


In the last six months, when your mother/mother-figure was WORRIED/ANXIOUS, what did YOU do?

\begin{tabular}{|c|c|c|c|c|c|}
\hline & $\begin{array}{l}1 \text { Not at all } \\
\text { typical }\end{array}$ & 2 & $\begin{array}{c}3 \text { Somewhat } \\
\text { typical }\end{array}$ & 4 & $\begin{array}{l}5 \text { Very } \\
\text { typical }\end{array}$ \\
\hline I don't notice her anxiety & $\mathrm{O}$ & $\mathrm{O}$ & $\mathrm{O}$ & $\mathrm{O}$ & 0 \\
\hline Give her space to deal with it & $\mathrm{O}$ & $\mathrm{O}$ & $\mathrm{O}$ & $\mathrm{O}$ & $\mathrm{O}$ \\
\hline Ask her what is wrong & $\mathrm{O}$ & $\mathrm{O}$ & $\mathrm{O}$ & $\mathrm{O}$ & $\mathrm{O}$ \\
\hline Tell her not to be anxious & $\mathrm{O}$ & $\mathrm{O}$ & $\mathrm{O}$ & $\mathrm{O}$ & $\mathrm{O}$ \\
\hline I don't respond & $\mathrm{O}$ & $\mathrm{O}$ & $\mathrm{O}$ & $\mathrm{O}$ & $\mathrm{O}$ \\
\hline $\begin{array}{l}\text { Help her deal with the } \\
\text { problem }\end{array}$ & $\mathrm{O}$ & $\mathrm{O}$ & $\mathrm{O}$ & $\mathrm{O}$ & $\mathrm{O}$ \\
\hline Hug her & $\mathrm{O}$ & $\mathrm{O}$ & $\mathrm{O}$ & $\mathrm{O}$ & $\mathrm{O}$ \\
\hline Say I am worried, too & $\mathrm{O}$ & $\mathrm{O}$ & $\mathrm{O}$ & $\mathrm{O}$ & $\mathrm{O}$ \\
\hline Punish her & O & $\mathrm{O}$ & $\mathrm{O}$ & $\mathrm{O}$ & $\mathrm{O}$ \\
\hline Tell her to grow up & $\mathrm{O}$ & $\mathrm{O}$ & $\mathrm{O}$ & $\mathrm{O}$ & $\mathrm{O}$ \\
\hline Distract her & $\mathrm{O}$ & $\mathrm{O}$ & $\mathrm{O}$ & $\mathrm{O}$ & $\mathrm{O}$ \\
\hline Become worried myself & O & $\mathrm{O}$ & $\mathrm{O}$ & $\mathrm{O}$ & $\mathrm{O}$ \\
\hline Get worried myself & $\mathrm{O}$ & $\mathrm{O}$ & $\mathrm{O}$ & $\mathrm{O}$ & $\mathrm{O}$ \\
\hline $\begin{array}{l}\text { Tell her not to be a } \\
\text { "worry wart" }\end{array}$ & $\mathrm{O}$ & $\mathrm{O}$ & $\mathrm{O}$ & $\mathrm{O}$ & $\mathrm{O}$ \\
\hline Tell her not to worry & O & $\mathrm{O}$ & O & $\mathrm{O}$ & O \\
\hline
\end{tabular}


In the last six months, when your mother/mother-figure was HAPPY, what did YOU do?

\begin{tabular}{|c|c|c|c|c|c|}
\hline & $\begin{array}{l}1 \text { Not at all } \\
\text { typical }\end{array}$ & 2 & $\begin{array}{l}3 \text { Somewhat } \\
\text { typical }\end{array}$ & 4 & $\begin{array}{l}5 \text { Very } \\
\text { typical }\end{array}$ \\
\hline Become very happy myself & $\mathrm{O}$ & $\mathrm{O}$ & $\mathrm{O}$ & $\mathrm{O}$ & $\mathrm{O}$ \\
\hline Say I am happy, too & $\mathrm{O}$ & $\mathrm{O}$ & $\mathrm{O}$ & $\mathrm{O}$ & $\mathrm{O}$ \\
\hline Change the subject & $\mathrm{O}$ & $\mathrm{O}$ & 0 & 0 & $\mathrm{O}$ \\
\hline Join in her happiness & $\mathrm{O}$ & $\mathrm{O}$ & 0 & 0 & $\mathrm{O}$ \\
\hline $\begin{array}{l}\text { Encourage her to share } \\
\text { her happiness }\end{array}$ & O & O & O & O & O \\
\hline I'm usually not around & $\mathrm{O}$ & $\mathrm{O}$ & $\mathrm{O}$ & $\mathrm{O}$ & $\mathrm{O}$ \\
\hline $\begin{array}{c}\text { Show that I do not like } \\
\text { her being happy }\end{array}$ & $\mathrm{O}$ & $\mathrm{O}$ & O & O & O \\
\hline Tell her to settle down & $\mathrm{O}$ & $\mathrm{O}$ & $\mathrm{O}$ & $\mathrm{O}$ & $\mathrm{O}$ \\
\hline Listen to her & $\mathrm{O}$ & $\mathrm{O}$ & $\mathrm{O}$ & 0 & $\mathrm{O}$ \\
\hline Tell her to keep it to herself & $\mathrm{O}$ & $\mathrm{O}$ & $\mathrm{O}$ & 0 & $\mathrm{O}$ \\
\hline $\begin{array}{c}\text { Tell her that there are } \\
\text { other things that are } \\
\text { more important }\end{array}$ & O & O & O & O & O \\
\hline $\begin{array}{l}\text { Notice her feelings and } \\
\text { quickly move on to } \\
\text { something else }\end{array}$ & O & O & $\mathrm{O}$ & O & O \\
\hline Don't ask about it & $\mathrm{O}$ & $\mathrm{O}$ & $\mathrm{O}$ & $\mathrm{O}$ & $\mathrm{O}$ \\
\hline $\begin{array}{l}\text { Am interested in why } \\
\text { she is happy }\end{array}$ & O & O & O & O & O \\
\hline I usually don't notice & 0 & 0 & $\mathrm{O}$ & 0 & $\mathrm{O}$ \\
\hline
\end{tabular}




\section{Emotion Socialization by Friend}

As part of your participation in this study, you are required to leave contact information for at least one close friend that you have known for more than one year. The friend should be platonic and not a romantic partner. Space has been allotted for you to leave numerous methods for us to contact your friend to participate in a survey. Please leave as much information as possible and choose a friend who is most likely to complete the survey. Your friend will also be compensated for completing their survey, one option which is to give you an additional one hour of extra credit. Contact information must be verified (but they do not have to participate) in order for you to receive your extra credit for completing this survey.

Friend contact information:

Friend name

Friend email

Friend cell phone

\section{Type of Friend}

The following questions are about your relationship with your friend.

\begin{tabular}{|l|l|l|l|l|l|l|l|l|l|l|}
\hline \multicolumn{1}{|l|}{ Friend } & \multicolumn{5}{|c|}{ Best Friend } \\
\hline 0 & 10 & 20 & 30 & 40 & 50 & 60 & 70 & 80 & 90 & 100 \\
\hline
\end{tabular}

Use the slider to illustrate how you consider your friend. 


\section{Emerging Adult Emotion Socialization of Friend}

This last set of surveys is about what YOU do when your FRIEND is experiencing or expressing different emotions.

In the last six months, when your friend was SAD, what did YOU do?

\begin{tabular}{|c|c|c|c|c|c|}
\hline & $\begin{array}{l}1 \text { not at all } \\
\text { typical }\end{array}$ & 2 & $\begin{array}{l}3 \text { somewhat } \\
\text { typical }\end{array}$ & 4 & $\begin{array}{l}5 \text { not at all } \\
\text { typical }\end{array}$ \\
\hline Get sad too & 0 & $\mathrm{O}$ & $\mathrm{O}$ & $\mathrm{O}$ & $\mathrm{O}$ \\
\hline Push them away or hit them & $\mathrm{O}$ & $\mathrm{O}$ & $\mathrm{O}$ & $\mathrm{O}$ & $\mathrm{O}$ \\
\hline $\begin{array}{l}\text { Say that you'll stop liking them } \\
\text { if they don't change their } \\
\text { attitude }\end{array}$ & $\mathrm{O}$ & $\mathrm{O}$ & $\mathrm{O}$ & O & $\mathrm{O}$ \\
\hline $\begin{array}{c}\text { Try to get them to do } \\
\text { something else that makes them } \\
\text { less sad }\end{array}$ & $\mathrm{O}$ & $\mathrm{O}$ & $\mathrm{O}$ & $\mathrm{O}$ & O \\
\hline $\begin{array}{l}\text { Tell them that things aren't so } \\
\text { bad }\end{array}$ & $\mathrm{O}$ & $\mathrm{O}$ & $\mathrm{O}$ & $\mathrm{O}$ & O \\
\hline $\begin{array}{l}\text { Act like you don't notice that } \\
\text { they feel sad }\end{array}$ & $\mathrm{O}$ & $\mathrm{O}$ & $\mathrm{O}$ & $\mathrm{O}$ & $\mathrm{O}$ \\
\hline $\begin{array}{l}\text { Tell other people secrets and } \\
\text { mean things about them }\end{array}$ & $\mathrm{O}$ & $\mathrm{O}$ & $\mathrm{O}$ & O & O \\
\hline $\begin{array}{l}\text { Help them to deal with what } \\
\text { has made them sad }\end{array}$ & $\mathrm{O}$ & $\mathrm{O}$ & $\mathrm{O}$ & $\mathrm{O}$ & $\mathrm{O}$ \\
\hline Get upset at what is going on & $\mathrm{O}$ & $\mathrm{O}$ & $\mathrm{O}$ & $\mathrm{O}$ & O \\
\hline $\begin{array}{l}\text { Say something like, "It's okay, } \\
\text { we all feel sad sometimes" }\end{array}$ & $\mathrm{O}$ & $\mathrm{O}$ & $\mathrm{O}$ & $\mathrm{O}$ & $\mathrm{O}$ \\
\hline $\begin{array}{l}\text { Ignore the fact that they feel } \\
\text { sad }\end{array}$ & $\mathrm{O}$ & $\mathrm{O}$ & $\mathrm{O}$ & $\mathrm{O}$ & $\mathrm{O}$ \\
\hline $\begin{array}{c}\text { Say something like, "Cheer } \\
\text { up!” }\end{array}$ & $\mathrm{O}$ & $\mathrm{O}$ & O & $\mathrm{O}$ & O \\
\hline Not say or do anything about it & $\mathrm{O}$ & $\mathrm{O}$ & $\mathrm{O}$ & 0 & 0 \\
\hline $\begin{array}{l}\text { Tell them that they have a good } \\
\text { reason to feel really sad }\end{array}$ & 0 & 0 & 0 & 0 & 0 \\
\hline $\begin{array}{l}\text { Say something like, "It's ok; } \\
\text { we all feel sad sometimes." }\end{array}$ & 0 & 0 & 0 & 0 & 0 \\
\hline $\begin{array}{l}\text { Ask them about what has made } \\
\text { them feel sad }\end{array}$ & 0 & 0 & 0 & 0 & 0 \\
\hline $\begin{array}{l}\text { Leave them out of the group, or } \\
\text { any activities for a while. }\end{array}$ & 0 & 0 & 0 & 0 & 0 \\
\hline $\begin{array}{l}\text { Say that you don't like it when } \\
\text { they act this way }\end{array}$ & 0 & 0 & 0 & 0 & 0 \\
\hline
\end{tabular}


In the last six months, when your friend was ANGRY, what did YOU do?

\begin{tabular}{|c|c|c|c|c|c|}
\hline & $\begin{array}{l}1 \text { Not at all } \\
\text { typical }\end{array}$ & 2 & $\begin{array}{l}3 \text { Somewhat } \\
\text { typical }\end{array}$ & 4 & $\begin{array}{l}5 \text { Very } \\
\text { typical }\end{array}$ \\
\hline $\begin{array}{l}\text { Ask them about what has made } \\
\text { them feel angry }\end{array}$ & O & O & O & $\mathrm{O}$ & $\mathrm{O}$ \\
\hline $\begin{array}{l}\text { Tell other people secrets or } \\
\text { mean things about them. }\end{array}$ & $\mathrm{O}$ & $\mathrm{O}$ & $\mathrm{O}$ & $\mathrm{O}$ & $\mathrm{O}$ \\
\hline Get upset at what is going on & $\mathrm{O}$ & $\mathrm{O}$ & $\mathrm{O}$ & $\mathrm{O}$ & $\mathrm{O}$ \\
\hline Not say or do anything about it & $\mathrm{O}$ & $\mathrm{O}$ & $\mathrm{O}$ & $\mathrm{O}$ & $\mathrm{O}$ \\
\hline $\begin{array}{l}\text { Say something like, "you're } \\
\text { ridiculous." or, "you're being } \\
\text { stupid." }\end{array}$ & $\mathrm{O}$ & $\mathrm{O}$ & $\mathrm{O}$ & $\mathrm{O}$ & $\mathrm{O}$ \\
\hline $\begin{array}{l}\text { Act like you don't notice that } \\
\text { they feel angry }\end{array}$ & $\mathrm{O}$ & O & $\mathrm{O}$ & $\mathrm{O}$ & O \\
\hline $\begin{array}{l}\text { Say that you don't like it when } \\
\text { they act this way }\end{array}$ & $\mathrm{O}$ & O & $\mathrm{O}$ & $\mathrm{O}$ & $\mathrm{O}$ \\
\hline $\begin{array}{l}\text { Try to get them to do something } \\
\text { else to get their mind off feeling } \\
\text { angry }\end{array}$ & $\mathrm{O}$ & O & O & $\mathrm{O}$ & O \\
\hline Say something like, "cheer up!" & $\mathrm{O}$ & $\mathrm{O}$ & $\mathrm{O}$ & $\mathrm{O}$ & $\mathrm{O}$ \\
\hline $\begin{array}{l}\text { Tell them that things aren't so } \\
\text { bad }\end{array}$ & $\mathrm{O}$ & O & $\mathrm{O}$ & $\mathrm{O}$ & $\mathrm{O}$ \\
\hline $\begin{array}{l}\text { Ignore the fact that they feel } \\
\text { angry }\end{array}$ & $\mathrm{O}$ & O & $\mathrm{O}$ & $\mathrm{O}$ & O \\
\hline Get angry too & $\mathrm{O}$ & $\mathrm{O}$ & $\mathrm{O}$ & $\mathrm{O}$ & $\mathrm{O}$ \\
\hline $\begin{array}{l}\text { Help them deal with what has } \\
\text { made them feel angry }\end{array}$ & $\mathrm{O}$ & $\mathrm{O}$ & $\mathrm{O}$ & O & O \\
\hline $\begin{array}{l}\text { Tell them that they have a good } \\
\text { reason to feel angry }\end{array}$ & $\mathrm{O}$ & O & $\mathrm{O}$ & $\mathrm{O}$ & $\mathrm{O}$ \\
\hline Push them away or hit them & O & O & $\mathrm{O}$ & $\mathrm{O}$ & $\mathrm{O}$ \\
\hline $\begin{array}{l}\text { Leave them out of the group or } \\
\text { any activities for a while }\end{array}$ & $\mathrm{O}$ & O & O & O & O \\
\hline $\begin{array}{l}\text { Say something like, "It's okay } \\
\text { we all feel angry sometimes." }\end{array}$ & $\mathrm{O}$ & $\mathrm{O}$ & O & O & $\mathrm{O}$ \\
\hline $\begin{array}{l}\text { Say that you'll stop liking them } \\
\text { if they don't change their } \\
\text { attitude }\end{array}$ & $\mathrm{O}$ & O & O & $\mathrm{O}$ & O \\
\hline
\end{tabular}


In the last six months, when your friend was ANXIOUS/WORRIED, what did YOU do?

\begin{tabular}{|c|c|c|c|c|c|}
\hline & $\begin{array}{l}1 \text { not at all } \\
\text { typical }\end{array}$ & 2 & $\begin{array}{l}3 \text { somewhat } \\
\text { typical }\end{array}$ & 4 & 5 very typical \\
\hline $\begin{array}{l}\text { Leave them out of the group or } \\
\text { any activities for a while }\end{array}$ & $\mathrm{O}$ & $\mathrm{O}$ & O & $\mathrm{O}$ & $\mathrm{O}$ \\
\hline $\begin{array}{l}\text { Tell other people secrets or } \\
\text { mean things about them }\end{array}$ & $\mathrm{O}$ & $\mathrm{O}$ & $\mathrm{O}$ & $\mathrm{O}$ & $\mathrm{O}$ \\
\hline $\begin{array}{c}\text { Say something like, "You're } \\
\text { being ridiculous." Or, "You're } \\
\text { stupid." }\end{array}$ & $\mathrm{O}$ & $\mathrm{O}$ & $\mathrm{O}$ & $\mathrm{O}$ & $\mathrm{O}$ \\
\hline $\begin{array}{l}\text { Say you'll stop talking to them } \\
\text { if they don't change their } \\
\text { attitude }\end{array}$ & $\mathrm{O}$ & $\mathrm{O}$ & O & $\mathrm{O}$ & $\mathrm{O}$ \\
\hline $\begin{array}{l}\text { Tell them that they have a good } \\
\text { reason to be really worried }\end{array}$ & $\mathrm{O}$ & $\mathrm{O}$ & $\mathrm{O}$ & $\mathrm{O}$ & $\mathrm{O}$ \\
\hline Not say or do anything about it & $\mathrm{O}$ & $\mathrm{O}$ & $\mathrm{O}$ & $\mathrm{O}$ & $\mathrm{O}$ \\
\hline $\begin{array}{l}\text { Ignore the fact that they feel } \\
\text { worried }\end{array}$ & O & $\mathrm{O}$ & O & $\mathrm{O}$ & O \\
\hline $\begin{array}{l}\text { Help them to deal with what } \\
\text { has made them feel worried }\end{array}$ & $\mathrm{O}$ & $\mathrm{O}$ & O & $\mathrm{O}$ & $\mathrm{O}$ \\
\hline $\begin{array}{l}\text { Say that you don't like it when } \\
\text { they act this way }\end{array}$ & $\mathrm{O}$ & $\mathrm{O}$ & $\mathrm{O}$ & $\mathrm{O}$ & $\mathrm{O}$ \\
\hline $\begin{array}{l}\text { Try to get them to do } \\
\text { something else, that will take } \\
\text { their mind off feeling worried }\end{array}$ & $\mathrm{O}$ & $\mathrm{O}$ & $\mathrm{O}$ & $\mathrm{O}$ & $\mathrm{O}$ \\
\hline Get upset at what is going on & $\mathrm{O}$ & $\mathrm{O}$ & $\mathrm{O}$ & $\mathrm{O}$ & $\mathrm{O}$ \\
\hline $\begin{array}{l}\text { Ask them about what has made } \\
\text { them feel worried }\end{array}$ & $\mathrm{O}$ & $\mathrm{O}$ & $\mathrm{O}$ & $\mathrm{O}$ & $\mathrm{O}$ \\
\hline Get worried too & $\mathrm{O}$ & $\mathrm{O}$ & $\mathrm{O}$ & $\mathrm{O}$ & $\mathrm{O}$ \\
\hline $\begin{array}{l}\text { Tell them that things aren't so } \\
\text { bad }\end{array}$ & $\mathrm{O}$ & $\mathrm{O}$ & $\mathrm{O}$ & $\mathrm{O}$ & $\mathrm{O}$ \\
\hline $\begin{array}{c}\text { Say something like, "Cheer } \\
\text { up!" }\end{array}$ & $\mathrm{O}$ & $\mathrm{O}$ & $\mathrm{O}$ & $\mathrm{O}$ & $\mathrm{O}$ \\
\hline $\begin{array}{l}\text { Say something like, "It's ok, } \\
\text { we all feel worried sometimes." }\end{array}$ & $\mathrm{O}$ & $\mathrm{O}$ & $\mathrm{O}$ & $\mathrm{O}$ & $\mathrm{O}$ \\
\hline $\begin{array}{l}\text { Act like you don't notice that } \\
\text { they feel worried }\end{array}$ & $\mathrm{O}$ & $\mathrm{O}$ & $\mathrm{O}$ & O & O \\
\hline Push them away or hit them & $\mathrm{O}$ & $\mathrm{O}$ & $\mathrm{O}$ & $\mathrm{O}$ & $\mathrm{O}$ \\
\hline
\end{tabular}


In the last six months, when your friend was HAPPY, what did YOU do?

\begin{tabular}{|c|c|c|c|c|c|}
\hline & $\begin{array}{l}1 \text { not at all } \\
\text { typical }\end{array}$ & 2 & $\begin{array}{l}3 \text { somewhat } \\
\text { typical }\end{array}$ & 4 & 5 very typical \\
\hline $\begin{array}{l}\text { Ask them to do fun activities } \\
\text { with me }\end{array}$ & $\mathrm{O}$ & $\mathrm{O}$ & $\mathrm{O}$ & $\mathrm{O}$ & O \\
\hline $\begin{array}{l}\text { Notice their feelings and } \\
\text { quickly move on to } \\
\text { something else }\end{array}$ & $\mathrm{O}$ & $\mathrm{O}$ & $\mathrm{O}$ & $\mathrm{O}$ & $\mathrm{O}$ \\
\hline $\begin{array}{l}\text { Show that you don't like } \\
\text { their being happy }\end{array}$ & $\mathrm{O}$ & $\mathrm{O}$ & O & $\mathrm{O}$ & O \\
\hline Say you are happy, too & $\mathrm{O}$ & $\mathrm{O}$ & $\mathrm{O}$ & $\mathrm{O}$ & $\mathrm{O}$ \\
\hline $\begin{array}{l}\text { Encourage them to share } \\
\text { their happiness }\end{array}$ & $\mathrm{O}$ & O & $\mathrm{O}$ & $\mathrm{O}$ & $\mathrm{O}$ \\
\hline Listen to them & $\mathrm{O}$ & O & $\mathrm{O}$ & $\mathrm{O}$ & $\mathrm{O}$ \\
\hline $\begin{array}{l}\text { Not be interested in why } \\
\text { they are happy }\end{array}$ & $\mathrm{O}$ & $\mathrm{O}$ & $\mathrm{O}$ & O & $\mathrm{O}$ \\
\hline $\begin{array}{l}\text { Tell them that there are other } \\
\text { things that are more } \\
\text { important }\end{array}$ & $\mathrm{O}$ & $\mathrm{O}$ & $\mathrm{O}$ & $\mathrm{O}$ & $\mathrm{O}$ \\
\hline Not notice & $\mathrm{O}$ & $\mathrm{O}$ & $\mathrm{O}$ & $\mathrm{O}$ & $\mathrm{O}$ \\
\hline Tell them to settle down & $\mathrm{O}$ & $\mathrm{O}$ & $\mathrm{O}$ & $\mathrm{O}$ & $\mathrm{O}$ \\
\hline I am usually not around & $\mathrm{O}$ & $\mathrm{O}$ & $\mathrm{O}$ & $\mathrm{O}$ & $\mathrm{O}$ \\
\hline Not ask about it & $\mathrm{O}$ & $\mathrm{O}$ & $\mathrm{O}$ & $\mathrm{O}$ & $\mathrm{O}$ \\
\hline $\begin{array}{l}\text { Tell them to keep it to } \\
\text { themselves }\end{array}$ & $\mathrm{O}$ & $\mathrm{O}$ & $\mathrm{O}$ & $\mathrm{O}$ & $\mathrm{O}$ \\
\hline Become very happy yourself & $\mathrm{O}$ & $\mathrm{O}$ & $\mathrm{O}$ & $\mathrm{O}$ & $\mathrm{O}$ \\
\hline Join in with their happiness & 0 & 0 & 0 & 0 & 0 \\
\hline
\end{tabular}


Appendix B

\section{Demographics}

Parent-report Measures

What is your age in years?

What is your gender?
○ Male
- Female
○ Nonbinary

What is your ethnicity? (choose all that apply)
○ White/European
- Black/African
American
- Asian/Asian
- Native American or
American
Alaskan Native
○ Hispanic/Latino
- Native Hawaiian or other Pacific Islander

What is your relationship status?
o Married
- Single
- Divorced
○ Living with partner
- Separated
- Widowed

What is your annual household income?
- Less than $\$ 19,999$
- $\$ 20,000-39,999$
- $\$ 80,000-99,999$
- $\$ 40,000-59,999$
- \$60,000-79,999
- $\$ 140,000-159,999$
○ $\$ 100,000-119,999$
- $\$ 120,000-139,999$
- Over $\$ 200,000$
- $\$ 160,000-179,999$
- $\$ 180,000-199,999$
○ Prefer not to answer

How much difficulty do you have paying your bills?
- None/Not at all
- A little
$\circ$ Some
- A great deal
○ Prefer not to answer

What is the highest level of education you have completed?
○ Did not attend school
$\circ 8^{\text {th }}$ grade or less
- $9^{\text {th }}-11^{\text {th }}$ grade
- High school graduate or equivalent
- Some college
○ 2-year college degree
○ 4-year college degree
○ Some graduate school
○ Master's or 2-3-year degree
○ Completed MD or $\mathrm{PhD}$


Please enter the first and last name of your participating child. Your child's name will only be used to temporarily link your responses to your child's, and his/her name will be deleted from the dataset after that. For the remaining questions, if you are asked about your child, please answer in relation to this specific child. Thank you.

What is your relationship with your child (the one who is indicated in the email with the link for this survey and you have named above)?
○ Biological Mother
- Step-Mother
- Biological Father
o Step-Father
- Adoptive Mother
O Other
○ Adoptive Father 


\section{Closeness with Emerging Adult Child}

The following questions are about your relationship with your son/daughter. Please answer them as honestly as possible.

\begin{tabular}{|c|c|c|c|c|c|}
\hline & $\begin{array}{c}1 \\
\text { Not at all }\end{array}$ & 2 & 3 & 4 & $\begin{array}{c}5 \\
\text { Very }\end{array}$ \\
\hline $\begin{array}{l}\text { How openly do you talk with your } \\
\text { son/daughter? }\end{array}$ & ○ & O & ○ & ○ & O \\
\hline $\begin{array}{l}\text { How careful do you feel you have to be about } \\
\text { what you say to your son/daughter? }\end{array}$ & O & O & ○ & ○ & O \\
\hline $\begin{array}{l}\text { How comfortable do you feel admitting doubts } \\
\text { and fears to your son/daughter? }\end{array}$ & o & O & ○ & ○ & ○ \\
\hline $\begin{array}{l}\text { How interested is your son/daughter in talking } \\
\text { to you when you want to talk? }\end{array}$ & ○ & O & ○ & ○ & o \\
\hline $\begin{array}{l}\text { How often does your son/daughter express } \\
\text { affection or liking for you? }\end{array}$ & ○ & O & ○ & $\circ$ & ○ \\
\hline $\begin{array}{l}\text { How well does your son/daughter know what } \\
\text { you are really like? }\end{array}$ & o & O & o & ○ & ○ \\
\hline How close do you feel to your son/daughter? & 0 & 0 & O & ○ & 0 \\
\hline $\begin{array}{l}\text { How confident are you that your son/daughter } \\
\text { would help if you had a problem? }\end{array}$ & ○ & 0 & 0 & O & 0 \\
\hline $\begin{array}{l}\text { If you needed money how comfortable would } \\
\text { you be asking your son/daughter for it? }\end{array}$ & O & 0 & O & 0 & 0 \\
\hline $\begin{array}{l}\text { How interested is your son/daughter in the } \\
\text { things you do? }\end{array}$ & 0 & 0 & O & O & 0 \\
\hline
\end{tabular}




\section{Schedule of Positive and Negative Experiences (SPANE)}

Please think about what you have been doing and experiencing during the past four weeks. Then report how much you experience each of the following feelings, using the scale below. For each item, select a number from 1 to 5 .

\begin{tabular}{|c|c|c|c|c|c|}
\hline & $\begin{array}{c}1 \text { Very Rarely } \\
\text { or Never }\end{array}$ & 2 Rarely & 3 Sometimes & 4 Often & $\begin{array}{c}5 \text { Very Often or } \\
\text { Always }\end{array}$ \\
\hline Positive & 0 & 0 & 0 & O & $\mathrm{O}$ \\
\hline Negative & 0 & $\mathrm{O}$ & 0 & 0 & 0 \\
\hline Good & 0 & 0 & 0 & 0 & 0 \\
\hline $\mathrm{Bad}$ & $\mathrm{O}$ & $\mathrm{O}$ & 0 & 0 & $\mathrm{O}$ \\
\hline Pleasant & 0 & 0 & O & 0 & 0 \\
\hline Unpleasant & 0 & $\mathrm{O}$ & 0 & 0 & $\mathrm{O}$ \\
\hline Happy & 0 & $\mathrm{O}$ & 0 & 0 & 0 \\
\hline $\mathrm{Sad}$ & 0 & $\mathrm{O}$ & $\mathrm{O}$ & $\mathrm{O}$ & $\mathrm{O}$ \\
\hline Afraid & 0 & 0 & 0 & 0 & 0 \\
\hline Joyful & $\mathrm{O}$ & $\mathrm{O}$ & $\mathrm{O}$ & 0 & $\mathrm{O}$ \\
\hline Angry & 0 & 0 & 0 & 0 & $\mathrm{O}$ \\
\hline Contented & 0 & 0 & 0 & 0 & 0 \\
\hline
\end{tabular}




\section{Subjective Happiness Scale (SHS)}

For each of the following statements and/or questions, please select the point on the scale that you feel is most appropriate in describing you.

\begin{tabular}{|c|c|c|c|c|c|c|c|}
\hline & $\begin{array}{c}1 \text { not a } \\
\text { very } \\
\text { happy } \\
\text { person }\end{array}$ & 2 & 3 & 4 & 5 & 6 & $\begin{array}{c}7 \text { a very } \\
\text { happy } \\
\text { person }\end{array}$ \\
\hline $\begin{array}{c}\text { In general, I } \\
\text { consider myself: }\end{array}$ & O & O & 0 & 0 & 0 & 0 & $\bigcirc$ \\
\hline
\end{tabular}

\begin{tabular}{|c|c|c|c|c|c|c|c|}
\hline & $\begin{array}{c}1 \text { less } \\
\text { happy }\end{array}$ & 2 & 3 & 4 & 5 & 6 & $\begin{array}{c}7 \text { more } \\
\text { happy }\end{array}$ \\
\hline $\begin{array}{c}\text { Compared to most } \\
\text { of my peers, I } \\
\text { consider myself: }\end{array}$ & 0 & 0 & 0 & $\bigcirc$ & 0 & $\bigcirc$ & $\bigcirc$ \\
\hline
\end{tabular}

\begin{tabular}{|c|c|c|c|c|c|c|c|}
\hline & $\begin{array}{c}1 \text { not at } \\
\text { all }\end{array}$ & 2 & 3 & 4 & 5 & 6 & $\begin{array}{c}7 \text { a great } \\
\text { deal }\end{array}$ \\
\hline $\begin{array}{c}\text { Some people are } \\
\text { generally very } \\
\text { happy. They enjoy } \\
\text { life regardless of } \\
\text { what is going on, } \\
\text { getting the most out } \\
\text { of everything. To } \\
\text { what extent does } \\
\text { this characterization } \\
\text { describe you? }\end{array}$ & 0 & 0 & 0 & 0 & 0 & 0 & 0 \\
\hline $\begin{array}{c}\text { Some people are } \\
\text { generally not very } \\
\text { happy. Although } \\
\text { they are not } \\
\text { depressed, they } \\
\text { never seem as } \\
\text { happy as they might } \\
\text { be. To what extent } \\
\text { does this } \\
\text { characterization } \\
\text { describe you? }\end{array}$ & 0 & 0 & 0 & 0 & 0 & 0 & \\
\hline
\end{tabular}




\section{Satisfaction with Life Scale (SWLS)}

Below are five statements that you may agree or disagree with. Using the 1-7 scale below, indicate your agreement with each item by selecting the option by that item. Please be open and honest in your responding.

\begin{tabular}{|c|c|c|c|c|c|c|c|}
\hline & $\begin{array}{c}1 \text { Strongly } \\
\text { disagree }\end{array}$ & $\begin{array}{c}2 \\
\text { Disagree }\end{array}$ & $\begin{array}{c}3 \text { Slightly } \\
\text { disagree }\end{array}$ & $\begin{array}{c}4 \text { Neither } \\
\text { agree nor } \\
\text { disagree }\end{array}$ & $\begin{array}{c}5 \text { Slightly } \\
\text { agree }\end{array}$ & 6 Agree & $\begin{array}{c}7 \text { Strongly } \\
\text { agree }\end{array}$ \\
\hline $\begin{array}{c}\text { In most ways, my } \\
\text { life is close to my } \\
\text { ideal. }\end{array}$ & 0 & 0 & 0 & 0 & 0 & 0 & 0 \\
\hline $\begin{array}{c}\text { The conditions of } \\
\text { my life are } \\
\text { excellent. }\end{array}$ & 0 & 0 & 0 & 0 & 0 & 0 & 0 \\
\hline $\begin{array}{c}\text { I am satisfied with } \\
\text { my life. }\end{array}$ & 0 & 0 & 0 & 0 & 0 & 0 & 0 \\
\hline $\begin{array}{c}\text { So far, I have } \\
\text { gotten the } \\
\text { important things I } \\
\text { want in life. }\end{array}$ & 0 & 0 & 0 & 0 & 0 & 0 & 0 \\
\hline $\begin{array}{c}\text { If I could live my } \\
\text { life over, I would } \\
\text { change almost } \\
\text { nothing. }\end{array}$ & 0 & 0 & 0 & 0 & 0 & 0 & 0 \\
\hline
\end{tabular}




\section{Parent Emotion Socialization}

In the last six months, when your son/daughter was SAD, what did YOU do?

\begin{tabular}{|c|c|c|c|c|c|}
\hline & $\begin{array}{l}1 \text { Not at all } \\
\text { typical }\end{array}$ & 2 & $\begin{array}{l}3 \text { Somewhat } \\
\text { typical }\end{array}$ & 4 & 5 Very typical \\
\hline Comfort them & $\mathrm{O}$ & $\mathrm{O}$ & $\mathrm{O}$ & 0 & $\mathrm{O}$ \\
\hline $\begin{array}{l}\text { I express disapproval } \\
\text { verbally }\end{array}$ & $\mathrm{O}$ & $\mathrm{O}$ & O & $\mathrm{O}$ & $\mathrm{O}$ \\
\hline Ask them about it & $\mathrm{O}$ & O & $\mathrm{O}$ & $\mathrm{O}$ & $\mathrm{O}$ \\
\hline I get upset & O & O & O & O & 0 \\
\hline $\begin{array}{l}\text { Help them deal with the } \\
\text { issue }\end{array}$ & $\mathrm{O}$ & $\mathrm{O}$ & $\mathrm{O}$ & $\mathrm{O}$ & $\mathrm{O}$ \\
\hline $\begin{array}{c}\text { Give them a } \\
\text { discouraging look }\end{array}$ & $\mathrm{O}$ & $\mathrm{O}$ & $\mathrm{O}$ & $\mathrm{O}$ & $\mathrm{O}$ \\
\hline $\begin{array}{l}\text { Buy something they } \\
\text { like }\end{array}$ & $\mathrm{O}$ & $\mathrm{O}$ & O & O & $\mathrm{O}$ \\
\hline I don't respond & $\mathrm{O}$ & $\mathrm{O}$ & $\mathrm{O}$ & $\mathrm{O}$ & $\mathrm{O}$ \\
\hline $\begin{array}{l}\text { Give them space to deal } \\
\text { with it }\end{array}$ & $\mathrm{O}$ & $\mathrm{O}$ & $\mathrm{O}$ & $\mathrm{O}$ & $\mathrm{O}$ \\
\hline $\begin{array}{l}\text { Say they are silly or } \\
\text { foolish }\end{array}$ & $\mathrm{O}$ & O & O & O & $\mathrm{O}$ \\
\hline Tell them to cheer up & $\mathrm{O}$ & $\mathrm{O}$ & $\mathrm{O}$ & $\mathrm{O}$ & $\mathrm{O}$ \\
\hline $\begin{array}{l}\text { I don't notice their } \\
\text { sadness }\end{array}$ & $\mathrm{O}$ & $\mathrm{O}$ & O & $\mathrm{O}$ & $\mathrm{O}$ \\
\hline Get sad myself & $\mathrm{O}$ & $\mathrm{O}$ & $\mathrm{O}$ & $\mathrm{O}$ & $\mathrm{O}$ \\
\hline Get tearful or cry & $\mathrm{O}$ & $\mathrm{O}$ & $\mathrm{O}$ & $\mathrm{O}$ & $\mathrm{O}$ \\
\hline Tell them not to worry & $\mathrm{O}$ & $\mathrm{O}$ & $\mathrm{O}$ & $\mathrm{O}$ & $\mathrm{O}$ \\
\hline
\end{tabular}


In the last six months, when your son/daughter was ANGRY, what did YOU do?

\begin{tabular}{|c|c|c|c|c|c|}
\hline & $\begin{array}{l}1 \text { Not at all } \\
\text { typical }\end{array}$ & 2 & $\begin{array}{l}3 \text { Somewhat } \\
\text { typical }\end{array}$ & 4 & 5 Very typical \\
\hline \multicolumn{6}{|l|}{$\begin{array}{l}\text { Help them deal with } \\
\text { the problem }\end{array}$} \\
\hline Punish them & O & O & $\mathrm{O}$ & $\mathrm{O}$ & $\mathrm{O}$ \\
\hline I don't respond & $\mathrm{O}$ & $\mathrm{O}$ & $\mathrm{O}$ & $\mathrm{O}$ & $\mathrm{O}$ \\
\hline $\begin{array}{l}\text { Tell them to change } \\
\text { their attitude }\end{array}$ & $\mathrm{O}$ & $\mathrm{O}$ & $\mathrm{O}$ & O & O \\
\hline $\begin{array}{c}\text { I don't notice their } \\
\text { anger }\end{array}$ & O & O & $\mathrm{O}$ & O & O \\
\hline $\begin{array}{c}\text { Say they should be } \\
\text { ashamed }\end{array}$ & O & $\mathrm{O}$ & O & O & O \\
\hline $\begin{array}{l}\text { Find out what made } \\
\text { them angry }\end{array}$ & O & $\mathrm{O}$ & $\mathrm{O}$ & $\mathrm{O}$ & O \\
\hline $\begin{array}{l}\text { Say something like, } \\
\text { "Get a grip!" }\end{array}$ & $\mathrm{O}$ & O & O & $\mathrm{O}$ & O \\
\hline $\begin{array}{l}\text { Give them space to } \\
\text { deal with it }\end{array}$ & $\mathrm{O}$ & $\mathrm{O}$ & O & $\mathrm{O}$ & O \\
\hline Empathize with them & $\mathrm{O}$ & $\mathrm{O}$ & $\mathrm{O}$ & $\mathrm{O}$ & 0 \\
\hline Get upset & 0 & $\mathrm{O}$ & $\mathrm{O}$ & $\mathrm{O}$ & $\mathrm{O}$ \\
\hline $\begin{array}{l}\text { Tell them things } \\
\text { aren't so bad }\end{array}$ & $\mathrm{O}$ & $\mathrm{O}$ & $\mathrm{O}$ & O & O \\
\hline Get angry with them & $\mathrm{O}$ & $\mathrm{O}$ & $\mathrm{O}$ & $\mathrm{O}$ & $\mathrm{O}$ \\
\hline $\begin{array}{l}\text { Give them something } \\
\text { else to do }\end{array}$ & $\mathrm{O}$ & O & O & O & O \\
\hline Yell back at them & $\mathrm{O}$ & $\mathrm{O}$ & $\mathrm{O}$ & $\mathrm{O}$ & $\mathrm{O}$ \\
\hline
\end{tabular}


In the last six months, when your son/daughter was WORRIED/ANXIOUS, what did YOU do?

\begin{tabular}{|c|c|c|c|c|c|}
\hline & $\begin{array}{l}1 \text { Not at all } \\
\text { typical }\end{array}$ & 2 & $\begin{array}{l}3 \text { Somewhat } \\
\text { typical }\end{array}$ & 4 & 5 Very typical \\
\hline $\begin{array}{l}\text { Become worried } \\
\text { myself }\end{array}$ & $\mathrm{O}$ & $\mathrm{O}$ & $\mathrm{O}$ & $\mathrm{O}$ & $\mathrm{O}$ \\
\hline $\begin{array}{c}\text { Tell them not to be } \\
\text { worried }\end{array}$ & $\mathrm{O}$ & $\mathrm{O}$ & O & $\mathrm{O}$ & $\mathrm{O}$ \\
\hline Distract them & 0 & 0 & 0 & 0 & 0 \\
\hline $\begin{array}{l}\text { I don't notice their } \\
\text { anxiety }\end{array}$ & $\mathrm{O}$ & $\mathrm{O}$ & $\mathrm{O}$ & O & $\mathrm{O}$ \\
\hline I don't respond & $\mathrm{O}$ & 0 & 0 & 0 & $\mathrm{O}$ \\
\hline Get worried myself & $\mathrm{O}$ & $\mathrm{O}$ & $\mathrm{O}$ & $\mathrm{O}$ & $\mathrm{O}$ \\
\hline Hug them & $\mathrm{O}$ & $\mathrm{O}$ & $\mathrm{O}$ & $\mathrm{O}$ & $\mathrm{O}$ \\
\hline $\begin{array}{l}\text { Tell them not to be a } \\
\text { "worry wart" }\end{array}$ & $\mathrm{O}$ & $\mathrm{O}$ & $\mathrm{O}$ & O & $\mathrm{O}$ \\
\hline $\begin{array}{l}\text { Ask them what is } \\
\text { wrong }\end{array}$ & O & $\mathrm{O}$ & $\mathrm{O}$ & O & 0 \\
\hline Tell them to grow up & $\mathrm{O}$ & $\mathrm{O}$ & $\mathrm{O}$ & $\mathrm{O}$ & $\mathrm{O}$ \\
\hline $\begin{array}{l}\text { Help them to deal with } \\
\text { the problem }\end{array}$ & $\mathrm{O}$ & $\mathrm{O}$ & $\mathrm{O}$ & $\mathrm{O}$ & O \\
\hline Say I am worried, too & $\mathrm{O}$ & $\mathrm{O}$ & $\mathrm{O}$ & $\mathrm{O}$ & $\mathrm{O}$ \\
\hline $\begin{array}{c}\text { Tell them not to be } \\
\text { anxious }\end{array}$ & $\mathrm{O}$ & $\mathrm{O}$ & $\mathrm{O}$ & $\mathrm{O}$ & $\mathrm{O}$ \\
\hline $\begin{array}{l}\text { Give them space to } \\
\text { deal with it }\end{array}$ & $\mathrm{O}$ & $\mathrm{O}$ & O & $\mathrm{O}$ & O \\
\hline Punish them & O & $\mathrm{O}$ & $\mathrm{O}$ & 0 & $\mathrm{O}$ \\
\hline
\end{tabular}


In the last six months, when your son/daughter was HAPPY, what did YOU do?

\begin{tabular}{|c|c|c|c|c|c|}
\hline & $\begin{array}{l}1 \text { Not at all } \\
\text { typical }\end{array}$ & 2 & $\begin{array}{l}3 \text { Somewhat } \\
\text { typical }\end{array}$ & 4 & 5 Very typical \\
\hline $\begin{array}{l}\text { Tell them that there } \\
\text { are other things that } \\
\text { are more important }\end{array}$ & O & O & $\mathrm{O}$ & O & $\mathrm{O}$ \\
\hline Listen to them & $\mathrm{O}$ & $\mathrm{O}$ & $\mathrm{O}$ & $\mathrm{O}$ & $\mathrm{O}$ \\
\hline $\begin{array}{l}\text { Encourage them to } \\
\text { share their happiness }\end{array}$ & O & O & O & $\mathrm{O}$ & $\mathrm{O}$ \\
\hline $\begin{array}{l}\text { Tell them to keep it to } \\
\text { themselves }\end{array}$ & O & O & $\mathrm{O}$ & $\mathrm{O}$ & O \\
\hline $\begin{array}{l}\text { Notice their feelings } \\
\text { and quickly move on } \\
\text { to something else }\end{array}$ & $\mathrm{O}$ & $\mathrm{O}$ & $\mathrm{O}$ & $\mathrm{O}$ & $\mathrm{O}$ \\
\hline $\begin{array}{l}\text { Tell them to settle } \\
\text { down }\end{array}$ & $\mathrm{O}$ & $\mathrm{O}$ & $\mathrm{O}$ & $\mathrm{O}$ & $\mathrm{O}$ \\
\hline $\begin{array}{l}\text { Become very happy } \\
\text { myself }\end{array}$ & $\mathrm{O}$ & $\mathrm{O}$ & $\mathrm{O}$ & $\mathrm{O}$ & $\mathrm{O}$ \\
\hline Don't ask about it & $\mathrm{O}$ & $\mathrm{O}$ & $\mathrm{O}$ & $\mathrm{O}$ & $\mathrm{O}$ \\
\hline Join in their happiness & $\mathrm{O}$ & $\mathrm{O}$ & $\mathrm{O}$ & $\mathrm{O}$ & $\mathrm{O}$ \\
\hline $\begin{array}{l}\text { Show that I do not like } \\
\text { their being happy }\end{array}$ & $\mathrm{O}$ & $\mathrm{O}$ & $\mathrm{O}$ & $\mathrm{O}$ & $\mathrm{O}$ \\
\hline $\begin{array}{l}\text { Am interested in why } \\
\text { they are happy }\end{array}$ & $\mathrm{O}$ & O & $\mathrm{O}$ & $\mathrm{O}$ & $\mathrm{O}$ \\
\hline Usually don't notice & $\mathrm{O}$ & $\mathrm{O}$ & 0 & 0 & 0 \\
\hline Change the subject & $\mathrm{O}$ & $\mathrm{O}$ & $\mathrm{O}$ & $\mathrm{O}$ & $\mathrm{O}$ \\
\hline Usually not around & $\mathrm{O}$ & $\mathrm{O}$ & $\mathrm{O}$ & 0 & $\mathrm{O}$ \\
\hline Say I am happy too & $\mathrm{O}$ & $\mathrm{O}$ & $\mathrm{O}$ & $\mathrm{O}$ & $\mathrm{O}$ \\
\hline
\end{tabular}




\section{Regulation of Emotions Questionnaire (REQ)}

The following questions ask you to think about how often you do certain things in response to your emotions. You do not have to think about specific negative emotions but just how often you generally do the things listed below when you feel badly. Please select the answer that fits best. We all respond to our emotions in different ways so there are no right or wrong answers.

\begin{tabular}{|c|c|c|c|c|c|}
\hline & 1 Never & 2 Seldom & 3 Often & 4 Very Often & 5 Always \\
\hline $\begin{array}{l}\text { I talk to someone about how I } \\
\text { feel }\end{array}$ & O & O & $\mathrm{O}$ & $\mathrm{O}$ & $\mathrm{O}$ \\
\hline $\begin{array}{l}\text { I take my feelings out on others } \\
\text { verbally (e.g., shouting, } \\
\text { arguing) }\end{array}$ & O & O & $\mathrm{O}$ & $\mathrm{O}$ & O \\
\hline $\begin{array}{c}\text { I seek physical contact from } \\
\text { friends or family (e.g., a hug, } \\
\text { hold hands) }\end{array}$ & $\mathrm{O}$ & $\mathrm{O}$ & $\mathrm{O}$ & $\mathrm{O}$ & $\mathrm{O}$ \\
\hline $\begin{array}{l}\text { I review (rethink) my thoughts } \\
\text { or beliefs }\end{array}$ & $\mathrm{O}$ & $\mathrm{O}$ & $\mathrm{O}$ & $\mathrm{O}$ & O \\
\hline $\begin{array}{l}\text { I harm or punish myself in } \\
\text { some way }\end{array}$ & $\mathrm{O}$ & $\mathrm{O}$ & $\mathrm{O}$ & $\mathrm{O}$ & O \\
\hline $\begin{array}{l}\text { I do something energetic (e.g., } \\
\text { play sport, go for a walk) }\end{array}$ & O & $\mathrm{O}$ & $\mathrm{O}$ & $\mathrm{O}$ & O \\
\hline $\begin{array}{l}\text { I dwell on my thoughts and } \\
\text { feelings (e.g., it goes around } \\
\text { and around in my head and I } \\
\text { can't stop it) }\end{array}$ & O & $\mathrm{O}$ & O & O & O \\
\hline I ask others for advice & $\mathrm{O}$ & $\mathrm{O}$ & $\mathrm{O}$ & $\mathrm{O}$ & $\mathrm{O}$ \\
\hline $\begin{array}{l}\text { I review (rethink) my goals or } \\
\text { plans }\end{array}$ & O & O & 0 & $\mathrm{O}$ & O \\
\hline $\begin{array}{c}\text { I take my feelings out on others } \\
\text { physically (e.g., fighting, } \\
\text { lashing out) }\end{array}$ & $\mathrm{O}$ & $\mathrm{O}$ & $\mathrm{O}$ & $\mathrm{O}$ & O \\
\hline $\begin{array}{l}\text { I put the situation into } \\
\text { perspective }\end{array}$ & O & $\mathrm{O}$ & $\mathrm{O}$ & O & O \\
\hline $\begin{array}{l}\text { I concentrate on a pleasant } \\
\text { activity }\end{array}$ & $\mathrm{O}$ & $\mathrm{O}$ & O & O & O \\
\hline $\begin{array}{l}\text { I try to make others feel bad } \\
\text { (e.g., being rude, ignoring } \\
\text { them) }\end{array}$ & $\mathrm{O}$ & $\mathrm{O}$ & $\mathrm{O}$ & $\mathrm{O}$ & O \\
\hline $\begin{array}{l}\text { I think about people better off } \\
\text { and make myself feel worse }\end{array}$ & O & O & $\mathrm{O}$ & O & O \\
\hline $\begin{array}{l}\text { I keep the feeling locked up } \\
\text { inside }\end{array}$ & $\mathrm{O}$ & $\mathrm{O}$ & $\mathrm{O}$ & $\mathrm{O}$ & $\mathrm{O}$ \\
\hline
\end{tabular}




\begin{tabular}{|c|c|c|c|c|c|}
\hline $\begin{array}{l}\text { I plan what I could do better } \\
\text { next time }\end{array}$ & $\mathrm{O}$ & $\mathrm{O}$ & $\mathrm{O}$ & $\mathrm{O}$ & O \\
\hline $\begin{array}{l}\text { I bully other people (e.g., } \\
\text { saying nasty thinks to them, } \\
\text { hitting them) }\end{array}$ & $\mathrm{O}$ & $\mathrm{O}$ & $\mathrm{O}$ & $\mathrm{O}$ & O \\
\hline $\begin{array}{l}\text { I take my feelings out on } \\
\text { objects around me (e.g., } \\
\text { deliberately causing damage to } \\
\text { my house, or outdoor things) }\end{array}$ & $\mathrm{O}$ & $\mathrm{O}$ & O & $\mathrm{O}$ & O \\
\hline $\begin{array}{l}\text { Things feel unreal (e.g., I feel } \\
\text { strange, things around me feel } \\
\text { strange, I daydream) }\end{array}$ & $\mathrm{O}$ & $\mathrm{O}$ & $\mathrm{O}$ & $\mathrm{O}$ & O \\
\hline I telephone friends or family & $\mathrm{O}$ & $\mathrm{O}$ & O & $\mathrm{O}$ & $\mathrm{O}$ \\
\hline $\begin{array}{l}\text { I go out and do something nice } \\
\text { (e.g., movies, shopping, go for } \\
\text { a meal, meet people) }\end{array}$ & $\mathrm{O}$ & O & O & $\mathrm{O}$ & O \\
\hline
\end{tabular}




\section{Positive Affect and Responses Survey (PAARS)}

When you are feeling really GOOD, and HAPPY, how likely are you to do any of the following things?

\begin{tabular}{|c|c|c|c|c|c|}
\hline & $\begin{array}{l}1 \text { Not at all } \\
\text { likely }\end{array}$ & 2 & $\begin{array}{l}3 \text { Somewhat } \\
\text { likely }\end{array}$ & 4 & 5 Very likely \\
\hline $\begin{array}{l}\text { Not think about your good } \\
\text { feelings much }\end{array}$ & $\mathrm{O}$ & $\mathrm{O}$ & $\mathrm{O}$ & O & $\mathrm{O}$ \\
\hline $\begin{array}{c}\text { Become physically } \\
\text { affectionate (e.g., hug } \\
\text { someone) }\end{array}$ & $\mathrm{O}$ & $\mathrm{O}$ & $\mathrm{O}$ & $\mathrm{O}$ & $\mathrm{O}$ \\
\hline $\begin{array}{l}\text { Think, "my streak of luck is } \\
\text { going to end soon." }\end{array}$ & $\mathrm{O}$ & O & $\mathrm{O}$ & O & O \\
\hline $\begin{array}{l}\text { Tell a lot of people at once } \\
\text { how good you feel (e.g., post } \\
\text { online, mass text) }\end{array}$ & $\mathrm{O}$ & $\mathrm{O}$ & $\mathrm{O}$ & $\mathrm{O}$ & $\mathrm{O}$ \\
\hline $\begin{array}{c}\text { Decide that your good } \\
\text { feelings are not important }\end{array}$ & $\mathrm{O}$ & $\mathrm{O}$ & $\mathrm{O}$ & $\mathrm{O}$ & $\mathrm{O}$ \\
\hline $\begin{array}{l}\text { Tell a close friend of family } \\
\text { member how happy you are }\end{array}$ & O & $\mathrm{O}$ & $\mathrm{O}$ & $\mathrm{O}$ & $\mathrm{O}$ \\
\hline $\begin{array}{l}\text { Think about how things could } \\
\text { go wrong }\end{array}$ & $\mathrm{O}$ & $\mathrm{O}$ & $\mathrm{O}$ & $\mathrm{O}$ & $\mathrm{O}$ \\
\hline $\begin{array}{c}\text { Really try to enjoy the good } \\
\text { feelings and absorb the } \\
\text { moment }\end{array}$ & $\mathrm{O}$ & $\mathrm{O}$ & $\mathrm{O}$ & $\mathrm{O}$ & $\mathrm{O}$ \\
\hline Think, "I don't deserve this." & $\mathrm{O}$ & $\mathrm{O}$ & $\mathrm{O}$ & $\mathrm{O}$ & $\mathrm{O}$ \\
\hline $\begin{array}{c}\text { Think about how good you } \\
\text { feel }\end{array}$ & $\mathrm{O}$ & $\mathrm{O}$ & $\mathrm{O}$ & $\mathrm{O}$ & $\mathrm{O}$ \\
\hline $\begin{array}{l}\text { Think about how lucky you } \\
\text { are compared to other people }\end{array}$ & $\mathrm{O}$ & $\mathrm{O}$ & $\mathrm{O}$ & $\mathrm{O}$ & $\mathrm{O}$ \\
\hline $\begin{array}{c}\text { Think about things that have } \\
\text { not gone well for you }\end{array}$ & $\mathrm{O}$ & $\mathrm{O}$ & $\mathrm{O}$ & $\mathrm{O}$ & $\mathrm{O}$ \\
\hline $\begin{array}{c}\text { Express your emotions in } \\
\text { some way (e.g., smile, laugh) }\end{array}$ & $\mathrm{O}$ & $\mathrm{O}$ & $\mathrm{O}$ & $\mathrm{O}$ & $\mathrm{O}$ \\
\hline $\begin{array}{c}\text { Tell a person who seems sad } \\
\text { or upset how good you are } \\
\text { feeling }\end{array}$ & O & $\mathrm{O}$ & $\mathrm{O}$ & $\mathrm{O}$ & $\mathrm{O}$ \\
\hline $\begin{array}{l}\text { Remind yourself these } \\
\text { feelings won't last }\end{array}$ & $\mathrm{O}$ & $\mathrm{O}$ & $\mathrm{O}$ & $\mathrm{O}$ & $\mathrm{O}$ \\
\hline $\begin{array}{c}\text { Be careful not to show people } \\
\text { how happy you feel }\end{array}$ & O & $\mathrm{O}$ & $\mathrm{O}$ & $\mathrm{O}$ & $\mathrm{O}$ \\
\hline Not notice that you are happy & $\mathrm{O}$ & $\mathrm{O}$ & $\mathrm{O}$ & $\mathrm{O}$ & $\mathrm{O}$ \\
\hline $\begin{array}{l}\text { Reflect on your good } \\
\text { qualities }\end{array}$ & $\mathrm{O}$ & $\mathrm{O}$ & O & $\mathrm{O}$ & $\mathrm{O}$ \\
\hline
\end{tabular}




\begin{tabular}{|c|c|c|c|c|c|}
\hline $\begin{array}{c}\text { Think, "this is too good to be } \\
\text { true." }\end{array}$ & $\mathrm{O}$ & $\mathrm{O}$ & $\mathrm{O}$ & $\mathrm{O}$ & $\mathrm{O}$ \\
\hline Celebrate your good feelings & $\mathrm{O}$ & $\mathrm{O}$ & $\mathrm{O}$ & $\mathrm{O}$ & $\mathrm{O}$ \\
\hline $\begin{array}{l}\text { Think about how hard it is to } \\
\text { concentrate }\end{array}$ & $\mathrm{O}$ & $\mathrm{O}$ & $\mathrm{O}$ & $\mathrm{O}$ & $\mathrm{O}$ \\
\hline $\begin{array}{l}\text { Mark your feelings in some } \\
\text { way (e.g., take a picture, } \\
\text { write about them) }\end{array}$ & $\mathrm{O}$ & $\mathrm{O}$ & $\mathrm{O}$ & $\mathrm{O}$ & O \\
\hline Be thankful & $\mathrm{O}$ & $\mathrm{O}$ & $\mathrm{O}$ & $\mathrm{O}$ & $\mathrm{O}$ \\
\hline $\begin{array}{l}\text { Think, "people will think I'm } \\
\text { bragging." }\end{array}$ & $\mathrm{O}$ & $\mathrm{O}$ & $\mathrm{O}$ & $\mathrm{O}$ & O \\
\hline $\begin{array}{c}\text { Think about your good } \\
\text { qualities and characteristics }\end{array}$ & $\mathrm{O}$ & $\mathrm{O}$ & O & $\mathrm{O}$ & O \\
\hline
\end{tabular}




\section{Appendix C}

\section{Demographics}

Friend-report Measures

What is your age in years?

What is your gender?
○ Male
- Female
○ Nonbinary

What is your ethnicity? (choose all that apply)
○ White/European
- Black/African
American
- Asian/Asian
- Native American or
American
Alaskan Native
○ Hispanic/Latino
- Native Hawaiian or other Pacific Islander

What is your parents' relationship status?
o Married
○ Separated
○ Divorced
- Single
- Living with partner
○ Widowed

How much difficulty do your parents have paying the bills?
- None/Not at
○ A little
- Some all
A great deal

What is the highest level of education your mother completed?
- Did not attend school
- $8^{\text {th }}$ grade or less
- Some college
○ $9^{\text {th }}-11^{\text {th }}$ grade
- High school graduate
○ Some graduate school
○ 4-year college degree
○ 2-year college degree
o Master's or 2-3-year degree

○ Completed MD or $\mathrm{PhD}$

What is the highest level of education your father completed?
- Did not attend school
$\begin{array}{ll}\circ & 8^{\text {th }} \text { grade or less } \\ \circ & \text { Some college }\end{array}$
- $9^{\text {th }}-11^{\text {th }}$ grade
- High school graduate or equivalent
○ 2-year college degree
○ 4-year college degree $\quad \circ$ Some graduate school
- Master's or 2-3-year degree
- Completed MD or $\mathrm{PhD}$


What is your current living situation?
I I live alone
I I live with a roommate
I live with my mother or mother-figure only
- I live with my father or father-figure only
- I live with both of my parents
o Other

Do you attend West Virginia University?
○ Yes
○ No

The following questions are about your relationship with your friend.

\begin{tabular}{|l|l|l|l|l|l|l|l|l|l|l|}
\hline \multicolumn{1}{|l|}{ Friend } & Best Friend \\
\hline 0 & 10 & 20 & 30 & 40 & 50 & 60 & 70 & 80 & 90 & 100 \\
\hline
\end{tabular}

Use the slider to illustrate how you consider your friend. 


\section{Schedule of Positive and Negative Experiences (SPANE)}

Please think about what you have been doing and experiencing during the past four weeks. Then report how much you experience each of the following feelings, using the scale below. For each item, select a number from 1 to 5 .

\begin{tabular}{|c|c|c|c|c|c|}
\hline & $\begin{array}{l}1 \text { Very Rarely } \\
\text { or Never }\end{array}$ & 2 Rarely & 3 Sometimes & 4 Often & $\begin{array}{c}5 \text { Very Often or } \\
\text { Always }\end{array}$ \\
\hline Positive & $\mathrm{O}$ & $\mathrm{O}$ & 0 & $\mathrm{O}$ & 0 \\
\hline Negative & $\mathrm{O}$ & $\mathrm{O}$ & $\mathrm{O}$ & $\mathrm{O}$ & $\mathrm{O}$ \\
\hline Good & $\mathrm{O}$ & $\mathrm{O}$ & $\mathrm{O}$ & O & $\mathrm{O}$ \\
\hline $\mathrm{Bad}$ & 0 & $\mathrm{O}$ & $\mathrm{O}$ & O & 0 \\
\hline Pleasant & $\mathrm{O}$ & $\mathrm{O}$ & $\mathrm{O}$ & $\mathrm{O}$ & $\mathrm{O}$ \\
\hline Unpleasant & $\mathrm{O}$ & $\mathrm{O}$ & $\mathrm{O}$ & $\mathrm{O}$ & $\mathrm{O}$ \\
\hline Happy & $\mathrm{O}$ & $\mathrm{O}$ & $\mathrm{O}$ & $\mathrm{O}$ & $\mathrm{O}$ \\
\hline $\mathrm{Sad}$ & $\mathrm{O}$ & $\mathrm{O}$ & $\mathrm{O}$ & $\mathrm{O}$ & $\mathrm{O}$ \\
\hline Afraid & $\mathrm{O}$ & $\mathrm{O}$ & $\mathrm{O}$ & $\mathrm{O}$ & $\mathrm{O}$ \\
\hline Joyful & $\mathrm{O}$ & 0 & $\mathrm{O}$ & $\mathrm{O}$ & $\mathrm{O}$ \\
\hline Angry & $\mathrm{O}$ & 0 & 0 & O & $\mathrm{O}$ \\
\hline Contented & $\mathrm{O}$ & 0 & 0 & 0 & $\mathrm{O}$ \\
\hline
\end{tabular}




\section{Subjective Happiness Scale (SHS)}

For each of the following statements and/or questions, please select the point on the scale that you feel is most appropriate in describing you.

\begin{tabular}{|c|c|c|c|c|c|c|c|}
\hline & $\begin{array}{c}1 \text { not a } \\
\text { very } \\
\text { happy } \\
\text { person }\end{array}$ & 2 & 3 & 4 & 5 & 6 & $\begin{array}{c}7 \text { a very } \\
\text { happy } \\
\text { person }\end{array}$ \\
\hline $\begin{array}{c}\text { In general, I } \\
\text { consider myself: }\end{array}$ & O & 0 & 0 & 0 & 0 & 0 & $\bigcirc$ \\
\hline
\end{tabular}

\begin{tabular}{|c|c|c|c|c|c|c|c|}
\hline & $\begin{array}{c}1 \text { less } \\
\text { happy }\end{array}$ & 2 & 3 & 4 & 5 & 6 & $\begin{array}{c}7 \text { more } \\
\text { happy }\end{array}$ \\
\hline $\begin{array}{c}\text { Compared to most } \\
\text { of my peers, I } \\
\text { consider myself: }\end{array}$ & 0 & 0 & 0 & $\bigcirc$ & 0 & $\bigcirc$ & $\bigcirc$ \\
\hline
\end{tabular}

\begin{tabular}{|c|c|c|c|c|c|c|c|}
\hline & $\begin{array}{c}1 \text { not at } \\
\text { all }\end{array}$ & 2 & 3 & 4 & 5 & 6 & $\begin{array}{c}7 \text { a great } \\
\text { deal }\end{array}$ \\
\hline $\begin{array}{c}\text { Some people are } \\
\text { generally very } \\
\text { happy. they enjoy } \\
\text { life regardless of } \\
\text { what is going on, } \\
\text { getting the most out } \\
\text { of everything. To } \\
\text { what extent does } \\
\text { this characterization } \\
\text { describe you? }\end{array}$ & 0 & 0 & 0 & 0 & 0 & 0 & 0 \\
\hline $\begin{array}{c}\text { Some people are } \\
\text { generally not very } \\
\text { happy. Although } \\
\text { they are not } \\
\text { depressed, they } \\
\text { never seem as } \\
\text { happy as they might } \\
\text { be. To what extent } \\
\text { does this } \\
\text { characterization } \\
\text { describe you? }\end{array}$ & 0 & 0 & 0 & 0 & 0 & 0 & \\
\hline
\end{tabular}




\section{Satisfaction with Life Scale (SWLS)}

Below are five statements that you may agree or disagree with. Using the 1-7 scale below, indicate your agreement with each item by selecting the option by that item. Please be open and honest in your responding.

\begin{tabular}{|c|c|c|c|c|c|c|c|}
\hline & $\begin{array}{c}\text { 1 Strongly } \\
\text { disagree }\end{array}$ & $\begin{array}{c}2 \\
\text { Disagree }\end{array}$ & $\begin{array}{c}3 \text { Slightly } \\
\text { disagree }\end{array}$ & $\begin{array}{c}4 \text { Neither } \\
\text { agree nor } \\
\text { disagree }\end{array}$ & $\begin{array}{c}5 \text { Slightly } \\
\text { agree }\end{array}$ & 6 Agree & $\begin{array}{c}7 \text { Strongly } \\
\text { agree }\end{array}$ \\
\hline $\begin{array}{c}\text { In most ways, my } \\
\text { life is close to my } \\
\text { ideal }\end{array}$ & 0 & 0 & 0 & 0 & 0 & 0 & 0 \\
\hline $\begin{array}{c}\text { The conditions of } \\
\text { my life are } \\
\text { excellent }\end{array}$ & 0 & 0 & 0 & 0 & 0 & 0 & 0 \\
\hline $\begin{array}{c}\text { I am satisfied with } \\
\text { my life }\end{array}$ & O & 0 & 0 & 0 & 0 & 0 & 0 \\
\hline $\begin{array}{c}\text { So far, I have } \\
\text { gotten the } \\
\text { important things I } \\
\text { want in life }\end{array}$ & 0 & 0 & 0 & 0 & 0 & 0 & 0 \\
\hline $\begin{array}{c}\text { If I could live my } \\
\text { life over, I would } \\
\text { change almost } \\
\text { nothing }\end{array}$ & 0 & 0 & 0 & 0 & 0 & 0 & 0 \\
\hline
\end{tabular}




\section{Closeness with Friend}

The following questions are about your relationship with your FRIEND. Please answer them as honestly as possible.

\begin{tabular}{|c|c|c|c|c|c|}
\hline & 1 not at all & 2 & 3 & 4 & 5 very \\
\hline $\begin{array}{l}\text { How openly do you talk with } \\
\text { your friend? }\end{array}$ & 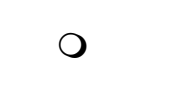 & O & O & $\mathrm{O}$ & O \\
\hline $\begin{array}{l}\text { How careful do you feel you } \\
\text { have to about what you say to } \\
\text { your friend? }\end{array}$ & 0 & O & O & O & 0 \\
\hline $\begin{array}{l}\text { How comfortable do you feel } \\
\text { admitting doubts and fears to } \\
\text { your friend }\end{array}$ & 0 & O & O & O & 0 \\
\hline $\begin{array}{l}\text { How interested in your friend in } \\
\text { talking to you when you want to } \\
\text { talk? }\end{array}$ & $\mathrm{O}$ & O & 0 & O & 0 \\
\hline $\begin{array}{l}\text { How often does your friend } \\
\text { express affection or liking for } \\
\text { you? }\end{array}$ & O & O & O & O & 0 \\
\hline $\begin{array}{c}\text { How well does your friend know } \\
\text { what you are really like? }\end{array}$ & O & O & $\mathrm{O}$ & O & 0 \\
\hline $\begin{array}{l}\text { How confident are you that your } \\
\text { friend would help if you had a } \\
\text { problem }\end{array}$ & 0 & O & 0 & O & 0 \\
\hline $\begin{array}{l}\text { If you needed money, how } \\
\text { comfortable would you be } \\
\text { asking your friend for it? }\end{array}$ & O & $\mathrm{O}$ & $\mathrm{O}$ & O & $\mathrm{O}$ \\
\hline $\begin{array}{c}\text { How interested is your friend in } \\
\text { the things you do? }\end{array}$ & O & 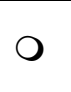 & 0 & 0 & 0 \\
\hline
\end{tabular}




\section{Friend Emotion Socialization of Emerging Adult}

In the last six months, when your FRIEND was SAD, what did YOU do?

\begin{tabular}{|c|c|c|c|c|c|}
\hline & $\begin{array}{l}1 \text { not at all } \\
\text { typical }\end{array}$ & 2 & $\begin{array}{l}3 \text { somewhat } \\
\text { typical }\end{array}$ & 4 & $\begin{array}{l}5 \text { very } \\
\text { typical }\end{array}$ \\
\hline $\begin{array}{c}\text { Say something like, "You're } \\
\text { being ridiculous," or, "You're } \\
\text { being stupid." }\end{array}$ & $\mathrm{O}$ & O & $\mathrm{O}$ & O & O \\
\hline $\begin{array}{l}\text { Please answer 3, "somewhat } \\
\text { typical." For this question. }\end{array}$ & $\mathrm{O}$ & $\mathrm{O}$ & $\mathrm{O}$ & $\mathrm{O}$ & $\mathrm{O}$ \\
\hline $\begin{array}{l}\text { Tell them that things aren't so } \\
\text { bad }\end{array}$ & $\mathrm{O}$ & $\mathrm{O}$ & $\mathrm{O}$ & $\mathrm{O}$ & $\mathrm{O}$ \\
\hline $\begin{array}{c}\text { Say something like, "Cheer } \\
\text { up!" }\end{array}$ & $\mathrm{O}$ & $\mathrm{O}$ & O & $\mathrm{O}$ & O \\
\hline $\begin{array}{l}\text { Tell them that they have a good } \\
\text { reason to feel sad }\end{array}$ & $\mathrm{O}$ & $\mathrm{O}$ & $\mathrm{O}$ & $\mathrm{O}$ & $\mathrm{O}$ \\
\hline $\begin{array}{l}\text { Leave them out of the group or } \\
\text { any activities for a while }\end{array}$ & O & O & $\mathrm{O}$ & O & $\mathrm{O}$ \\
\hline Push them away or hit them & $\mathrm{O}$ & $\mathrm{O}$ & $\mathrm{O}$ & $\mathrm{O}$ & $\mathrm{O}$ \\
\hline $\begin{array}{l}\text { Say something like, "It's okay, } \\
\text { we all feel sad sometimes." }\end{array}$ & $\mathrm{O}$ & $\mathrm{O}$ & $\mathrm{O}$ & $\mathrm{O}$ & $\mathrm{O}$ \\
\hline $\begin{array}{l}\text { Ignore the fact that they feel } \\
\text { sad }\end{array}$ & O & $\mathrm{O}$ & O & O & O \\
\hline Get sad too & $\mathrm{O}$ & $\mathrm{O}$ & $\mathrm{O}$ & $\mathrm{O}$ & $\mathrm{O}$ \\
\hline $\begin{array}{l}\text { Act like you don't notice that } \\
\text { they feel sad }\end{array}$ & $\mathrm{O}$ & $\mathrm{O}$ & $\mathrm{O}$ & $\mathrm{O}$ & $\mathrm{O}$ \\
\hline Not say or do anything about it & $\mathrm{O}$ & $\mathrm{O}$ & $\mathrm{O}$ & $\mathrm{O}$ & $\mathrm{O}$ \\
\hline $\begin{array}{l}\text { Try to get them to do } \\
\text { something else to take their } \\
\text { mind off feeling sad }\end{array}$ & O & O & O & O & O \\
\hline $\begin{array}{l}\text { Say that you will stop liking } \\
\text { them if they don't change their } \\
\text { attitude }\end{array}$ & $\mathrm{O}$ & O & O & O & $\mathrm{O}$ \\
\hline $\begin{array}{l}\text { Ask them about what has made } \\
\text { them feel sad }\end{array}$ & $\mathrm{O}$ & $\mathrm{O}$ & O & O & O \\
\hline $\begin{array}{l}\text { Tell other people secrets and } \\
\text { mean things about them }\end{array}$ & O & $\mathrm{O}$ & $\mathrm{O}$ & O & $\mathrm{O}$ \\
\hline $\begin{array}{l}\text { Say that you don't like it when } \\
\text { they act this way }\end{array}$ & O & O & O & O & O \\
\hline Get upset at what is going on & $\mathrm{O}$ & $\mathrm{O}$ & $\mathrm{O}$ & $\mathrm{O}$ & $\mathrm{O}$ \\
\hline
\end{tabular}


In the last six months, when your FRIEND was ANGRY, what did YOU do?

\begin{tabular}{|c|c|c|c|c|c|}
\hline & $\begin{array}{c}1 \text { not at all } \\
\text { typical }\end{array}$ & 2 & $\begin{array}{l}3 \text { somewhat } \\
\text { typical }\end{array}$ & 4 & 5 very typical \\
\hline $\begin{array}{l}\text { Say something like, "Cheer } \\
\text { up!" }\end{array}$ & $\mathrm{O}$ & $\mathrm{O}$ & $\mathrm{O}$ & $\mathrm{O}$ & $\mathrm{O}$ \\
\hline Not say or do anything about it & $\mathrm{O}$ & $\mathrm{O}$ & $\mathrm{O}$ & $\mathrm{O}$ & $\mathrm{O}$ \\
\hline Push them away or hit them & 0 & 0 & 0 & 0 & 0 \\
\hline Get upset at what is going on & $\mathrm{O}$ & $\mathrm{O}$ & $\mathrm{O}$ & $\mathrm{O}$ & $\mathrm{O}$ \\
\hline Get angry too & O & $\mathrm{O}$ & $\mathrm{O}$ & $\mathrm{O}$ & $\mathrm{O}$ \\
\hline $\begin{array}{c}\text { Say something like, "You're } \\
\text { being ridiculous," or "You're } \\
\text { stupid." }\end{array}$ & O & $\mathrm{O}$ & $\mathrm{O}$ & $\mathrm{O}$ & $\mathrm{O}$ \\
\hline $\begin{array}{l}\text { Ask them about what has made } \\
\text { them feel angry }\end{array}$ & $\mathrm{O}$ & $\mathrm{O}$ & O & $\mathrm{O}$ & O \\
\hline $\begin{array}{l}\text { Tell them that they have a good } \\
\text { reason to feel really angry }\end{array}$ & $\mathrm{O}$ & $\mathrm{O}$ & O & $\mathrm{O}$ & $\mathrm{O}$ \\
\hline $\begin{array}{l}\text { Tell other people secrets or } \\
\text { mean things about them }\end{array}$ & $\mathrm{O}$ & $\mathrm{O}$ & O & $\mathrm{O}$ & $\mathrm{O}$ \\
\hline $\begin{array}{l}\text { Try to get them to do } \\
\text { something else, to take their } \\
\text { mind off feeling angry }\end{array}$ & O & $\mathrm{O}$ & $\mathrm{O}$ & O & $\mathrm{O}$ \\
\hline $\begin{array}{l}\text { Act like you don't notice that } \\
\text { they feel angry }\end{array}$ & $\mathrm{O}$ & $\mathrm{O}$ & O & $\mathrm{O}$ & $\mathrm{O}$ \\
\hline $\begin{array}{l}\text { Say something like, "It's okay, } \\
\text { we all feel angry sometimes." }\end{array}$ & $\mathrm{O}$ & $\mathrm{O}$ & O & $\mathrm{O}$ & $\mathrm{O}$ \\
\hline $\begin{array}{l}\text { Leave them out of the group or } \\
\text { any activities for a while }\end{array}$ & $\mathrm{O}$ & O & O & $\mathrm{O}$ & $\mathrm{O}$ \\
\hline $\begin{array}{l}\text { Tell them that things aren't so } \\
\text { bad }\end{array}$ & $\mathrm{O}$ & $\mathrm{O}$ & 0 & 0 & 0 \\
\hline $\begin{array}{l}\text { Say that you don't like it when } \\
\text { they act this way }\end{array}$ & O & O & O & 0 & $\mathrm{O}$ \\
\hline $\begin{array}{c}\text { Say that you'll stop liking them } \\
\text { if they don't change their } \\
\text { attitude }\end{array}$ & 0 & 0 & 0 & 0 & 0 \\
\hline $\begin{array}{l}\text { Ignore the fact that they feel } \\
\text { angry }\end{array}$ & O & O & O & 0 & 0 \\
\hline $\begin{array}{l}\text { Help them to deal with what } \\
\text { has made them feel angry }\end{array}$ & $\mathrm{O}$ & 0 & O & $\mathrm{O}$ & $\mathrm{O}$ \\
\hline
\end{tabular}


In the last six months, when your FRIEND was WORRIED/ANXIOUS, what did YOU do?

\begin{tabular}{|c|c|c|c|c|c|}
\hline & $\begin{array}{l}1 \text { not at all } \\
\text { typical }\end{array}$ & 2 & $\begin{array}{l}3 \text { somewhat } \\
\text { typical }\end{array}$ & 4 & 5 very typical \\
\hline $\begin{array}{l}\text { Tell them that things aren't so } \\
\text { bad }\end{array}$ & O & O & O & O & O \\
\hline $\begin{array}{l}\text { Help them to deal with what } \\
\text { has made them feel worried }\end{array}$ & $\mathrm{O}$ & $\mathrm{O}$ & O & O & O \\
\hline $\begin{array}{l}\text { Tell them that they have a god } \\
\text { reason to be really worried }\end{array}$ & $\mathrm{O}$ & O & $\mathrm{O}$ & $\mathrm{O}$ & O \\
\hline $\begin{array}{l}\text { Say something like, "Cheer } \\
\text { up!” }\end{array}$ & $\mathrm{O}$ & O & $\mathrm{O}$ & $\mathrm{O}$ & $\mathrm{O}$ \\
\hline Get worried too & 0 & $\mathrm{O}$ & $\mathrm{O}$ & $\mathrm{O}$ & 0 \\
\hline $\begin{array}{l}\text { Leave the, out of the group or } \\
\text { any activities for a while }\end{array}$ & $\mathrm{O}$ & O & $\mathrm{O}$ & $\mathrm{O}$ & $\mathrm{O}$ \\
\hline $\begin{array}{l}\text { Say something like, "It's okay, } \\
\text { we all feel worried sometimes." }\end{array}$ & $\mathrm{O}$ & $\mathrm{O}$ & $\mathrm{O}$ & $\mathrm{O}$ & $\mathrm{O}$ \\
\hline $\begin{array}{l}\text { Say that you don't like it when } \\
\text { they act this way }\end{array}$ & $\mathrm{O}$ & O & $\mathrm{O}$ & $\mathrm{O}$ & $\mathrm{O}$ \\
\hline $\begin{array}{l}\text { Act like you don't notice that } \\
\text { they feel worried }\end{array}$ & $\mathrm{O}$ & $\mathrm{O}$ & $\mathrm{O}$ & $\mathrm{O}$ & O \\
\hline $\begin{array}{l}\text { Try to get them to do } \\
\text { something else, to take their } \\
\text { mind off feeling worried }\end{array}$ & $\mathrm{O}$ & O & $\mathrm{O}$ & $\mathrm{O}$ & O \\
\hline Push them away or hit them & $\mathrm{O}$ & $\mathrm{O}$ & $\mathrm{O}$ & $\mathrm{O}$ & $\mathrm{O}$ \\
\hline $\begin{array}{l}\text { Tell other people secrets or } \\
\text { mean things about them }\end{array}$ & O & $\mathrm{O}$ & O & O & O \\
\hline $\begin{array}{l}\text { Ask them about what has made } \\
\text { them feel worried }\end{array}$ & O & O & O & O & O \\
\hline Get upset at what is going on & $\mathrm{O}$ & $\mathrm{O}$ & $\mathrm{O}$ & $\mathrm{O}$ & $\mathrm{O}$ \\
\hline Not say or do anything about it & $\mathrm{O}$ & $\mathrm{O}$ & $\mathrm{O}$ & $\mathrm{O}$ & $\mathrm{O}$ \\
\hline $\begin{array}{l}\text { Ignore the fact that they feel } \\
\text { worried }\end{array}$ & O & O & $\mathrm{O}$ & $\mathrm{O}$ & O \\
\hline $\begin{array}{c}\text { Say something like "You're } \\
\text { being ridiculous," or "You're } \\
\text { stupid" }\end{array}$ & $\mathrm{O}$ & $\mathrm{O}$ & $\mathrm{O}$ & O & O \\
\hline $\begin{array}{l}\text { Say you'll stop liking them if } \\
\text { they don't change their attitude }\end{array}$ & O & $\mathrm{O}$ & $\mathrm{O}$ & O & $\mathrm{O}$ \\
\hline
\end{tabular}


In the last six months, when your FRIEND was HAPPY, what did YOU do?

\begin{tabular}{|c|c|c|c|c|c|}
\hline & $\begin{array}{l}1 \text { not at all } \\
\text { typical }\end{array}$ & 2 & $\begin{array}{l}3 \text { somewhat } \\
\text { typical }\end{array}$ & 4 & 5 very typical \\
\hline Not ask about it & $\mathrm{O}$ & $\mathrm{O}$ & $\mathrm{O}$ & 0 & 0 \\
\hline $\begin{array}{l}\text { Show that you don't like } \\
\text { their being happy }\end{array}$ & $\mathrm{O}$ & $\mathrm{O}$ & $\mathrm{O}$ & $\mathrm{O}$ & $\mathrm{O}$ \\
\hline $\begin{array}{l}\text { Encourage them to share } \\
\text { their happiness }\end{array}$ & $\mathrm{O}$ & $\mathrm{O}$ & $\mathrm{O}$ & $\mathrm{O}$ & O \\
\hline Say you are happy too & $\mathrm{O}$ & $\mathrm{O}$ & O & $\mathrm{O}$ & $\mathrm{O}$ \\
\hline Join in their happiness & $\mathrm{O}$ & $\mathrm{O}$ & $\mathrm{O}$ & $\mathrm{O}$ & $\mathrm{O}$ \\
\hline Change the subject & $\mathrm{O}$ & $\mathrm{O}$ & $\mathrm{O}$ & $\mathrm{O}$ & $\mathrm{O}$ \\
\hline Become very happy yourself & $\mathrm{O}$ & $\mathrm{O}$ & $\mathrm{O}$ & $\mathrm{O}$ & $\mathrm{O}$ \\
\hline $\begin{array}{l}\text { Tell them that there are other } \\
\text { things that are more } \\
\text { important }\end{array}$ & $\mathrm{O}$ & O & $\mathrm{O}$ & $\mathrm{O}$ & $\mathrm{O}$ \\
\hline $\begin{array}{l}\text { Not be interested in why } \\
\text { they are happy }\end{array}$ & $\mathrm{O}$ & O & $\mathrm{O}$ & $\mathrm{O}$ & $\mathrm{O}$ \\
\hline $\begin{array}{l}\text { Notice their feelings and } \\
\text { quickly move on to } \\
\text { something else }\end{array}$ & $\mathrm{O}$ & $\mathrm{O}$ & $\mathrm{O}$ & $\mathrm{O}$ & $\mathrm{O}$ \\
\hline Usually isn't around & $\mathrm{O}$ & $\mathrm{O}$ & $\mathrm{O}$ & $\mathrm{O}$ & $\mathrm{O}$ \\
\hline Not notice & $\mathrm{O}$ & $\mathrm{O}$ & $\mathrm{O}$ & $\mathrm{O}$ & $\mathrm{O}$ \\
\hline $\begin{array}{l}\text { Tell them to keep it to } \\
\text { themselves }\end{array}$ & $\mathrm{O}$ & $\mathrm{O}$ & $\mathrm{O}$ & $\mathrm{O}$ & $\mathrm{O}$ \\
\hline Tell them to settle down & $\mathrm{O}$ & O & $\mathrm{O}$ & 0 & $\mathrm{O}$ \\
\hline Listen to them & $\mathrm{O}$ & 0 & 0 & 0 & 0 \\
\hline
\end{tabular}




\section{Regulation of Emotions Questionnaire (REQ)}

The following questions ask you to think about how often you do certain things in response to your emotions. You do not have to think about specific negative emotions but just how often you generally do the things listed below when you feel badly. Please select the answer that fits best. We all respond to our emotions in different ways so there are no right or wrong answers.

\begin{tabular}{|c|c|c|c|c|c|}
\hline & 1 Never & 2 Seldom & 3 Often & 4 Very Often & 5 Always \\
\hline $\begin{array}{l}\text { I talk to someone about how I } \\
\text { feel }\end{array}$ & O & O & $\mathrm{O}$ & $\mathrm{O}$ & $\mathrm{O}$ \\
\hline $\begin{array}{l}\text { I take my feelings out on others } \\
\text { verbally (e.g., shouting, } \\
\text { arguing) }\end{array}$ & O & O & $\mathrm{O}$ & $\mathrm{O}$ & O \\
\hline $\begin{array}{c}\text { I seek physical contact from } \\
\text { friends or family (e.g., a hug, } \\
\text { hold hands) }\end{array}$ & $\mathrm{O}$ & $\mathrm{O}$ & $\mathrm{O}$ & $\mathrm{O}$ & $\mathrm{O}$ \\
\hline $\begin{array}{l}\text { I review (rethink) my thoughts } \\
\text { or beliefs }\end{array}$ & $\mathrm{O}$ & $\mathrm{O}$ & $\mathrm{O}$ & $\mathrm{O}$ & O \\
\hline $\begin{array}{l}\text { I harm or punish myself in } \\
\text { some way }\end{array}$ & $\mathrm{O}$ & $\mathrm{O}$ & $\mathrm{O}$ & $\mathrm{O}$ & O \\
\hline $\begin{array}{l}\text { I do something energetic (e.g., } \\
\text { play sport, go for a walk) }\end{array}$ & O & $\mathrm{O}$ & $\mathrm{O}$ & $\mathrm{O}$ & O \\
\hline $\begin{array}{l}\text { I dwell on my thoughts and } \\
\text { feelings (e.g., it goes around } \\
\text { and around in my head and I } \\
\text { can't stop it) }\end{array}$ & O & $\mathrm{O}$ & O & O & O \\
\hline I ask others for advice & $\mathrm{O}$ & $\mathrm{O}$ & $\mathrm{O}$ & $\mathrm{O}$ & $\mathrm{O}$ \\
\hline $\begin{array}{l}\text { I review (rethink) my goals or } \\
\text { plans }\end{array}$ & O & O & 0 & $\mathrm{O}$ & O \\
\hline $\begin{array}{c}\text { I take my feelings out on others } \\
\text { physically (e.g., fighting, } \\
\text { lashing out) }\end{array}$ & $\mathrm{O}$ & $\mathrm{O}$ & $\mathrm{O}$ & $\mathrm{O}$ & O \\
\hline $\begin{array}{l}\text { I put the situation into } \\
\text { perspective }\end{array}$ & O & $\mathrm{O}$ & $\mathrm{O}$ & O & O \\
\hline $\begin{array}{l}\text { I concentrate on a pleasant } \\
\text { activity }\end{array}$ & $\mathrm{O}$ & $\mathrm{O}$ & O & O & O \\
\hline $\begin{array}{l}\text { I try to make others feel bad } \\
\text { (e.g., being rude, ignoring } \\
\text { them) }\end{array}$ & $\mathrm{O}$ & $\mathrm{O}$ & $\mathrm{O}$ & $\mathrm{O}$ & O \\
\hline $\begin{array}{l}\text { I think about people better off } \\
\text { and make myself feel worse }\end{array}$ & O & O & $\mathrm{O}$ & O & O \\
\hline $\begin{array}{l}\text { I keep the feeling locked up } \\
\text { inside }\end{array}$ & $\mathrm{O}$ & $\mathrm{O}$ & $\mathrm{O}$ & $\mathrm{O}$ & $\mathrm{O}$ \\
\hline
\end{tabular}




\begin{tabular}{|c|c|c|c|c|c|}
\hline $\begin{array}{l}\text { I plan what I could do better } \\
\text { next time }\end{array}$ & O & $\mathrm{O}$ & $\mathrm{O}$ & $\mathrm{O}$ & O \\
\hline $\begin{array}{l}\text { I bully other people (e.g., } \\
\text { saying nasty thinks to them, } \\
\text { hitting them) }\end{array}$ & $\mathrm{O}$ & $\mathrm{O}$ & $\mathrm{O}$ & $\mathrm{O}$ & O \\
\hline $\begin{array}{l}\text { I take my feelings out on } \\
\text { objects around me (e.g., } \\
\text { deliberately causing damage to } \\
\text { my house, or outdoor things) }\end{array}$ & $\mathrm{O}$ & $\mathrm{O}$ & $\mathrm{O}$ & $\mathrm{O}$ & $\mathrm{O}$ \\
\hline $\begin{array}{l}\text { Things feel unreal (e.g., I feel } \\
\text { strange, things around me feel } \\
\text { strange, I daydream) }\end{array}$ & $\mathrm{O}$ & $\mathrm{O}$ & $\mathrm{O}$ & $\mathrm{O}$ & O \\
\hline I telephone friends or family & O & $\mathrm{O}$ & $\mathrm{O}$ & $\mathrm{O}$ & $\mathrm{O}$ \\
\hline $\begin{array}{l}\text { I go out and do something nice } \\
\text { (e.g., movies, shopping, go for } \\
\text { a meal, meet people) }\end{array}$ & $\mathrm{O}$ & $\mathrm{O}$ & $\mathrm{O}$ & O & $\mathrm{O}$ \\
\hline
\end{tabular}




\section{Positive Affect and Responses Survey (PAARS)}

When you are feeling really GOOD, and HAPPY, how likely are you to do any of the following things?

\begin{tabular}{|c|c|c|c|c|c|}
\hline & $\begin{array}{l}1 \text { Not at all } \\
\text { likely }\end{array}$ & 2 & $\begin{array}{l}3 \text { Somewhat } \\
\text { likely }\end{array}$ & 4 & 5 Very likely \\
\hline $\begin{array}{l}\text { Not think about your good } \\
\text { feelings much }\end{array}$ & $\mathrm{O}$ & O & $\mathrm{O}$ & O & O \\
\hline $\begin{array}{c}\text { Become physically } \\
\text { affectionate (e.g., hug } \\
\text { someone) }\end{array}$ & $\mathrm{O}$ & $\mathrm{O}$ & $\mathrm{O}$ & $\mathrm{O}$ & $\mathrm{O}$ \\
\hline $\begin{array}{l}\text { Think, "my streak of luck is } \\
\text { going to end soon." }\end{array}$ & $\mathrm{O}$ & $\mathrm{O}$ & O & O & $\mathrm{O}$ \\
\hline $\begin{array}{l}\text { Tell a lot of people at once } \\
\text { how good you feel (e.g., post } \\
\text { online, mass text) }\end{array}$ & $\mathrm{O}$ & $\mathrm{O}$ & O & $\mathrm{O}$ & O \\
\hline $\begin{array}{c}\text { Decide that your good } \\
\text { feelings are not important }\end{array}$ & $\mathrm{O}$ & $\mathrm{O}$ & $\mathrm{O}$ & $\mathrm{O}$ & $\mathrm{O}$ \\
\hline $\begin{array}{l}\text { Tell a close friend of family } \\
\text { member how happy you are }\end{array}$ & $\mathrm{O}$ & $\mathrm{O}$ & $\mathrm{O}$ & O & $\mathrm{O}$ \\
\hline $\begin{array}{l}\text { Think about how things could } \\
\text { go wrong }\end{array}$ & $\mathrm{O}$ & O & $\mathrm{O}$ & $\mathrm{O}$ & $\mathrm{O}$ \\
\hline $\begin{array}{c}\text { Really try to enjoy the good } \\
\text { feelings and absorb the } \\
\text { moment }\end{array}$ & $\mathrm{O}$ & $\mathrm{O}$ & $\mathrm{O}$ & O & $\mathrm{O}$ \\
\hline Think, "I don't deserve this." & $\mathrm{O}$ & $\mathrm{O}$ & $\mathrm{O}$ & $\mathrm{O}$ & $\mathrm{O}$ \\
\hline $\begin{array}{l}\text { Think about how good you } \\
\text { feel }\end{array}$ & $\mathrm{O}$ & $\mathrm{O}$ & $\mathrm{O}$ & O & $\mathrm{O}$ \\
\hline $\begin{array}{l}\text { Think about how lucky you } \\
\text { are compared to other people }\end{array}$ & $\mathrm{O}$ & $\mathrm{O}$ & O & O & O \\
\hline $\begin{array}{l}\text { Think about things that have } \\
\text { not gone well for you }\end{array}$ & $\mathrm{O}$ & $\mathrm{O}$ & $\mathrm{O}$ & $\mathrm{O}$ & O \\
\hline $\begin{array}{c}\text { Express your emotions in } \\
\text { some way (e.g., smile, laugh) }\end{array}$ & O & O & O & $\mathrm{O}$ & O \\
\hline $\begin{array}{c}\text { Tell a person who seems sad } \\
\text { or upset how good you are } \\
\text { feeling }\end{array}$ & $\mathrm{O}$ & O & $\mathrm{O}$ & $\mathrm{O}$ & O \\
\hline $\begin{array}{l}\text { Remind yourself these } \\
\text { feelings won't last }\end{array}$ & $\mathrm{O}$ & $\mathrm{O}$ & $\mathrm{O}$ & $\mathrm{O}$ & $\mathrm{O}$ \\
\hline $\begin{array}{c}\text { Be careful not to show people } \\
\text { how happy you feel }\end{array}$ & $\mathrm{O}$ & $\mathrm{O}$ & $\mathrm{O}$ & $\mathrm{O}$ & O \\
\hline Not notice that you are happy & $\mathrm{O}$ & $\mathrm{O}$ & $\mathrm{O}$ & $\mathrm{O}$ & $\mathrm{O}$ \\
\hline $\begin{array}{c}\text { Reflect on your good } \\
\text { qualities }\end{array}$ & $\mathrm{O}$ & O & $\mathrm{O}$ & O & O \\
\hline
\end{tabular}




\begin{tabular}{|c|c|c|c|c|c|}
\hline $\begin{array}{c}\text { Think, "this is too good to be } \\
\text { true." }\end{array}$ & $\mathrm{O}$ & $\mathrm{O}$ & $\mathrm{O}$ & $\mathrm{O}$ & $\mathrm{O}$ \\
\hline Celebrate your good feelings & $\mathrm{O}$ & $\mathrm{O}$ & $\mathrm{O}$ & $\mathrm{O}$ & $\mathrm{O}$ \\
\hline $\begin{array}{l}\text { Think about how hard it is to } \\
\text { concentrate }\end{array}$ & $\mathrm{O}$ & $\mathrm{O}$ & $\mathrm{O}$ & $\mathrm{O}$ & $\mathrm{O}$ \\
\hline $\begin{array}{l}\text { Mark your feelings in some } \\
\text { way (e.g., take a picture, } \\
\text { write about them) }\end{array}$ & $\mathrm{O}$ & $\mathrm{O}$ & $\mathrm{O}$ & $\mathrm{O}$ & O \\
\hline Be thankful & $\mathrm{O}$ & $\mathrm{O}$ & $\mathrm{O}$ & $\mathrm{O}$ & $\mathrm{O}$ \\
\hline $\begin{array}{l}\text { Think, "people will think I'm } \\
\text { bragging." }\end{array}$ & $\mathrm{O}$ & $\mathrm{O}$ & $\mathrm{O}$ & $\mathrm{O}$ & O \\
\hline $\begin{array}{c}\text { Think about your good } \\
\text { qualities and characteristics }\end{array}$ & $\mathrm{O}$ & $\mathrm{O}$ & O & $\mathrm{O}$ & O \\
\hline
\end{tabular}




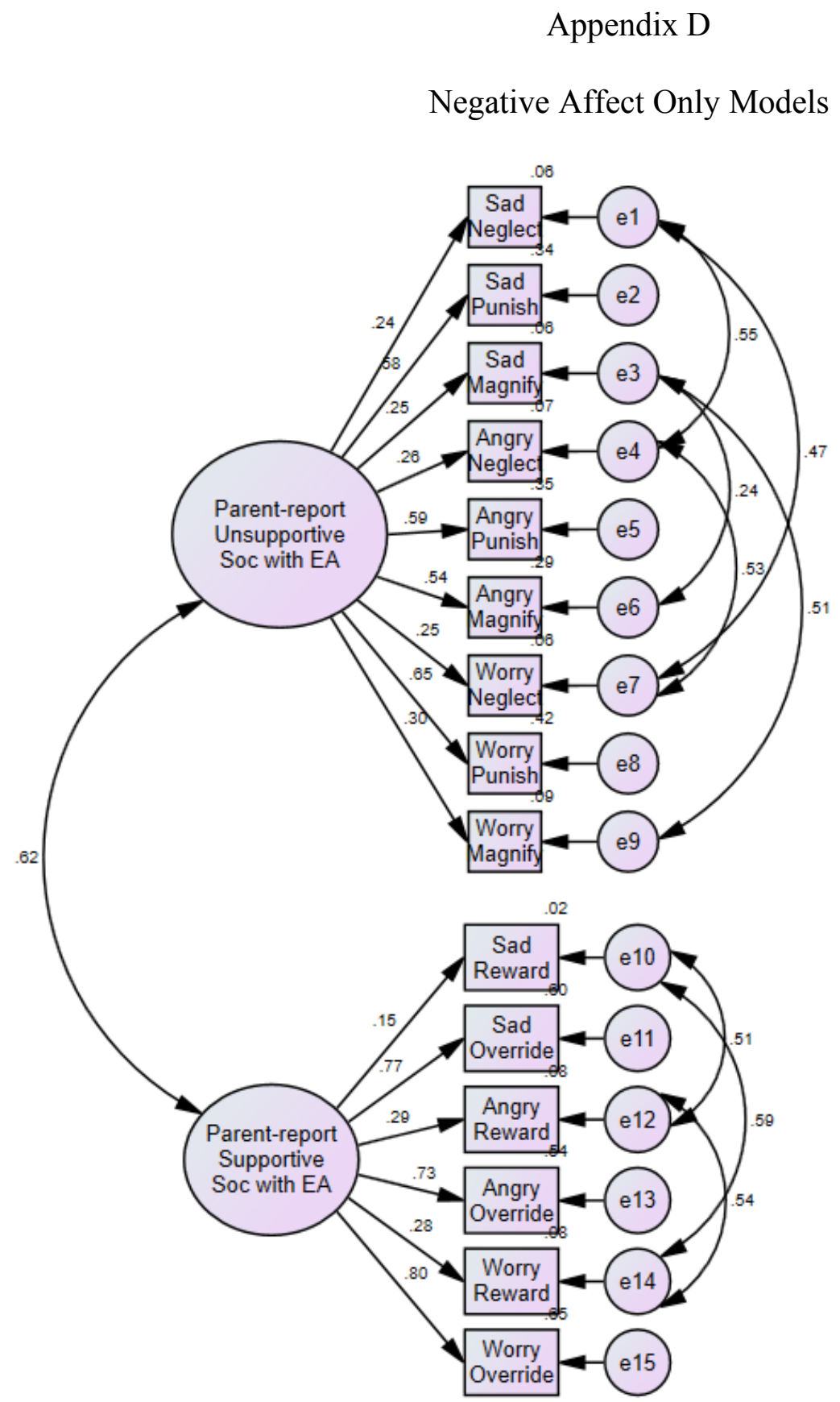

Figure D1. RQ1 - Confirmatory Factor Analysis of Parent-report of their Socialization of their Emerging Adults Child's Negative Emotions. Model fit: $\chi^{2}(81, N=461)=321.13, p<.001$, $\mathrm{CMIN} / \mathrm{df}=3.97, \mathrm{CFI}=.88, \mathrm{RMSEA}=.08[.07, .09]$. Because many $(7$ out of 15$)$ of the indicators loaded below the standard of .30, observed variables were used for parents' supportive and unsupportive emotion socialization in the remaining analyses. 


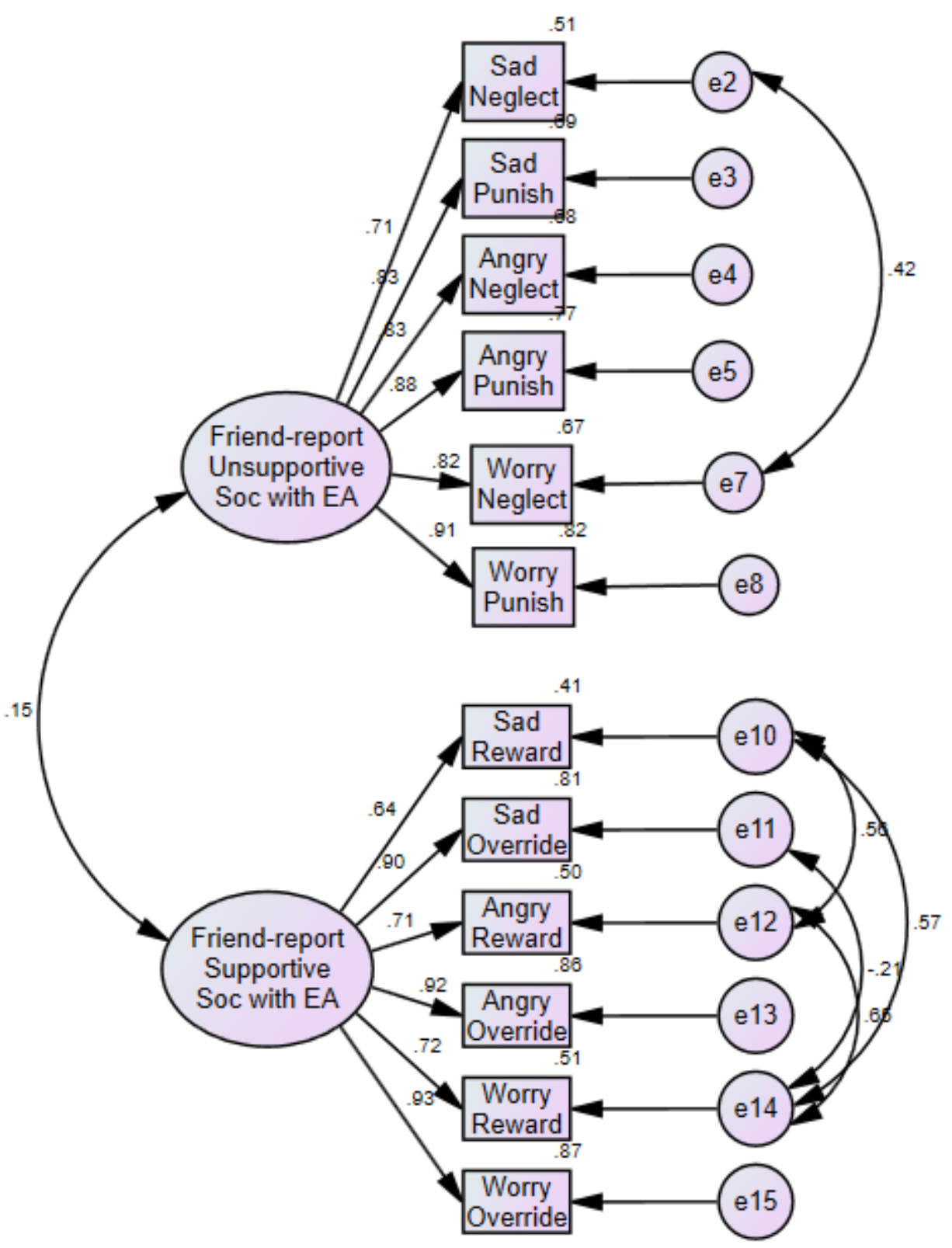

Figure D2. RQ1 - Confirmatory Factor Analysis of Friend-report of their Socialization of their Emerging Adult Friends' Negative Emotions. Model fit: $\chi^{2}(48, N=261)=167.24, p<.001$, $\mathrm{CMIN} / \mathrm{df}=3.48, \mathrm{CFI}=.95, \mathrm{RMSEA}=.10[.08, .11]$. Items Magnify with Sad, Angry, and Worry loaded below .3 and were dropped from the model. 


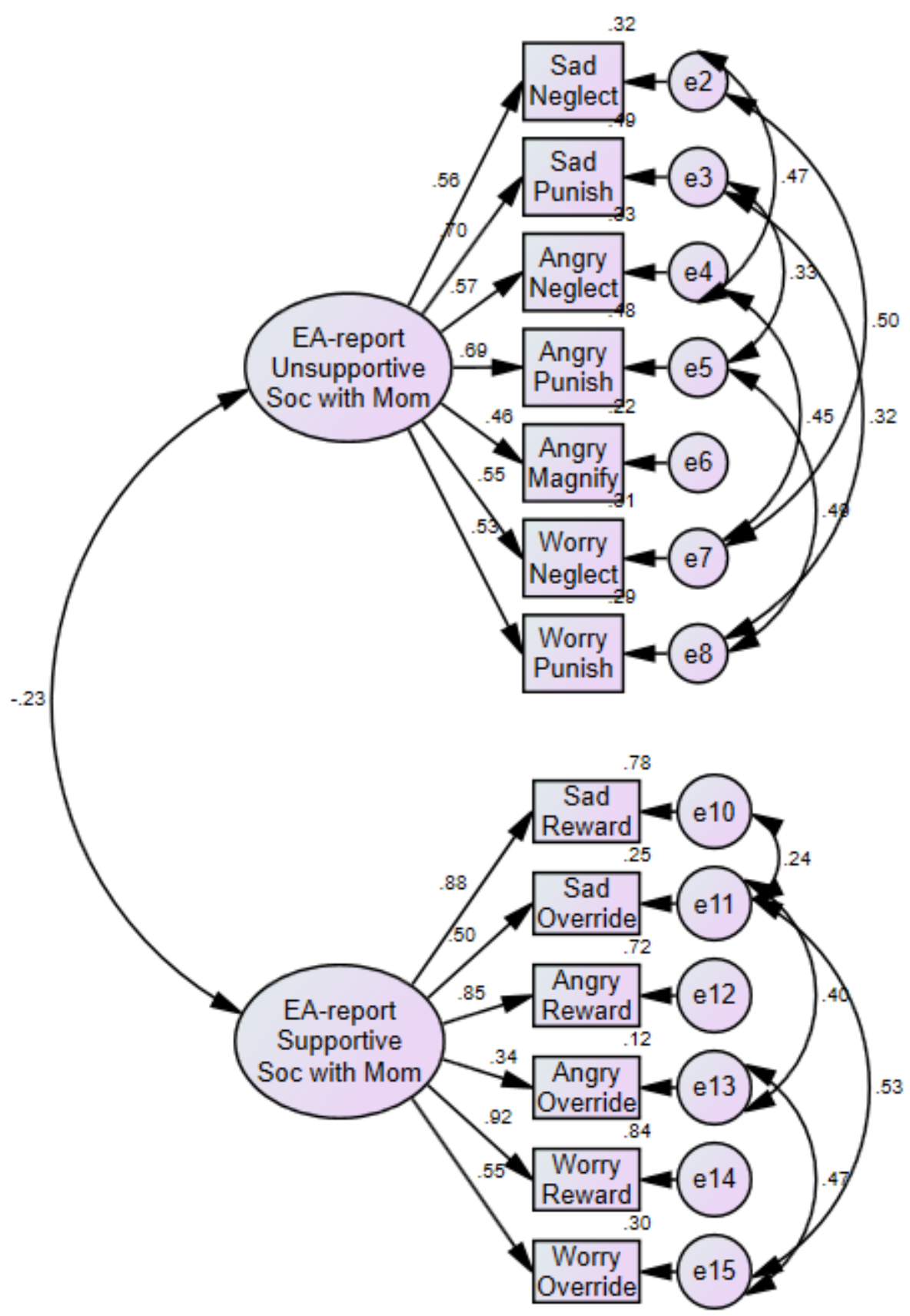

Figure D3. RQ1 - Confirmatory Factor Analysis of Emerging adult-report of their Socialization of their Mothers' Negative Emotions. Model fit: $\chi^{2}(54, N=612)=295.12, p<.001, \mathrm{CMIN} / \mathrm{df}=$ 5.47, CFI $=.94$, RMSEA $=.08$ [.07, .09]. Items Magnify with Sad and Worry loaded below .3 and were dropped from the model. 


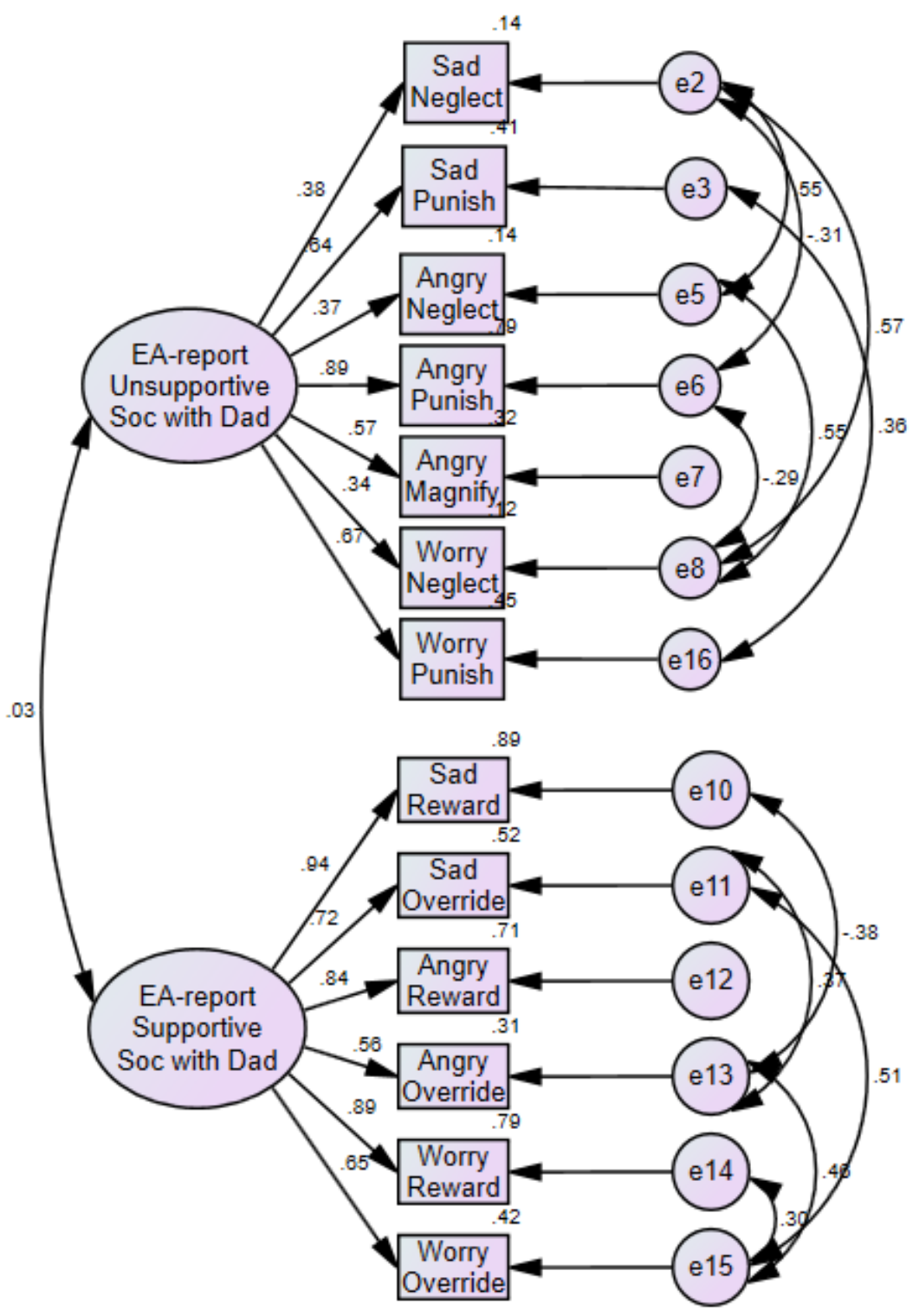

Figure D4. RQ1 - Confirmatory Factor Analysis of Emerging adult-report of their Socialization of their Fathers' Negative Emotions. Model fit: $\chi^{2}(53, N=612)=352.13, p<.001, \mathrm{CMIN} / \mathrm{df}=$ $6.64, \mathrm{CFI}=.93, \mathrm{RMSEA}=.09[.08, .10]$. Items Magnify with Sad and Worry loaded below .3 and were dropped from the model. 


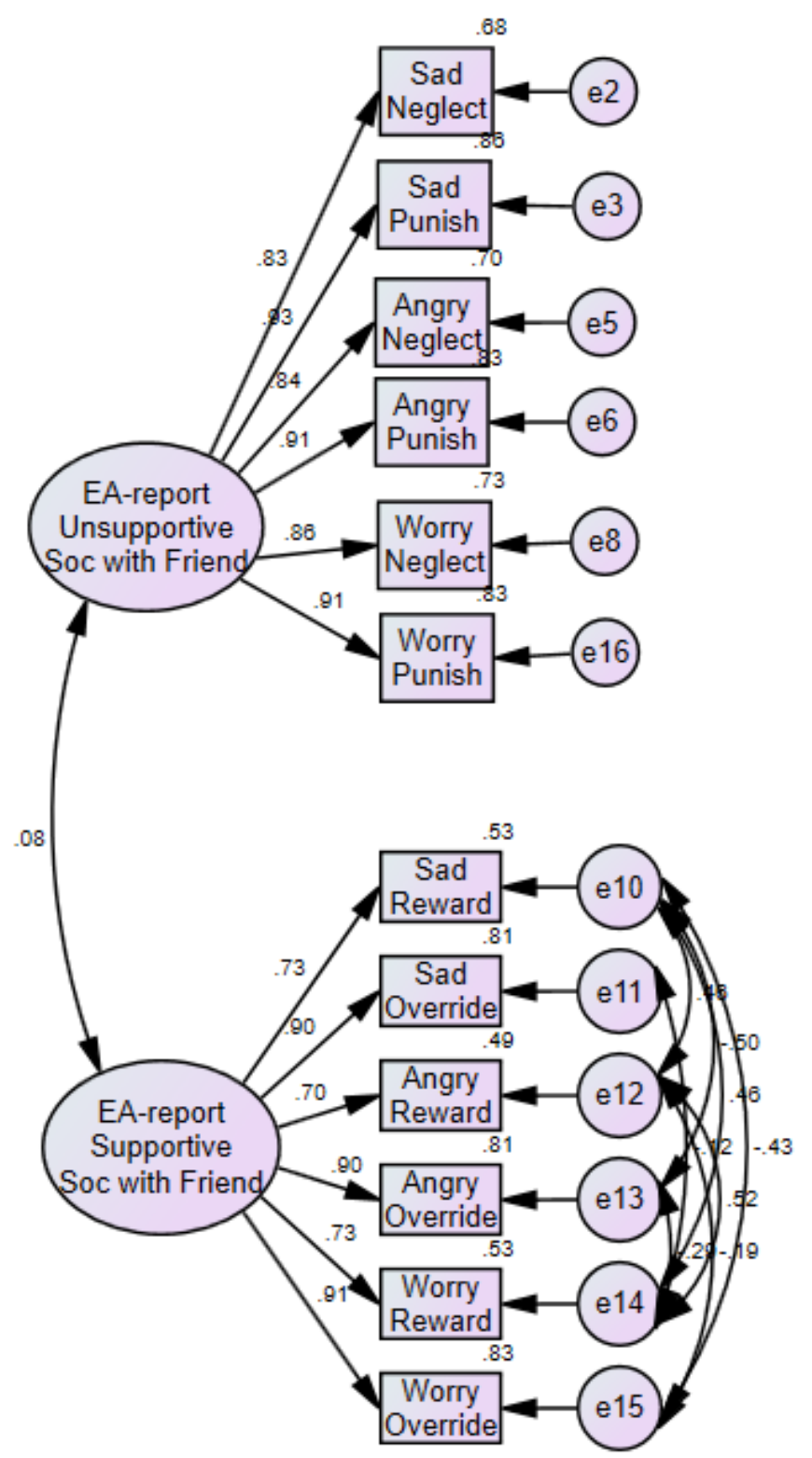

Figure D5. RQ1 - Confirmatory Factor Analysis of Emerging adult-report of their Socialization of their Friends' Negative Emotions. Model fit: $\chi^{2}(45, N=612)=295.26, p<.001, \mathrm{CMIN} / \mathrm{df}=$ $6.46, \mathrm{CFI}=.96, \mathrm{RMSEA}=.09[.08, .10]$. Items Magnify with Sad, Angry, and Worry loaded below .3 and were dropped from the model. 


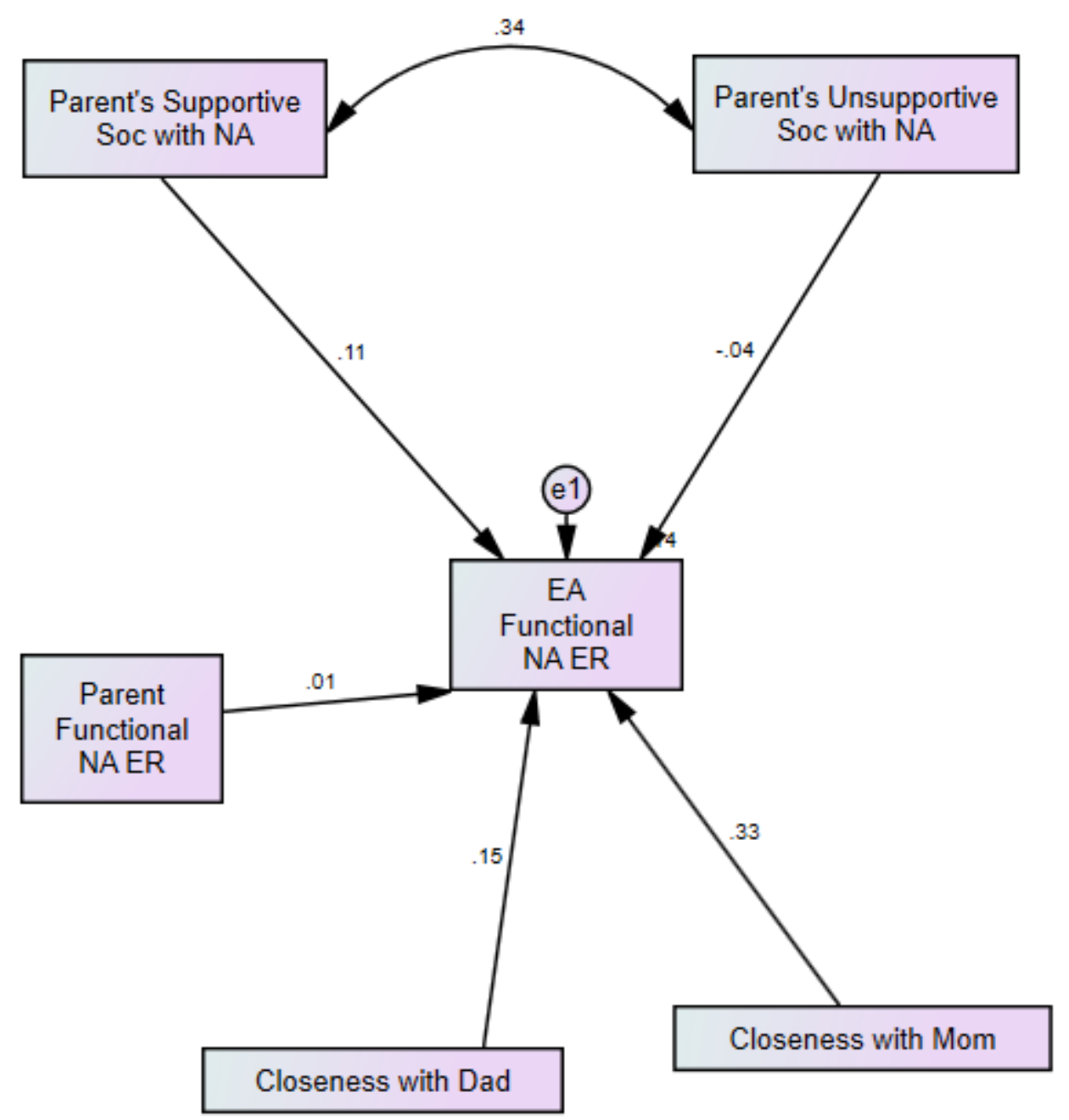

Figure D6. RQ2a - Parent-reported Negative Emotion Socialization predicting Emerging Adultreported Functional Emotion Regulation, controlling for Emerging Adult-reported Closeness with Mother and Father. Model fit: $\chi^{2}(9, N=461)=116.17, p<.001, \mathrm{CMIN} / \mathrm{df}=12.91, \mathrm{CFI}=$ $.53, \mathrm{RMSEA}=.16[.14, .19]$. The latent variables for emotion regulation (all reporters) were unstable (e.g., negative error variances in some models); therefore, observed variables are used in the all analyses. See Table F1 for comparison with Combined and PA models. 


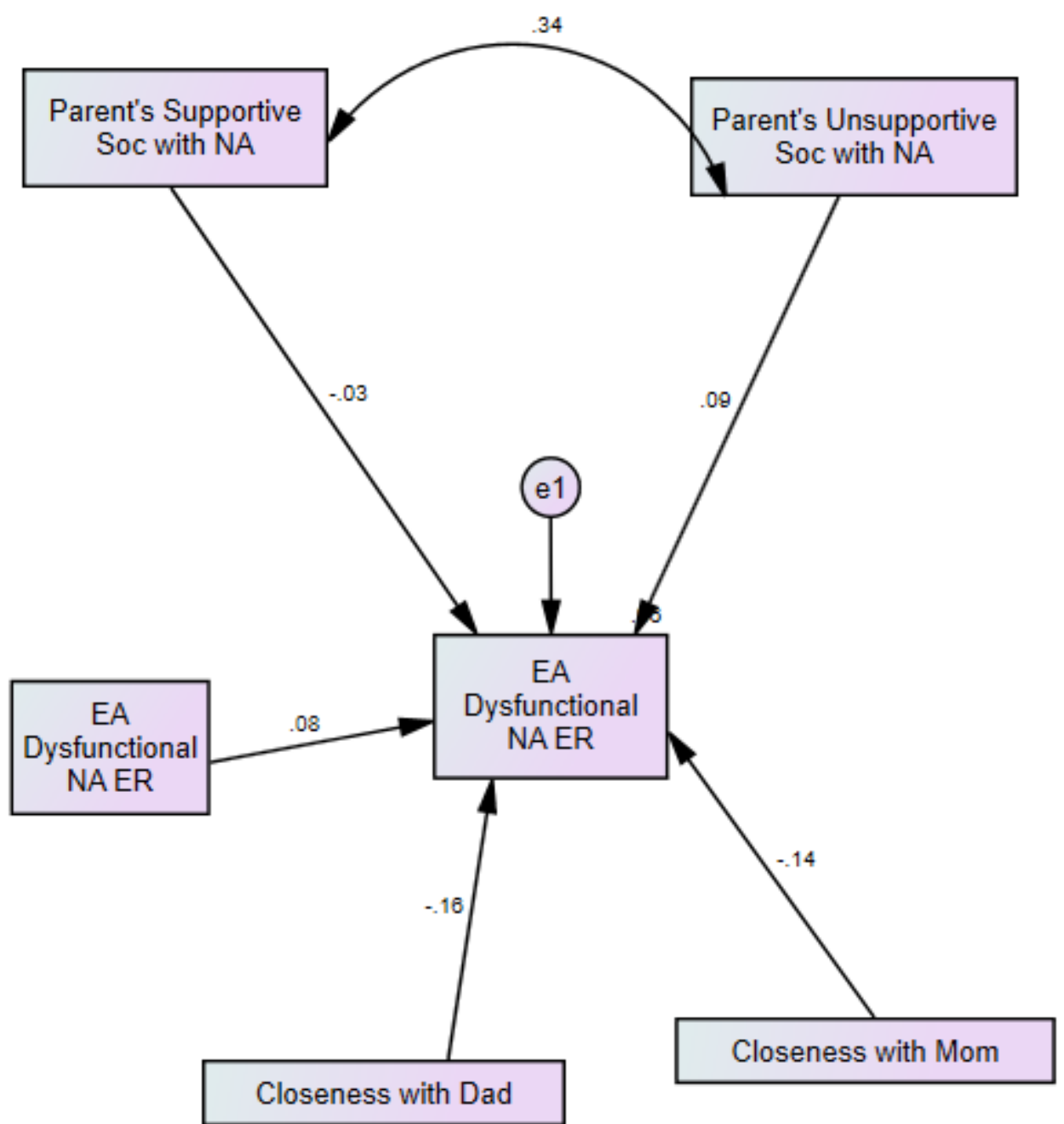

Figure D7. RQ2b - Parent-reported Negative Emotion Socialization predicting Emerging Adultreported Dysfunctional Emotion Regulation, controlling for Emerging Adult-reported Closeness with Mother and Father. Model fit: $\chi^{2}(9, N=461)=114.26, p<.001, \mathrm{CMIN} / \mathrm{df}=12.70, \mathrm{CFI}=$ $.41, \mathrm{RMSEA}=.16[.13, .19]$. See Table F2 for comparison with Combined and PA models 


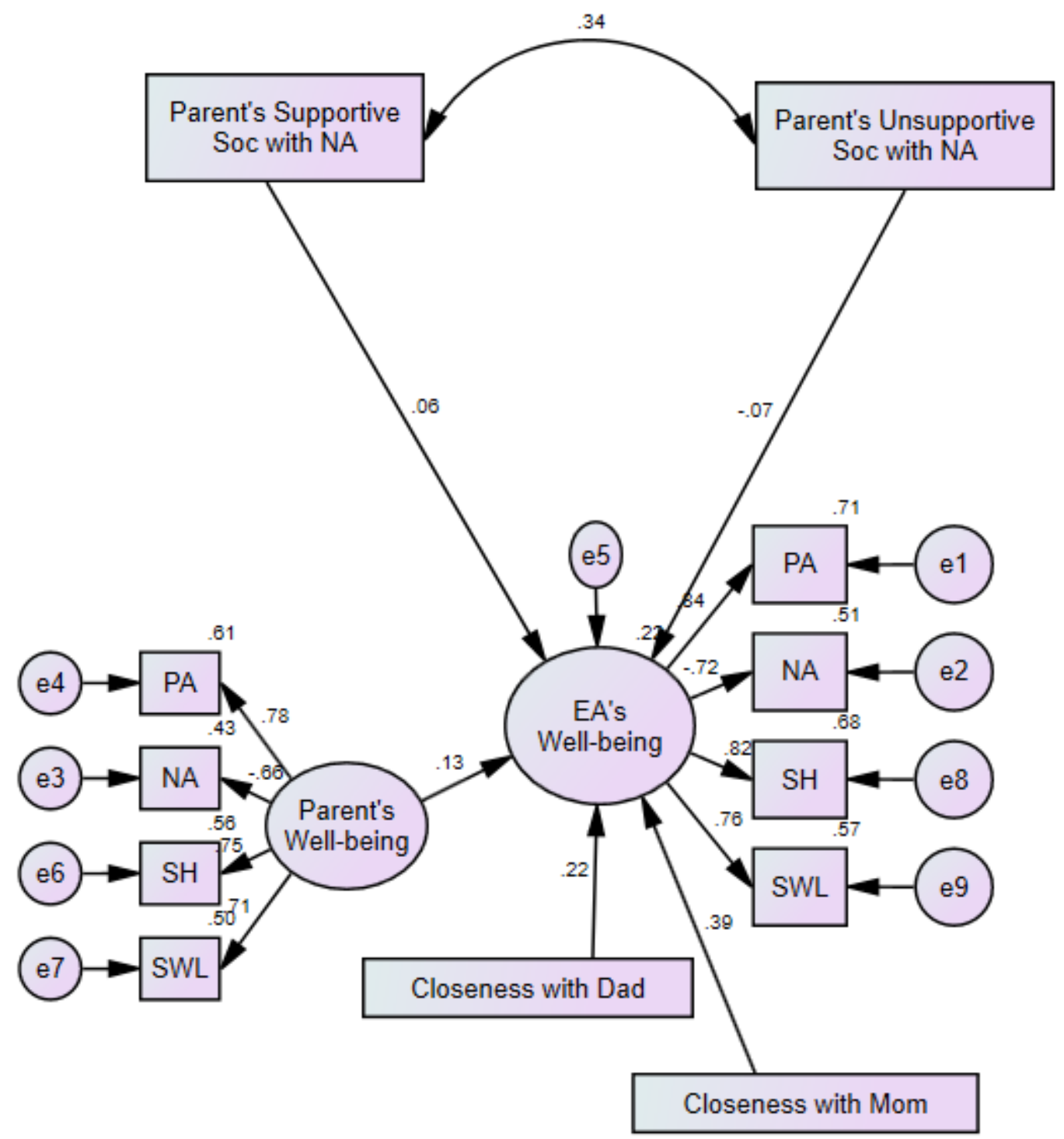

Figure D8. RQ2c - Parent-reported Negative Emotion Socialization predicting Emerging Adultreported Well-being, controlling for Emerging Adult-reported Closeness with Mother and Father. Model fit: $\chi^{2}(52, N=461)=216.96, p<.001, \mathrm{CMIN} / \mathrm{df}=4.17, \mathrm{CFI}=.90, \mathrm{RMSEA}=.08[.07$, .10]. See Table F3 for comparison with Combined and PA models 


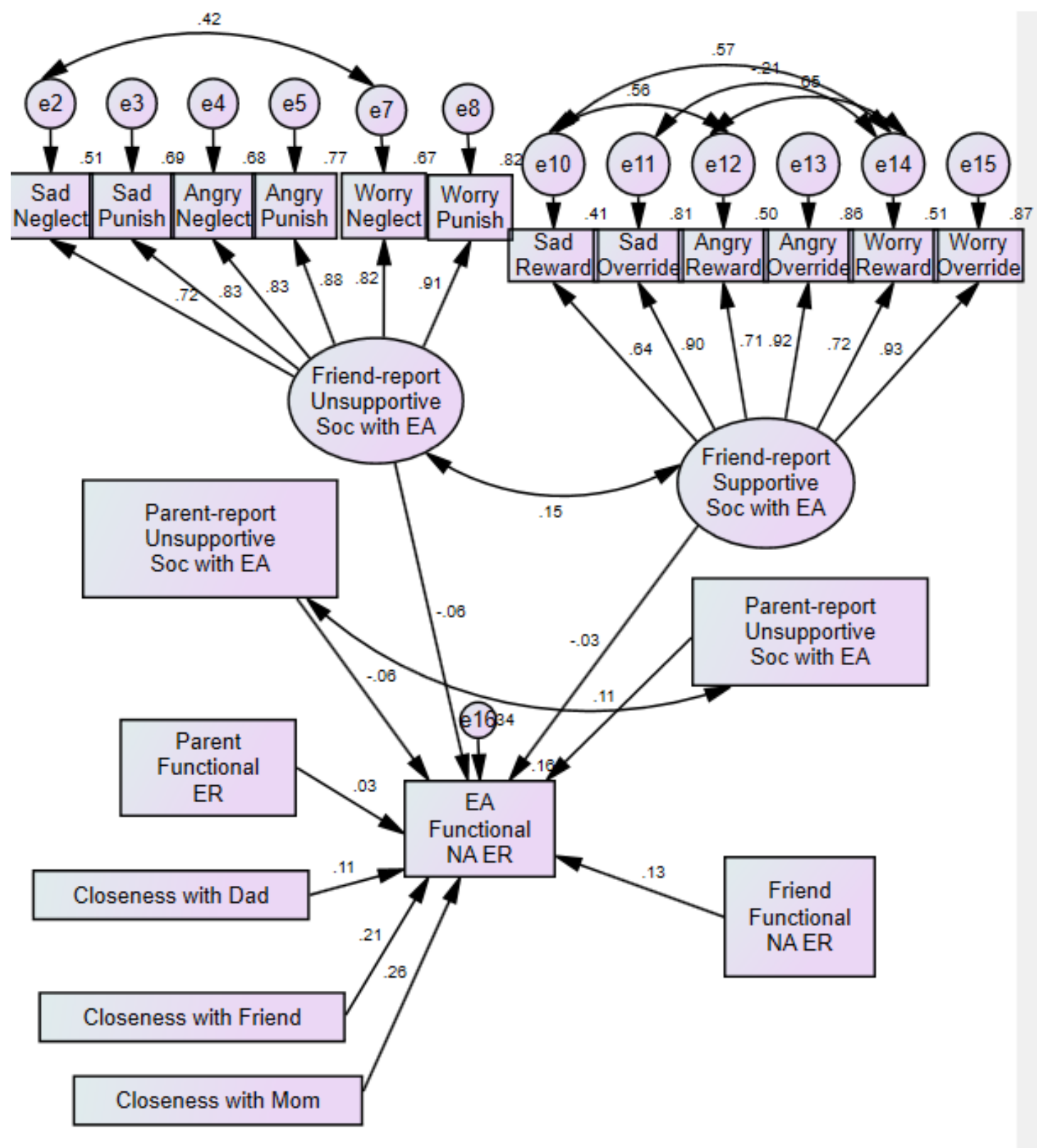

Figure D9. RQ3a - Parent- and Friend-reported Negative Emotion Socialization predicting Emerging Adult-reported Functional Emotion Regulation, controlling for Emerging Adultreported Closeness with Mother, Father, and Friend. Model fit: $\chi^{2}(162, N=512)=476.99, p<$ $.001, \mathrm{CMIN} / \mathrm{df}=2.94, \mathrm{CFI}=.90, \mathrm{RMSEA}=.05[.05, .06]$. See Table F4 for comparison with Combined and PA models. To examine whether Parents' and Friends' socialization significantly differed from one another, critical ratios (CR) were examined with values above 1.96 indicating a significant difference. Parents' and Friends' Supportive Emotion Socialization $(\mathrm{CR}=2.15)$ significantly differed, with Parents' Supportive Emotion Socialization relating more strongly to Emerging Adult Functional NA Emotion Regulation than Friends'. Parents' and Friends' Unsupportive Emotion Socialization did not differ $(\mathrm{CR}=.67)$. 


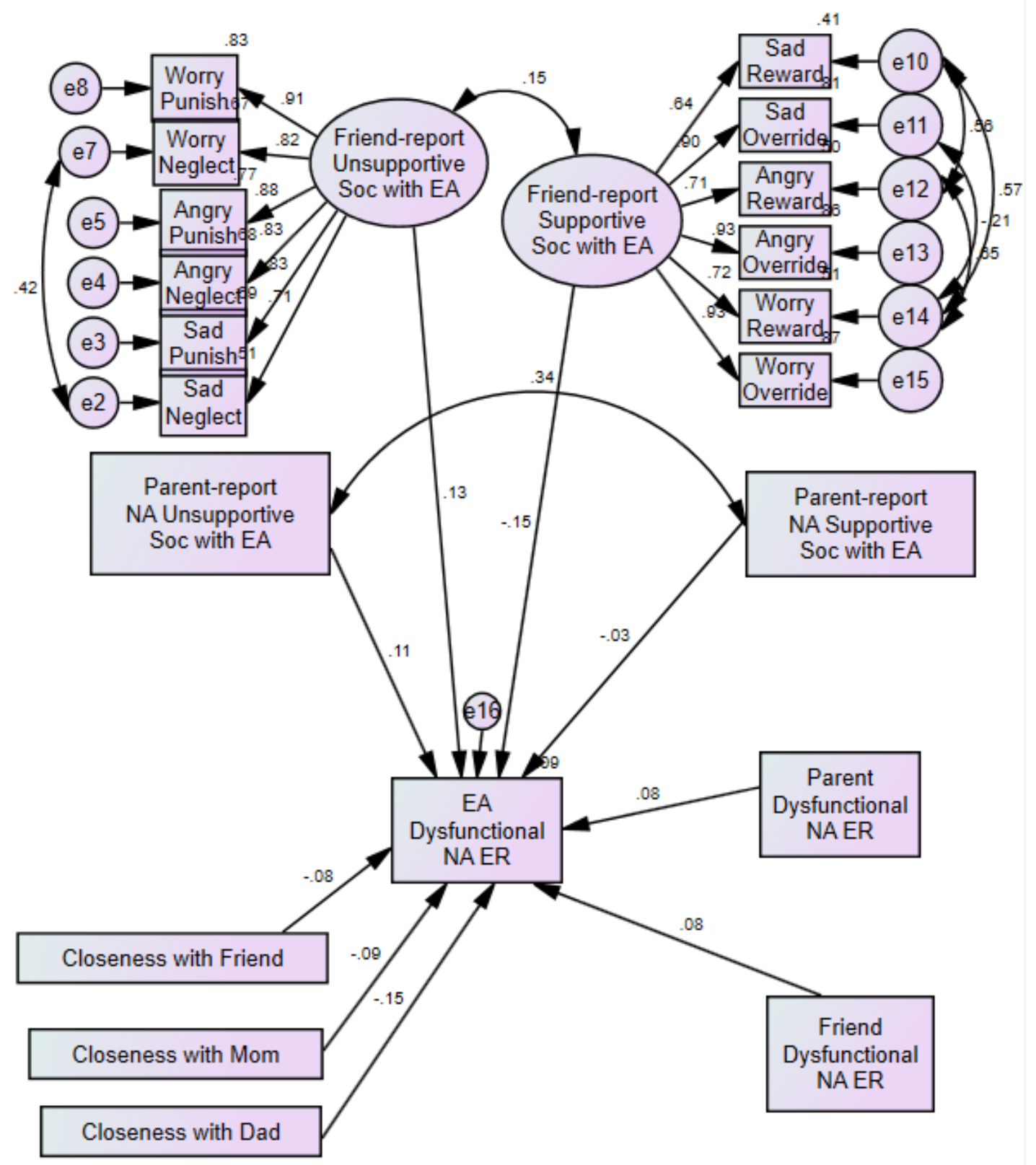

Figure D10. RQ3b - Parent- and Friend reported Negative Emotion Socialization predicting Emerging Adult-reported Dysfunctional Emotion Regulation, controlling for Emerging Adultreported Closeness with Mother, Father, and Friend. Model fit: $\chi^{2}(162, N=512)=462.91, p<$ $.001, \mathrm{CMIN} / \mathrm{df}=2.86, \mathrm{CFI}=.90, \mathrm{RMSEA}=.05[.05, .06]$. See Table F5 for comparison with Combined and PA models. Parent- and Friend-report did not significantly differ from one another on Supportive $(\mathrm{CR}=.83)$ or Unsupportive Emotion Socialization $(\mathrm{CR}=-1.06)$. 


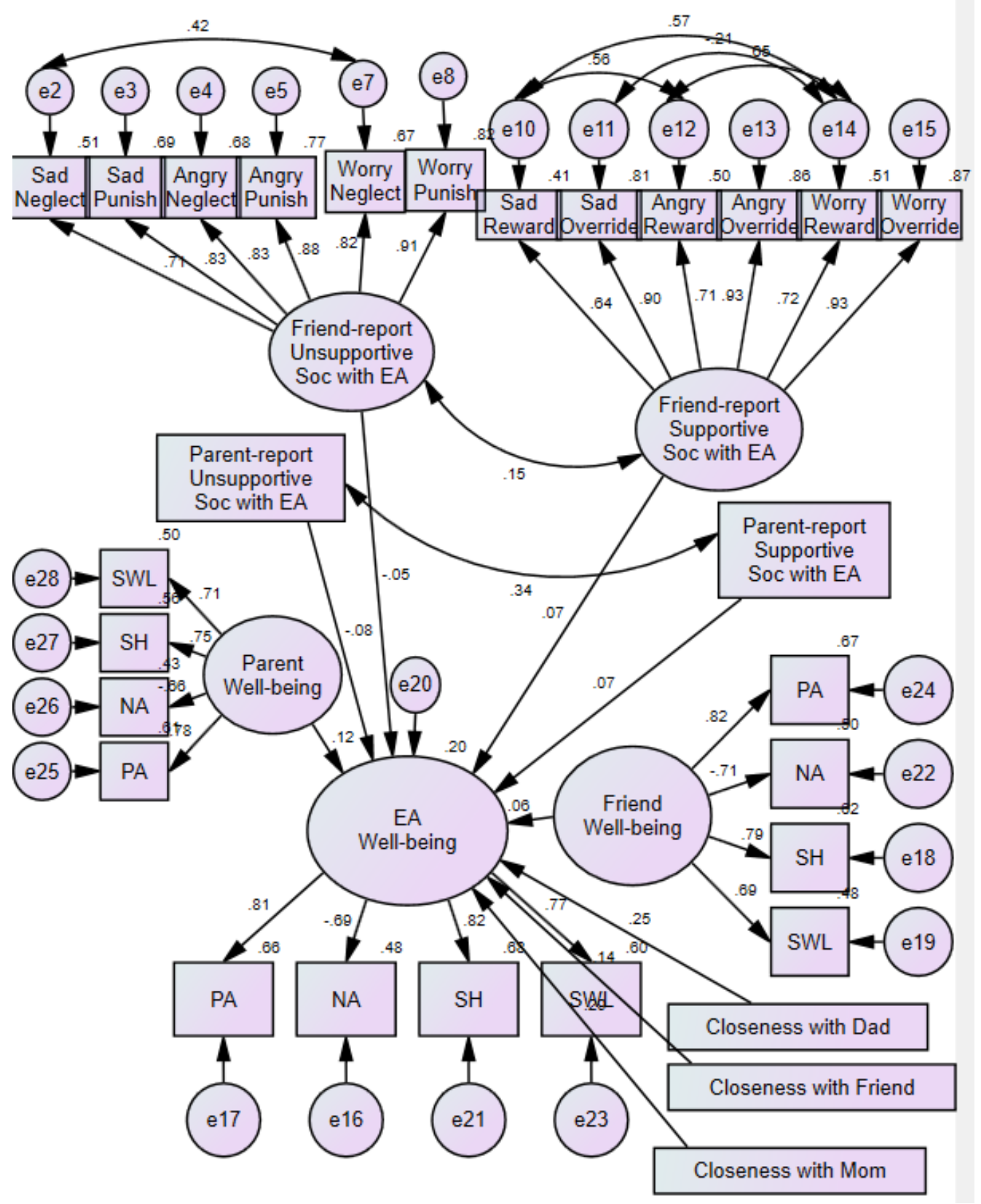

Figure D11. RQ3c - Parent- and Friend-reported Negative Emotion Socialization predicting Emerging Adult-reported Well-being, controlling for Emerging Adult-reported Closeness with Mother, Father, and Friend. Model fit: $\chi^{2}(336, N=461)=729.05, p<.001, \mathrm{CMIN} / \mathrm{df}=1.99$, CFI $=.93$, RMSEA $=.04[.03, .04]$. See Table F6 for comparison with Combined and PA models. Parent- and Friend-report did not significantly differ from one another on Supportive $(\mathrm{CR}=.41)$ or Unsupportive Emotion Socialization $(\mathrm{CR}=-1.13)$. 


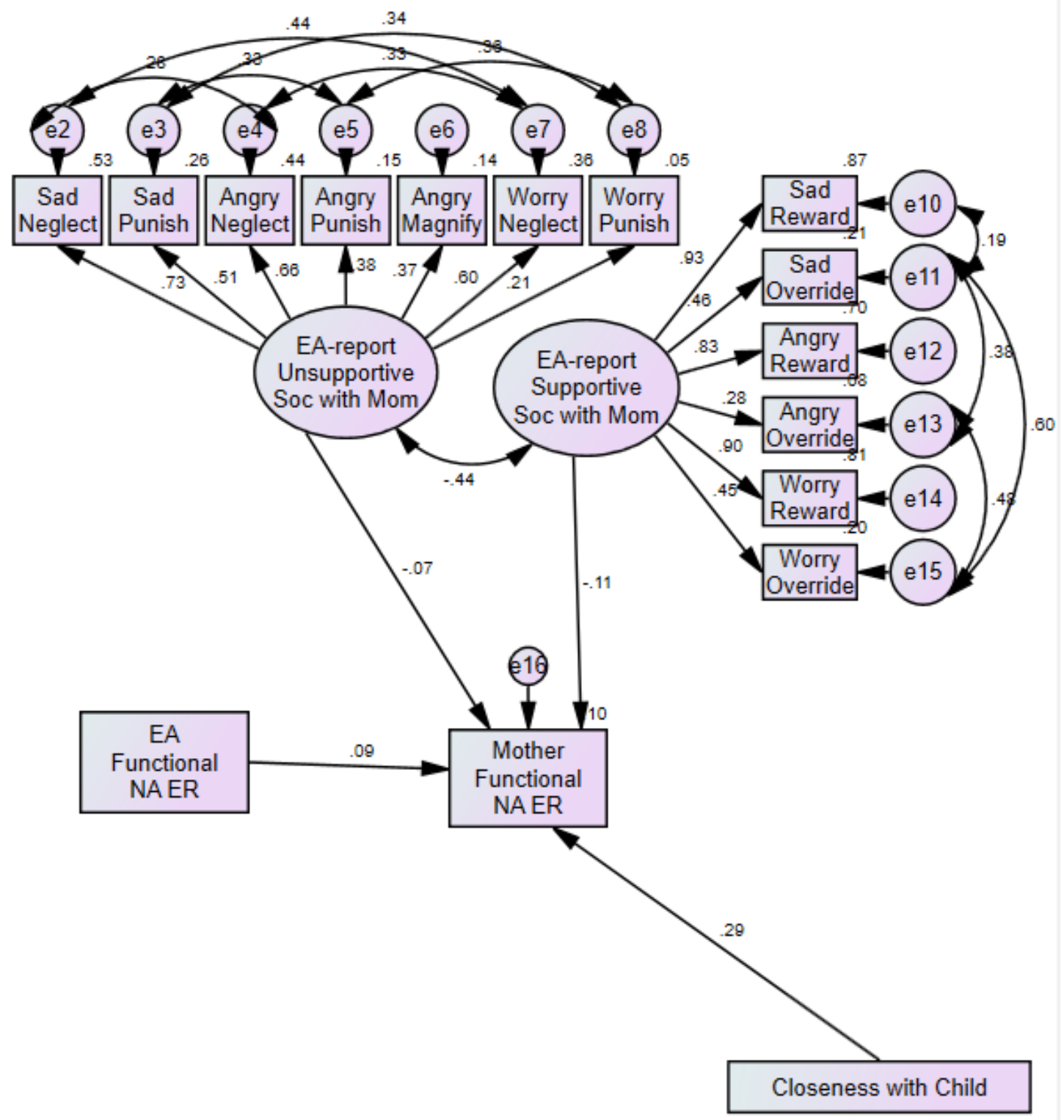

Figure D12. RQ4aa - Emerging Adult-reported Negative Emotion Socialization predicting Mother-reported Functional Emotion Regulation, controlling for Mother-reported Closeness with Emerging Adult Child. Model fit: $\chi^{2}(92, N=338)=400.93, p<.001, \mathrm{CMIN} / \mathrm{df}=4.36, \mathrm{CFI}=$ .86, RMSEA $=.10[.09, .11]$. See Table F7 for comparison with Combined and PA models. 


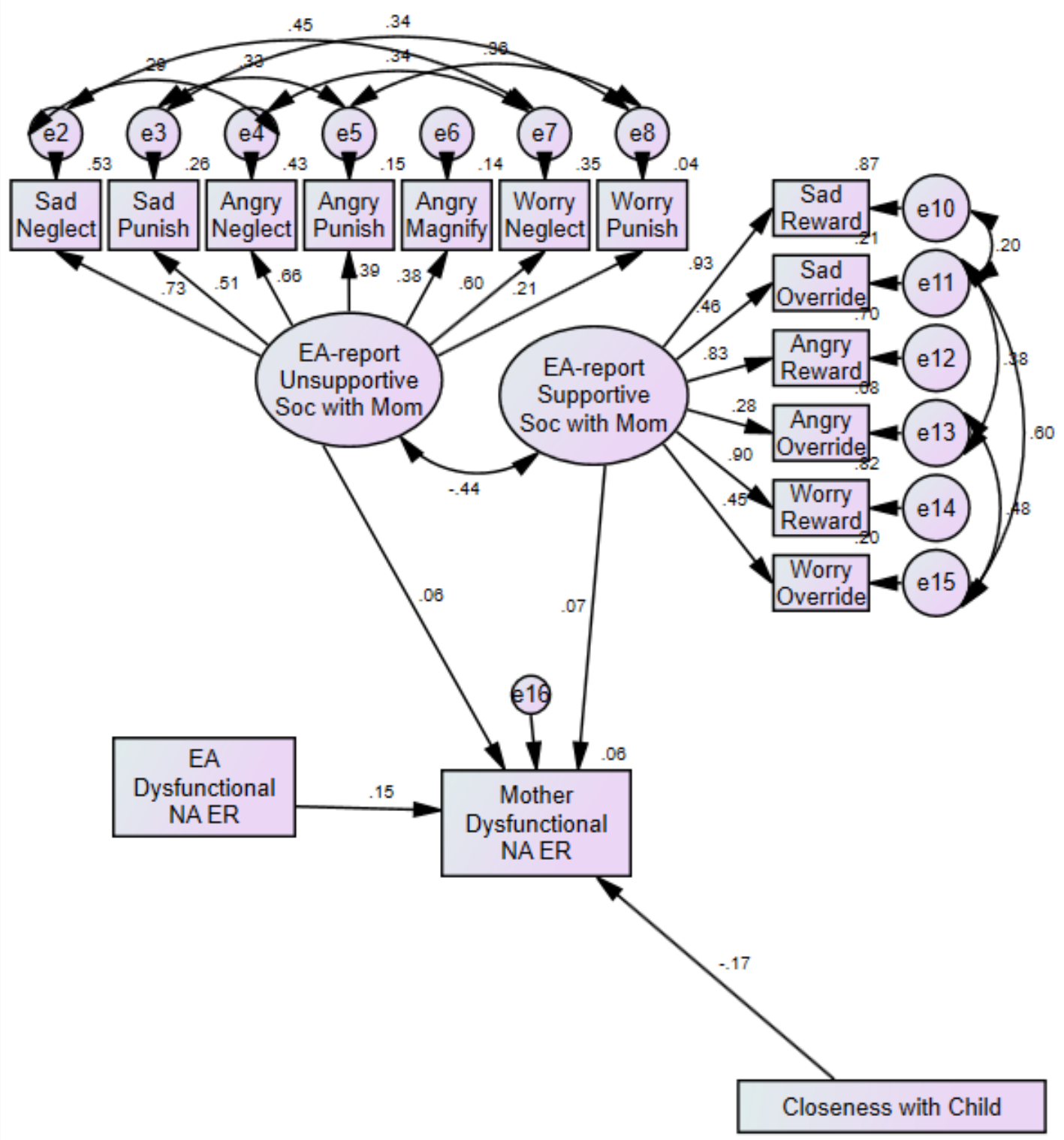

Figure D13. RQ4ab - Emerging Adult-reported Negative Emotion Socialization predicting Mother-reported Dysfunctional Emotion Regulation, controlling for Mother-reported Closeness with Emerging Adult Child. Model fit: $\chi^{2}(92, N=338)=314.46, p<.001, \mathrm{CMIN} / \mathrm{df}=3.42$, CFI $=.89$, RMSEA $=.09[.08, .10]$. See Table F8 for comparison with Combined and PA models. 


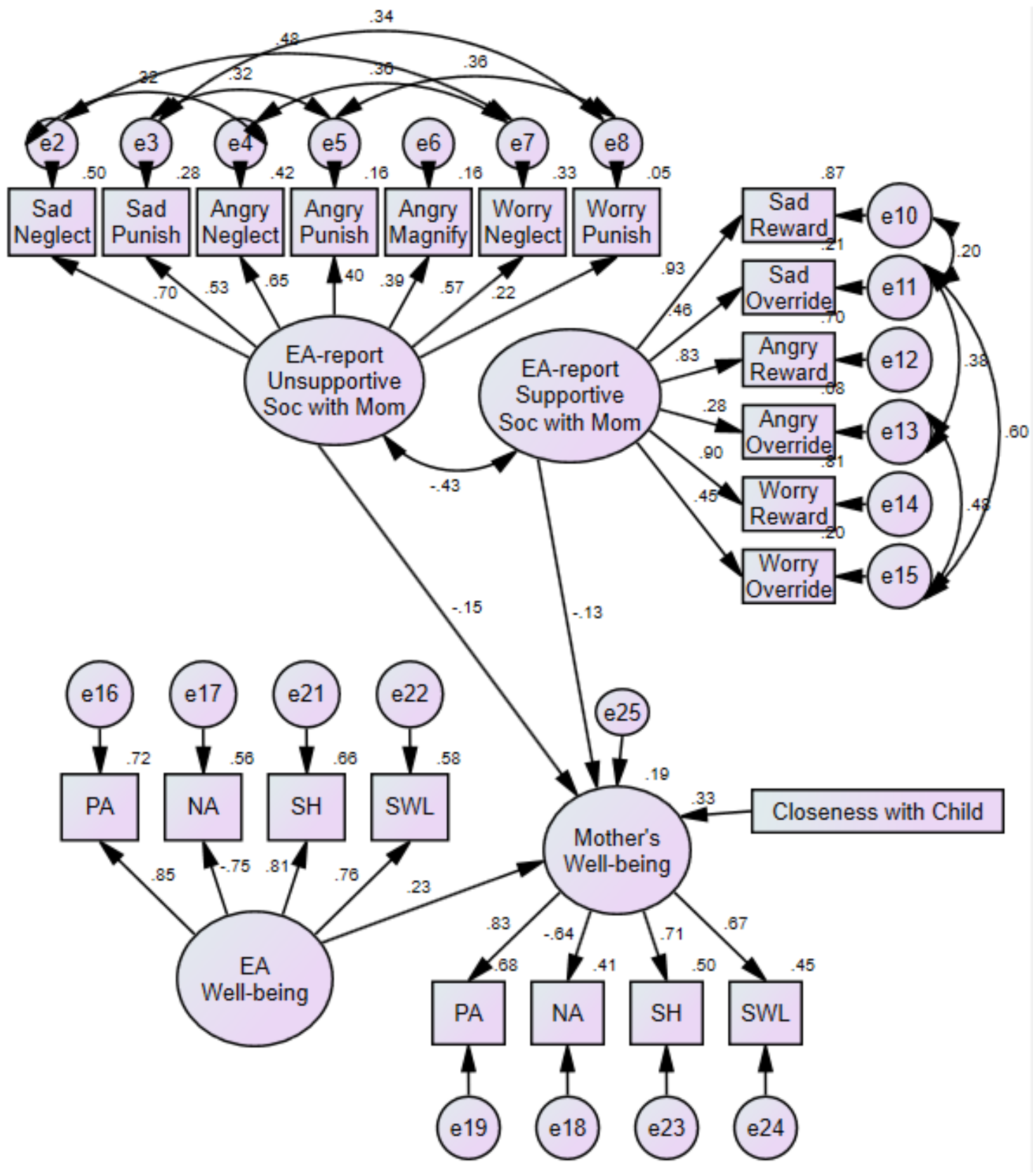

Figure D14. RQ4ac - Emerging Adult-reported Negative Emotion Socialization predicting Mother-reported Well-being, controlling for Mother-reported Closeness with Emerging Adult Child. Model fit: $\chi^{2}(195, N=338)=456.69, p<.001, \mathrm{CMIN} / \mathrm{df}=2.34, \mathrm{CFI}=.92, \mathrm{RMSEA}=.06$ $[.06, .07]$. See Table F9 for comparison with Combined and PA models. 


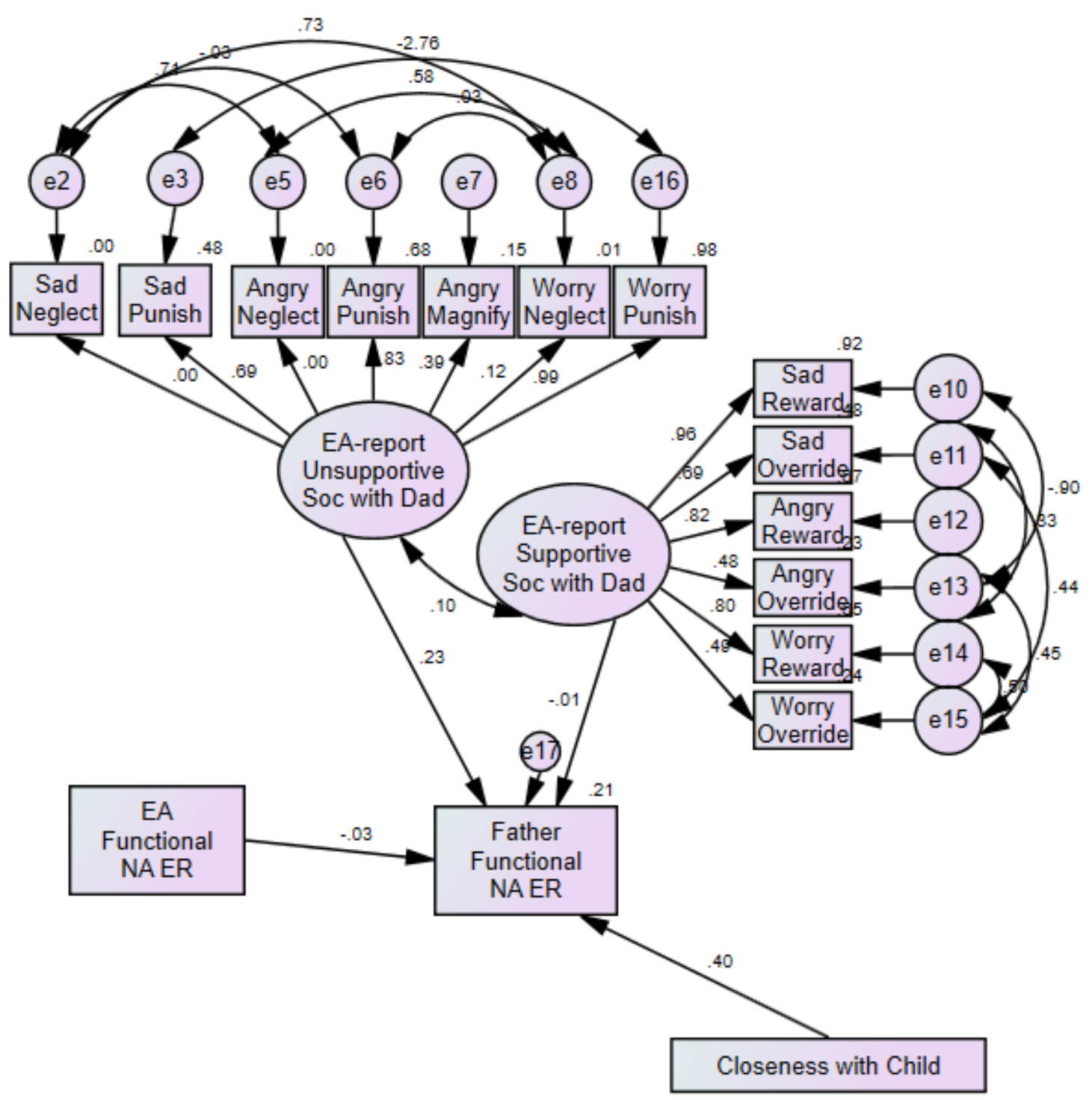

Figure D15. RQ4ba - Emerging Adult-reported Negative Emotion Socialization predicting Father-reported Functional Emotion Regulation, controlling for Father-reported Closeness with Emerging Adult Child. Model fit: $\chi^{2}(91, N=123)=165.41, p<.001, \mathrm{CMIN} / \mathrm{df}=1.82$, CFI $=$ $.86, \mathrm{RMSEA}=.08[.06, .10]$. See Table F10 for comparison with Combined and PA models. 


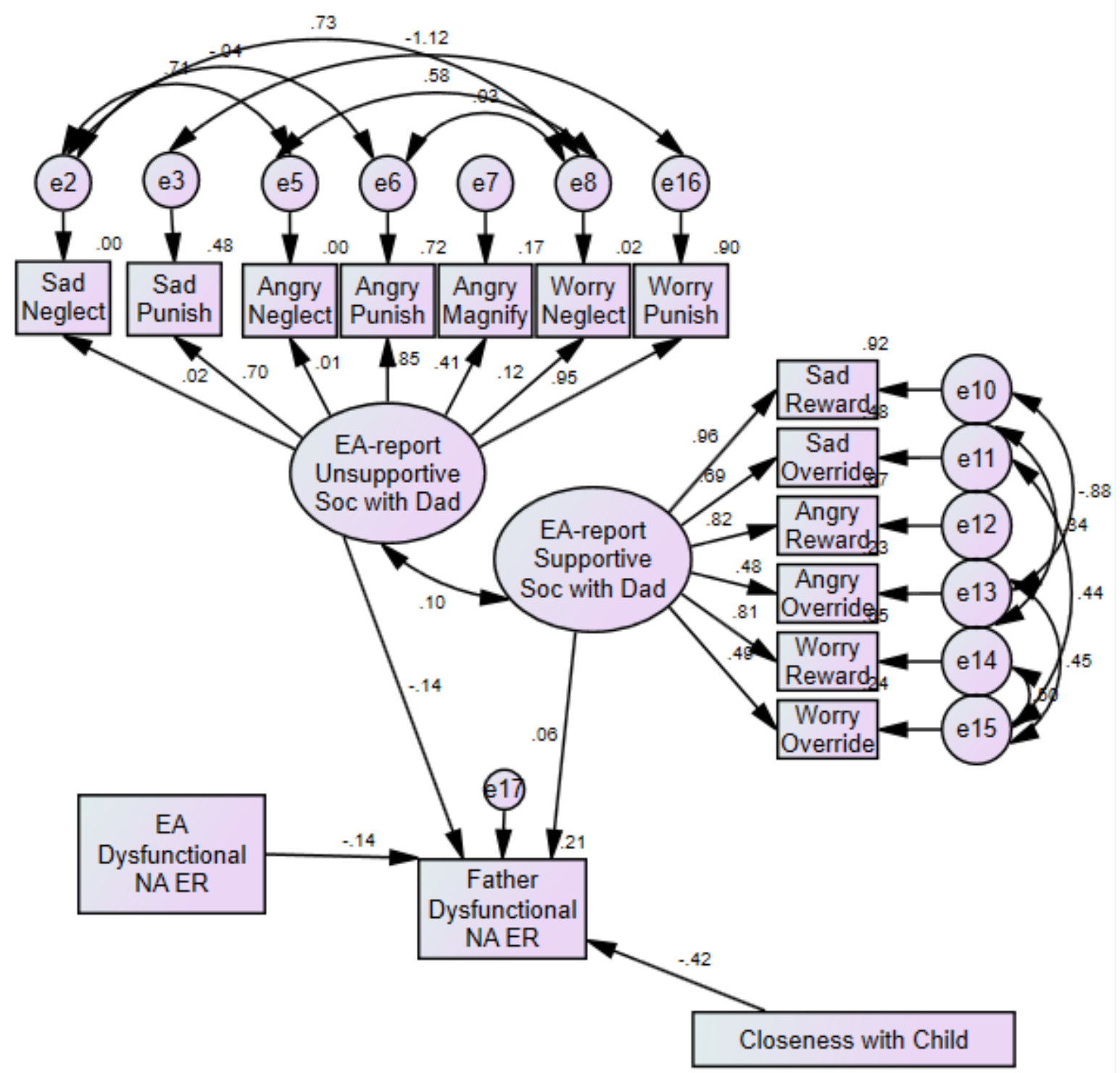

Figure D16. RQ4bb - Emerging Adult-reported Negative Emotion Socialization predicting Father-reported Dysfunctional Emotion Regulation, controlling for Father-reported Closeness with Emerging Adult Child. Model fit: $\chi^{2}(91, N=123)=188.11, p<.001, \mathrm{CMIN} / \mathrm{df}=2.07$, CFI $=.82$, RMSEA $=.09[.08, .11]$. See Table F11 for comparison with Combined and PA models. 


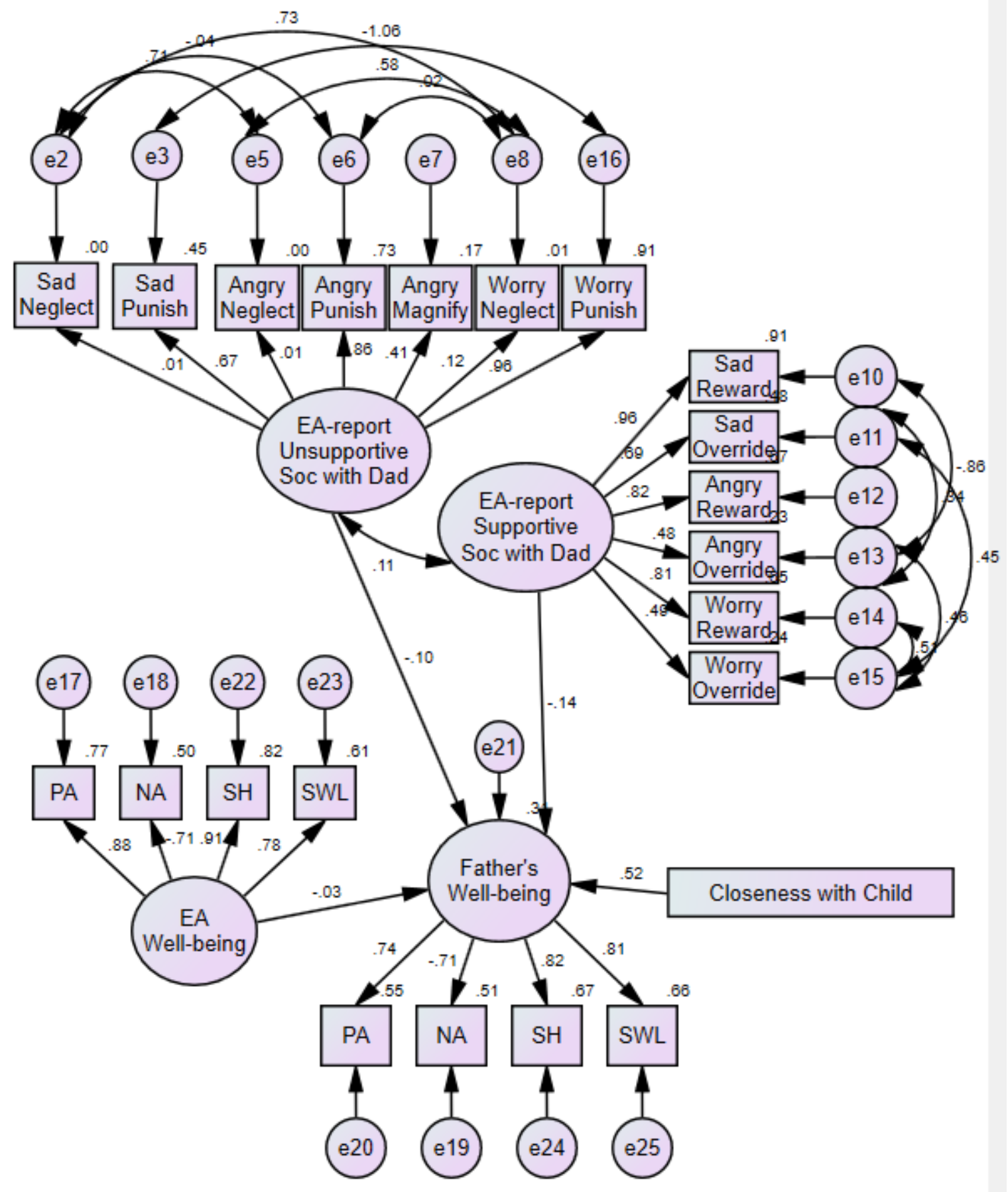

Figure D17. RQ4bc - Emerging Adult-reported Negative Emotion Socialization predicting Father-reported Well-being, controlling for Father-reported Closeness with Emerging Adult Child. Model fit: $\chi^{2}(194, N=123)=291.85, p<.001, \mathrm{CMIN} / \mathrm{df}=1.50, \mathrm{CFI}=.89, \mathrm{RMSEA}=.06$ $[.05, .08]$. See Table F12 for comparison with Combined and PA models. 


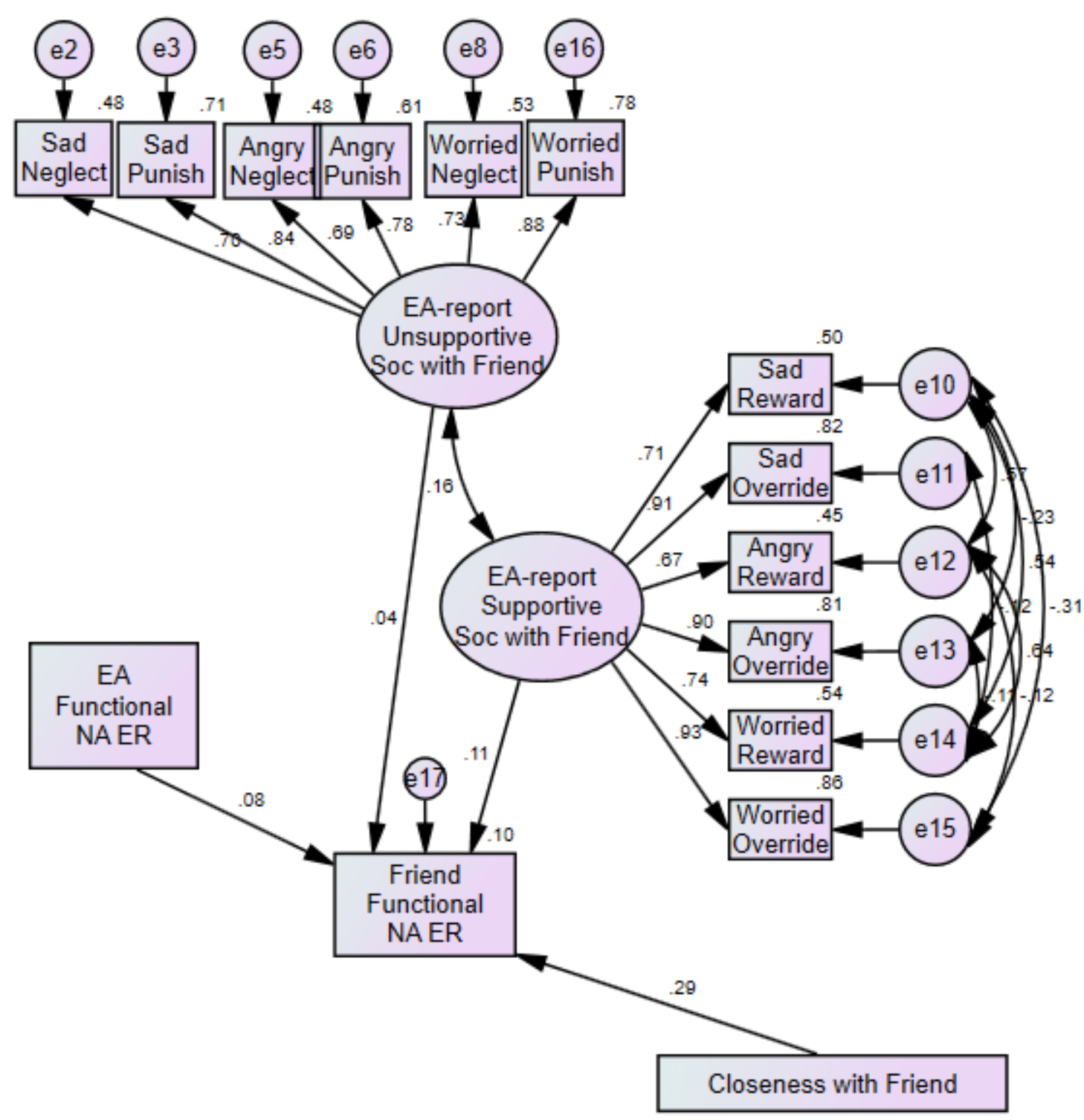

Figure D18. RQ5a - Emerging Adult-reported Negative Emotion Socialization predicting Friend-reported Functional Emotion Regulation, controlling for Friend-reported Closeness with Emerging Adult Friend. Model fit: $\chi^{2}(80, N=261)=303.25, p<.001, \mathrm{CMIN} / \mathrm{df}=3.79, \mathrm{CFI}=$ .91 , RMSEA $=.10[.09, .12]$. See Table F13 for comparison with Combined and PA models. 


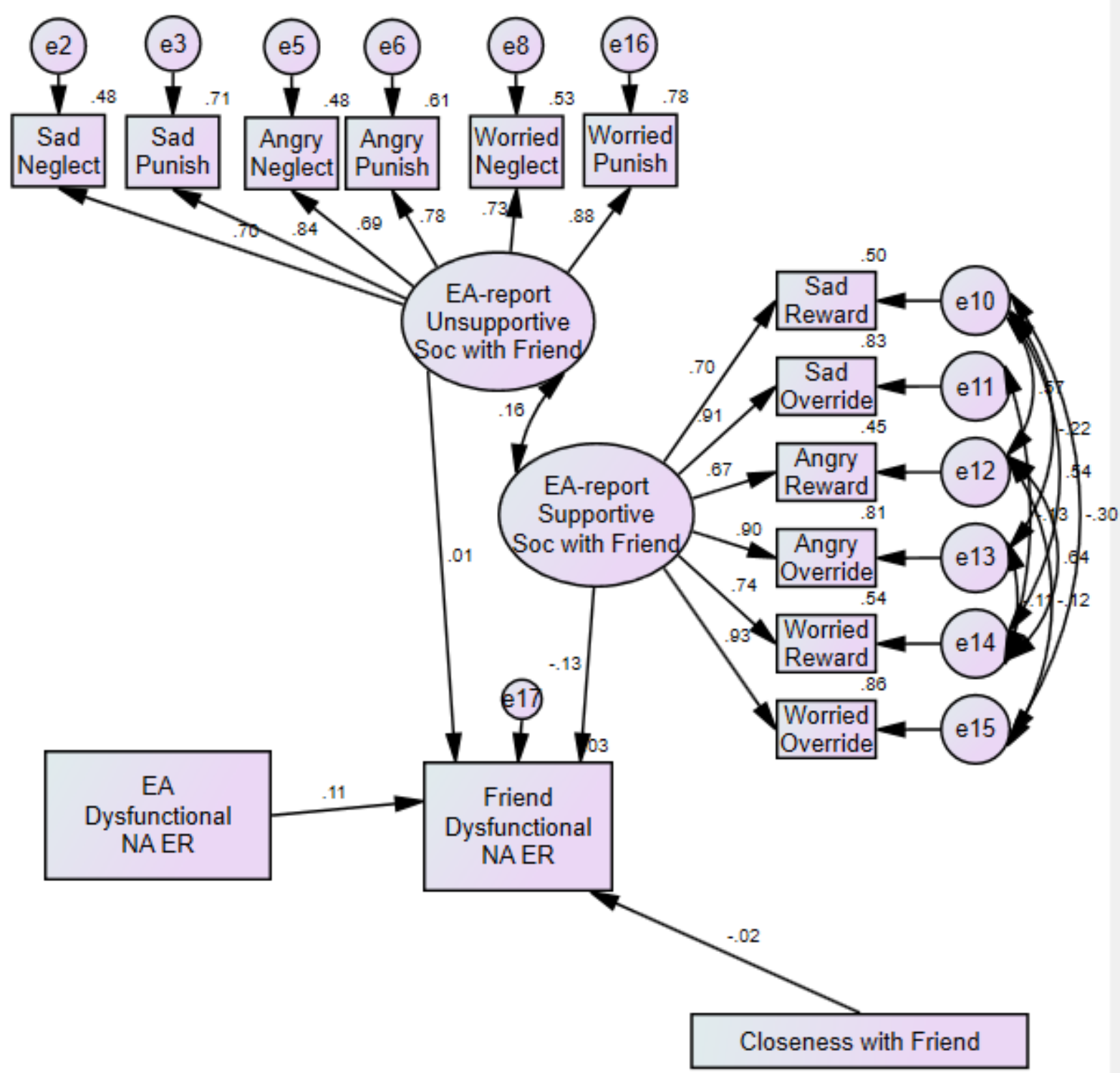

Figure D19. RQ5b - Emerging Adult-reported Negative Emotion Socialization predicting Friend-reported Dysfunctional Emotion Regulation, controlling for Friend-reported Closeness with Emerging Adult Friend. Model fit: $\chi^{2}(80, N=261)=259.15, p<.001, \mathrm{CMIN} / \mathrm{df}=3.24$, $\mathrm{CFI}=.93, \mathrm{RMSEA}=.09[.08, .11]$. See Table F14 for comparison with Combined and PA models. 


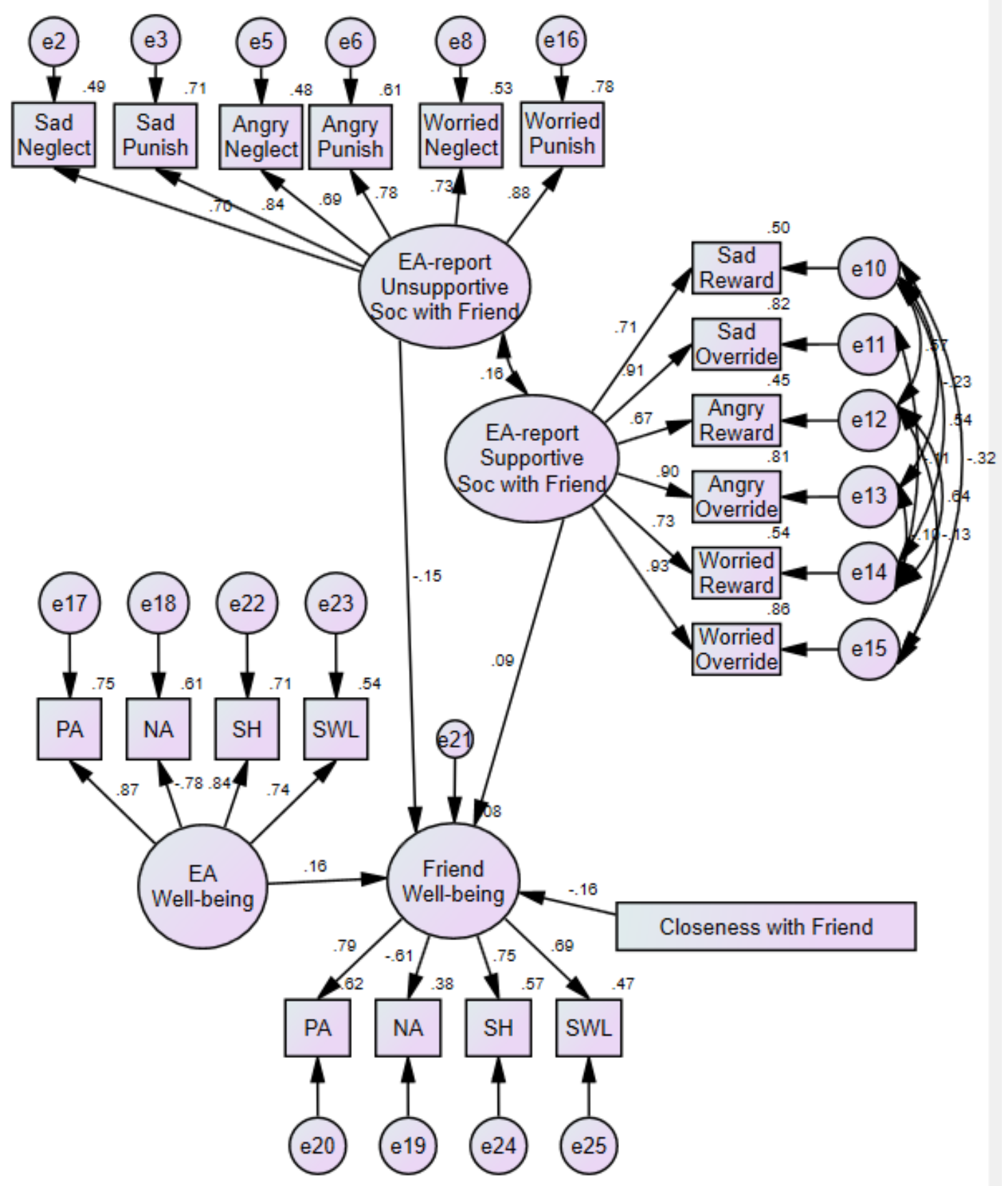

Figure D20. RQ5c - Emerging Adult-reported Negative Emotion Socialization predicting Friend-reported Well-being, controlling for Friend-reported Closeness with Emerging Adult Friend. Model fit: $\chi^{2}(177, N=261)=415.15, p<.001, \mathrm{CMIN} / \mathrm{df}=2.35, \mathrm{CFI}=.93, \mathrm{RMSEA}=$ $.07[.06, .08]$. See Table F15 for comparison with Combined and PA models. 


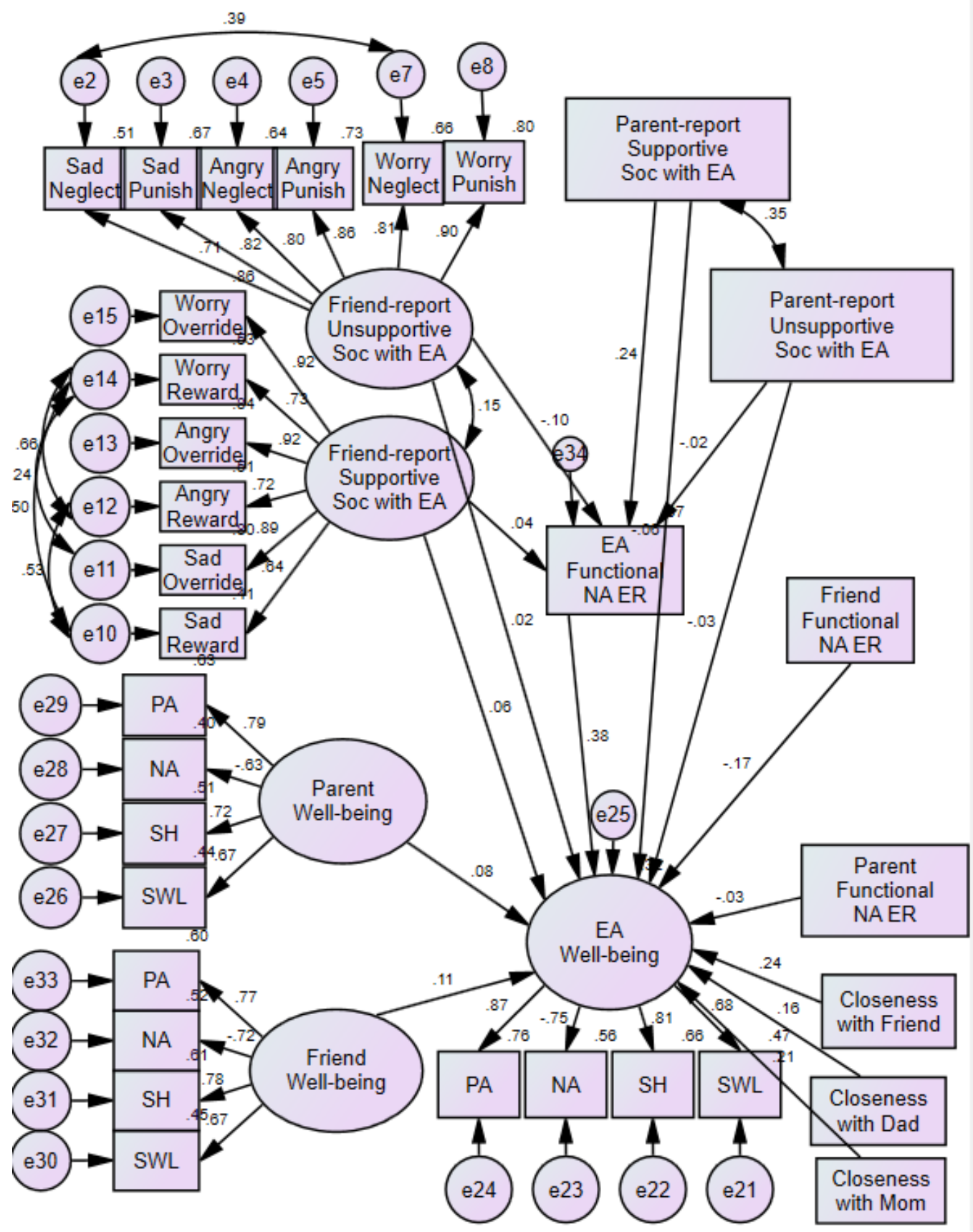

Figure D21. RQ6a - Emerging Adult-reported Functional Emotion Regulation Mediates the Link between Parent- and Friend-reported Negative Emotion Socialization and Emerging Adultreported Well-being, controlling for Emerging Adult Closeness with Mother, Father, and Friend. Model fit: $\chi^{2}(194, N=190)=291.85, p<.001, \mathrm{CMIN} / \mathrm{df}=1.50, \mathrm{CFI}=.89$, RMSEA $=.06[.05$, .08]. One significant indirect effect: Parents' Supportive Socialization with NA $\rightarrow$ EA Functional NA ER $\rightarrow$ EA Well-being $(\beta=.09, p=.001[95 \%$ CI .03, .18]). See Table F16 for comparison with Combined and PA models. 


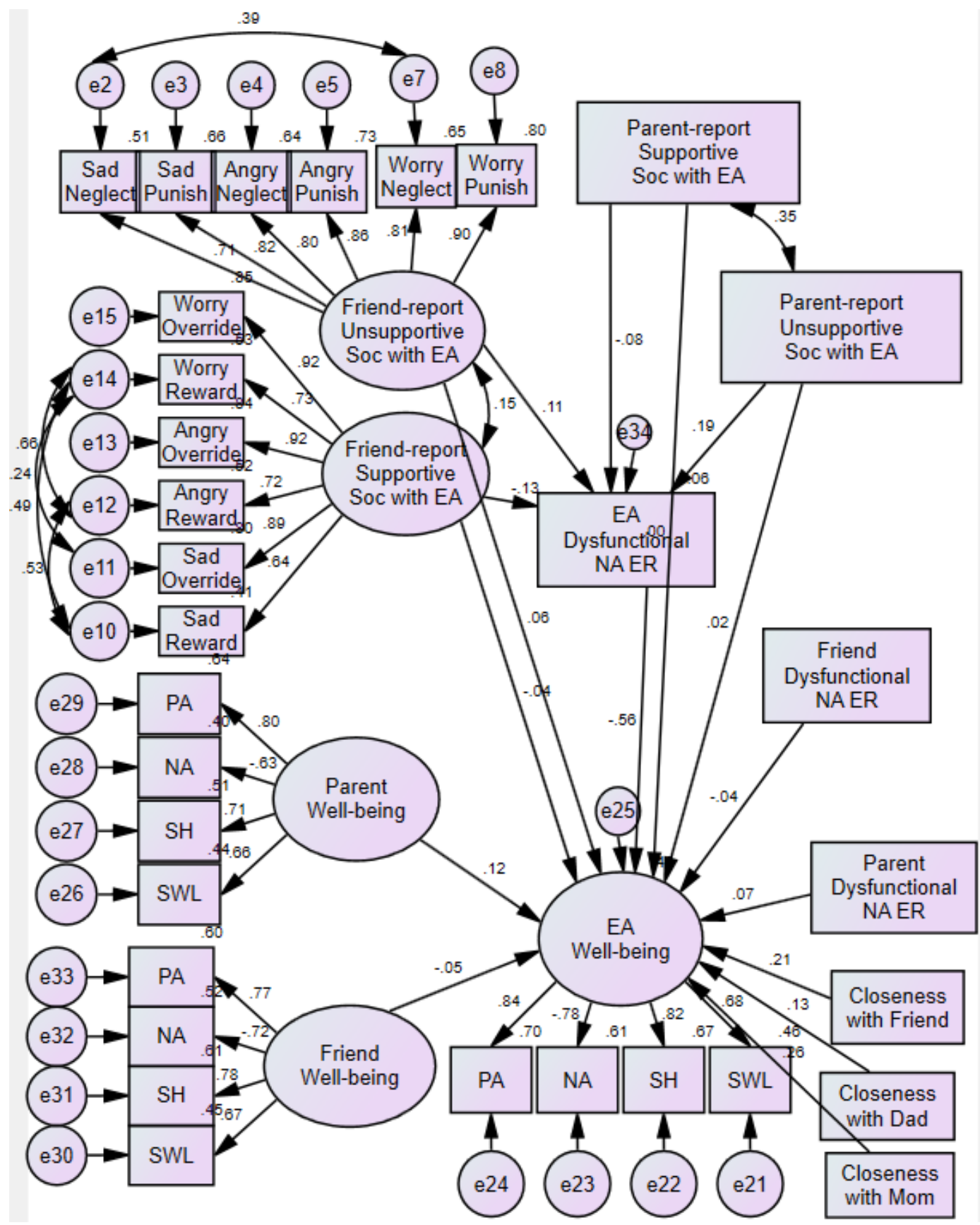

Figure D22. RQ6b - Emerging Adult-reported Dysfunctional Emotion Regulation Mediates the Link between Parent- and Friend-reported Negative Emotion Socialization and Emerging Adult-reported Well-being, controlling for Emerging Adult Closeness with Mother, Father, and Friend. Model fit: $\chi^{2}(194, N=190)=291.85, p<.001, \mathrm{CMIN} / \mathrm{df}=1.50, \mathrm{CFI}=.89, \mathrm{RMSEA}=.06[.05, .08]$. Three significant indirect effects: Parents' Unsupportive Socialization with NA $\rightarrow$ EA Dysfunctional NA ER $\rightarrow$ EA Well-being $(\beta=-.10, p=.014$ [95\% CI -.20, -.02]). Friends' Supportive Socialization with $\mathrm{NA} \rightarrow$ EA Dysfunctional NA ER $\rightarrow$ EA Well-being $(\beta=.08, p=.047$ [95\% CI .001, .16]). Friends' Unsupportive Socialization with NA $\rightarrow$ EA Dysfunctional NA ER $\rightarrow$ EA Well-being $(\beta=-.06, p=$ .049 [95\% CI -.14, -.001]). See Table F17 for comparison with Combined and PA models. 


\section{Appendix E}

\section{Positive Affect Only Models}

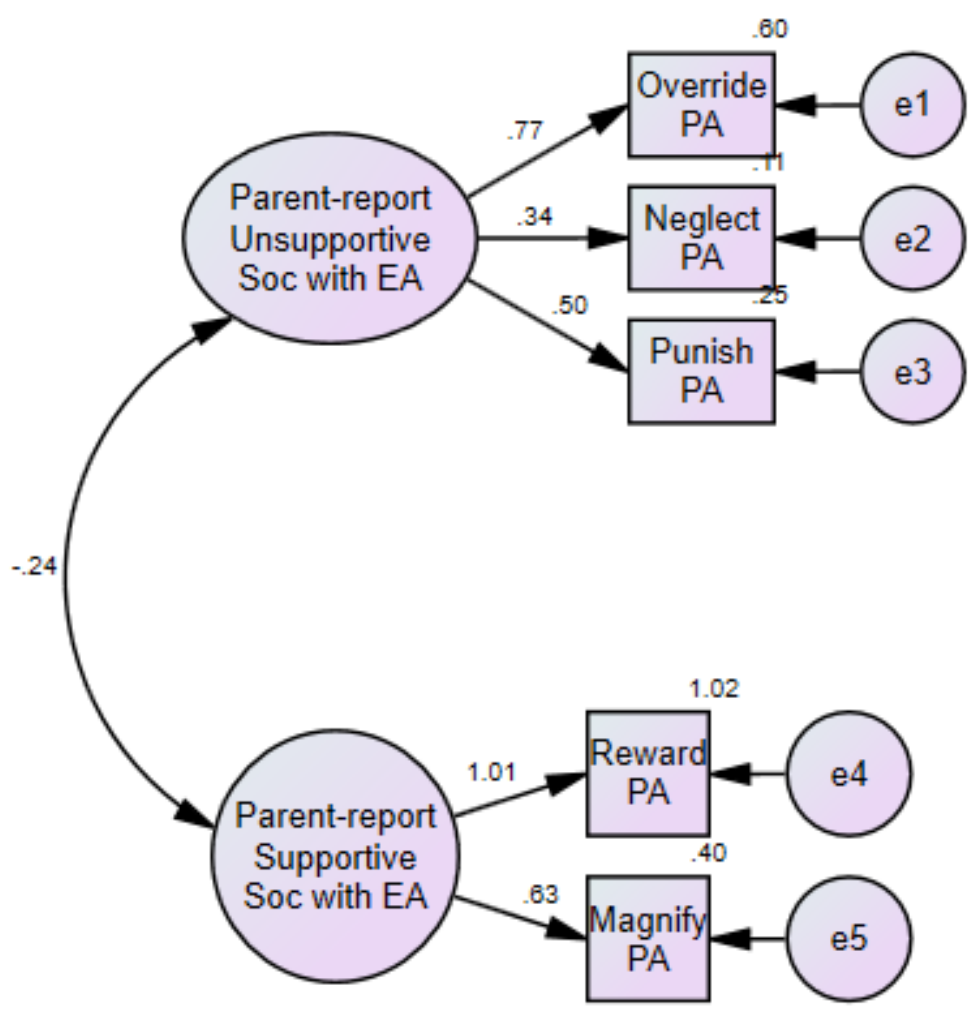

Figure E1. RQ1 - Confirmatory Factor Analysis of Parent-report of their Socialization of their Emerging Adults Children's Positive Emotions. Model fit: $\chi^{2}(4, N=461)=14.54, p=.006$, $\mathrm{CMIN} / \mathrm{df}=3.63, \mathrm{CFI}=.97, \mathrm{RMSEA}=.08[.04, .12]$. 


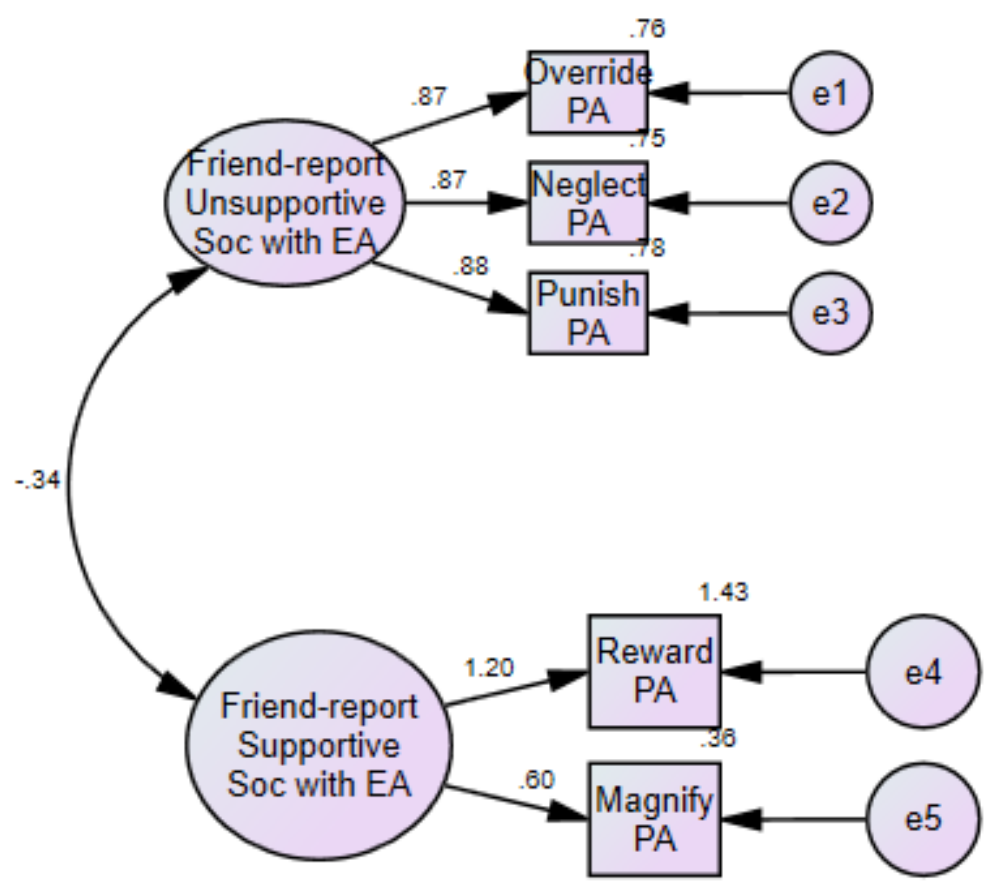

Figure E2. RQ1 - Confirmatory Factor Analysis of Friend-report of their Socialization of their Emerging Adults Friends' Positive Emotions. Model fit: $\chi^{2}(4, N=461)=2.45, p=.653$, $\mathrm{CMIN} / \mathrm{df}=.61, \mathrm{CFI}=1.00, \mathrm{RMSEA}=.00[.00, .08]$. 


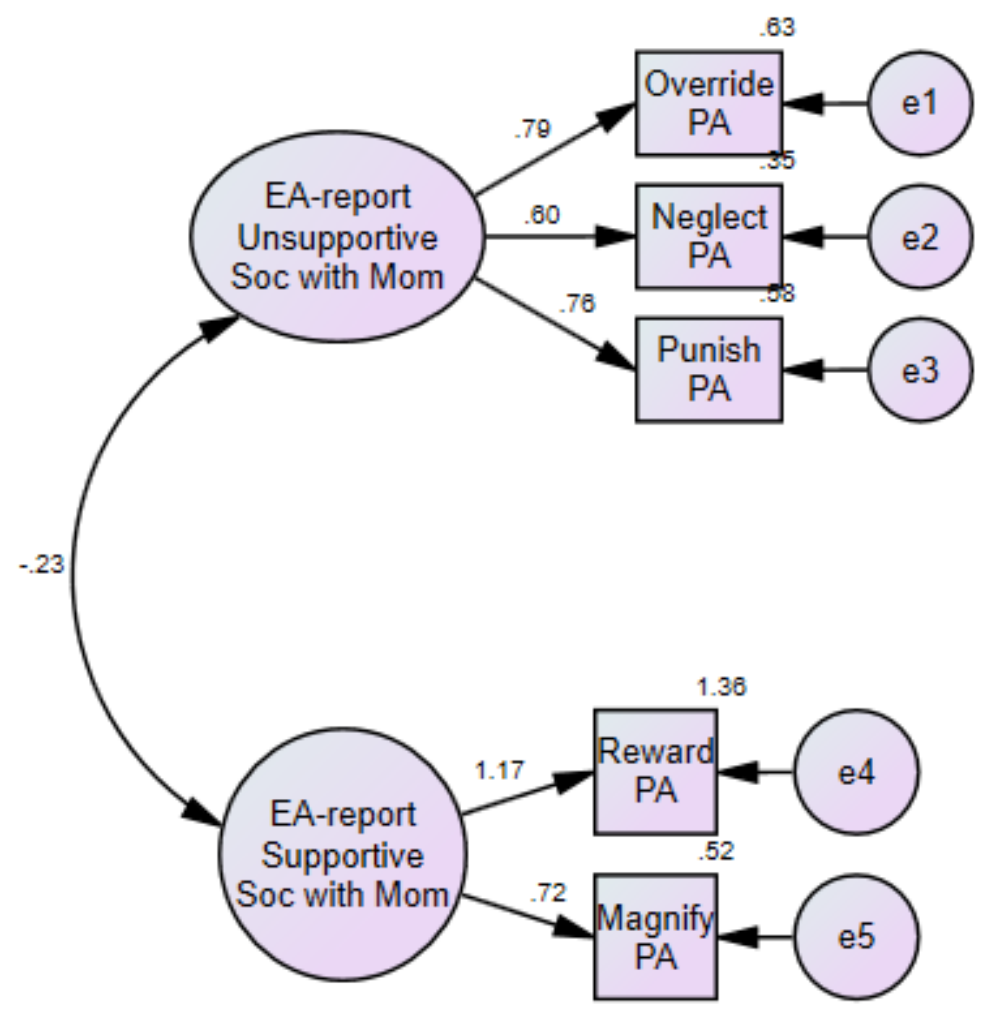

Figure E3. RQ1 - Confirmatory Factor Analysis of Emerging Adult-report of their Socialization of their Mothers' Positive Emotions. Model fit: $\chi^{2}(4, N=612)=73.30, p<.001, \mathrm{CMIN} / \mathrm{df}=$ $.18 .33, \mathrm{CFI}=.94, \mathrm{RMSEA}=.16[.13, .19]$. 


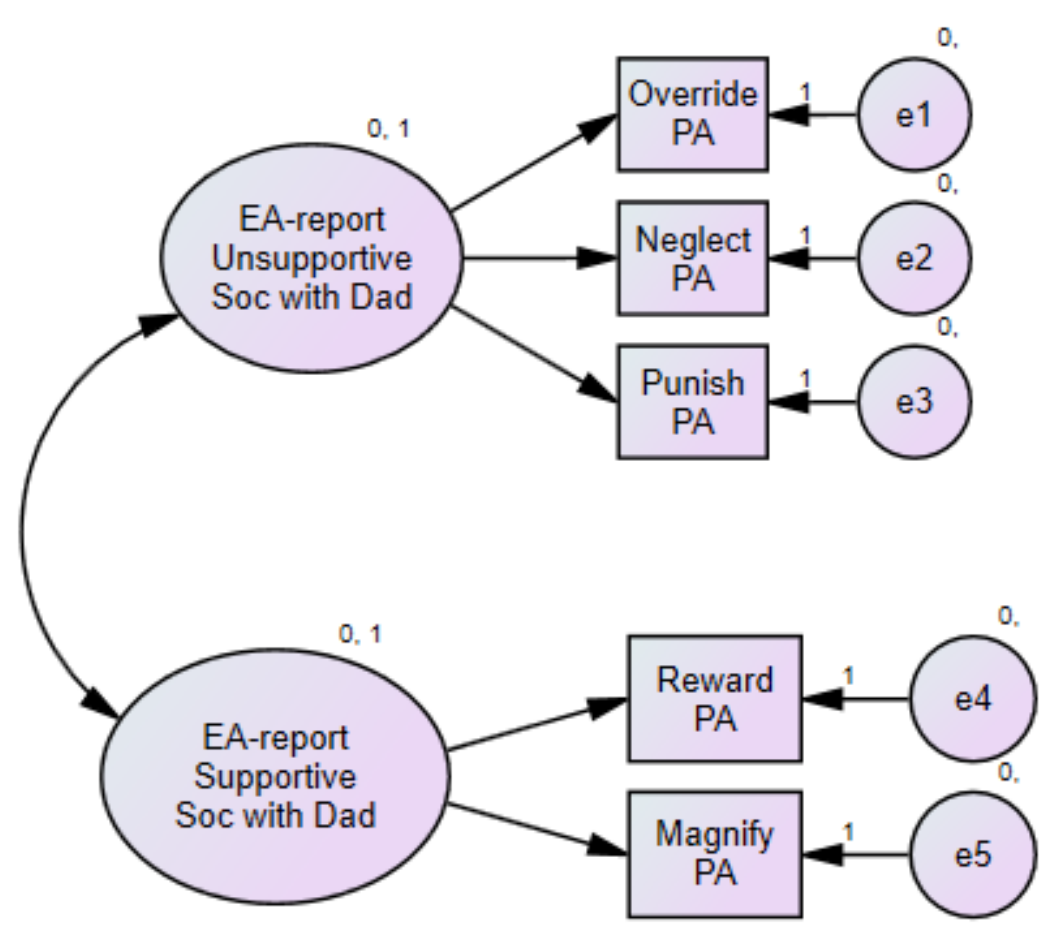

Figure E4. RQ1 - Confirmatory Factor Analysis of Emerging Adult-report of their Socialization of their Fathers' Positive Emotions. Model fit: N/A. There were issues with multicollinearity among the indicators which prevented the model from running. Therefore, an observed variable was used in analyses. 


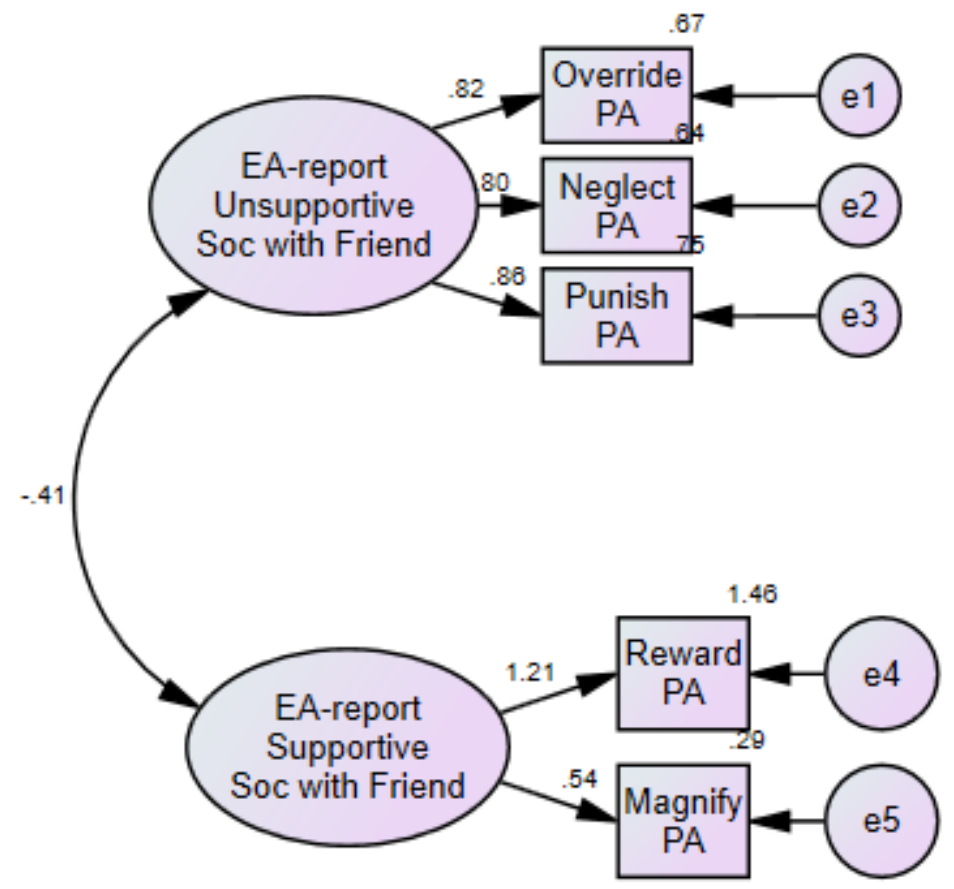

Figure E5. RQ1 - Confirmatory Factor Analysis of Emerging Adult-report of their Socialization of their Friends' Positive Emotions. Model fit: $\chi^{2}(4, N=612)=21.10, p<.001, \mathrm{CMIN} / \mathrm{df}=5.27$, $\mathrm{CFI}=.99, \mathrm{RMSEA}=.08[.05, .11]$. 


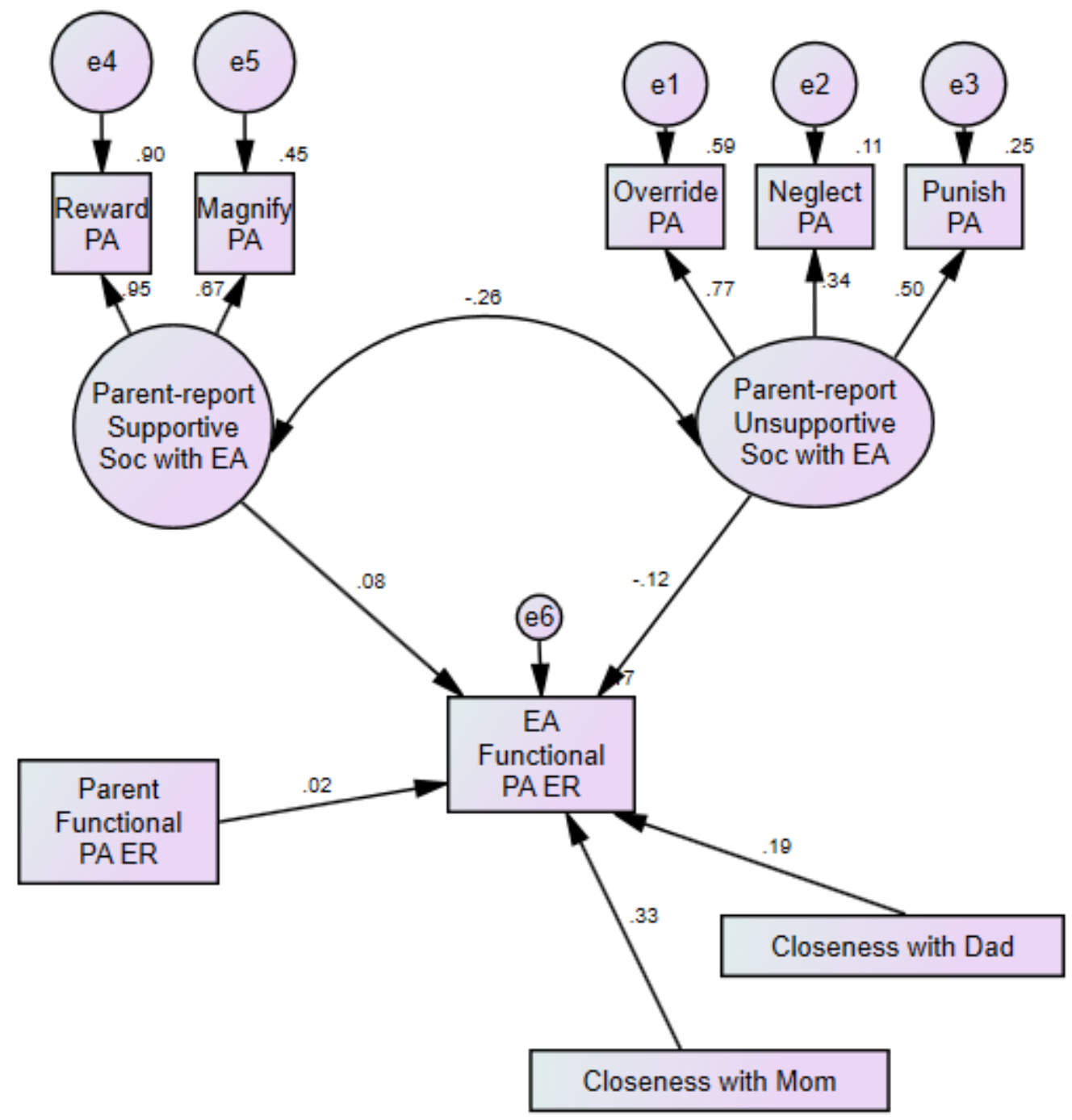

Figure E6. RQ2a - Parent-reported Positive Emotion Socialization predicting Emerging Adultreported Functional Emotion Regulation, controlling for Emerging Adult-reported Closeness with Mother and Father. Model fit: $\chi^{2}(25, N=461)=218.41, p<.001, \mathrm{CMIN} / \mathrm{df}=8.74, \mathrm{CFI}=$ $.69, \mathrm{RMSEA}=.13[.11, .15]$. See Table F1 for comparison with Combined and NA models. 


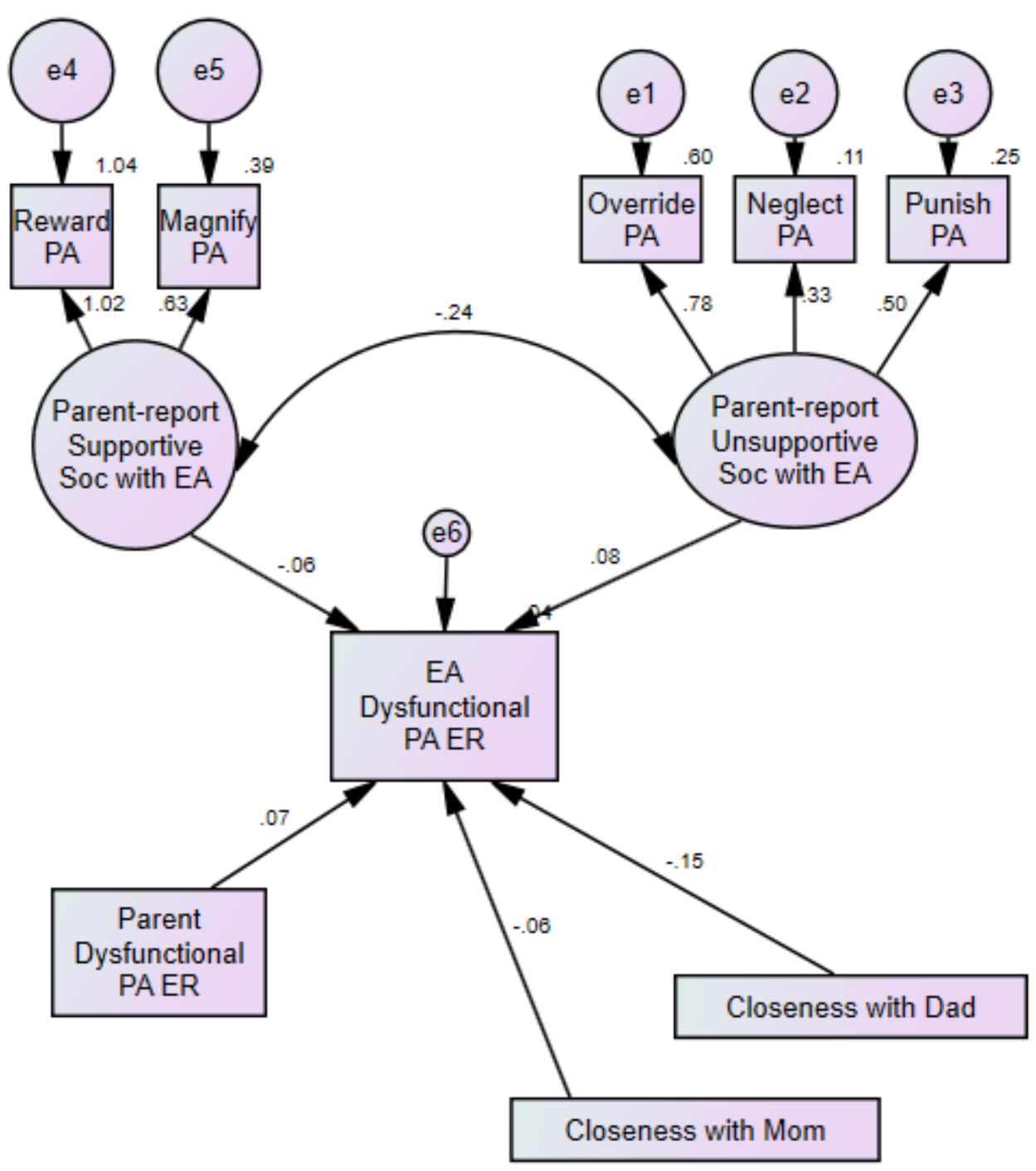

Figure E7. RQ2b - Parent-reported Positive Emotion Socialization predicting Emerging Adultreported Dysfunctional Emotion Regulation, controlling for Emerging Adult-reported Closeness with Mother and Father. Model fit: $\chi^{2}(25, N=461)=119.54, p<.001, \mathrm{CMIN} / \mathrm{df}=4.78, \mathrm{CFI}=$ $.79, \mathrm{RMSEA}=.09[.08, .11]$. See Table F2 for comparison with Combined and NA models. 


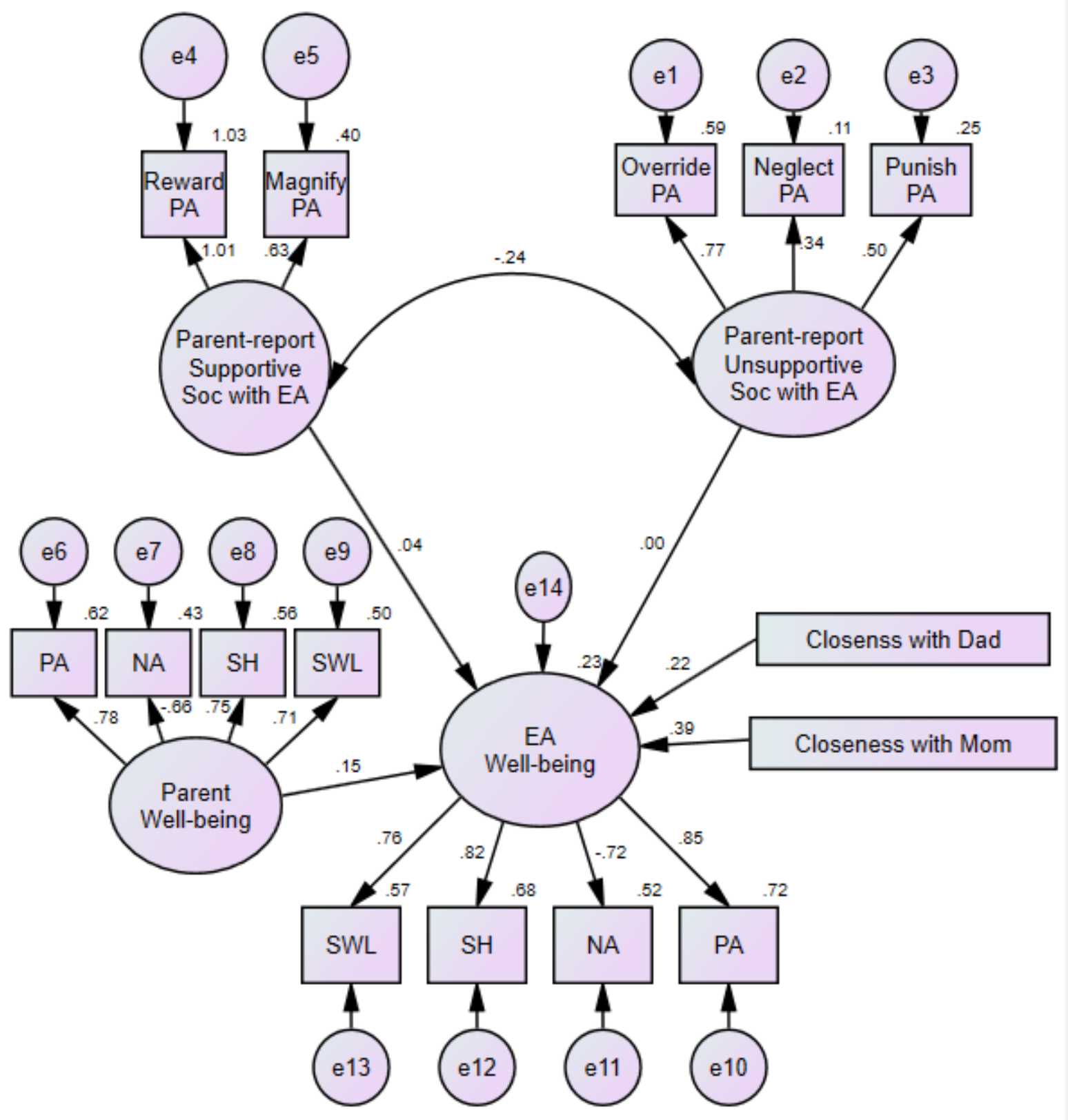

Figure E8. RQ2c - Parent-reported Positive Emotion Socialization predicting Emerging Adultreported Well-being, controlling for Emerging Adult-reported Closeness with Mother and Father. Model fit: $\chi^{2}(86, N=461)=238.40, p<.001, \mathrm{CMIN} / \mathrm{df}=2.77, \mathrm{CFI}=.92, \mathrm{RMSEA}=.06[.05$, .07]. See Table F3 for comparison with Combined and NA models. 


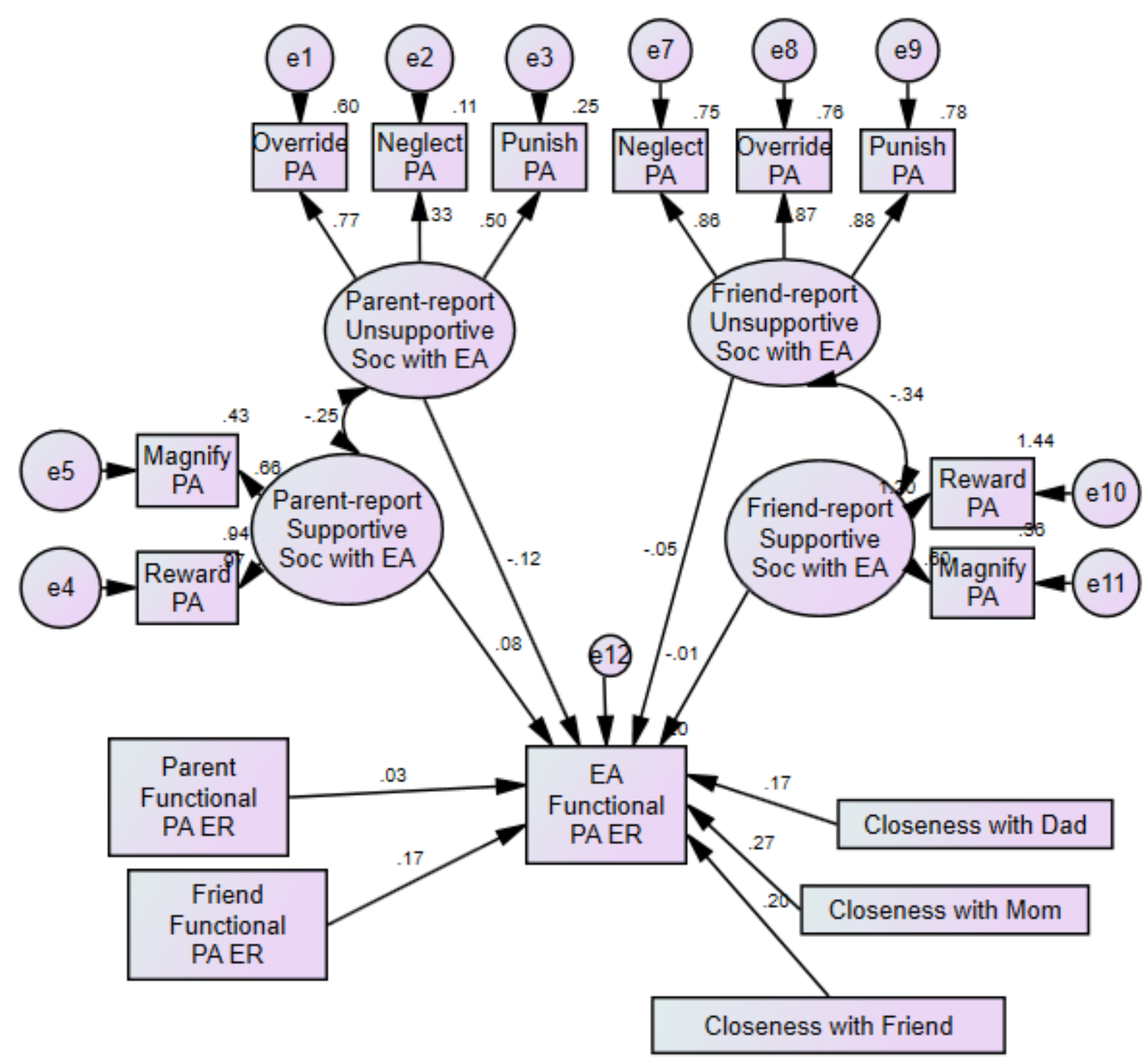

Figure E9. RQ3a - Parent- and Friend-reported Positive Emotion Socialization predicting Emerging Adult-reported Functional Emotion Regulation, controlling for Emerging Adultreported Closeness with Mother, Father, and Friend. Model fit: $\chi^{2}(99, N=512)=429.95, p<$ $.001, \mathrm{CMIN} / \mathrm{df}=4.34, \mathrm{CFI}=.78, \mathrm{RMSEA}=.08[.07, .09]$. See Table F4 for comparison with Combined and NA models. Parent- and Friend-report did not significantly differ from one another on Supportive $(\mathrm{CR}=1.35)$ or Unsupportive Emotion Socialization $(\mathrm{CR}=-.77)$. 


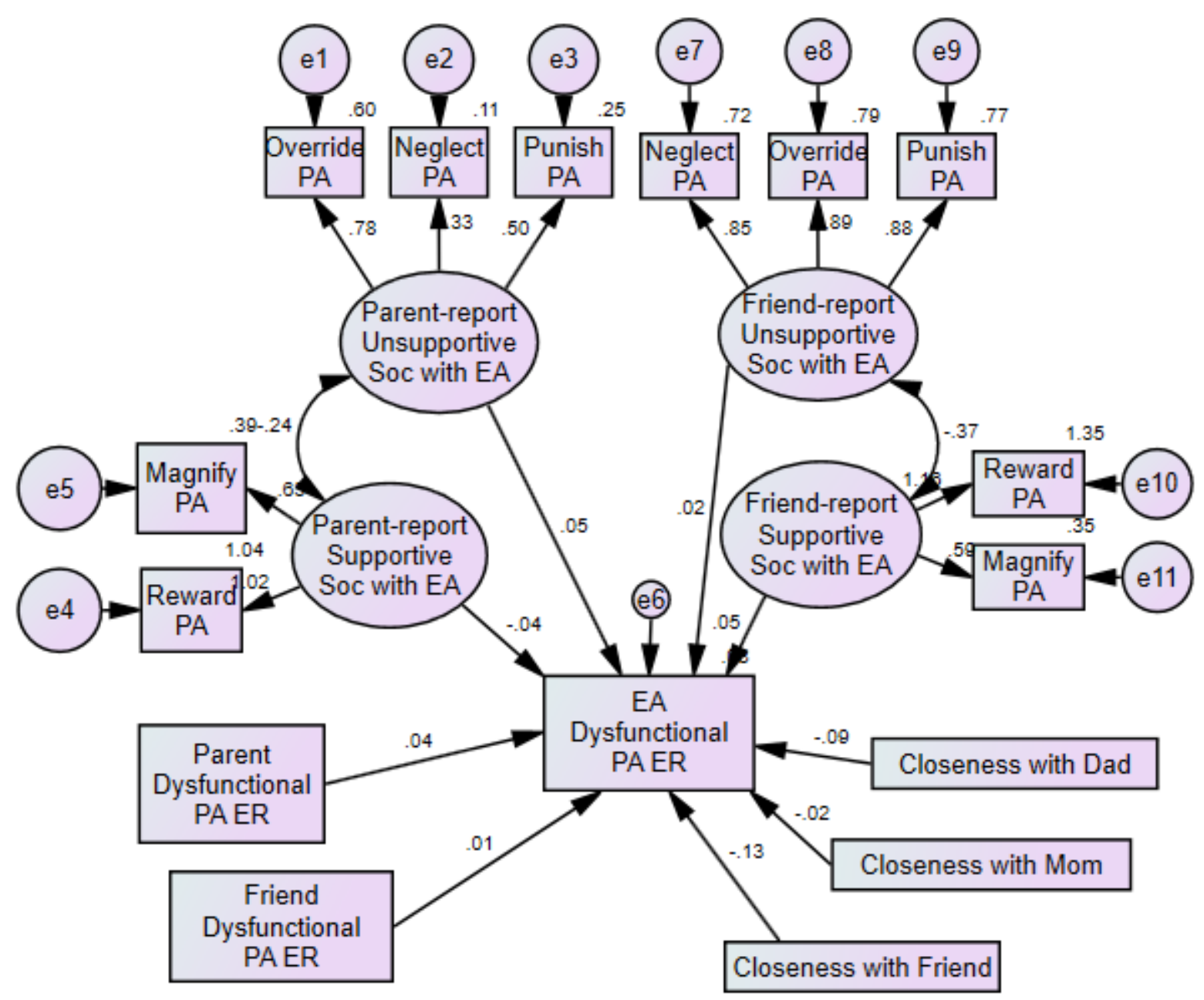

Figure E10. RQ3b - Parent- and Friend-reported Positive Emotion Socialization predicting Emerging Adult-reported Dysfunctional Emotion Regulation, controlling for Emerging Adultreported Closeness with Mother, Father, and Friend. Model fit: $\chi^{2}(99, N=512)=331.96, p<$ $.001, \mathrm{CMIN} / \mathrm{df}=3.32, \mathrm{CFI}=.78, \mathrm{RMSEA}=.07[.06, .08]$. See Table F5 for comparison with Combined and NA models. Parent- and Friend-report did not significantly differ from one another on Supportive ( $C R=-1.09$ ) or Unsupportive Emotion Socialization $(C R=.29)$. 


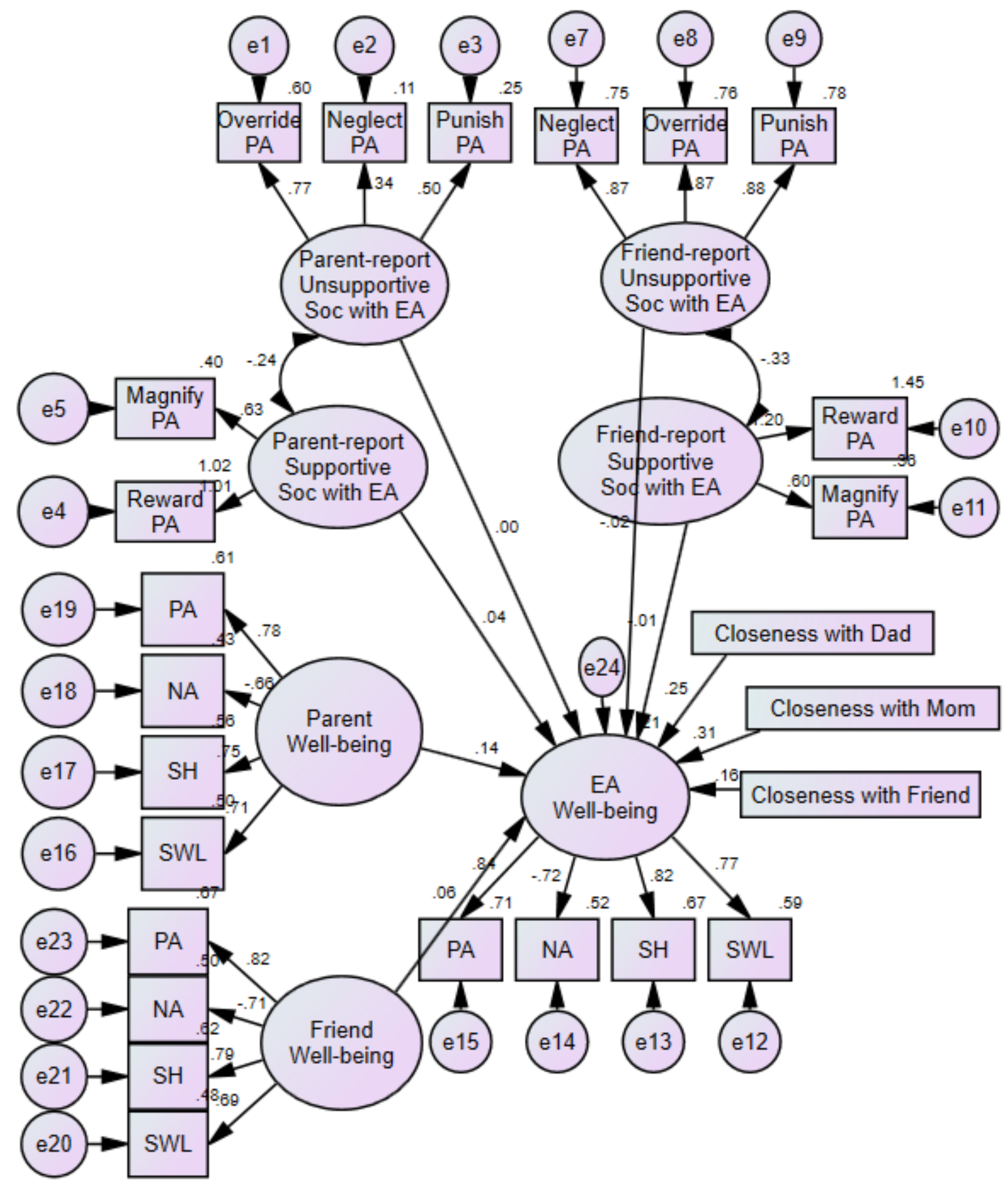

Figure E11. RQ3c - Parent- and Friend-reported Positive Emotion Socialization predicting Emerging Adult-reported Well-being, controlling for Emerging Adult-reported Closeness with Mother, Father, and Friend. Model fit: $\chi^{2}(267, N=512)=484.65, p<.001, \mathrm{CMIN} / \mathrm{df}=1.82$, CFI $=.93$, RMSEA $=.04[.03, .05]$. See Table F6 for comparison with Combined and NA models. Parent- and Friend-report did not significantly differ from one another on Supportive $(\mathrm{CR}=.73)$ or Unsupportive Emotion Socialization $(\mathrm{CR}=.21)$. 


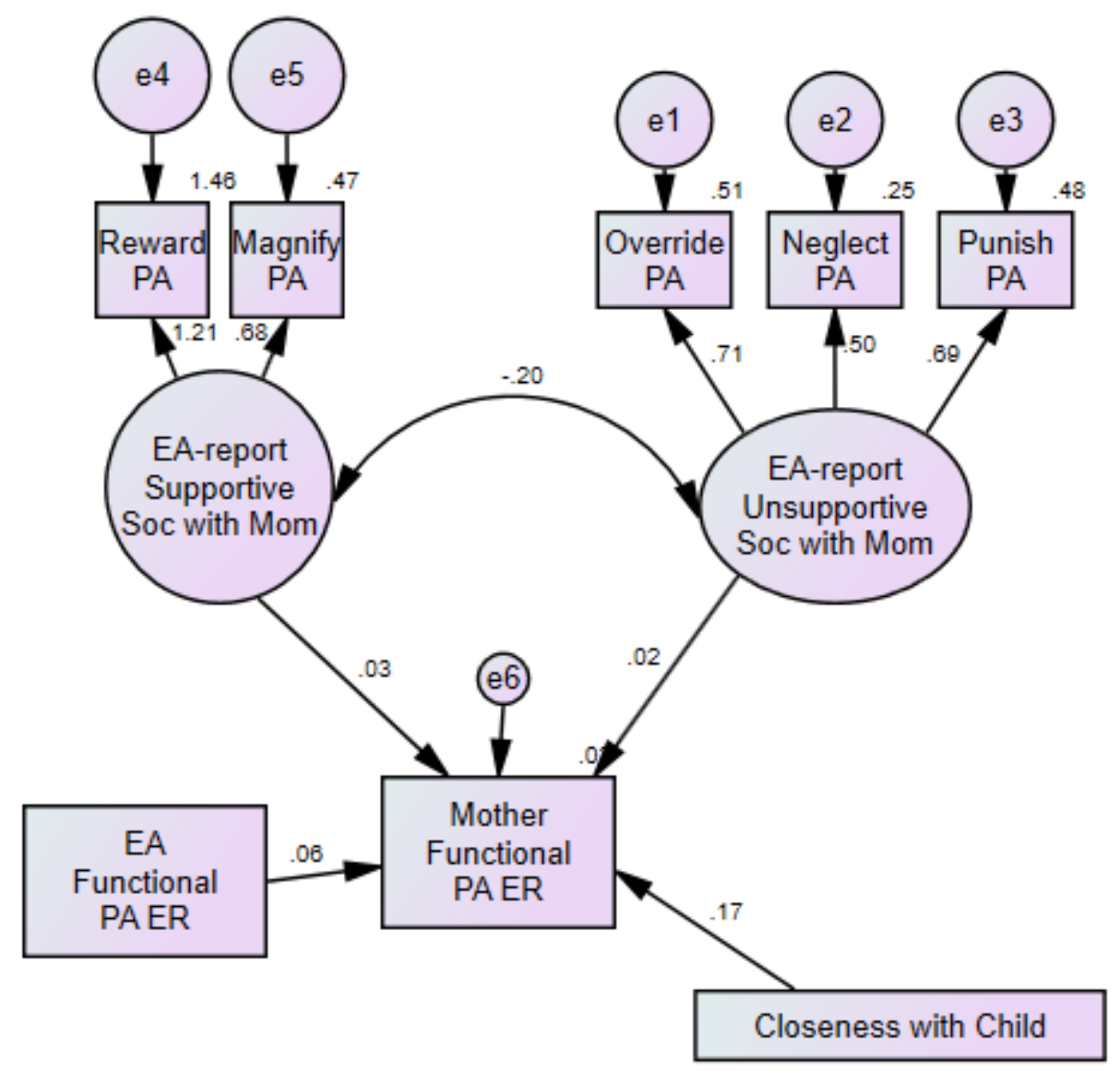

Figure E12. RQ4aa - Emerging Adult-reported Positive Emotion Socialization predicting Mother-reported Functional Emotion Regulation, controlling for Mother-reported Closeness with Emerging Adult Child. Model fit: $\chi^{2}(18, N=338)=213.14, p<.001, \mathrm{CMIN} / \mathrm{df}=11.84, \mathrm{CFI}=$ .74 , RMSEA $=.18[.16, .20]$. See Table F7 for comparison with Combined and NA models. 


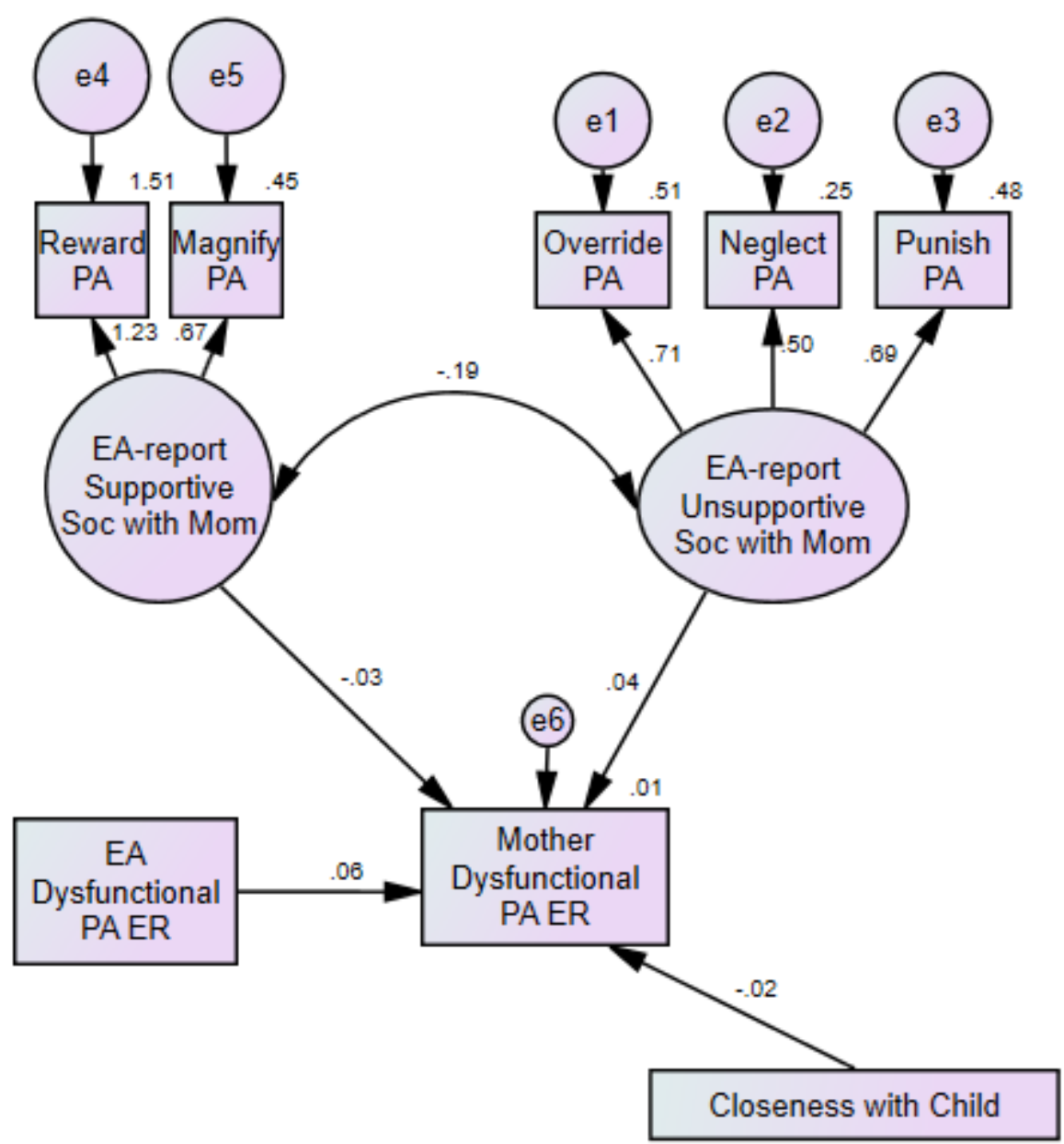

Figure E13. RQ4ab - Emerging Adult-reported Positive Emotion Socialization predicting Mother-reported Dysfunctional Emotion Regulation, controlling for Mother-reported Closeness with Emerging Adult Child. Model fit: $\chi^{2}(18, N=338)=111.73, p<.001, \mathrm{CMIN} / \mathrm{df}=6.21$, CFI $=.85$, RMSEA $=.12[.10, .15]$. See Table F8 for comparison with Combined and NA models. 


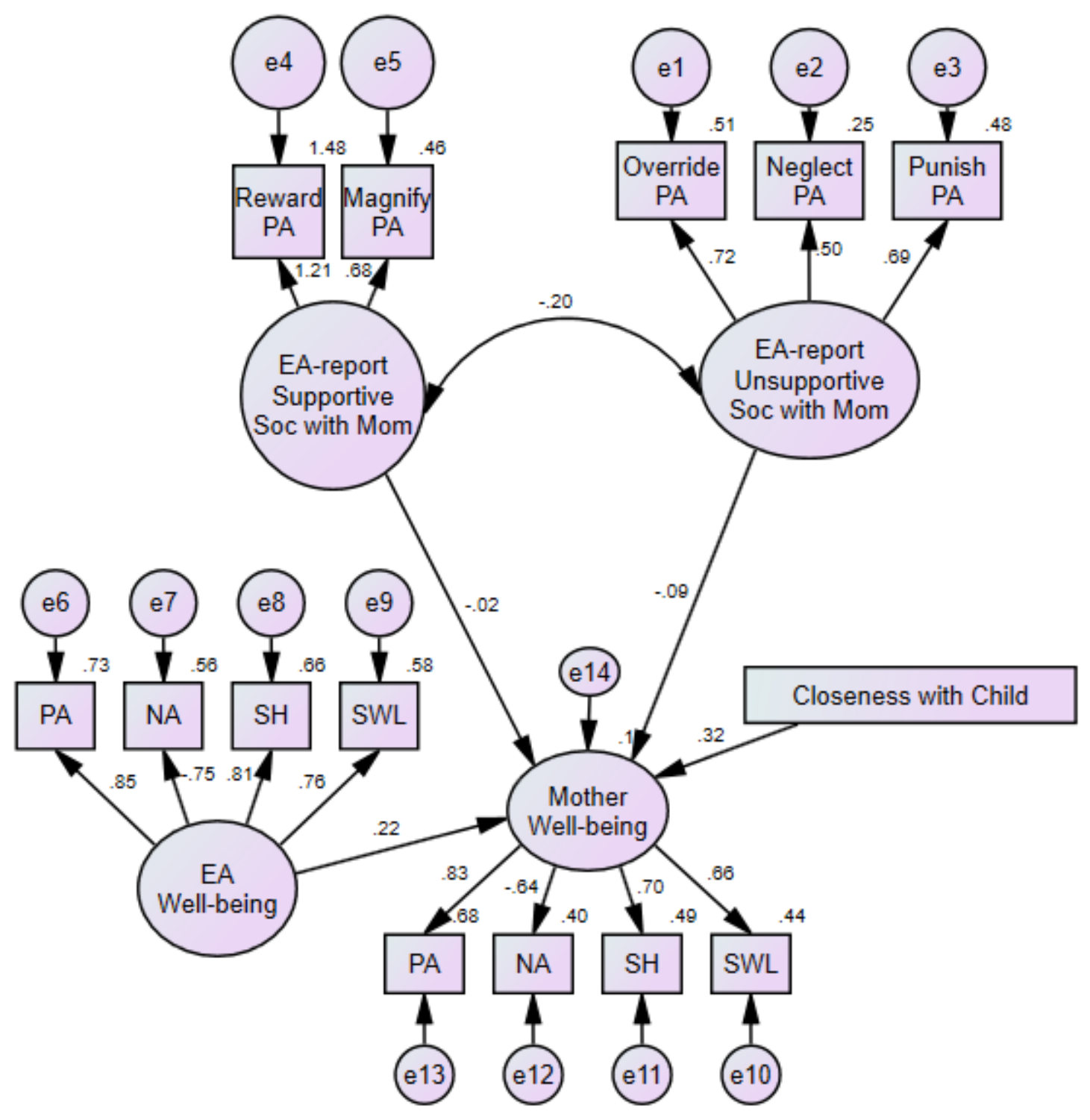

Figure E14. RQ4ac - Emerging Adult-reported Positive Emotion Socialization predicting Mother-reported Well-being, controlling for Mother-reported Closeness with Emerging Adult Child. Model fit: $\chi^{2}(73, N=338)=259.64, p<.001, \mathrm{CMIN} / \mathrm{df}=3.56, \mathrm{CFI}=.90, \mathrm{RMSEA}=.09$ $[.08, .10]$. See Table F9 for comparison with Combined and NA models. 


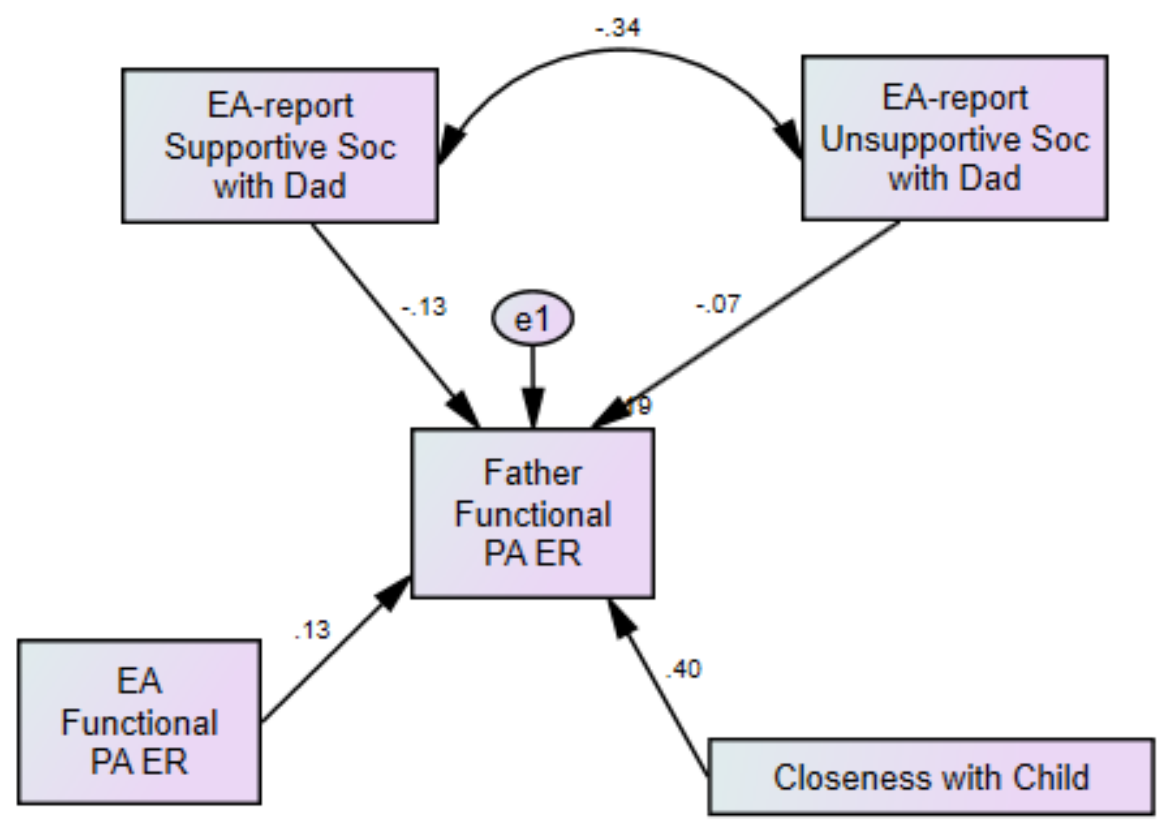

Figure E15. RQ4ba - Emerging Adult-reported Positive Emotion Socialization predicting Father-reported Functional Emotion Regulation, controlling for Father-reported Closeness with Emerging Adult Child. Model fit: $\chi^{2}(5, N=123)=26.45, p<.001, \mathrm{CMIN} / \mathrm{df}=5.29, \mathrm{CFI}=.46$, RMSEA $=.19[.12, .26]$. See Table F10 for comparison with Combined and NA models. 


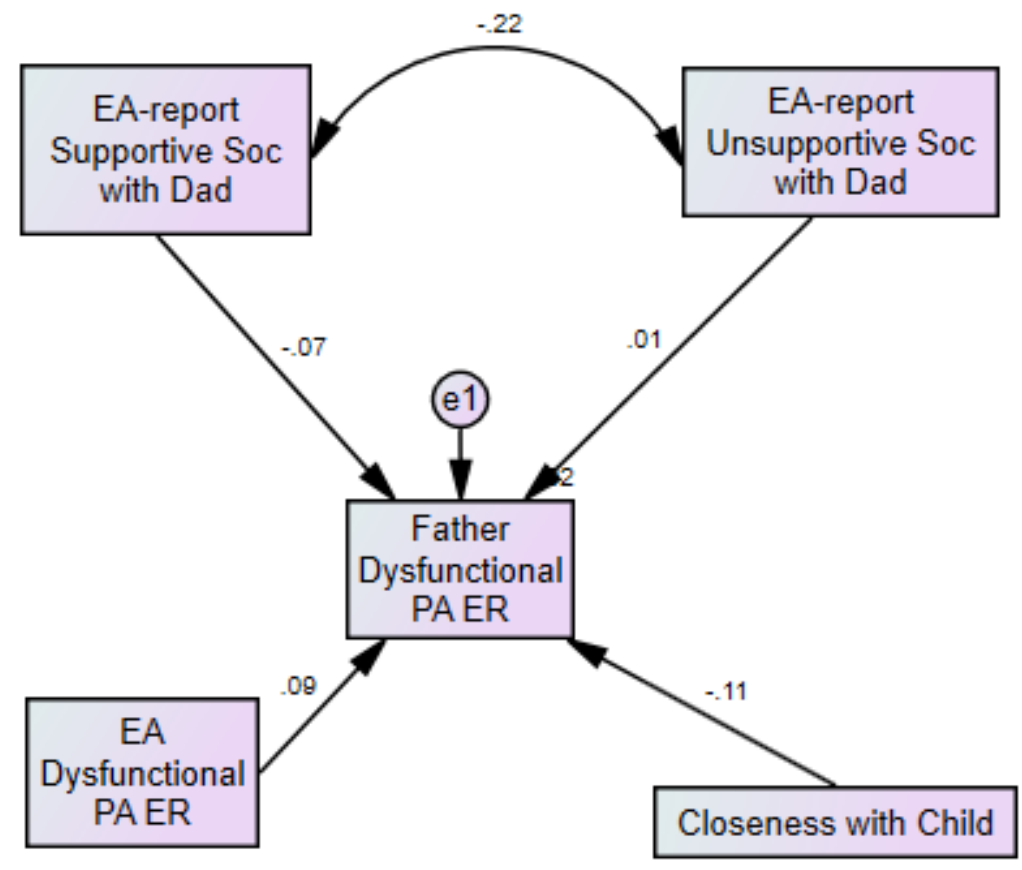

Figure E16. RQ4bb - Emerging Adult-reported Positive Emotion Socialization predicting Father-reported Dysfunctional Emotion Regulation, controlling for Father-reported Closeness with Emerging Adult Child. Model fit: $\chi^{2}(5, N=123)=38.49, p<.001, \mathrm{CMIN} / \mathrm{df}=7.70$, CFI $=$ $.38, \mathrm{RMSEA}=.12[.09, .16]$. See Table F11 for comparison with Combined and NA models. 


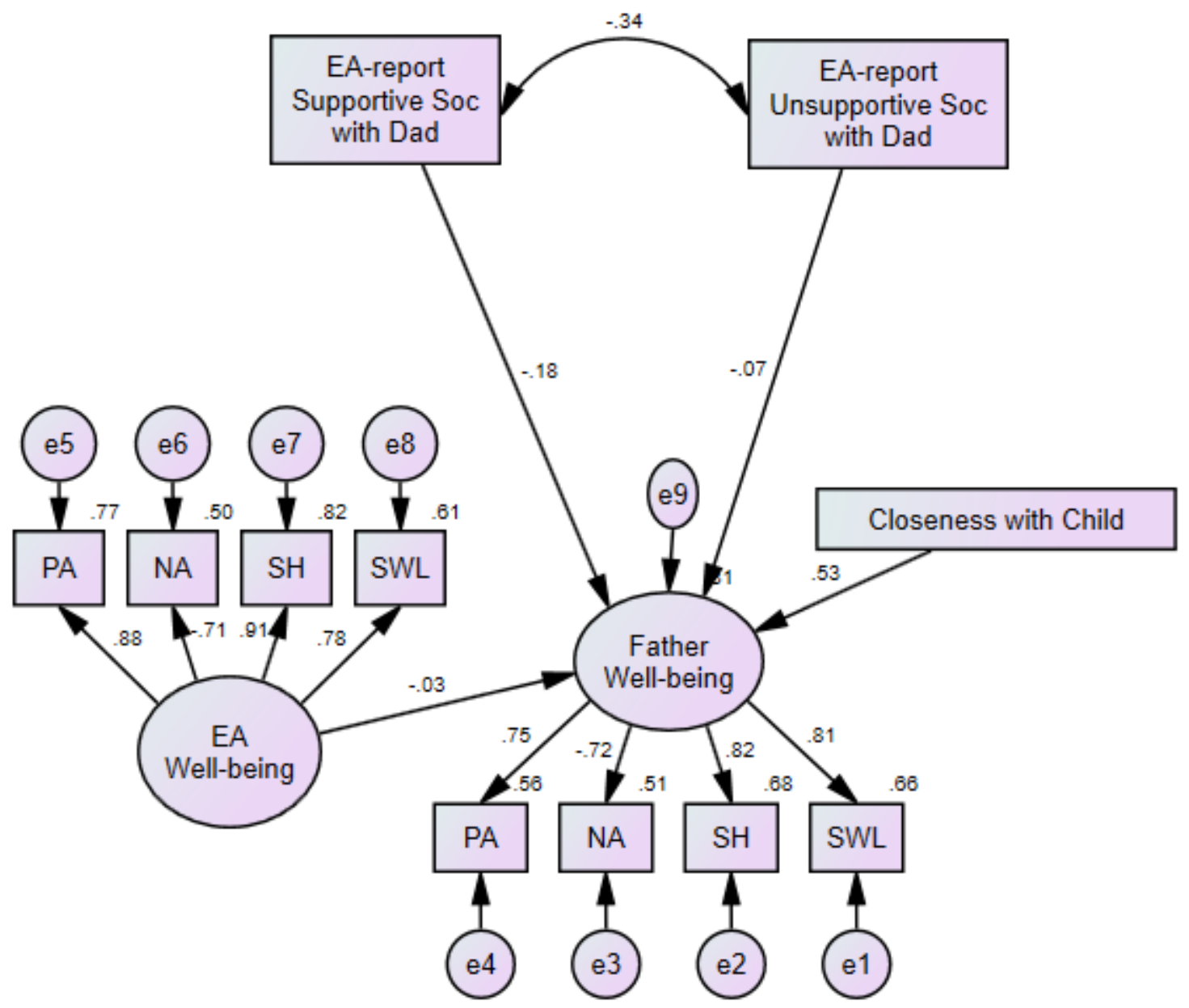

Figure E17. RQ4bc - Emerging Adult-reported Positive Emotion Socialization predicting Father-reported Well-being, controlling for Father-reported Closeness with Emerging Adult Child. Model fit: $\chi^{2}(42, N=123)=71.43, p<.001, \mathrm{CMIN} / \mathrm{df}=1.70, \mathrm{CFI}=.93, \mathrm{RMSEA}=.08$ $[.04, .11]$. See Table F12 for comparison with Combined and NA models. 


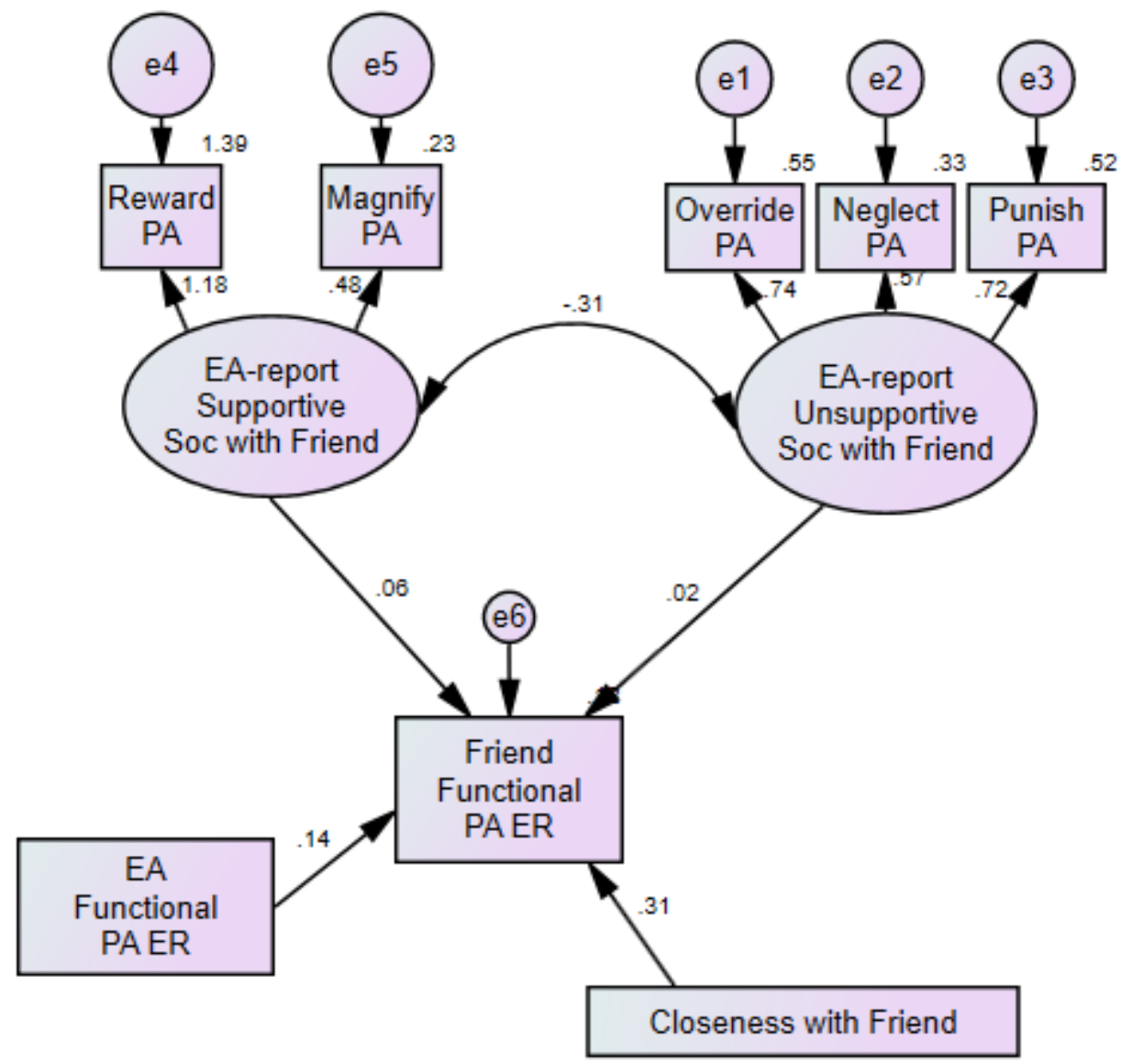

Figure E18. RQ5a - Emerging Adult-reported Positive Emotion Socialization predicting Friendreported Functional Emotion Regulation, controlling for Friend-reported Closeness with Emerging Adult Friend. Model fit: $\chi^{2}(18, N=261)=98.07, p<.001, \mathrm{CMIN} / \mathrm{df}=5.45, \mathrm{CFI}=$ .79 , RMSEA $=.13[.11, .16]$. See Table F13 for comparison with Combined and NA models. 


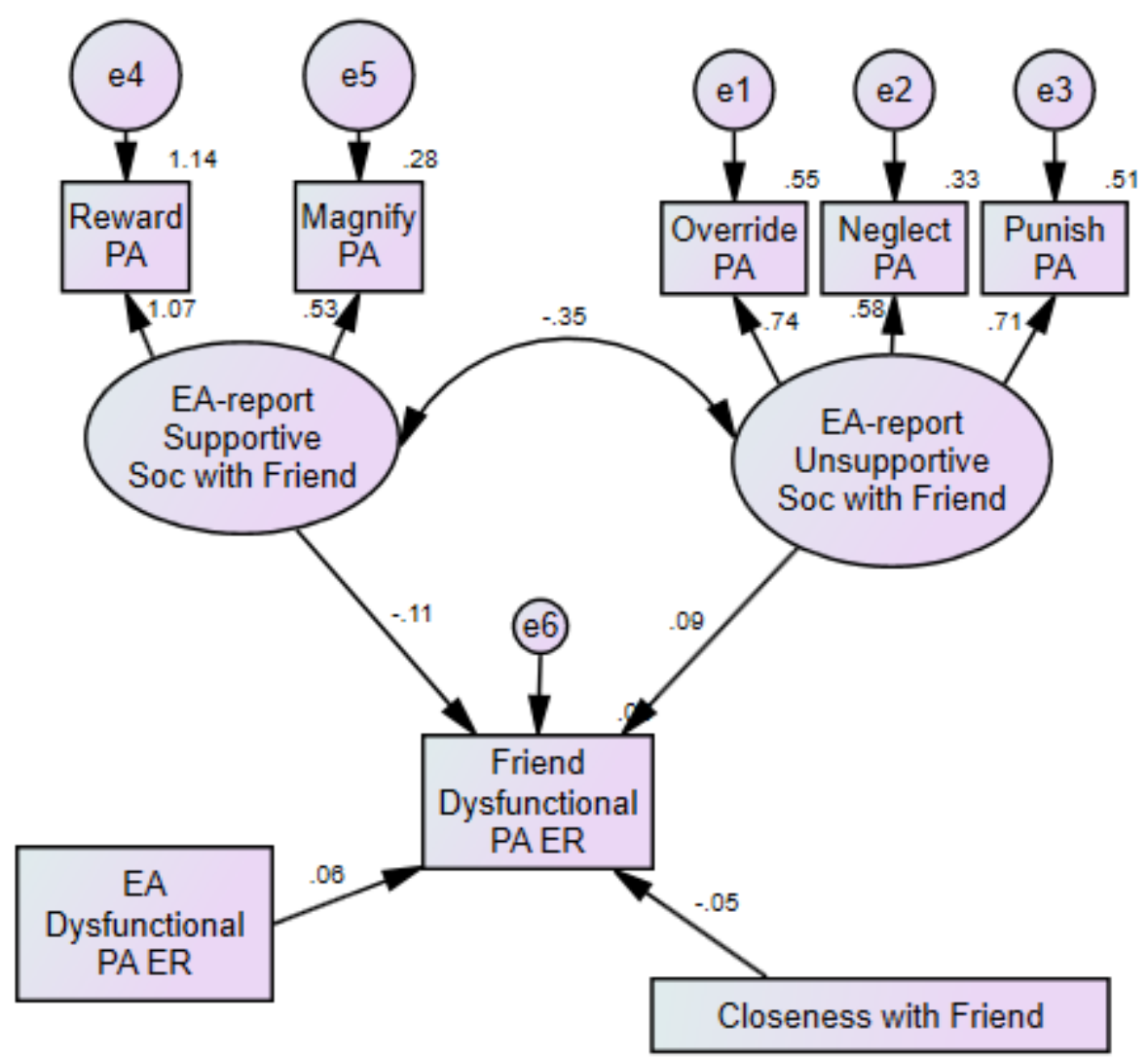

Figure E19. RQ5b - Emerging Adult-reported Positive Emotion Socialization predicting Friendreported Dysfunctional Emotion Regulation, controlling for Friend-reported Closeness with Emerging Adult Friend. Model fit: $\chi^{2}(18, N=261)=63.48, p<.001, \mathrm{CMIN} / \mathrm{df}=3.53$, CFI $=$ .86, RMSEA $=.10[.07, .13]$. See Table F14 for comparison with Combined and NA models. 


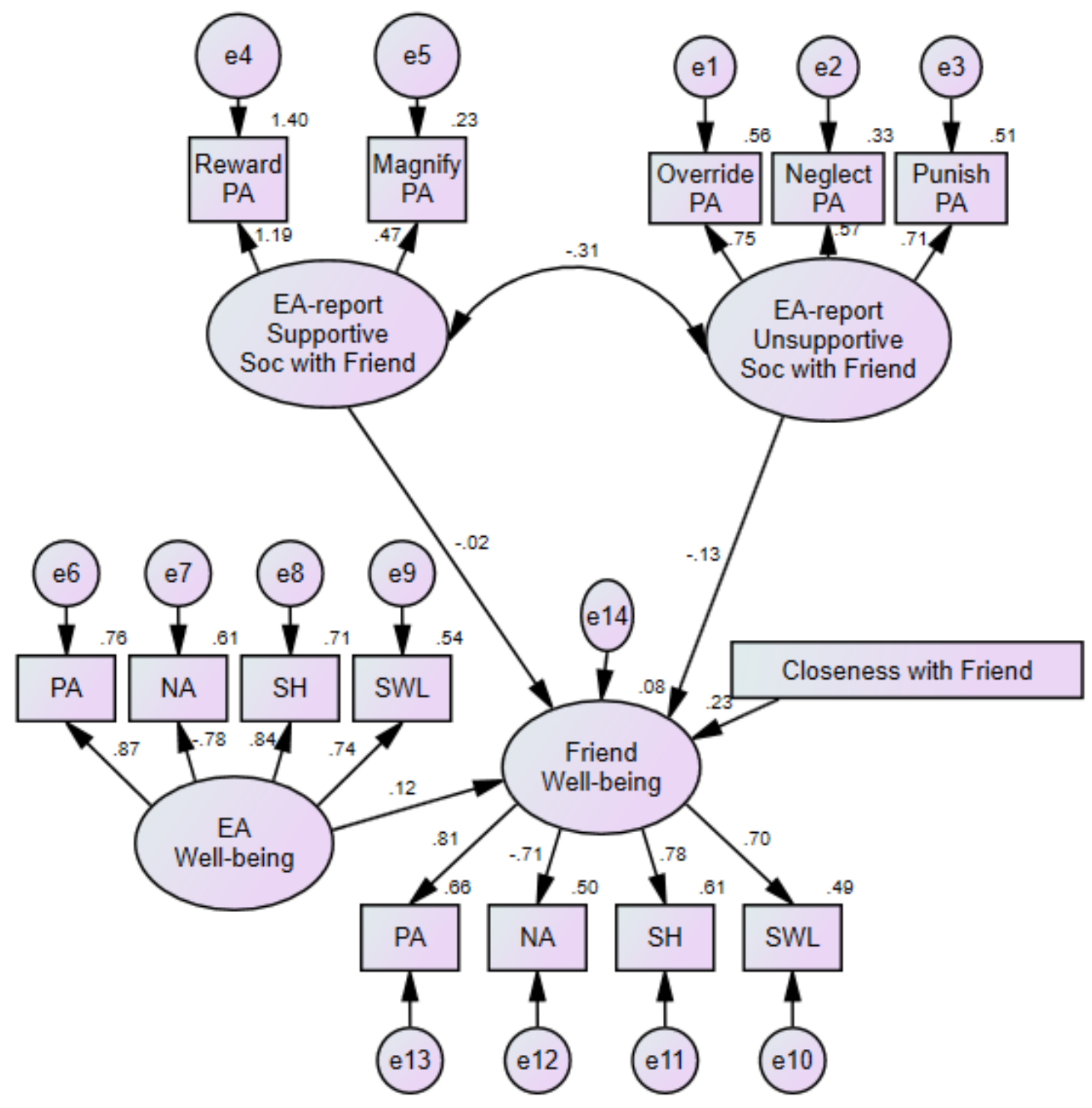

Figure E20. RQ5c - Emerging Adult-reported Positive Emotion Socialization predicting Friendreported Well-being, controlling for Friend-reported Closeness with Emerging Adult Friend. Model fit: $\chi^{2}(73, N=261)=108.55, p<.001, \mathrm{CMIN} / \mathrm{df}=1.49, \mathrm{CFI}=.97, \mathrm{RMSEA}=.04[.03$, .06]. See Table F15 for comparison with Combined and NA models. 


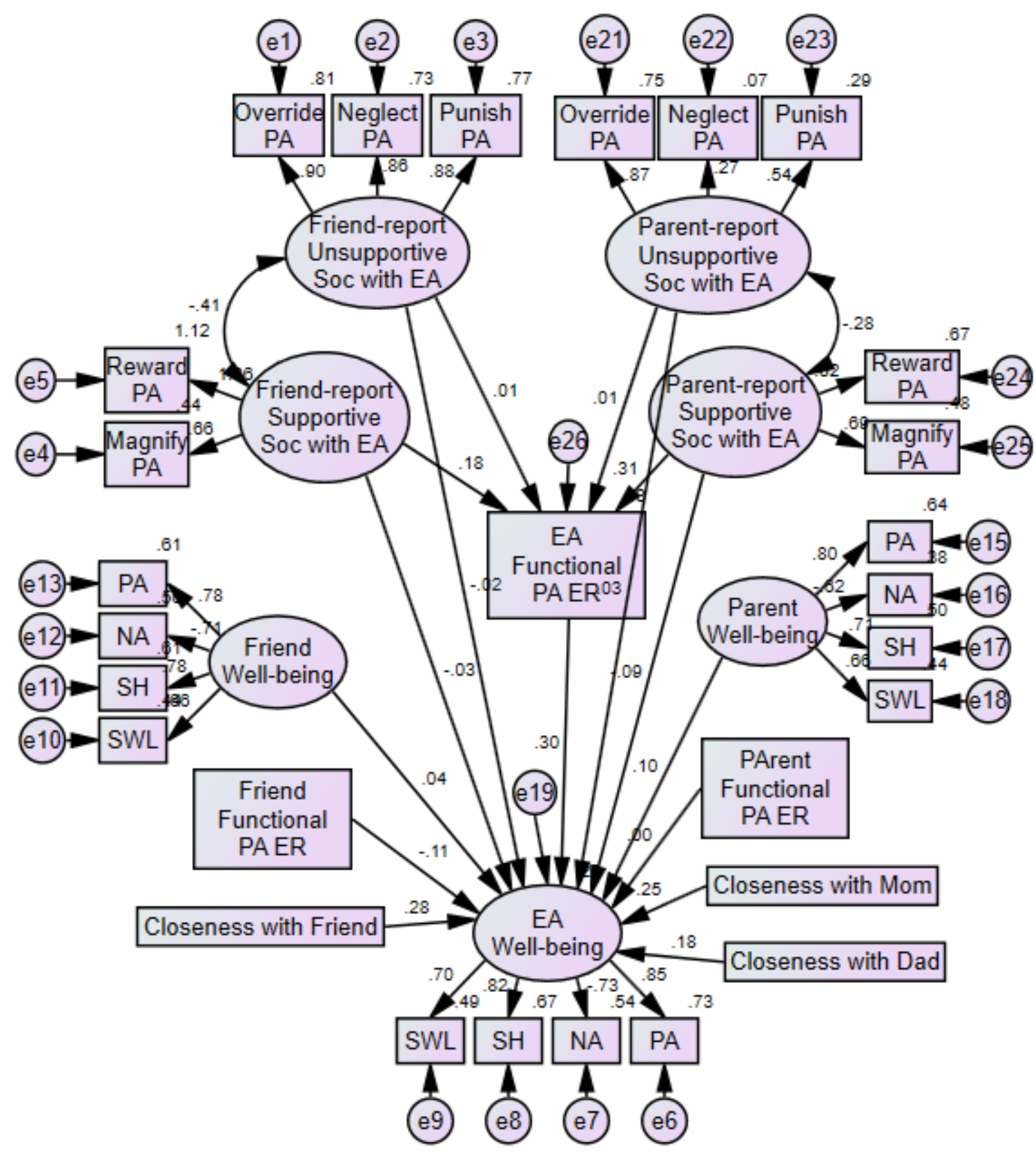

Figure E21. RQ6a - Emerging Adult-reported Functional Emotion Regulation Mediates the Link between Parent- and Friend-reported Positive Emotion Socialization and Emerging Adultreported Well-being, controlling for Emerging Adult Closeness with Mother, Father, and Friend. Model fit: $\chi^{2}(338, N=193)=634.99, p<.001, \mathrm{CMIN} / \mathrm{df}=1.88, \mathrm{CFI}=.85, \mathrm{RMSEA}=.07[.06$, .08]. Two significant indirect effects: Parents' Supportive Socialization with PA $\rightarrow$ EA Functional PA ER $\rightarrow$ EA Well-being $(\beta=.10, p=.001[95 \% \mathrm{CI} .03, .23])$ and Friends' Supportive Socialization with PA $\rightarrow$ EA Functional PA ER $\rightarrow$ EA Well-being $(\beta=.05, p=.038$ $[95 \%$ CI .002, .16]). See Table F16 for comparison with Combined and NA models. 


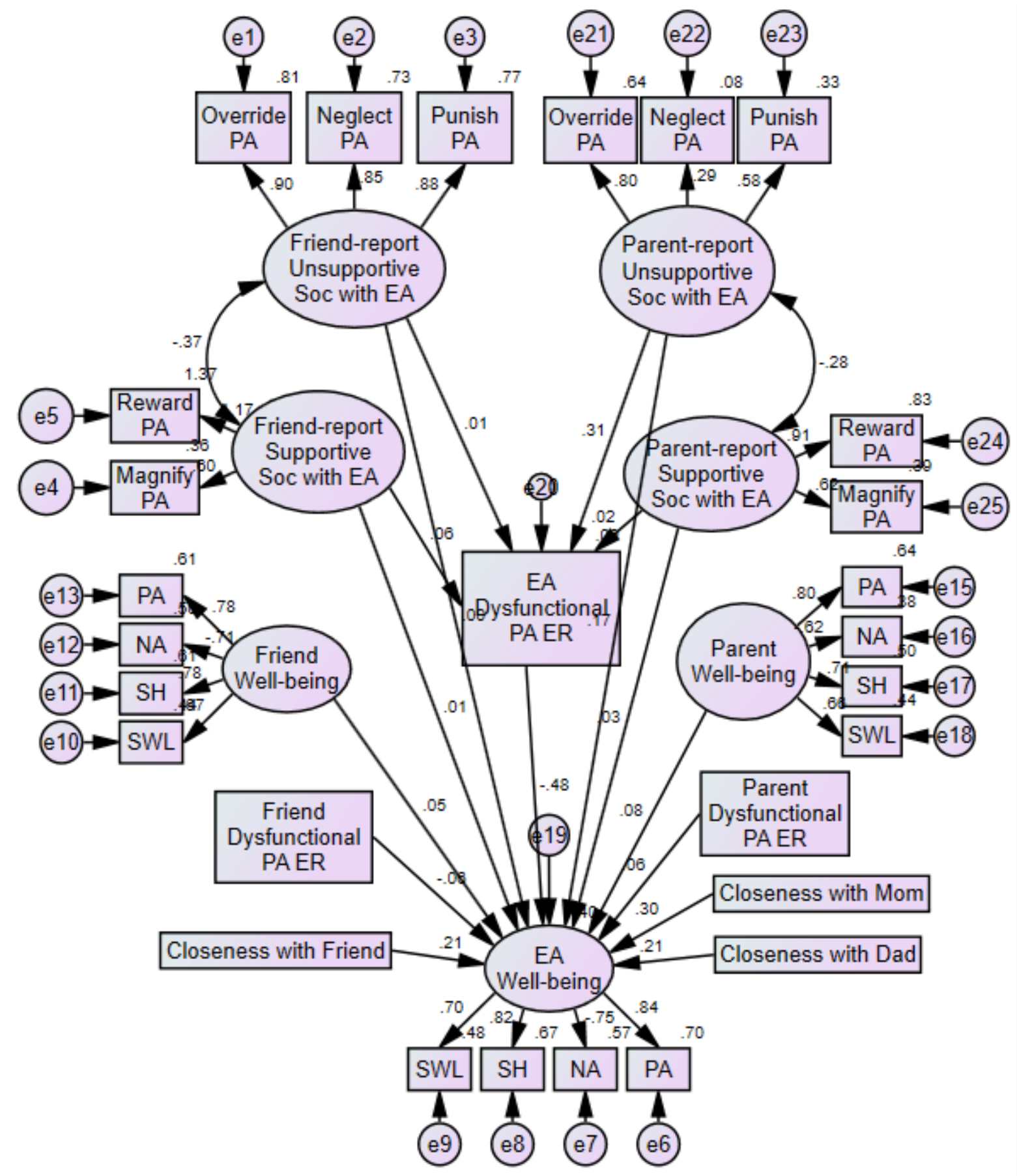

Figure E22. RQ6b - Emerging Adult-reported Dysfunctional Emotion Regulation Mediates the Link between Parent- and Friend-reported Positive Emotion Socialization and Emerging Adultreported Well-being, controlling for Emerging Adult Closeness with Mother, Father, and Friend. Model fit: $\chi^{2}(194, N=190)=291.85, p<.001, \mathrm{CMIN} / \mathrm{df}=1.50, \mathrm{CFI}=.89$, RMSEA $=.06[.05$, .08]. One significant indirect effects: Parents' Unsupportive Socialization with PA $\rightarrow$ EA Dysfunctional PA ER $\rightarrow$ EA Well-being $(\beta=-.15, p=.003$ [95\% CI -.27, -.05]). See Table F17 for comparison with Combined and NA models. 


\section{Appendix F}

Comparisons across Combined, Negative Affect, and Positive Affect Models

Table F1. Comparisons across Combined, NA, and PA Models. RQ2a: Parents' Emotion Socialization Predicting Emerging Adult Functional Emotion Regulation, Controlling for Emerging Adult-reported Closeness with Mother and Father.

\begin{tabular}{lccc}
\hline Outcome: Functional Emotion Regulation & Combined & NA & PA \\
\hline Parents' Supportive Socialization & .11 & $.11^{*}$ & .08 \\
Parents' Unsupportive Socialization & $-.16^{*}$ & -.05 & $-.12^{*}$ \\
Parents' Modeling Functional Emotion Regulation & -.01 & .01 & .02 \\
Closeness with Dad & $.21^{* * *}$ & $.15^{* * *}$ & $.19^{* * *}$ \\
Closeness with Mom & $.40^{* * *}$ & $.33^{* * *}$ & $.33^{* * *}$ \\
\hline
\end{tabular}
Note. ${ }^{*} p<.05 .{ }^{*} p<.01 .{ }^{* * *} p<.001$. All reported values are standardized regression weights. 
Table F2. Comparisons across Combined, NA, and PA Models. RQ2b: Parents' Emotion Socialization Predicting Emerging Adult Dysfunctional Emotion Regulation, Controlling for Emerging Adult-reported Closeness with Mother and Father.

\begin{tabular}{lccc}
\hline Outcome: Dysfunctional Emotion Regulation & Combined & NA & PA \\
\hline Parents' Supportive Socialization & -.05 & -.04 & -.06 \\
Parents' Unsupportive Socialization & .13 & .09 & .08 \\
Parents' Modeling Dysfunctional Emotion Regulation & $.19^{* * *}$ & .08 & .07 \\
Closeness with Dad & $-.22^{* * *}$ & $-.16^{* * *}$ & $-.15^{* *}$ \\
Closeness with Mom & $-.12^{*}$ & $-.14^{* *}$ & -.06 \\
\hline
\end{tabular}
Note. $* p<.05 . * * p<.01 . * * * p<.001$. All reported values are standardized regression weights. 
Table F3. Comparisons across Combined, NA, and PA Models. RQ2c: Parents' Emotion Socialization Predicting Emerging Adult Well-being, Controlling for Emerging Adult-reported Closeness with Mother and Father.

\begin{tabular}{lccc}
\hline Outcome: Well-being & Combined & NA & PA \\
\hline Parents' Supportive Socialization & .04 & .07 & .04 \\
Parents' Unsupportive Socialization & .01 & -.07 & .00 \\
Parents' Modeling Well-being & $.15^{* * *}$ & $.13^{*}$ & $.15^{* *}$ \\
Closeness with Dad & $.22^{* * *}$ & $.22^{* * *}$ & $.22^{* * *}$ \\
Closeness with Mom & $.39^{* * *}$ & $.39^{* * *}$ & $.39^{* * *}$ \\
\hline
\end{tabular}
Note. ${ }^{*} p<.05 . * * p<.01 .{ }^{* * *} p<.001$. All reported values are standardized regression weights. 
Table F4. Comparisons across Combined, NA, and PA Models. RQ3a: Parents' and Friends' Emotion Socialization Predicting Emerging Adult Functional Emotion Regulation, Controlling for Emerging Adult-reported Closeness with Mother, Father, and Friend.

\begin{tabular}{lccc}
\hline Outcome: Functional Emotion Regulation & Combined & NA & PA \\
\hline Parents' Supportive Socialization & .12 & $.11^{*}$ & .08 \\
Parents' Unsupportive Socialization & $-.15^{*}$ & -.06 & $-.12^{*}$ \\
Parents' Modeling Functional Emotion Regulation & .01 & .03 & .03 \\
Friends' Supportive Socialization & -.01 & -.03 & -.01 \\
Friends' Unsupportive Socialization & -.06 & -.06 & -.05 \\
Friends' Modeling Functional Emotion Regulation & $.19^{* *}$ & $.16^{*}$ & $.17^{* *}$ \\
Closeness with Dad & $.18^{* * *}$ & $.12^{*}$ & $.17^{* * *}$ \\
Closeness with Mom & $.35^{* * *}$ & $.26^{* * *}$ & $.27^{* * *}$ \\
Closeness with Friend & $.26^{* * *}$ & $.21^{* * *}$ & $.20^{* * *}$ \\
\hline
\end{tabular}

Note. ${ }^{*} p<.05 .{ }^{* *} p<.01 .{ }^{* *} p<.001$. All reported values are standardized regression weights. 
Table F5. Comparisons across Combined, NA, and PA Models. RQ3b: Parents' and Friends' Emotion Socialization Predicting Emerging Adult Dysfunctional Emotion Regulation, Controlling for Emerging Adult-reported Closeness with Mother, Father, and Friend.

\begin{tabular}{lccc}
\hline Outcome: Dysfunctional Emotion Regulation & Combined & NA & PA \\
\hline Parents' Supportive Socialization & -.05 & -.03 & -.04 \\
Parents' Unsupportive Socialization & .11 & $.11^{*}$ & .05 \\
Parents' Modeling Dysfunctional Emotion Regulation & $.19^{* * *}$ & .08 & .04 \\
Friends' Supportive Socialization & -.06 & $-.15^{*}$ & .05 \\
Friends' Unsupportive Socialization & .06 & $.13^{*}$ & .02 \\
Friends' Modeling Dysfunctional Emotion Regulation & .09 & .08 & .01 \\
Closeness with Dad & $-.22^{* * *}$ & $-.15^{* * *}$ & -.09 \\
Closeness with Mom & -.08 & $-.09^{*}$ & -.02 \\
Closeness with Friend & $-.14^{* *}$ & $-.08^{*}$ & $-.13^{* *}$ \\
\hline
\end{tabular}

Note. ${ }^{*} p<.05$. ${ }^{* *} p<.01 .{ }^{* * *} p<.001$. All reported values are standardized regression weights. 
Table F6. Comparisons across Combined, NA, and PA Models. RQ3c: Parents' and Friends' Emotion Socialization Predicting Emerging Adult Well-being, Controlling for Emerging Adult-reported Closeness with Mother, Father, and Friend.

\begin{tabular}{lccc}
\hline Outcome: Well-being & Combined & NA & PA \\
\hline Parents' Supportive Socialization & .03 & .07 & .04 \\
Parents' Unsupportive Socialization & -.01 & -.08 & .00 \\
Parents' Modeling Well-being & $.14^{*}$ & $.12^{*}$ & $.14^{*}$ \\
Friends' Supportive Socialization & -.02 & .07 & -.01 \\
Friends' Unsupportive Socialization & -.02 & -.05 & -.02 \\
Friends' Modeling Well-being & .07 & .06 & .07 \\
Closeness with Dad & $.25^{* * *}$ & $.26^{* * *}$ & $.25^{* * *}$ \\
Closeness with Mom & $.31^{* * *}$ & $.29^{* * *}$ & $.31^{* * *}$ \\
Closeness with Friend & $.16^{* * *}$ & $.14^{* * *}$ & $.16^{* * *}$ \\
\hline
\end{tabular}

Note. ${ }^{*} p<.05 .{ }^{* *} p<.01 .{ }^{* *} p<.001$. All reported values are standardized regression weights. 
Table F7. Comparisons across Combined, NA, and PA Models. RQ4aa: Emerging Adults' Emotion Socialization Predicting Mothers' Functional Emotion Regulation, Controlling for Mother-reported Closeness with Emerging Adult Child.

\begin{tabular}{lccc}
\hline Outcome: Functional Emotion Regulation & Combined & NA & PA \\
\hline EAs' Supportive Socialization & -.08 & -.11 & .03 \\
EAs' Unsupportive Socialization & -.09 & -.07 & .02 \\
EAs' Modeling Functional Emotion Regulation & -.11 & .09 & .06 \\
Closeness with EA Child & $.34^{* * *}$ & $.29^{* * *}$ & $.17^{* *}$ \\
\hline
\end{tabular}
Note. ${ }^{*} p<.05 . * * p<.01 . * * * p<.001$. All reported values are standardized regression weights. 
Table F8. Comparisons across Combined, NA, and PA Models. RQ4ab: Emerging Adults' Emotion Socialization Predicting Mothers' Dysfunctional Emotion Regulation, Controlling for Mother-reported Closeness with Emerging Adult Child.

Outcome: Dysfunctional Emotion Regulation Combined

EAs' Unsupportive Socialization .08

EAs' Modeling Dysfunctional Emotion Regulation .06

$.20^{* *}$ $-.12^{*}$
NA .07 .06 $.15^{* *}$ $-.17^{* *}$
PA

$-.03$

.04

.06

Closeness with EA Child

Note. ${ }^{*} p<.05 .{ }^{* *} p<.01 .{ }^{* *} p<.001$. All reported values are standardized regression weights. 
Table F9. Comparisons across Combined, NA, and PA Models. RQ4ac: Emerging Adults' Emotion Socialization Predicting Mothers' Well-being, Controlling for Mother-reported Closeness with Emerging Adult Child.

\begin{tabular}{lccc}
\hline Outcome: Well-being & Combined & NA & PA \\
\hline EAs' Supportive Socialization & -.06 & -.13 & -.02 \\
EAs' Unsupportive Socialization & -.13 & -.15 & -.09 \\
EAs' Modeling Well-being & $.23^{* * *}$ & $.23^{* * *}$ & $.22^{* * *}$ \\
Closeness with EA Child & $.33^{* * *}$ & $.33^{* * *}$ & $.32^{* * *}$ \\
\hline
\end{tabular}
Note. ${ }^{*} p<.05 . * * p<.01 . * * * p<.001$. All reported values are standardized regression weights. 
Table F10. Comparisons across Combined, NA, and PA Models. RQ4ba: Emerging Adults' Emotion Socialization Predicting Fathers' Functional Emotion Regulation, Controlling for Father-reported Closeness with Emerging Adult Child.

\begin{tabular}{lccc}
\hline Outcome: Functional Emotion Regulation & Combined & NA & PA \\
\hline EAs' Supportive Socialization & -.02 & -.01 & -.13 \\
EAs' Unsupportive Socialization & -.13 & $.23^{*}$ & -.07 \\
EAs' Modeling Functional Emotion Regulation & .01 & -.03 & .13 \\
Closeness with EA Child & $.47^{* * *}$ & $.40^{* * *}$ & $.40^{* * *}$ \\
\hline
\end{tabular}
Note. ${ }^{*} p<.05 . * * p<.01 . * * * p<.001$. All reported values are standardized regression weights. 
Table F11. Comparisons across Combined, NA, and PA Models. RQ4bb: Emerging Adults' Emotion Socialization Predicting Fathers' Dysfunctional Emotion Regulation, Controlling for Father-reported Closeness with Emerging Adult Child.

\begin{tabular}{lccc}
\hline Outcome: Dysfunctional Emotion Regulation & Combined & NA & PA \\
\hline EAs' Supportive Socialization & .02 & .06 & -.15 \\
EAs' Unsupportive Socialization & -.21 & -.14 & -.09 \\
EAs' Modeling Dysfunctional Emotion Regulation & .10 & -.14 & .17 \\
Closeness with EA Child & $-.46^{* * *}$ & $-.42^{* * *}$ & $-.28^{* *}$ \\
\hline
\end{tabular}
Note. ${ }^{*} p<.05 .{ }^{* *} p<.01 .{ }^{* *} p<.001$. All reported values are standardized regression weights. 
Table F12. Comparisons across Combined, NA, and PA Models. RQ4bc: Emerging Adults' Emotion Socialization Predicting Fathers' Well-being, Controlling for Father-reported Closeness with Emerging Adult Child.

\begin{tabular}{lccc}
\hline Outcome: Well-being & Combined & NA & PA \\
\hline EAs' Supportive Socialization & -.15 & -.14 & -.18 \\
EAs' Unsupportive Socialization & -.08 & -.10 & -.07 \\
EAs' Modeling Well-being & -.03 & -.03 & -.03 \\
Closeness with EA Child & $.53^{* * *}$ & $.52^{* * *}$ & $.53^{* * *}$ \\
\hline
\end{tabular}
Note. ${ }^{*} p<.05 . * * p<.01 . * * * p<.001$. All reported values are standardized regression weights. 
Table F13. Comparisons across Combined, NA, and PA Models. RQ5a: Emerging Adults' Emotion Socialization Predicting Friends' Functional Emotion Regulation, Controlling for Friend-reported Closeness with Emerging Adult Friend.

\begin{tabular}{lccc}
\hline Outcome: Functional Emotion Regulation & Combined & NA & PA \\
\hline EAs' Supportive Socialization & .05 & .11 & .06 \\
EAs' Unsupportive Socialization & .08 & .04 & .02 \\
EAs' Modeling Functional Emotion Regulation & $.14^{*}$ & .08 & $.14^{*}$ \\
Closeness with EA Friend & $.37^{* * *}$ & $.29^{* * *}$ & $.31^{* * *}$ \\
\hline
\end{tabular}
Note. ${ }^{*} p<.05 . * * p<.01 . * * * p<.001$. All reported values are standardized regression weights. 
Table F14. Comparisons across Combined, NA, and PA Models. RQ5a: Emerging Adults' Emotion Socialization Predicting Friends' Dysfunctional Emotion Regulation, Controlling for Friend-reported Closeness with Emerging Adult Friend.

Outcome: Dysfunctional Emotion Regulation

EAs' Supportive Socialization

\section{Combined}

$-.12$

EAs' Unsupportive Socialization

EAs' Modeling Dysfunctional Emotion Regulation

Closeness with EA Friend

Note. ${ }^{*} p<.05 . * * p<.01 . * * * p<.001$. All reported values are standardized regression weights.

$06-01$

.06

$-.04 \quad-.02 \quad-.05$


Table F15. Comparisons across Combined, NA, and PA Models. RQ5a: Emerging Adults' Emotion Socialization Predicting Friends' Well-being, Controlling for Friend-reported Closeness with Emerging Adult Friend.

Outcome: Well-being

\section{Combined}

.04

EAs' Unsupportive Socialization

EAs' Modeling Well-being

Closeness with EA Friend

Note. ${ }^{*} p<.05 .{ }^{* *} p<.01 . * * * p<.001$. All reported values are standardized regression

$-.08-15-13$

.11

$22^{* * *}$

$.16^{*}$

.12

$.23^{* * *}$ weights. 
Table F16. Comparisons across Combined, NA, and PA Models. RQ6a: Parents' and Friends' Emotion Socialization Predicting Emerging Adult Well-being through Emerging Adult Functional Emotion Regulation, Controlling for Emerging Adult-reported Closeness with Mother, Father, and Friend and Parent and Friend Modeling Functional Emotion Regulation and Well-being.

\begin{tabular}{lccc}
\hline & Combined & NA & PA \\
\hline Outcome: EA Functional Emotion Regulation & & & $.31^{* * *}$ \\
\hline Parents' Supportive Socialization & $.31^{* * *}$ & $.24^{* *}$ & .01 \\
Parents' Unsupportive Socialization & -.04 & -.02 & $.18^{*}$ \\
Friends' Supportive Socialization & $.19^{*}$ & .04 & .01 \\
Friends' Unsupportive Socialization & -.06 & -.10 & \\
\hline Outcome: Well-being & & & -.09 \\
Parents' Supportive Socialization & -.15 & -.06 & .03 \\
Parents' Unsupportive Socialization & .03 & -.03 & .00 \\
Parents' Modeling Functional Emotion Regulation & .01 & -.03 & .10 \\
Parents' Modeling Well-being & .07 & .08 & -.03 \\
Friends' Supportive Socialization & -.02 & .06 & -.02 \\
Friends' Unsupportive Socialization & .03 & .02 & -.11 \\
Friends' Modeling Functional Emotion Regulation & $-.22^{* *}$ & $-.17^{*}$ & .04 \\
Friends' Modeling Well-being & .13 & .11 & $.18^{* *}$ \\
Closeness with Dad & $.14^{*}$ & $.16^{*}$ & $.25^{* * *}$ \\
Closeness with Mom & $.20^{* *}$ & $.21^{* *}$ & $.28^{* * *}$ \\
Closeness with Friend & $.23^{* * *}$ & $.24^{* * *}$ & $.30^{* * *}$ \\
EA Functional Emotion Regulation & $.48^{* * *}$ & $.38^{* * *}$ & \\
\hline Indirect Effects through EA Functional Emotion Regulation & & $.10^{* *}$ \\
\hline Indirect Effect (Parent Supportive Soc) & $.15^{* *}$ & $.09^{* *}$ & .00 \\
Indirect Effect (Parent Unsupportive Soc) & -.02 & -.01 & $.05^{*}$ \\
Indirect Effect (Friend Supportive Soc) & .09 & .01 & .00 \\
Indirect Effect (Friend Unsupportive Soc) & -.03 & -.04 & \\
\hline Note, & & \\
\hline
\end{tabular}
Note. $* p<.05 . * * p<.01 . * * * p<.001$. All reported values are standardized regression weights. 
Table F17. Comparisons across Combined, NA, and PA Models. RQ6a: Parents' and Friends' Emotion Socialization Predicting Emerging Adult Well-being through Emerging Adult Dysfunctional Emotion Regulation, Controlling for Emerging Adult-reported Closeness with Mother, Father, and Friend and Parent and Friend Modeling Dysfunctional Emotion Regulation and Well-being.

\begin{tabular}{lccc}
\hline & Combined & NA & PA \\
\hline Outcome: EA Dysfunctional Emotion Regulation & & & \\
\hline Parents' Supportive Socialization & .04 & -.08 & .02 \\
Parents' Unsupportive Socialization & $.32^{* *}$ & $.19^{*}$ & $.31^{* * *}$ \\
Friends' Supportive Socialization & -.06 & -.13 & .06 \\
Friends' Unsupportive Socialization & .05 & .11 & .01 \\
\hline Outcome: Well-being & & & \\
\hline Parents' Supportive Socialization & .07 & .00 & .03 \\
Parents' Unsupportive Socialization & $.26^{* *}$ & .02 & .17 \\
Parents' Modeling Dysfunctional Emotion Regulation & .01 & .07 & .06 \\
Parents' Modeling Well-being & .07 & .12 & .08 \\
Friends' Supportive Socialization & -.07 & -.04 & .01 \\
Friends' Unsupportive Socialization & .04 & .06 & .00 \\
Friends' Modeling Dysfunctional Emotion Regulation & -.07 & -.04 & -.06 \\
Friends' Modeling Well-being & .01 & -.05 & .05 \\
Closeness with Dad & $.13^{*}$ & $.13^{*}$ & $.21^{* * *}$ \\
Closeness with Mom & $.27^{* * *}$ & $.26^{* * *}$ & $.30^{* * *}$ \\
Closeness with Friend & $.17^{* *}$ & $.21^{* * *}$ & $.21^{* *}$ \\
EA Dysfunctional Emotion Regulation & $-.78^{* * *}$ & $-.56^{* * *}$ & $-.48^{* * *}$ \\
\hline Indirect Effects through EA Functional Emotion Regulation & & \\
\hline Indirect Effect (Parent Supportive Soc) & -.03 & .04 & -.01 \\
Indirect Effect (Parent Unsupportive Soc) & $-.25^{* *}$ & $-.10^{*}$ & $-.15^{* *}$ \\
Indirect Effect (Friend Supportive Soc) & .05 & $.08^{*}$ & -.03 \\
Indirect Effect (Friend Unsupportive Soc) & -.03 & $-.06^{*}$ & -.01 \\
\hline Note, $p<.05 . * * p<.01 * * * p<.001 . A 11$ reported & & & \\
\hline
\end{tabular}
Note. $* p<.05 . * * p<.01 . * * * p<.001$. All reported values are standardized regression weights. 